Universidad deValladolid

PROGRAMA DE DOCTORADO EN CIENCIAS DE LA SALUD

TESIS DOCTORAL:

\title{
ESTUDIO EPIDEMIOLÓGICO DE LA SALUD BUCODENTAL ANTES Y DESPUÉS DE UNA INSTRUCCIÓN PREVENTIVA EN UNA POBLACION MILITAR (2006-2015)
}

\author{
Presentada por \\ Manuel Tello Pellitero \\ para optar al grado de Doctor por la \\ Universidad de Valladolid
}

Dirigida por el

Dr. Manuel Garrosa García

Dra. Belén Cantón Álvarez 

UVa Secretaría Administrativa. Escuela de Doctorado. Casa del Estudiante. C/ Real de Burgos s/n. 47011-Valladolid. ESPAÑA Tfno.: + 34983 184343 ; 34983 423908; + 34983186471 - Fax 983186397 - E-mail: 

ÍNDICE

1. JUSTIFICACIÓN, PLANTEAMIENTO DEL TRABAJO E HIPOTESIS

2. INTRODUCCIÓN 11

2.1. Marco civil 14

2.1.1. Un giro hacia la promoción y prevención de la salud 14

2.1.2. La carga de la salud oral en la sociedad 15

2.1.3. Demanda de atención odontológica. 17

2.1.4. Salud bucodental: Plan de acción para la promoción y la prevención. $\quad 18$

2.1.4.1. Encuestas de salud 19

2.1.4.2. Planificación de una encuesta básica de salud

Bucodental 20

2.2. Marco militar 21

2.2.1. Exigencias de cambio en la Sanidad Militar 21

2.2.2. Organización del servicio de sanidad de las FAS 22

2.2.3. El Servicio de Sanidad de las FAS en operaciones 23

2.2.4. Apoyo sanitario en operaciones 23

2.2.4.1. Principios del apoyo sanitario 24

2.2.4.2. Actividades sanitarias en las operaciones 26

2.2.5. Escalonamiento sanitario en las operaciones 29

2.2.5.1. Primer escalón 30

2.2.5.2. Segundo escalón 31

2.2.5.3. Tercer escalón 33

2.2.5.4. Cuarto escalón 34

2.2.5.5. Adaptación al escalonamiento de sanidad en la doctrina OTAN. $\quad 34$

2.2.6. Seguimiento de evacuación a TN por motivos médicos. 35

2.2.7. Exigencias de cambio en la prevención sanitaria de las FAS 37

2.2.7.1. Desarrollo de la prevención sanitaria 38 
2.2.7.2. Actividades preventivas en los despliegues. 39

2.2.7.2.1. Fase previa al despliegue 39

2.2.7.2.2. Fase de despliegue $\quad 40$

2.2.7.2.3. Fase posterior al despliegue 40

2.2.7.3. Organización de la prevención sanitaria 41

2.2.7.3.1. Primer y segundo escalón 41

2.2.7.3.2. Tercer escalón 41

2.2.7.3.3. Cuarto escalón. 41

2.2.7.4. Medidas higiénicas $\quad 42$

2.2.7.4.1. Higiene bucodental 42

2.2.8. La odontología en la sanidad militar $\quad 44$

2.2.8.1. Odontología asistencial 44

2.2.8.2. Odontología pericial 44

2.2.8.3. Odontología de apoyo a operaciones 45

2.2.8.4. Odontología preventiva 48

2.2.9. Competencias especificas de los cuerpos comunes de la defensa (cuerpo militar de sanidad) - especialidad complementaria: Odontología.

3. OBJETIVOS 53

3.4. Objetivos generales $\quad 55$

3.5. Objetivos específicos $\quad 55$

4. MATERIAL Y MÉTODOS

4.1. Diseño y tipo de estudio $\quad 59$

4.2. Ámbito y población $\quad 60$

4.3. Muestreo $\quad 60$

4.3.1. Duración y tamaño de la muestra 60

4.3.2. Técnica de muestreo 60

4.3.3. Criterios de inclusión y exclusión 61

4.4. Datos recogidos $\quad 61$

4.4.1. Variables sociodemográficas 61

4.4.2. Variables de salud $\quad 62$

4.4.3. Evaluación clínica 62

4.5. Programa de educación para la salud bucodental 73

4.6. Exploradores y Calibración $\quad 74$

4.7. Análisis estadístico $\quad 75$

Anexo : Ficha dental 77 
5.1. Hábitos de cepillado, tabaquismo y frecuencia de visitas al dentista

5.1.1. Visita 1

5.1.2. Visita 2

5.2. Estado de la articulación témporo-mandibular, presencia de bruxismo, utilización de férulas oclusales y presencia de torus mandibulares.

5.2.1. Visita $1 \quad 88$

5.2.2. Visita 2

5.3. Opacidades e hipoplasias del esmalte y tinción por tetraciclinas 93

$\begin{array}{ll}\text { 5.3.1. Visita } 1 & 93\end{array}$

5.3.2. Visita 2

5.4. Estado periodontal y la necesidad de tratamiento y presencia de pendientes en labios y lengua. $\quad 97$

$\begin{array}{lr}\text { 5.4.1. Visita } 1 & 97\end{array}$

5.4.2. Visita 20100

5.5. Índice CAO-D y componentes, necesidades de tratamiento y $\begin{array}{ll}\text { grado de aptitud dental } & 103\end{array}$

5.5.1. Visita 12103

5.5.2. Visita $2 \quad 105$

5.6. Estado de prótesis, necesidad de tratamiento y presencia de Implantes 108

5.6.1. Visita $1 \quad 108$

5.6.2. Visita $2 \quad 111$

5.7. Estado oclusal (anomalías dentofaciales), presencia de tratamientos ortodóncicos, presencia de dientes parcialmente erupcionados y necesidad de exodoncia e los terceros molares. 115

5.7.1. Visita $1 \quad 115$

5.7.2. Visita $2 \quad 118$

5.8. Análisis del grado de aptitud dental 120

$\begin{array}{ll}\text { 5.8.1. Visita } 1 & 120\end{array}$

5.8.2. Visita $2 \quad 121$

Anexo: Tablas totales de la primera y segunda visita 122 
6.1. Hábitos de cepillado y tabaquismo así como la frecuencia de visitas al dentista.

6.2. Estado de la articulación témporo-mandibular, presencia de bruxismo, utilización de férulas oclusales y presencia de torus mandibulares.

6.3. Opacidades e hipoplasias del esmalte y tinción por tetraciclinas

6.4. Estado periodontal y la necesidad de tratamiento y presencia de pendientes en labios y lengua

6.5. Estado dental y necesidad de tratamiento

Anexo. Tablas comparativas de las visitas 1 y 2 con los resultados para cada uno de los factores estudiados y el tratamiento estadístico de los mismos. 


\section{Justificación, planteamiento del trabajo e hipótesis.}


Estudio epidemiológico de la salud bucodental y ... 


\section{JUSTIFICACIÓN, PLANTEAMIENTO DEL TRABAJO E HIPÓTESIS.}

Las afecciones bucodentales, por su alta prevalencia, constituyen un problema de salud pública de primer orden en nuestro entorno. De todas ellas, las que presentan mayor trascendencia en salud oral son la caries dental y las enfermedades periodontales. Ambas, se encuentran entre las más prevalentes en la población infantil y son prácticamente universales en la edad adulta.

En los últimos años la población adulta ha mejorado muy sustancialmente en parámetros muy objetivos tales como la media de dientes ausentes, la prevalencia de desdentados totales, los índices de restauración y los índices periodontales, que son parámetros clínicos de objetividad más compleja. Además en cuanto a los índices de restauración se viene observando un aumento muy considerable de la atención restauradora.

En el entorno militar la pérdida de salud oral era la principal causa de atención sanitaria en despliegues y maniobras por lo cual las necesidades operativas en las Fuerzas Armadas (FAS) hacen que la odontología asistencial se dirija a personas que presentan unas necesidades de salud oral específicas y diferentes a la población general. Por ello la realización de estudios epidemiológicos sobre la prevalencia y la necesidad de tratamientos, es de gran importancia para obtener 
información sobre las necesidades en la planificación de las medidas de prevención en la sanidad militar, así como, para establecer comparaciones entre diferentes poblaciones y colectivos.

Además de su elevada frecuencia, las enfermedades orales tienen un gran impacto individual y comunitario en términos de dolor y sufrimiento, limitaciones en la alimentación, restricciones en la comunicación, insatisfacción estética y disminución de la calidad de vida. Por otra parte, en el ámbito militar los problemas dentales son caros para las personas a título individual y para el grupo, por la pérdida de un miembro del equipo, que podría ser temporal o definitivo, por lo que en ese tiempo se verá comprometida la eficiencia y eficacia de la unidad, retrasando la misión. También hay que añadir el coste de estos tratamientos que van a suponer gastos de personal, material y tiempo dedicados a esta actividad sanitaria.

Con el fin de conseguir reducir los esfuerzos de apoyo dental en las FAS, en operaciones fuera del territorio nacional solo a emergencias imprevisibles, se creo la Instrucción Técnica 01/03 de 10 de julio de 2003 de la Inspección General de Sanidad (IGESAN) que entre otras normas, protocolizaba las revisiones dentales previas a misión. Y con la Instrucción técnica de 15 julio de 2011 de la Inspección General de Sanidad, actualizada a 30 julio de 2013 sobre "Requisitos sanitarios exigibles al personal militar que se desplace a zona de operaciones" la revisión dental previa, es un requisito obligatorio para todo el personal militar que va a participar en una misión u operación.

Esta evaluación del grado de aptitud dental, es un parámetro que se valora en las fuerzas armadas y que no se rige por las indicaciones de la OMS, ya que es puramente de ámbito militar. El resultado final es de "apto" o "no apto" para la misión aunque los "no aptos" son en un primer momento "no aptos temporales" y la mayoría de estos pasan a ser aptos en una segunda revisión, si en ese plazo de tiempo han mejorado su estado bucal cumpliendo con lo exigido. El resultado optimo al que se queremos llegar con estos protocolos de revisiones dentales previas y otras periódicas de prevención, es al $100 \%$ de aptos en cuanto a la salud dental se refiere.

En los últimos años el enfoque que se da a la salud oral ha cambiado. Las necesidades de tratamiento para recuperar o mejorar la salud bucodental, no deben de ser consideradas, solamente, desde un punto de vista clínico. Empiezan a tener mayor presencia los programas de prevención y educación oral. Por ello el presente estudio se enmarca en este contexto y han sido nueve años de seguimiento de estos sujetos, para que los resultados obtenidos no sólo nos 
orienten acerca del estado de salud oral en que se encuentran los militares de la población estudiada sino que también sea, por un lado, una de las herramientas básicas para la planificación y gestión de los recursos sanitarios destinados a la salud bucodental (planificar el futuro odontológico de dicha población) y por otro, nos permita comparar los niveles de salud oral que se han conseguido aquí con los del resto de las Unidades Militares en un futuro.

A su vez, queremos con este estudio seguir demostrando que el desarrollo de la medicina preventiva disminuye la incidencia de las enfermedades y bajas, no de combate, y que el conocimiento y aplicación de medidas preventivas tiene una gran importancia para los ejércitos, en su preocupación por proteger la salud de sus miembros y conservar el potencial operativo de la fuerza. Además, podremos comparar nuestros resultados con otros trabajos y encuestas que sigan la metodología de la OMS, sobre el estado de salud bucodental y las necesidades terapéuticas.

Por último para esta Tesis se estableció la siguiente hipótesis: En la población militar española, pueden existir diferencias con significación estadística en la distribución de las variables estudiadas sobre el estado su salud oral y la necesidad de asistencia, en relación a la escala, a la edad y al sexo. 


2. Introducción 
Estudio epidemiológico de la salud bucodental y ... 


\section{INTRODUCCIÓN}

La presente Memoria tiene como punto de partida la influencia de la salud oral en las actividades militares, fundamentalmente misiones y operaciones, de los miembros de una Base militar de las Fuerzas Armadas (FAS). Todo ello dentro del marco de un ejercito profesional con una importante participación en misiones internacionales. Partiendo de esa necesidad concreta se planificó un trabajo, bastante amplio, que se puede encuadrar en lo que llamaríamos datos necesarios para un programa de salud pública (bucodental) con el fin de poder recoger toda la información de nuestro estudio para definir un programa de prevención de salud oral. Además tiene una importante peculiaridad que lo diferencia de otros trabajos: el estudio se hace sobre la misma muestra durante nueve años y se analiza su evolución. Aunque el colectivo estudiado corresponde a los miembros de una Base militar, el desarrollo del estudio y los resultados tienen un alcance mucho más amplio, ya que se pueden comparar con estudios epidemiológicos realizados sobre la población civil, dentro del mismo intervalo de edades y distribución cultural y socio-económica. Por este doble motivo, en esta introducción se presenta una breve referencia a lo que podrían ser las políticas de prevención en la salud oral en general, lo que denominamos marco civil, y una introducción, un poco más amplia, a la que denominamos marco militar. En cuanto a las comparativas epidemiológicas, las referencias, mayoritariamente, se incorporan en la discusión. Por último se debe tener en cuenta que el marco general del presente trabajo es "la salud bucodental", su influencia en las actividades que deben realizar los miembros de la población estudiada y la importancia de la prevención a través de un programa de educación para la salud bucodental que instruya preventivamente al militar en este tema. 


\subsection{Marco civil}

\subsubsection{Un giro hacia la promoción y prevención de la salud}

En el momento actual la sociedad afronta dos retos íntimamente ligados, la transición demográfica y la epidemiológica, lo cual supone un cambio desde las enfermedades transmisibles a las no trasmisibles y la mayor prevalencia de las patologías crónicas a medida que aumenta la esperanza de vida de una población.

Las principales causas de la carga de enfermedad, tanto a nivel mundial como en nuestro entorno, tienen unos determinantes y unos factores de riesgo comunes. Por ello, abordarlos de forma conjunta e integradora mejora tanto el impacto de las acciones de promoción y prevención como su eficiencia ${ }^{1}$.

Por ello la Estrategia de Promoción y Prevención de la Salud, definida en el Sistema Nacional de Salud ${ }^{2}$ (SNS),facilita un marco común para la promoción de la salud y la prevención primaria. Además, en la definición de esta Estrategia se implica, activamente, a otros sectores de la sociedad y se promueve la participación de los individuos y de la población para incrementar su autonomía y su capacidad para ejercer un mayor control sobre la salud.

En la primera evaluación de esta nueva Estrategia se confirma que ha supuesto un nuevo impulso en la reorientación del $\mathrm{SNS}^{3}$. En este punto es interesante reseñar que este cambio era una demanda permanente de nuestro entorno y una reiterada recomendación de los organismos internacionales como la OMS y la Unión Europea.

En esta nueva Estrategia se analizan todos aquellos factores que tienen una importancia fundamental a la hora de abordar problemas básicos como la cronicidad, alimentación saludable, actividad física, riesgos en el consumo de tabaco y alcohol, bienestar emocional y la seguridad del entorno con el objetivo de prevenir lesiones no intencionadas.

A la hora de analizar cualquier Estrategia, no debemos olvidar que los programas de salud se desarrollan, mayoritariamente, en escenarios complejos, 
con procesos multifactoriales muy sensibles a un contexto siempre heterogéneo y cambiante, donde la evidencia de efectividad respecto a resultados finales es a veces difícil de demostrar.

Por otra parte sabemos que los ciudadanos le dan un alto valor a la salud y demandan respuestas conjuntas, coordinadas e integradas con intervenciones efectivas y mantenidas en el tiempo. Esto ha hecho que el concepto de "buena salud" sea uno de los pilares fundamentales de una sociedad económica y socialmente próspera. De hecho, los programas de salud ya son un indicador habitual en los análisis y definiciones de las estrategias globales de crecimiento económico, como la Estrategia 2020 de la Unión Europea ${ }^{4}$.

Sin embargo, en el actual contexto socioeconómico en el que vivimos, el sistema socio-sanitario está sujeto a ciertas tensiones derivadas de aspectos económicos y de la variabilidad de las estrategias. Por ello, más que nunca, es imperativo incrementar los esfuerzos, no demasiado costosos, dedicados a la promoción y la prevención. Dichos esfuerzos aumentarán el bienestar, lograrán una mayor cohesión social y ayudarán a la sostenibilidad del sistema de salud a medio y largo plazo.

\subsubsection{La carga de la salud oral en la sociedad}

Según la Organización Mundial de la Salud (OMS), ordenadas por su coste económico, las enfermedades bucodentales ocupan el cuarto lugar. No debemos olvidar que, por ejemplo, entre el $60 \%$ y el $90 \%$ de los escolares y el $100 \%$ de los adultos, a nivel mundial, presentan caries dental.

Evidentemente, la salud oral es mucho más amplia. Así, la OMS define a la salud bucodental como "la ausencia de dolor bucal o facial, de cáncer oral o de garganta, de infecciones o ulceras, de enfermedades periodontales, caries, pérdida dentaria así como de otras enfermedades y alteraciones que limiten la capacidad individual de morder, masticar, reír, hablar o comprometan el bienestar psicosocial".

A pesar de su importancia, las enfermedades orales han recibido muy pocos recursos para la vigilancia y prevención centrando los esfuerzos mas hacia su 
Estudio epidemiológico de la salud bucodental y ...

tratamiento, resultando ser una pesada carga en términos de calidad de vida y costes económicos.

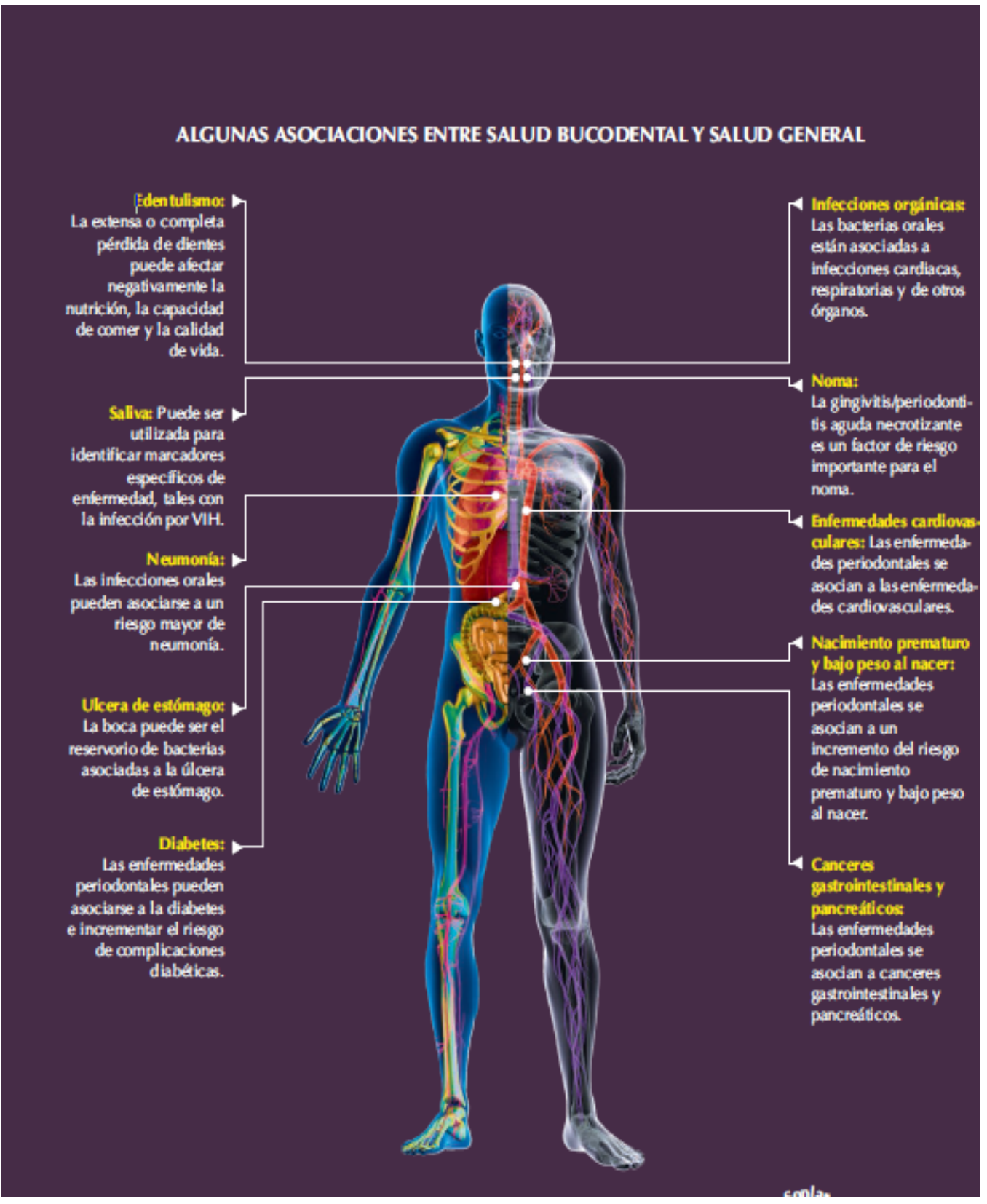

Figura 1.1. Esquema sobre algunas relaciones entre las enfermedades bucodentales y la salud general ${ }^{6}$. 
La salud oral aunque engloba a un área limitada del cuerpo humano, sus consecuencias e impacto por falta de cuidados y atención, afectan a la salud general ya que están íntimamente relacionadas con la salud general del cuerpo humano y deben ser consideradas de forma integral ${ }^{5}$. En la figura 1.1 se muestra un esquema ilustrativo de estas relaciones.

La mayoría de las enfermedades bucodentales comparten factores de riesgo comunes con otras Enfermedades No Transmisibles (ENT) como son las enfermedades cardiovasculares, canceres, diabetes y enfermedades respiratorias $^{7}$.

\subsubsection{Demanda de atención odontológica.}

La Federación Dental Internacional (FDI) considera la Salud Bucodental como un derecho fundamental, y se hace eco de la Declaración de Adelaida de $2010^{8}$ sobre la salud en todas las políticas, con su propio principio de "salud bucodental en todas las políticas".

Debido a este creciente reconocimiento de que la salud oral cumple, una función crucial en la salud general y en la calidad de vida de los ciudadanos, es por tanto que, la odontología debe jugar un importante papel en la detección y seguimiento de las enfermedades no transmisibles $(\mathrm{ENT})^{5,7}$.

Para lograr que los programas de prevención primaria y secundaria resulten eficaces, económicos y viables, es fundamental incorporar a los odontólogos en la vigilancia de la salud mediante reconocimientos periódicos rutinarios a pacientes "sanos" o sin sintomatología. Se debe tener en cuenta que para combatir los factores de riesgo, es necesario tener en cuenta indicadores globales de salud oral ${ }^{9,10}$, tratar de abordarlos y, apoyarse en ellos con el fin de lograr que las personas adopten un comportamiento más saludable. Es evidente que para lograr estos objetivos es absolutamente necesario un programa que contemple la incorporación, a nivel de atención primaria, de los profesionales de la salud bucodental necesarios para realizar las funciones anteriores.

En todos los trabajos de investigación e informes sobre salud bucodental aparece la misma conclusión que, en forma muy resumida, se puede definir como: 
Abogar por la inclusión de la Salud Bucodental en el desarrollo de las políticas de salud general (local, regional, nacional y mundial) e incorporar a profesionales de la odontología en la toma de decisiones de dichas políticas, lo cual hará crecer la educación de la población en materia de salud oral, promoviendo a su vez una demanda de la comunidad hacia los gobiernos y contribuir a garantizar que estén en condiciones de acceder a los servicios de atención odontológica en todo momento.

\subsubsection{Salud bucodental: Plan de acción para la promoción y la prevención.}

Como se indicaba anteriormente, a pesar, de la naturaleza extendida de la caries a nivel mundial, el número de datos globales, estandarizados y fiables, son limitados debido fundamentalmente, a que los datos sobre salud bucodental no están integrados en la vigilancia nacional de enfermedades, sobre todo de los países con ingresos bajos o moderados. Esta situación se incrementa cuando se hace referencia a otras enfermedades orales, como las de nuestro estudio que no están ampliamente recogidas en la literatura.

Si nos fijamos en las encuestas sobre salud bucodental realizadas de manera separada, nos encontramos con el hecho de que son complejas y costosas, razón por la cual no son una prioridad. Esta falta de puesta al día, de información epidemiológica fiable, solo permite enfoques parciales que impiden programar acciones generales que lleven a la reducción de la carga de la enfermedad ${ }^{6}$.

Por ello, se debe hacer hincapié en la necesidad de incorporar programas específicos que adopten medidas ${ }^{11}$ para velar por la salud bucodental, por medio de programas que deben ser anexados, según proceda, a las políticas para la prevención y el tratamiento integrado de las enfermedades crónicas no transmisibles, a las enfermedades transmisibles y a las políticas de salud específicas de la madre y del niño.

En esta dirección se deben fortalecer las investigaciones y consolidar y adaptar los programas nacionales, que favorecerán el intercambio entre países de conocimientos sólidos y experiencias en programas comunitarios de salud bucodental. 
En este camino dirigido hacia la prevención y mejora de la salud oral desempeñan una función, fundamental, los centros colaboradores de la OMS, los asociados y las organizaciones no gubernamentales en todo el mundo. A este respecto se debe destacar la elaboración de las encuestas de salud ${ }^{12,13}$ que son una de las principales herramientas, fiables, para analizar las necesidades de tratamiento de la población y la prevalencia de las afecciones orales. Y que por tanto, nos van a suministrar unos datos a tener en cuenta a la hora de crear políticas de provisión de recursos que satisfagan las necesidades de los ciudadanos.

\subsubsection{Encuestas de salud}

Las encuestas de salud a nivel nacional o regional son el instrumento usual para obtener información de las aptitudes de una población en relación con la salud y morbilidad percibida, las conductas relacionadas con la propia salud (incluyendo las prácticas preventivas) y la utilización de los servicios sanitarios (tanto públicos como privados). Además, son útiles para conocer aspectos del entorno ambiental (físico y social) en el que conviven, se relacionan y enferman, las personas.

Las encuestas, además de cumplir los fines anteriores, tienen un valor añadido muy importante. Es el que se obtiene a partir de la comparación entre los resultados encuestas realizadas en periodos temporales diferentes, pero empleando similar metodología. Estos estudios comparativos permiten evaluar la existencia de tendencias en la evolución de indicadores de salud oral.

Estos estudios son de gran interés para quienes tengan la responsabilidad de planificar la política sanitaria bucodental, la política educativa odontológica y las políticas generales de salud ${ }^{14,15}$. Evidentemente, también tienen un clarísimo interés para los odontólogos en general, que a partir de estos estudios pueden y deben insistir en aquellos aspectos de salud oral que los estudios indiquen como deficitarios. 


\subsubsection{Planificación de una encuesta básica de salud bucodental}

La realización de encuestas para determinar la situación de la salud bucodental y las necesidades de tratamiento de colectividades y poblaciones, debe ser una de las actividades básicas de los responsables de realizar políticas de salud. Esto lo entendió, muy bien, la OMS que, desde hace tiempo, intenta involucrar a todos los gobiernos y administraciones a nivel mundial. En esta actividad se debe involucrar a los directores de servicios odontológicos, miembros de la asociación de odontología y a profesores de las instituciones de formación de personal de asistencia sanitaria oral. Además se debe tener en cuenta que la eficacia se basa, por un lado en la realización de las encuestas epidemiológicas de los trastornos de la salud bucodental con carácter periódico, y por otro en poner en marcha los correspondientes programas de salud.

Las encuestas básicas de salud bucodental ${ }^{12,13}$ no están destinadas a copiar información sobre los factores etiológicos que influyen en la distribución o gravedad de las enfermedades, ni acerca de la efectividad clínica de los distintos procedimientos preventivos o terapéuticos. Sin embargo, la información obtenida puede emplearse para vigilar aspectos de la efectividad de los servicios de asistencia bucodental.

Desde que se publicó la primera edición del manual de la OMS en 1971, más de 130 administraciones sanitarias de todo el mundo han realizado encuestas de salud bucodental conforme a los métodos básicos recomendados. Esas encuestas han mostrado que se han producido cambios relevantes de la salud bucodental en las diferentes poblaciones, como resultado de las modificaciones en las tendencias de la morbilidad y de las nuevas técnicas terapéuticas, así como de los cambios en la estructura de la sociedad.

La OMS recomienda la realización de encuestas de salud oral periódicas ${ }^{16}$, cada 5 años, con objeto de analizar la evolución del nivel de salud bucal de las poblaciones y cotejar los cambios ocurridos.

Los principales objetivos que contempla el manual ${ }^{12}$ son los siguientes:

- Proporcionar un método sistematizado de compilación y notificación de datos sobre trastornos y enfermedades orales. 
- Tener la seguridad de que los datos recogidos en una amplia gama de entornos son comparables.

- Impulsar a los administradores de servicios de salud bucodental de todos los países a que efectúen mediciones normalizadas de las enfermedades y trastornos orales, como base para planificar y evaluar programas de salud bucodental

\subsection{Marco militar}

En esta parte de la introducción se presenta, con cierto detalle, lo que denominamos el marco militar, con el fin de ver la importancia de las diferentes actividades de la sanidad militar y de la odontología militar en particular dentro de las FAS. Describimos las funciones de la odontología en este marco, que en muchos casos es decisoria para el análisis de la aptitud de aquellos que vayan a participar en una determinada operación. Para ello se presenta primero un marco general en el que se hace evidente el hecho de que la llamada sanidad militar es ya una pieza fundamental en las FAS aunque, cada vez, más enfocada a las misiones u operaciones, tanto a nivel nacional como internacional. Una vez que queda analizada, con carácter general, las funciones de la sanidad militar, el final de esta introducción está dedicada a analizar los cometidos específicos de la odontología dentro de una Base militar y en el tiempo previo, durante y posterior de las misiones u operaciones. Haciendo hincapié en los diferentes cometidos, como son el asistencial, el pericial, el de apoyo a operaciones o el preventivo siendo este un poco mas extenso, por ser el sujeto principal que aborda esta memoria.

\subsubsection{Exigencias de cambio en la Sanidad Militar}

En las Fuerzas Armadas (FAS) han ocurrido dos hechos fundamentales en los últimos tiempos. Por un lado su profesionalización y por otro su proyección en 
las diferentes misiones internacionales. Debido a esto, la Sanidad Militar ha necesitado potenciar su función logístico-operativa con una racionalización de las estructuras sanitarias y un empleo más eficiente de los miembros del Cuerpo Militar de Sanidad (CMS) ${ }^{17}$.

La salida de las fronteras con la plena integración de España en el contexto internacional, el progreso socio-económico que como nación ha experimentado y el espíritu de cooperación internacional en los últimos años, formando parte de contingentes de la Organización de las Naciones Unidas (ONU) de la Unión Europea (UE) o incorporándose a la Organización del Tratado del Atlántico Norte (OTAN) han llevado a nuestra Sanidad Militar ha tener una activa participación en el apoyo de los despliegues de los ejércitos e incluso como protagonista del apoyo.

La actuación sanitaria en todas estas misiones y despliegues es para la atención médica, tanto del personal propio como aliado y para la población local. Se realizara en cualquiera de las operaciones ya sean humanitarias de mantenimiento de la paz, de interposición, o las encuadradas dentro del marco político y estratégico de las organizaciones internacionales ${ }^{18,19,20}$ (ONU, OTAN, $\mathrm{UE)}$.

Para poder cumplir con estas misiones, es preciso disponer de una Sanidad Militar operativa, flexible, interoperable, proyectable y de calidad, que cuente con los medios necesarios, personales y materiales, para lograrlo.

\subsubsection{Organización del servicio de sanidad de las FAS}

El Servicio de Sanidad de las Fuerzas Armadas (FAS) está constituido por los órganos de sanidad pertenecientes al Órgano Central del Ministerio de Defensa, Inspección General de Sanidad (IGESAN), al Ejército de Tierra (ET), a la Armada, al Ejército del Aire (EA) y a las Direcciones de Sanidad (DISANs), que con la organización adecuada y coordinados mediante la aplicación de unos principios doctrinales se integran en la organización operativa a la que apoyan. Dentro de estos principios doctrinales se incluye la Doctrina Sanitaria Conjunta $(\text { DOSACON })^{21}$, aprobada por el Jefe del Estado Mayor de la Defensa (JEMAD). 
Los Servicios de Sanidad de las Bases, Acuartelamientos y Establecimientos (BAE,s) del Ejercito de Tierra (ET) se constituyen, con carácter general, con el personal facultativo y auxiliar relacionado con el Servicio Logístico Funcional de Sanidad destinado en las Unidades, Centros y Organismos (UCO,s) situados en la BAE, con las instalaciones y material de sanidad asignados a las UCO,s, en las que el Servicio de Sanidad realiza sus cometidos (Botiquín, Gabinetes de Odontología y Psicología, etc...) $)^{22}$.

\subsubsection{El Servicio de Sanidad de las FAS en operaciones}

La principal misión del Servicio de Sanidad es prestar el apoyo sanitario por medio de la selección, conservación y recuperación del personal, minimizando los efectos que las lesiones y enfermedades puedan tener sobre la efectividad, disponibilidad y moral de las unidades. Esta misión se alcanza cuando se dispone de un sistema sanitario progresivo y escalonado ${ }^{21,23}$.

La organización para la ejecución del apoyo sanitario será consecuencia del planeamiento a todos los niveles, en una Fuerza Operativa Conjunto Combinada (FOCC) constituida en el ámbito de una alianza o coalición, en la cual, la responsabilidad del apoyo sanitario puede ser nacional o multinacional ${ }^{19,20,24}$, 25,26 .

\subsubsection{Apoyo sanitario en operaciones}

Es el conjunto de acciones encaminadas a garantizar la protección de la salud de los componentes de la Fuerza, para mantener su capacidad de combate.

Dentro del apoyo sanitario y como parte fundamental se encuentra la asistencia sanitaria, que es el conjunto de actividades facultativas encaminadas al cuidado directo de la salud del personal.

Se denomina función logística de sanidad ${ }^{27}$ al conjunto de métodos, procesos y actividades homogéneas cuyo objetivo común es proporcionar el personal y los medios sanitarios adecuados para la conservación y recuperación de su salud así como su integridad tanto física como psíquica. 
Las unidades específicas de sanidad dispondrán a su nivel de las capacidades necesarias para ejecutar las actividades (apoyo médico, enfermería, odontológico, veterinario, psicológico y farmacéutico) propias de la función logística de sanidad.

\subsubsection{Principios del apoyo sanitario}

Los principios fundamentales a tener en cuenta para planificar y llevar a cabo el apoyo médico en las operaciones de la OTAN, siguen las directrices marcadas por la Doctrina OTAN ${ }^{20}$ que constituye un marco básico que permite gran flexibilidad en su aplicación y fomenta la cooperación entre los países miembros de la alianza, aunque existan algunas diferencias en las doctrinas nacionales. Los principios que rigen el apoyo sanitario en operaciones ${ }^{21}$ son los siguientes:

\section{Calidad}

El apoyo sanitario en operaciones militares debe proporcionar un nivel de asistencia sanitaria lo más aproximado al prestado en situación de paz en nuestra sociedad.

\section{* Oportunidad}

El despliegue del apoyo sanitario debe cubrir todo el escenario de forma que esté capacitado para intervenir en tiempo y lugar preciso.

\section{* Continuidad}

El despliegue debe alcanzar la capacidad necesaria para mantener el apoyo sanitario durante todas las fases de la operación.

\section{* Confidencialidad}

La información sanitaria tiene carácter clasificado y por tanto no debe ser transmitida a personas u organizaciones que no tengan necesidad de conocerla. 


\section{Disponibilidad}

Los recursos humanos y materiales designados para una posible intervención en operaciones estarán en condiciones de actuar en los plazos establecidos en el planeamiento o ante una variación imprevista.

\section{* Compatibilidad}

Los recursos materiales del apoyo sanitario tendrán el adecuado grado de normalización de forma que puedan ser interoperables.

\section{* Equilibrio}

El apoyo sanitario debe adecuarse a los riesgos previstos de las fuerzas desplegadas. Asimismo en el despliegue sanitario debe existir una adecuación entre los medios de evacuación y de tratamiento.

\section{Economía}

Consiste en emplear sólo los medios sanitarios necesarios y suficientes para cada ocasión con el objetivo de conseguir el máximo rendimiento de los medios empleados.

\section{Flexibilidad}

Es la capacidad de adaptación a las necesidades imprevistas de las operaciones.

\section{Sencillez}

Consiste en concebir planes y procedimientos de fácil ejecución.

Todos estos principios están basados en los criterios admitidos, sobre la práctica profesional de los facultativos sanitarios ${ }^{28}$, teniendo en consideración las condiciones del medio y el marco logístico en el que se desarrollan las operaciones, así como las normas de comportamiento recogidas en el Derecho Internacional Humanitario ${ }^{29}$. 


\subsubsection{Actividades sanitarias en las operaciones}

El Servicio de Sanidad de las Fuerzas Armadas desarrolla diversas actividades sanitarias fundamentales para poder prestar el apoyo sanitario necesario en las operaciones militares. Estas actividades, se resumen en la Figura 1.2 y que se describen a continuación, se enmarcan en los campos sanitarios de la medicina, enfermería, farmacia, veterinaria, odontología y psicología.

\begin{tabular}{|l|}
\hline ACTIVIDADES SANITARIAS EN OPERACIONES \\
\hline \\
\\
- Inteligencia Sanitaria \\
- Prevención Sanitaria \\
- Tratamiento \\
- Evacuación \\
- Abastecimiento y mantenimiento sanitario
\end{tabular}

Figura 1.2. Actividades sanitarias fundamentales en operaciones.

En primer lugar está la inteligencia sanitaria, que proporciona al mando información de interés para el planeamiento y ejecución de las operaciones. La prevención sanitaria, para el mantenimiento de la salud y la prevención de la enfermedad, el tratamiento como parte esencial de la asistencia médica de las lesiones y enfermedades y la evacuación para el traslado de las bajas hacia las instalaciones sanitarias más adecuadas para la asistencia de sus lesiones y enfermedades. Paralelamente a ellas, el abastecimiento y mantenimiento de los recursos sanitarios.

Todas estas actividades se llevan a cabo en tres fases sucesivas: La primera que es la fase preparatoria, la segunda durante la operación y la tercera tras el repliegue del contingente $e^{21,23,30}$. Estas tres fases se describen, de forma resumida, a continuación. 


\section{a. Apoyo sanitario previo a la operación (fase pre-despliegue)}

Durante esta fase de planeamiento y preparación de la operación, la Sanidad Militar orienta su actuación a la selección del personal y a proporcionar apoyo sanitario preventivo a las tropas. Ambas actividades buscan minimizar las bajas, no de combate, que pudieran producirse en la zona de operaciones.

Fundamentalmente las actividades desarrolladas durante esta fase previa recaen en el Instituto de Medicina Preventiva de la Defensa (IMPDEF) y los servicios sanitarios de las unidades. Dichas actividades dan lugar a un informe cuyo contenido aparece en la Figura 1.3.

\begin{tabular}{|l||}
\hline DATOS GENERALES \\
\hline - Situación \\
- Climatologia \\
- Riesgos de desastres naturales \\
- Vias de comunicación (aplicadas a la evacuación \\
sanitaria) \\
- Riesgos medioambientales industriales \\
- Riesgos NBQ \\
\hline GEOGRAFiA HUMANA \\
\hline - Datos e indices demográficos \\
- Razas o etnias \\
- Costumbres y prácticas religiosas \\
- Actitud de la población \\
- Tipos y disponibilidad de drogas ilicitas \\
- Prostitución \\
\hline ENFERMEDADES ENDEMOEPIDÉMICAS \\
\hline - Tipos por mecanismo de transmisión \\
- Calendario de vacunaciones \\
- Cobertura vacunal de la población. \\
- Seroepidemiologia \\
- Pautas de quimioprofilaxis \\
- Resistencia a los antibióticos y quimioresistencia \\
\hline
\end{tabular}

\begin{tabular}{|l|}
\hline HIGIENE Y SANEAMIENTO AMBIENTAL \\
\hline - Agua de bebida \\
- Recursos alimenticios \\
- Residuos urbanos e industriales \\
- Tratamiento de las aguas residuales \\
\hline FLORA Y FAUNA DE INTERES MÉDICO \\
\hline - Botánica médica \\
- Ganaderia (Zoonosis) \\
- Animales callejeros (Incontrolados) \\
- Zoologia médica \\
- Veclores \\
\hline SANIDADES MILITAR Y CIVIL \\
\hline - Organización, capacidades, material \\
- Instalaciones, localización \\
- Contactos \\
- Recursos farmacéuticos \\
- Juicio critico \\
\hline JUICIO CRITICO: CONCLUSIONES $Y$ \\
RECOMENDACIONES \\
\hline - Consideraciones generales y juicio critico \\
\hline - Medidas colectivas de protección a la fuerza \\
- Medidas individuales de protección \\
\hline
\end{tabular}

Figura 1.3. Contenido del informe de la inteligencia sanitaria.

Los principales puntos del informe se resumen a continuación.

- El informe de Inteligencia Sanitaria, con la información de interés científico-sanitario (biológico, ambiental) y militar relativa a la operación. 
- La prevención sanitaria, para la cual se elabora una Normativa Técnica en cada operación, que debe incluir las medidas de prevención sanitaria y los medios para realizarla con efectividad.

- La educación sanitaria, que conlleva programar sesiones informativas para los componentes de la operación, contando con la adecuada información sanitaria que debe mantenerse actualizada a lo largo de toda la operación.

- Los reconocimientos médico general, odontológico y psicológico, que se realizan con arreglo a lo establecido en la normativa de la IGESAN ${ }^{31}$.

\section{b. Apoyo sanitario durante la operación (fase de despliegue)}

Durante esta fase es necesario insistir en las medidas de prevención ya que en este período es cuando más se pueden relajar. Las principales actividades sanitarias irán encaminadas a:

- Vigilancia epidemiológica en tiempo real y control de riesgos (climáticos, infecciosos, psicológicos, etc.).

- Vigilancia constante y valoración global de la salud física y psíquica de las tropas.

- Vigilancia de la morbimortalidad e informe de las-causas de bajas.

- Por último, vigilancia del cumplimiento de las directrices sobre medicina preventiva.

\section{c. Apoyo sanitario al finalizar la operación (fase post-despliegue).}

La continuidad de las medidas preventivas individuales y colectivas debe mantenerse durante un tiempo tras finalizar la operación, siempre que así lo aconsejen los servicios de medicina preventiva. 
En la Figura 1.4 se muestran esquemáticamente las principales actuaciones de cada una de las fases indicadas anteriormente.

\begin{tabular}{|c|c|c|}
\hline FASEPRE-DESPLIEGUE & FASEDEDESPLIEGUE & $\begin{array}{l}\text { FASE POST- } \\
\text { DESPLIEGUE }\end{array}$ \\
\hline $\begin{array}{l}\text {-Informe de Inteligencia } \\
\text { Sanitaria. } \\
\text { - Medidas de prevención } \\
\text { sanitaria. } \\
\text {-Educación sanitaria. } \\
\text { - Reconocimientos médico, } \\
\text { odontológico y psicológico. }\end{array}$ & $\begin{array}{l}\text {-Asistencia médico-quirúrgica. } \\
\text { - Saneamiento ambiental. } \\
\text { - Vigilancia y valoración de la } \\
\text { salud colectiva. } \\
\text { - Informe de causa de bajas. } \\
\text { - Vigilancia del cumplimiento de } \\
\text { las medidas preventivas. } \\
\text { - Valoración e informe de } \\
\text { la situación sanitaria. }\end{array}$ & $\begin{array}{l}\text { - Continuidad de } \\
\text { las medidas } \\
\text { preventivas } \\
\text { individuales y } \\
\text { colectivas. } \\
\text { - Encuesta de salud. } \\
\text { - Consulta médica si } \\
\text { procede. }\end{array}$ \\
\hline
\end{tabular}

Figura 1.4. Fases y actividades del apoyo sanitario en las operaciones.

\subsubsection{Escalonamiento sanitario en las operaciones}

Se entiende por escalón sanitario al conjunto organizado de medios humanos y materiales con una capacidad determinada, que presta apoyo sanitario a una unidad u organización operativa.

Mientras que el escalonamiento sanitario se encarga de la distribución de los medios y capacidades sanitarias en el escenario de las operaciones, con el fin de asignar los medios y cometidos más elementales a los órganos que despliegan a vanguardia y los recursos más complejos, y con mayor capacidad asistencial, a los más retrasados.

El Servicio de Sanidad en operaciones se articula en escalones y en cada uno de ellos se despliegan unas formaciones sanitarias cuyas capacidades deben ser adecuadas a la misión. Habitualmente se consideran cuatro escalones (Figura 1.5). 
Todos los escalones sanitarios están conectados entre sí constituyendo una estructura funcional denominada cadena, por la que se pueden transmitir órdenes e instrucciones de carácter exclusivamente técnico. Partiendo del estudio de las diferentes formas de escalonar el Servicio se llega a los actuales conceptos que configuran nuestra Doctrina ${ }^{21,23,32}$ actual. Los escalones son los siguientes:

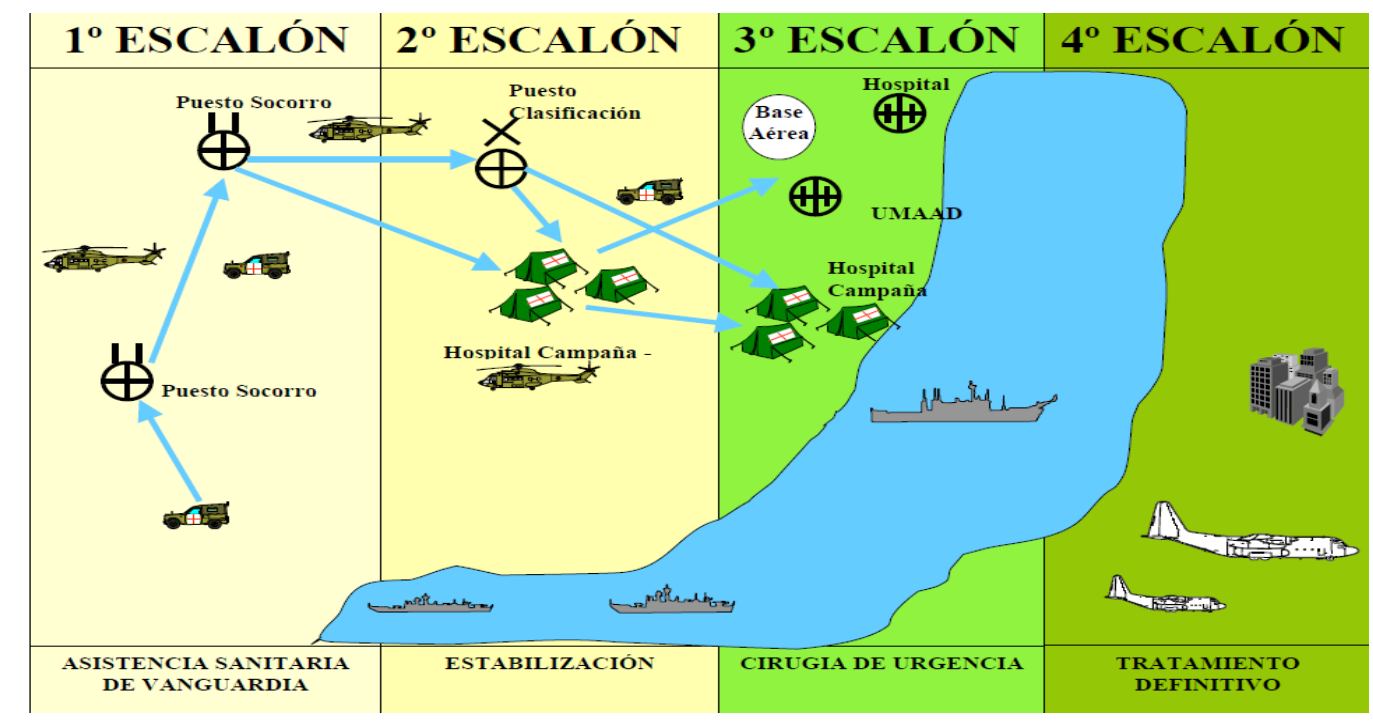

Figura 1.5. Esquema que muestra los escalones en los que se articula el servicio de sanidad en operaciones ${ }^{21}$.

\section{Primer escalón.}

La primera Formación Sanitaria de Tratamiento (FST) que actúa en el primer escalón es el Puesto de Socorro (PS). Debido a las limitaciones humanas y materiales que normalmente tienen estos PS sus actuaciones se reducen a: actuaciones de reconocimiento, realización de curas, clasificación inicial, registro de bajas y la anotación de los datos en la Ficha Médica de Campaña, en cuya redacción se pondrá la máxima atención para proporcionar documentación detallada de las acciones realizadas y de este modo facilitar el trabajo de la formación sanitaria superior, donde se cumplimentara la Ficha de Evacuación. ${ }^{23}$, 33,34. También son de aplicación en este escalón, todas aquellas medidas de 
urgencia destinadas a salvar la vida, un miembro, o preparar la baja para su evacuación.

En este primer escalón no hay atención odontológica primaria, algo que se debería tener en cuenta en un futuro, porque ya lo contempla la doctrina $\mathrm{OTAN}^{21,35,36}$ En la Figura 1.6 se muestra la doctrina OTAN sobre la atención dental y maxilofacial.

EXTEND OF DENTAL AND OROMAXILLOFACIAL TREATMENT AT ROLE 1-3

\begin{tabular}{|c|c|c|c|c|c|c|}
\hline Unit & Module & Capabilities & Outcome & Objective & Personnel & Equipment \\
\hline Role 1 & $\begin{array}{l}\text { Emergency } \\
\text { dental care }\end{array}$ & $\begin{array}{l}\text { - (Provide first aid) } \\
\text { - Provide emergency dental } \\
\text { care } \\
\text { - Provide pain relief in oro- } \\
\text { facial region }\end{array}$ & $\begin{array}{l}\text { - Prepared for medevac } \\
\text { - Prepared for a scheduled } \\
\text { / non-urgent appointment } \\
\text { at higher role } \\
\text { - Return to duty }\end{array}$ & \begin{tabular}{|l} 
Temporary dental \\
treatment
\end{tabular} & $\begin{array}{l}\cdot \mathrm{DO} / \mathrm{OS} \\
\cdot \mathrm{DA}\end{array}$ & $\begin{array}{l}\text { - Mobile dental unit } \\
\text { - Field sterilisation unit or } \\
\text { enough supplies to treat } \\
\text { at least } 30 \text { patients }\end{array}$ \\
\hline \multirow[t]{2}{*}{ Role 2} & $\begin{array}{l}\text { Primary dental } \\
\text { care }\end{array}$ & $\begin{array}{l}\text { - Provide primary dental care } \\
\text { - Provide intraoral radiography } \\
\text { and diagnosis }\end{array}$ & \multirow{2}{*}{$\begin{array}{l}\text { - Prepared for medevac } \\
\text { - Prepared for revisit } \\
\text { - Prepared for a scheduled } \\
\text { / non-urgent appointment } \\
\text { at higher role } \\
\text { - Return to duty }\end{array}$} & \multirow[t]{2}{*}{$\begin{array}{l}\text { Temporary and /or } \\
\text { definitive dental } \\
\text { treatment }\end{array}$} & \multirow[t]{2}{*}{$\begin{array}{l}\cdot \mathrm{DO} / \mathrm{OS} \\
\cdot \mathrm{DA}\end{array}$} & $\begin{array}{l}\text { - Mobile or fixed dental unit } \\
\text { - Dental radiology } \\
\text { equipment, preferably } \\
\text { digital (mobile or fixed) } \\
\text { - Sterilisation unit }\end{array}$ \\
\hline & $\begin{array}{l}\text { Dental alveolar } \\
\text { surgery }\end{array}$ & $\begin{array}{l}\text { - Provide dental alveolar } \\
\text { surgery }\end{array}$ & & & & - Surgical devices \\
\hline \multirow[t]{2}{*}{ Role 3} & $\begin{array}{l}\text { Secondary } \\
\text { dental care }\end{array}$ & $\begin{array}{l}\text { - Provide secondary dental } \\
\text { care } \\
\text { - Provide panoramic } \\
\text { radiography and diagnosis }\end{array}$ & \multirow{2}{*}{$\begin{array}{l}\text { - Prepared for medevac } \\
\text { - Hospitalize } \\
\text { - Prepared for revisit } \\
\text { - Prepared for a scheduled } \\
\text { / non-urgent appointment } \\
\text { at higher role } \\
\text { - Return to duty }\end{array}$} & \multirow[t]{2}{*}{$\begin{array}{l}\text { Definitive dental } \\
\text { treatment }\end{array}$} & \multirow{2}{*}{$\begin{array}{l}\text { - DO } \\
\cdot \text { DA } \\
\text { - OMFS/OS } \\
\text { - SA }\end{array}$} & $\begin{array}{l}\text { - Fixed dental unit } \\
\text { - Dental radiology } \\
\text { equipment, preferably } \\
\text { digital (intraoral and } \\
\text { panoramic) }\end{array}$ \\
\hline & $\begin{array}{l}\text { Oro- } \\
\text { maxillofacial } \\
\text { (OMF) surgery }\end{array}$ & $\begin{array}{l}\text { - Provide oro-maxillofacial } \\
\text { surgery }\end{array}$ & & & & $\begin{array}{l}\text { - Surgical operatory } \\
\text { Note: } \\
\text { Access to CT scanning } \\
\text { modality if available at role } \\
3 .\end{array}$ \\
\hline
\end{tabular}

Note: everv hiqher role includes all lower roles' capabilities

Figura 1.6. Resumen, en su versión original ${ }^{35}$, de los contenidos de la atención dental y maxilofacial en los Roles 1,2 y 3 contemplados en la doctrina OTAN.

\subsubsection{Segundo escalón.}

Para dar una mayor coherencia al escalonamiento sanitario con la nueva doctrina sanitaria de OTAN ${ }^{20}$, dentro del segundo escalón sanitario, se pueden distinguir dos tipos de escalones ${ }^{23}$ :

Segundo escalón ligero constituido normalmente por los Puestos de Cirugía Ligero Avanzado (PCLA) que se integran en los despliegues de las Brigadas y 
que disponen de las siguientes capacidades asistenciales: Cirugía de control de daños (siempre que se les asigne un cirujano y un anestesista) y Hospitalización (10 camas). Como estos puestos no disponen de la capacidad necesaria para desdoblarse y seguir garantizando la eficacia y continuidad del apoyo durante su movimiento, se apoyarán en otras formaciones sanitarias equivalentes (PCLA de una unidad colateral) o superiores: Escalón Médico Avanzado Terrestre/Equipo de Cirugía Avanzado (EMAT/ECA).

Segundo escalón reforzado constituido normalmente por los EMAT/ECA que puede disponer de diferentes especialidades para desarrollar la mayor parte de los cometidos del Servicio de Sanidad: cirugía principal, cuidados intensivos, cuidados postoperatorios esenciales y capacidad básica de exploración por imágenes. Para poder seguir prestando el apoyo durante el movimiento de los PCLA, en determinadas fases de una operación, los EMAT/ECA se desplegarán lo más a vanguardia posible en el despliegue de la Brigada a la que apoya.

Este escalón si dispondrá de apoyo odontológico, disponibilidad específica de servicios de radiodiagnóstico y laboratorio, y Telemedicina ${ }^{37,38,39}$. La OTAN define la telemedicina como, "el uso de tecnologías avanzadas de telecomunicaciones para el intercambio de información de salud y proporcionar una atención de los servicios de salud a través de barreras geográficas, de tiempo, sociales y culturales". También se la define como la medicina practicada a distancia.

A través de la telemedicina, podemos proporcionar mayor acceso a los especialistas clínicos, que no necesitan ser desplegados en la zona de conflicto con el fin de facilitar la aplicación de sus conocimientos, pudiendo aprovechar su experiencia en muchos lugares al mismo tiempo. La Telemedicina atenderá prioritariamente a las bajas tipo P1 o T1 y tipo P2 o T2 de la clasificación de las bajas sanitarias por su urgencia ${ }^{20,21,23}$. En cualquier caso se debe tener en cuenta que todos los tipos de bajas son susceptibles del apoyo, en caso de que se considere necesario por parte de la unidad solicitante, y para una especialidad sanitaria determinada (odontología, salud mental, cardiología, dermatología...... $)^{40}$.

En definitiva se puede concluir diciendo sobre la Telemedicina que el apoyo que representa, a nivel táctico ${ }^{41}$, resulta esencial ya que con sus actuaciones se puede encaminar adecuadamente la evacuación sanitaria hacia la formación sanitaria que cuente con las capacidades necesarias para su tratamiento. 


\subsubsection{Tercer escalón}

La principal formación de tratamiento esencial en el escalonamiento de la sanidad en operaciones es: el Hospital de Campaña (HOC) ${ }^{26,42}$ que proporciona apoyo de tercer escalón sanitario a las Grandes Unidades desplegadas en el Teatro de Operaciones (TO).

Se trata de una formación logística sanitaria desplegable de diagnóstico y de tratamiento médico-quirúrgico y hospitalización, así como de servicios especializados (Asistencia odontológica, Medicina preventiva, Hematología, Análisis clínicos y radiología, Psicología y Veterinaria) y farmacéuticos.

Al ser el HOC un órgano asistencial de carácter modular y activación progresiva, podrá ir desplegando sus elementos especializados en el TO de forma escalonada según las necesidades de cada tipo de operación. Con la principal idea de intentar evitar que el paciente tenga que ser evacuado, cuando puede ser intervenido, tratado, medicado y pasar la convalecencia en el, sin necesidad de trasladarlo a un escalón superior. Pero en caso de no poder atenderlo, el HOC dispondrá de los medios de evacuación necesarios para facilitar el traslado de bajas al cuarto escalón. En la Figura 1.7 se presenta un esquema de la configuración de un HOC.

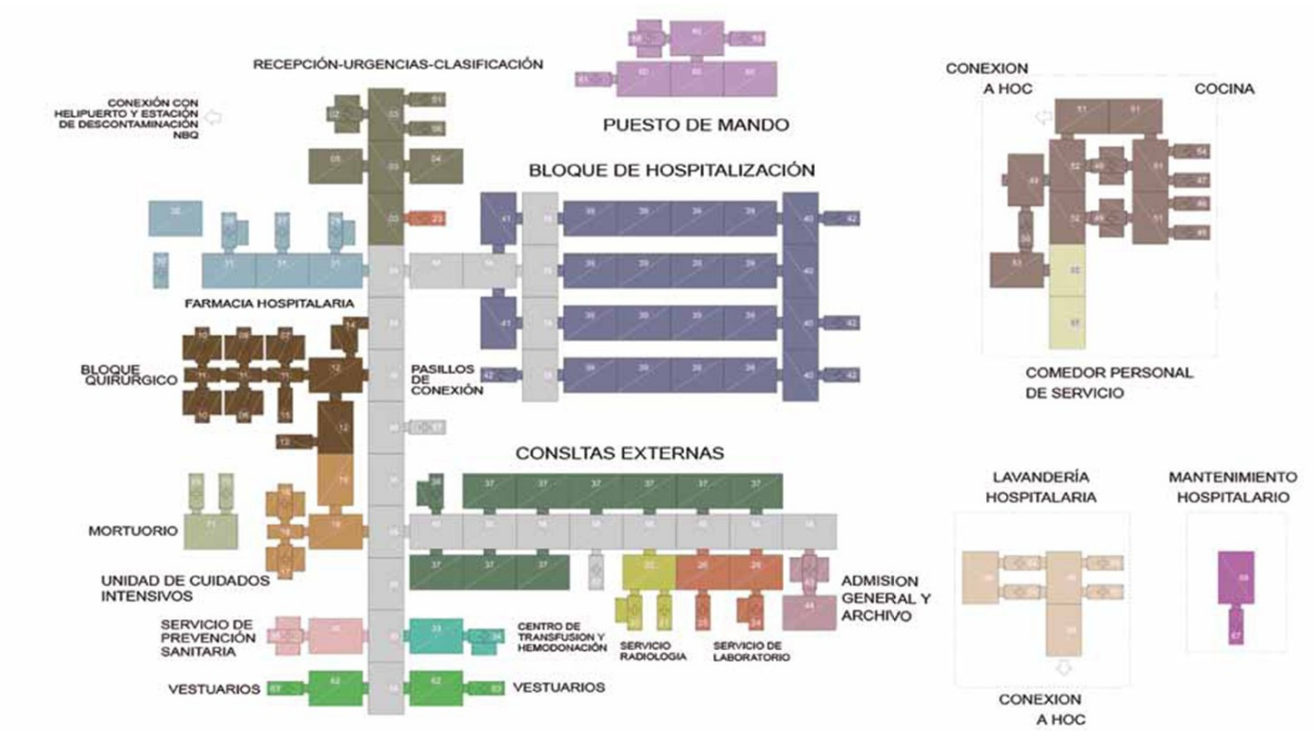

Figura 1.7. Composición modular de un hospital de campaña ${ }^{42}$. 


\subsubsection{Cuarto escalón}

Son instalaciones fijas, que se establecen sobre la infraestructura nacional o bien en territorio aliado o de la nación anfitriona.

Está constituido por la Red Sanitaria Militar (hospitales de Defensa) y el Servicio Nacional de Salud (hospitales de la Seguridad Social). Presta el apoyo sanitario más completo y se pueden incluir también hospitales de Defensa de la nación anfitriona o de naciones aliadas ${ }^{21,23,30}$.

\subsubsection{Adaptación al escalonamiento de sanidad en la doctrina OTAN.}

Una vez descrito el escalonamiento de sanidad en operaciones con sus correspondientes formaciones sanitarias, es necesario adaptar éstas a los diferentes roles, término que se aplica a las capacidades médicas de una unidad sanitaria militar, y que están marcados en la doctrina aliada ${ }^{20}$.

Actualmente se contemplan en OTAN cuatro roles (1, 2, 3 y 4)de los cuales el rol 2 se articula en dos niveles: Role 2 "basic" (Role 2B) con cirugía de control de daños y Role 2 "Enhanced" (Role 2E) que debe proporcionar todas las capacidades de la función básica del Role 2B pero mejoradas, ya que tiene más funciones como resultado de instalaciones adicionales y mayores recursos.

En nuestro escalonamiento sanitario en operaciones, los escalones sanitarios (1. ${ }^{\circ}, 2 .{ }^{\circ}$ Ligero, $2 .{ }^{\circ}$ Reforzado, $3{ }^{\circ}{ }^{\circ}$ Y $4 .{ }^{\circ}$ ) difieren de los roles de OTAN ya que la denominación de estos últimos $(1,2 \mathrm{~B}, 2 \mathrm{E}, 3$ y 4) dependen de las capacidades que se desplieguen en cada una de las formaciones sanitarias. Las capacidades de cada Role son las siguientes:

ROLE 1 comprende la atención básica y las primeras curas para una inmediata evacuación posterior. El ROLE 2 añade a las capacidades del Role1 la consulta médica, el análisis e intervenciones quirúrgicas y la evacuación del paciente, una vez intervenido y estabilizado. El ROLE 3 debe proporcionar todas las capacidades del Role 2 y llevar a cabo un número variable de especialidades quirúrgicas. Finalmente, el ROLE 4, que es el único no desplegable, se corresponde con la capacidad de un Hospital General, normalmente 
proporcionado por el país de origen de la víctima (o de otro miembro de la Alianza) y está dotado de todas las capacidades asistenciales para garantizar el tratamiento definitivo de las lesiones ${ }^{20,23}$.

Volvemos a insistir en la no equivalencia completa entre Role 1 y Primer Escalón Sanitario debido a que, entre otras funciones, el Role1 puede disponer de una mínima capacidad de atención dental primaria o de urgencia $^{43}$ (figura 1.7). En cualquier caso, en la Figura 1.8 se presenta una tabla de equivalencias. Tabla que debe ser entendida en términos generales, ya que bajando a los detalles, como acabamos de indicar, existen diferencias.

\begin{tabular}{|l|l|l|}
\hline \multicolumn{1}{|c|}{$\begin{array}{c}\text { ESCALONES } \\
\text { SANITARIOS }\end{array}$} & $\begin{array}{l}\text { FORMACIONES } \\
\text { SANITARIAS }\end{array}$ & $\begin{array}{l}\text { ADAPTACIÓNA } \\
\text { ROLES DE OTAN }\end{array}$ \\
\hline $1 .^{\text {er }}$ Escalón & PS & Role 1 \\
\hline $2 .^{\text {o }}$ Escalón ligero & PCLA & $\begin{array}{l}\text { Role 1 } \\
\text { Role 2B }\end{array}$ \\
\hline $2 .^{\text {o }}$ Escalón reforzado & EMAT/ECA & $\begin{array}{l}\text { Role 1 } \\
\text { Role 2B } \\
\text { Role 2E }\end{array}$ \\
\hline $3 .^{\text {er }}$ Escalón & HC & $\begin{array}{l}\text { Role 2E } \\
\text { Role 3 }\end{array}$ \\
\hline $4 .^{\text {o }}$ Escalón & HOSDEF (en TN) & Role 4 \\
\hline
\end{tabular}

Figura 1.8. Equiparación entre los escalones con los roles que describe la doctrina OTAN.

\subsubsection{Seguimiento de evacuación a TN por motivos médicos.}

Las peticiones de repatriación, por causa medica, son solicitadas al Comandante del Mando de Operaciones (CMOPS) por los Jefes de Fuerza (JEFZAs) para el personal a sus órdenes. En este proceso será la Sección de Sanidad Operativa del Mando de Operaciones (MOPS) la responsable de asesorar, planear y auxiliar en materia de Sanidad Operativa. Efectuará el seguimiento de las bajas médicas y, 
cuando proceda, participará en la gestión de su evacuación desde la Zona de Operaciones (ZO) al Territorio Nacional (TN), así como su seguimiento en el caso de que no causen baja en la operación. Las bajas médicas evacuadas a TN requerirán de una nueva certificación de aptitud para poder volver al despliegue y reincorporarse a la operación. En la figura 1.9 se describe la cadena de asistencia y evacuación.

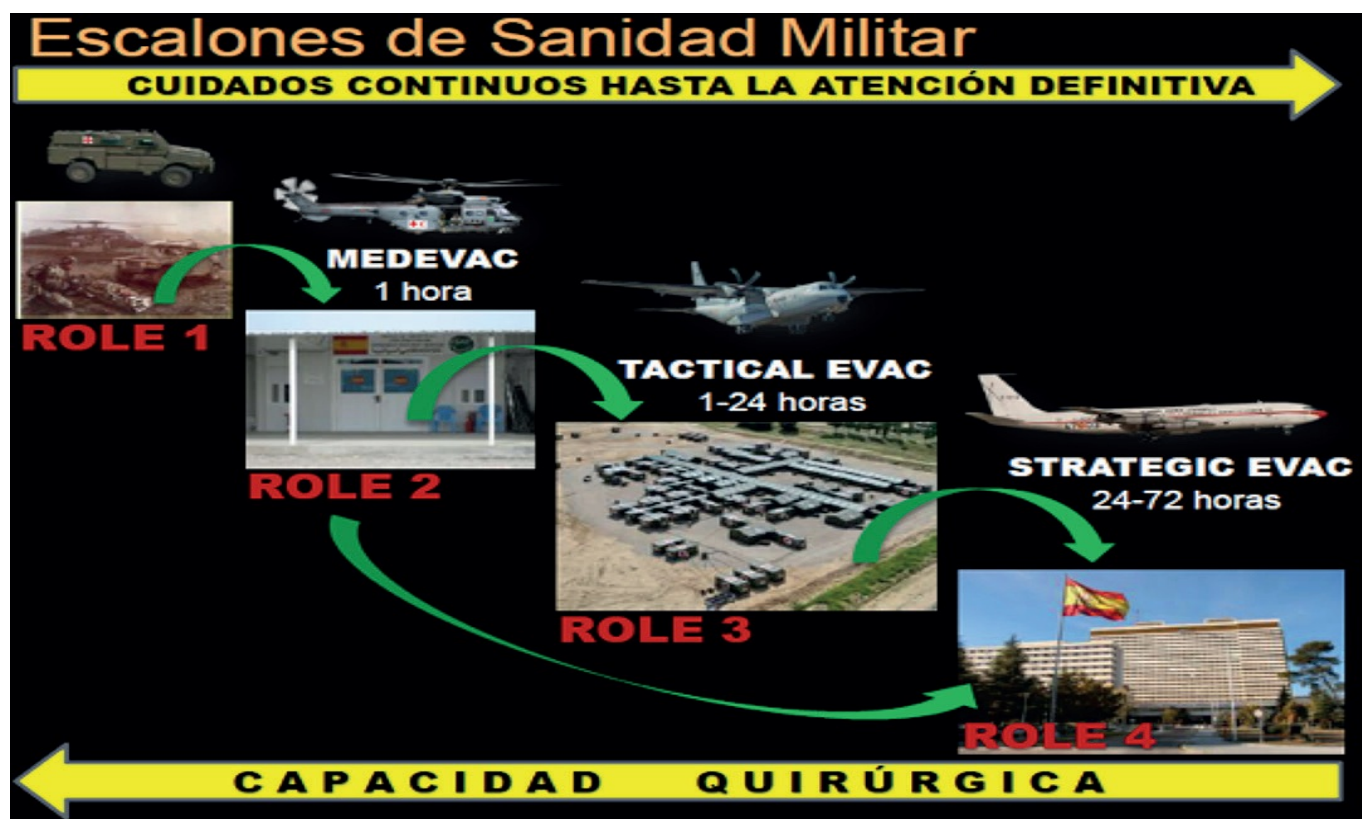

Figura 1.9. Cadena de asistencia y evacuación ${ }^{39}$.

Se entiende por baja médica, a la baja temporal o definitiva por enfermedad o daño físico. Solo puede ser solicitada por un Oficial del Cuerpo Militar de Sanidad (CMS) Médico y concedida por la Autoridad Militar que corresponda.

Los JEFZAs, de acuerdo con la estimación de tiempo de baja por causa médica y a propuesta del Jefe de Sanidad en la ZO, deberán solicitar la evacuación a TN, para su ingreso, diagnóstico y tratamiento en el Hospital Central de la Defensa (HCD), causando baja en la operación y la consiguiente reincorporación a su destino de procedencia orgánica. Esta baja no exigiría reemplazo si es asistida de forma inmediata y consigue su recuperación y reintegración a su puesto en $\mathrm{ZO}$ en un plazo inferior a quince días ${ }^{44}$. 


\subsubsection{Exigencias de cambio en la prevención sanitaria de las FAS}

Las Fuerzas Armadas españolas han experimentado un importante cambio, cualitativo y cuantitativo, en los últimos 20 años. Quizás lo más significativo de dicho cambio ha sido el paso de un ejército multitudinario de reemplazo a un ejercito profesional, muy inferior en número, pero muy superior en formación, profesionalidad y medios técnicos.

Estos cambios junto con las circunstancias económicas actuales han afectado también a la Sanidad Militar. Una de las consecuencias importantes que se ha puesto de manifiesto es la necesidad de profundizar en los esfuerzos de coordinación y convergencia entre los Ejércitos, el Mando de Operaciones (MOPS) y la Inspección General de Sanidad de la Defensa (IGESANDEF). Punto fundamental para conseguir la máxima eficacia en la organización y prestación del apoyo sanitario. Entre otras cosas, se ha realizado una reorganización de la Red Hospitalaria de la Defensa reestructurándose los centros sanitarios, transformándose o desapareciendo, obedeciendo a la racionalización de la Red Sanitaria Militar ${ }^{45,46,47,48,49,50,51}$. A la vez que se sucedían estos cambios, también ha variado la situación de la asistencia sanitaria al personal de FAS a raíz de la posibilidad de elección entre la Sanidad Militar, las entidades de seguro de asistencia sanitaria privadas, o el Sistema Público de Salud, para todo el personal sujeto al régimen especial de la Seguridad Social de las FAS $^{51,52,53,54}$.

Estos cambios han provocado un enfoque diferente de la Sanidad Militar, respecto a tiempos pasados, siendo las funciones más importantes actualmente las funciones Logístico-Operativa y Pericial, relegando a la función asistencial a un segundo plano, pero demostrando por otro lado que la medicina preventiva ha ganado en relevancia, especialmente en el ámbito de las operaciones militares $^{51,55,56,57}$.

En la actualidad, basándose en diferentes estudios sistemáticos, como el que contiene la presente memoria, se está demostrando que el desarrollo de la medicina preventiva disminuye la incidencia de las enfermedades y bajas no de combate $^{58,59}$ que pueden ser potencialmente una amenaza mayor que las bajas producidas en combate, lo que afectaría gravemente a la moral y a la efectividad de las unidades operativas y por tanto al éxito global de la misión. 
Por ello el conocimiento y aplicación de medidas preventivas tiene una gran importancia para los ejércitos, en su preocupación por proteger la salud de sus miembros y, además, para conservar el potencial operativo de la fuerza.

En 2009 se decretan Reales Ordenanzas que en lo relativo a la salud, en su artículo 40 del Capítulo II, dice "prestara especial atención y cuidado a todos los aspectos que afecten a la salud y a la prevención de conductas que atenten contra ella"60.

La dedicación al cuidado de la salud en su sentido más amplio, en cuanto al mantenimiento de la misma y a la prevención de enfermedades y a la mejor capacidad física, debe ser una finalidad propia del militar, no solo para la mejor eficacia en sus funciones sino también como refuerzo de su disciplina física y mental $^{56,61}$.

\subsubsection{Desarrollo de la prevención sanitaria}

En el nuevo marco surgen nuevas figuras que adquieren gran importancia en las operaciones y misiones. Una de ellas es el asesoramiento sanitario que tiene que ver con las actividades preventivas ${ }^{21,55}$ que conforman el apoyo sanitario. Las fuentes del asesoramiento son los estudios realizados sobre el personal, por ejemplo el odontológico de esta memoria, y la información que se recibe de la zona de operaciones ( $\mathrm{ZO}$ ) antes del despliegue. Todo este trabajo está coordinado por la inteligencia médica sanitaria ${ }^{62}$ cuya misión es la recogida y análisis de la información de interés sanitario. De este modo es posible obtener un conocimiento profundo de las zonas de operaciones y realizar una valoración de las amenazas, tipos de bajas, enfermedades transmisibles, lesiones por calor o frío, accidentes, artrópodos transmisores de enfermedades, etc.

Una vez conocidas las amenazas, se pueden aplicar las medidas preventivas ${ }^{55,63,64}$ adecuadas, como las inmunizaciones, quimioprofilaxis, desinsectación, educación sanitaria, etc., que se aplicarán tanto antes como después del despliegue y, naturalmente, durante la permanencia en la ZO. Estas actuaciones del servicio de sanidad militar son de gran importancia para los ejércitos, en su preocupación por proteger la salud de sus miembros y por la conservación del potencial operativo de la fuerza. 
Asimismo son muy importantes las medidas de promoción de la salud ${ }^{57,65}$ de todo el personal militar, principalmente mediante la educación sanitaria. Educación que les suministra las herramientas necesarias para que cada miembro, de forma individual, sea consciente, en todo momento, de los riesgos a los que se enfrenta y cuáles son las medidas que debe adoptar en cada caso para conservar un buen estado de salud. La consecuencia inmediata es contribuir a mantener la capacidad operativa de su unidad.

Las líneas anteriores han servido para demostrar la importancia y amplitud del campo de la medicina preventiva militar. Si además se añaden las peculiaridades de la profesión, donde todas las facetas sanitarias tienen un papel a desarrollar, es absolutamente necesario disponer de una sanidad militar multidisciplinar ${ }^{31,66}$ con la participación de expertos de las diferentes especialidades que tienen influencia directa en las misiones y operaciones.

\subsubsection{Actividades preventivas en los despliegues.}

La implantación de las medidas de prevención sanitaria se inicia en la fase previa al despliegue, continúa durante el desarrollo de la operación y se completan en el período posterior a la operación hasta el regreso a Territorio Nacional (TN). Afecta a todo el personal del TO/ZO, que debe ser alertado sobre las medidas necesarias de protección personal e instruida en consonancia ${ }^{21,23,55}$, $56,63,67$.

\subsection{Fase previa al despliegue}

Para esta fase se establecen unos criterios que deben incluir:

- Obtener, en los plazos establecidos, la calificación adecuada en el reconocimiento médico, la revisión dental y la evaluación psicológica ${ }^{31}$.

- Tener actualizado el calendario de vacunaciones, tanto el módulo básico como el específico (éste se determinará en cada misión u operación). Disponer de la Cartilla de Vacunación, con validez nacional e internacional, la cual debe llevarse consigo, conservarla y tenerla actualizada $^{64}$. 
- Haber cumplimentado las pruebas de identificación sanitaria ${ }^{68}$.

- Haber recibido educación sanitaria general y específica de la operación prevista e información, de manera individual o colectiva, de las medidas preventivas a adoptar en esa zona $^{55,57,63,69}$.

\subsection{Fase de despliegue}

Durante esta fase es necesario realizar las siguientes actividades:

- Continuación del calendario de vacunación y de la quimioprofilaxis, si procede.

- Valoración global de la salud del personal a través de los reconocimientos médicos establecidos y valoración continuada de la situación de prevención sanitaria del escenario y de las posibles situaciones generadoras de estrés.

- Vigilancia de la morbilidad-mortalidad y establecimiento de una red de alerta sanitaria conforme a los datos de los puntos anteriores.

\subsection{Fase posterior al despliegue}

Valoración del estado de salud del personal, incluyendo un reconocimiento médico al regreso de la misión, que debe ser realizado en la ZO.

Los cuestionarios de salud generados serán remitidos al Botiquín de la UCO de origen, en donde el servicio médico será responsable del seguimiento de los resultados, en especial, si hubiera habido alguna situación que pudiera haber afectado a la salud de sujetos $\operatorname{concretos}^{31,69}$.

Continuar con las medidas preventivas (vacunaciones y quimioprofilaxis) ya que los calendarios específicos deberán completarse, posteriormente, con las dosis y revacunaciones pertinentes ${ }^{64}$. 


\subsubsection{Organización de la prevención sanitaria}

Se sigue el esquema de escalones a los que hacen referencia los epígrafes 1.2.5.1, 1.2.5.2, 1.2.5.3 y 1.2.5.4 y la figura 1.9. (pgs. 18-23).

\subsection{Primer y segundo escalón}

En este apartado la normativa indica que el personal sanitario tiene la responsabilidad de la formación y aplicación de las medidas de prevención en el ámbito de su competencia. Función que depende de los medios disponibles y, en su caso, de la derivación de las actuaciones preventivas que requieran personal o equipo especializado. Además el personal sanitario debe mantener una relación permanente con el Mando a través de su función inspectora y asesora porque su apoyo e implicación, es indispensable para la protección y promoción de la salud de la $\operatorname{tropa}^{55,59}$.

\subsection{Tercer escalón.}

Entre las actuaciones que corresponden a este escalón está la del oficial médico especialista en Medicina Preventiva y Salud Pública (MPSP). Se encargará de constituir equipos específicos para la investigación epidemiológica, inmunizaciones, quimioprofilaxis preventiva, estrés de combate y controlar la ejecución en los escalones inferiores, revisando la planificación de la operación donde se debieron incluir los riesgos sanitarios y las medidas a adoptar. Su responsabilidad comprende toda el Área de Operaciones ${ }^{42,55}$.

\subsection{Cuarto escalón.}

En este cuarto escalón se realizan estudios y se proponen las medidas para elaborar la Normativa Técnica de prevención sanitaria para la Fuerza. Desde este cuarto escalón se ejerce la dirección y coordinación y se realizan las actividades de investigación y control epidemiológico y sanidad ambiental relativa a la operación. Es el tercer y último eslabón en la red de alerta sanitaria ${ }^{55,70}$. 


\subsubsection{Medidas higiénicas}

La primera meta de la prevención es conseguir que todo el personal de las FAS sea consciente de la importancia y necesidad de una buena higiene personal para la cual deben adquirir y practicar hábitos higiénicos correctos ${ }^{57,63,65}$.

El oficial médico asesorará al jefe de la Unidad y, auxiliado por el resto del personal sanitario (odontólogos, psicólogos, veterinarios y enfermeros), impartirá educación sanitaria en las conferencias periódicas, en el reconocimiento diario, y en general aprovechará todas las oportunidades que se presenten para ello. Asimismo instruirá a los suboficiales responsables, sobre las normas higiénicas a observar en operaciones.

El objetivo de la educación sanitaria es conseguir que el profesional de las FAS adquiera disciplina sanitaria, de manera que cuando adopte una medida sanitaria sea consciente de que se está autoprotegiendo, y lo haga pensando en mantenerse sano y operativo para así, poder realizar, en las mejores condiciones, la misión encomendada evitando ser una baja no de combate.

En este cometido de prevención de la sanidad militar, hay que hacer especial hincapié, con el colectivo probablemente más vulnerable a las alteraciones de la salud, que es el personal militar integrado en destacamentos que operan en territorios menos accesibles en la distancia y en el tiempo y con infraestructuras precarias. Para ellos, es fundamental el mantenimiento de un nivel higiénico individual adecuado, y que todos los integrantes de la unidad velen para que la higiene colectiva sea la mejor posible.

En este apartado le dedicaremos una especial atención a la higiene bucodental.

\subsection{Higiene bucodental}

En operaciones una importante causa de bajas son las afecciones bucodentales. Estas bajas, que son fácilmente prevenibles, pueden suponer una disminución de la operatividad de la unidad al afectar a personal que, aunque habitualmente no necesite el ingreso hospitalario, verá seriamente reducida su capacidad de acción debido al dolor, inflamación o infección. Por eso es bueno invertir tiempo 
en fomentar medidas de medicina preventiva encaminadas a reducir los factores de riesgo e incrementar el estado de salud y bienestar bucodental del personal $\operatorname{militar}^{57,63,65}$. Entre las medidas básicas para mantener, una buena higiene bucodental en operaciones, citaremos:

- Cuidar el estado bucal mediante revisiones periódicas (esto se debe hacer en TN).

- Lavarse los dientes al menos 1 vez al día, preferentemente antes de acostarse. Si es posible, mucho mejor después de cada comida. Se debe emplear un cepillo de dureza intermedia, con movimientos verticales en la dirección encía a diente.

- Usar preferentemente pastas de dientes con flúor, caso de no disponer de ella el perborato, bicarbonato sódico o cepillado en seco también pueden servir.

- Conviene usar el hilo dental antes de acostarse para arrastrar restos de comida entre las piezas dentales

- Lavarse los dientes con agua que haya sido autorizada para beber.

Estas lecciones sobre higiene conviene recordarlas con frecuencia y de una forma gráfica muy sencilla. Por ejemplo con carteles como el de la figura 1.10.

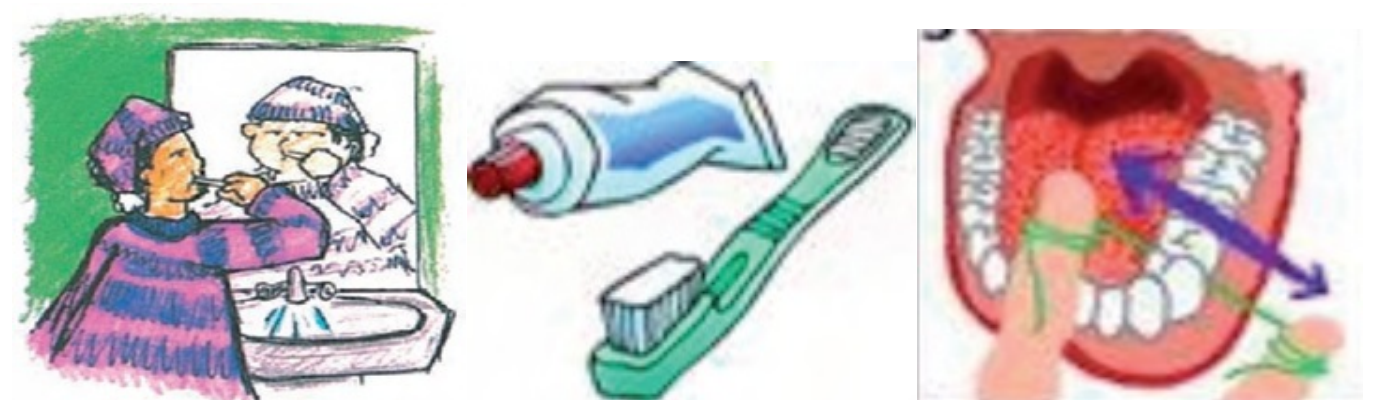

Figura 1.10. Instrucciones de higiene dental ${ }^{65}$. 


\subsubsection{La odontología en la sanidad militar}

Como ya se indicó, debido al proceso de transformación y la experiencia acumulada por las FAS españolas durante las múltiples y variadas operaciones internacionales en las que ha participado y continúa haciéndolo, evidencia la necesidad de disponer de una Sanidad Militar operativa, flexible, interoperable, proyectable y de calidad, que cuente con los medios de personal y material necesarios para cumplir su misión. Por ello ha tenido que reorganizarse para poder realizar sus funciones en las mejores condiciones posibles en su trabajo diario en territorio nacional (TN) pero sobre todo en las múltiples y variadas operaciones internacionales en las que participa. Un elemento importante en la sanidad militar lo ocupa la odontología a la cual se le asignan diferentes tipos de $\operatorname{cometidos}^{17}$ :Asistencial, pericial, de apoyo a operaciones y preventivo. Los cuatro son primordiales tanto en las Bases Militares como en Despliegues u Operaciones en el extranjero y están relacionados entre sí. Indicaremos el contenido de cada uno con un breve comentario, extendiéndonos en la función preventiva, por considerarla el sujeto principal que aborda esta memoria.

\subsubsection{Odontología asistencial}

Su función consiste en la valoración, diagnóstico y tratamiento de las urgencias bucodentales con el propósito de recuperar al personal para el servicio. En la actualidad hay que tener en cuenta que todo militar profesional tiene cobertura sanitaria mediante el Instituto Social de las Fuerzas Armadas (ISFAS) o entidad aseguradora privada, cuya cartera de servicios incluye además la posibilidad de realizar prestaciones bucodentales complementarias..$^{17,52,53,71 .}$

\subsubsection{Odontología pericial}

La función pericial consistirá en asesorar al Jefe de los Servicios Sanitarios en el ámbito oral haciendo la valoración de todas las lesiones producidas y evaluando las bajas temporales para el servicio por causas bucodentales.

Los Oficiales Odontólogos podrán ser comisionados como peritos para colaborar con los Equipos de Identificación de Víctimas, auxiliándoles en todo lo concerniente a los procesos de identificación odontológica, con la finalidad de 
recuperar, identificar y trasladar los restos mortales del personal militar fallecido fuera del Territorio Nacional (TN). ${ }^{17,72,73,74,75}$.

\subsubsection{Odontología de apoyo a operaciones}

El cometido de Apoyo a Operaciones ha pasado a ser primordial dejando en un segundo plano a la sanidad asistencial, tanto dentro como fuera del territorio nacional. Su misión consistirá en la selección, conservación y recuperación del personal al servicio de las FAS en lo relativo a la salud e higiene bucodental y en la familiarización de los Oficiales Odontólogos con el material y equipo tanto de las Formaciones Sanitarias de Tratamiento (FST) como de los Hospitales de Campaña (HOC), por si fueran comisionados en dichas misiones ${ }^{23,76,77}$.

Los Medios Odontológicos Básicos del Equipo de Odontología (EODO) en Operaciones son: el equipo o unidad dental, el sillón odontológico y todo aquel instrumental y material necesario para el cumplimiento de la misión.

En despliegues iniciales se suelen utilizar equipos odontológicos portátiles y sillones dentales desmontables que tienen una capacidad operativa muy limitada, pero que presentan gran capacidad táctica (portabilidad).

En las operaciones no bélicas de suficiente entidad y gran duración, los EODO se potencian gracias a la adquisición de sillones y equipos dentales más robustos con mayor capacidad operativa y normalmente dotados con equipos diagnósticos convencionales y más recientemente con equipos de radiografía digital.

Los $\mathrm{EODO}^{23}$ en los despliegues se escalonan de la siguiente manera: En el primer escalón no hay. En el segundo escalón ligero tampoco hay. En el segundo escalón reforzado hay, al menos, uno. En el tercer escalón hay, al menos, dos y en el cuarto escalón hay varios EODO en el Hospital en TN. Esta distribución se muestra esquemáticamente en la Figura 1.11.

El EODO se puede desplegar en entidades sanitarias operativas iguales o superiores al segundo escalón reforzado. En dicho escalón quedará integrado en la formación sanitaria del tipo Escalón Médico Avanzado Terrestre/Equipo de Cirugía Avanzado (EMAT/ECA) junto con otros equipos específicos como el de Farmacia, Veterinaria y Psicología. 


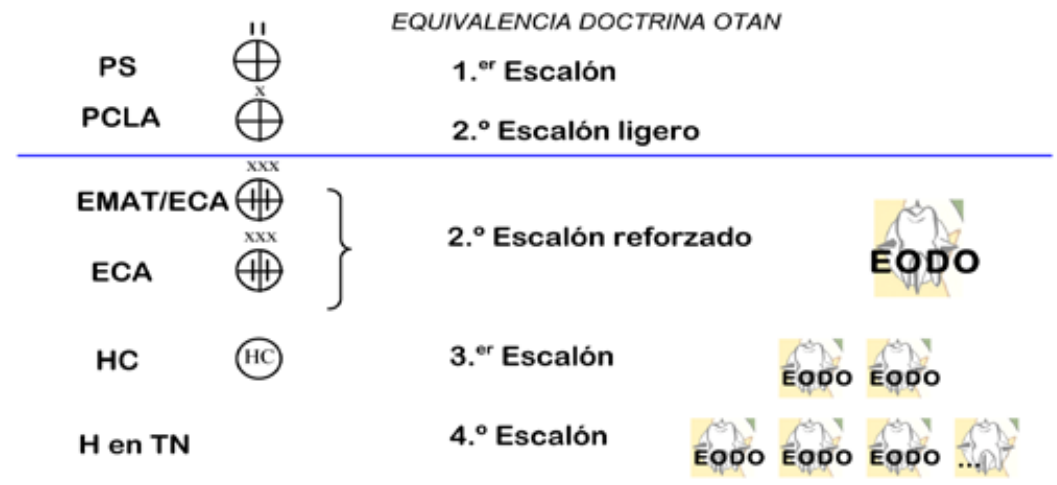

Figura 1.11. Despliegues de los equipos de odontología en los diferentes escalones $^{23}$.

En los escalones básicos donde no hay $\mathrm{EODO}^{36}$, el personal sanitario debe ser capaz de realizar una serie de técnicas básicas que permitan el tratamiento inicial del dolor agudo, o de aquellas infecciones provocadas por causas odontológicas. En caso de no resolver la situación, al igual que con cualquier otra baja médica, se debe organizar, en las mejores condiciones posibles, la evacuación de la baja odontológica hasta el EODO más cercano. Según la doctrina OTAN ${ }^{20}$ en el primer escalón se deben contemplar los cuidados dentales iniciales (asistencia dental primaria) y en caso necesario podrán ser apoyados mediante la Telemedicina ${ }^{37,40}$.

En los escalones superiores donde están presentes los EODO, las misiones generales $\operatorname{son}^{35}$ :

- Aliviar el dolor y evitar y limitar las lesiones en los tejidos duros y blandos.

- Diagnóstico y tratamiento previo a la evacuación.

- Evitar en lo posible las evacuaciones a escalones más retrasados.

- Colaborar con el diagnóstico y la determinación de las condiciones de evacuación para los casos que comprometan la región maxilofacial.

- Asesoramiento pericial y forense a nivel odontológico en TO. 
Se considerara baja odontológica ${ }^{23}$, al personal incapacitado temporalmente para desarrollar sus cometidos del servicio durante más de 24 horas y que precise el tratamiento o asistencia de su enfermedad o lesión odontológica. Los casos de baja por patología odontológica común (caries, enfermedad periodontal, etc.) son considerados bajas de no combate y cuantificadas según el número de días de baja. En el caso de caídas, golpes, enfrentamientos, accidentes, impactos, explosiones... que hayan afectado a la región orofacial durante el transcurso de la misión se pueden considerar como bajas de combate.

Todo personal que va a ser desplegado debe resultar "apto" en el reconocimiento odontológico previo a la misión ${ }^{31}$, porque las bajas odontológicas provocan una reducción de la operatividad de la unidad y se pueden disminuir en gran medida mediante la selección del personal desplegado y la aplicación de medidas de prevención específicas.

Una vez en el teatro de operaciones (TO) una baja, cualquiera que sea su causa, provoca sobrecarga al resto de la Unidad y suponen un problema en caso de necesidad de sustitución, además del riesgo inherente al traslado en caso que se requiera su evacuación.

Los recursos odontológicos así como, el mantenimiento de los equipos y materiales específicos se suministran a través de la cadena de abastecimiento y mantenimiento de recursos sanitarios de Clase $\mathrm{VIII}^{78}$. De esta forma se adquieren los productos farmacológicos generales utilizados en odontología (medicación y productos de higiene oral) y aquellos específicos que se consideraran como recursos libres. Las peticiones se elevan hasta la Unidad de Apoyo Logístico Sanitario (UALSAN) y se distribuyen vía cadena de abastecimiento sanitario a través del Mando de Apoyo Logístico de Operaciones (MALOG-OP). Como en toda cadena de abastecimiento se debe partir de los elementos de dotación de los EODO desplegados manteniendo unos niveles mínimos que eviten la pérdida de operatividad.

Además es importante destacar que, los TO suelen ser zonas que están expuestas a condiciones climatológicas extremas, y sabiendo que estos medios materiales (el equipo dental y algunos instrumentos rotatorios) son especialmente sensibles a la presencia de polvo, exceso de humedad y frío, es por ello, que se debe realizar un esfuerzo mayor en el mantenimiento y conservación de este tipo de equipos, porque cualquier interrupción en su funcionamiento puede mermar la eficacia del Equipo de Odontología por un largo periodo de tiempo ${ }^{77}$. 
Además el EODO constituye una estructura logística sanitaria que en algunos casos puede servir para la acomodación de bajas no críticas o incluso para la asistencia sanitaria en algunos casos menos graves. Cuando se producen ejercicios o situaciones de bajas masivas (MASCAL) debe coordinarse con el resto del personal de Sanidad desplegado. Y aunque su misión fundamental es el apoyo logístico sanitario de la fuerza también podrá participar en Campañas de Prevención de Salud Bucodental sobre la población civil ${ }^{79}$.

\subsubsection{Odontología preventiva}

De todos los cometidos de la Odontología Militar destacamos el que más tiene que ver con el trabajo de investigación que dio lugar a esta Memoria: la función preventiva. Esta función tiene como objetivo la vigilancia epidemiológica de la salud bucodental, con la cual intentaremos conservar la salud oral de la población. Para ello se planifican diferentes actuaciones, como son: el tratamiento preventivo de las caries y la enfermedad periodontal, la realización de campañas de detección y diagnóstico precoz de las patologías de alto riesgo, así como la realización de actividades para la promoción de la salud bucodental (conferencias educativas, elaboración de materiales divulgativos, etc.) ${ }^{17,65,80}$.

La población militar española presenta una alta incidencia en patología bucal, siendo en general escasas las medidas de tratamiento y prevención, por ello la odontología militar poco a poco se va orientando hacia actividades de promoción y prevención de la salud oral tanto a nivel individual como colectivo. Sin embargo, es importante priorizar este tipo de actividades eligiendo aquellas acciones que tengan un mayor impacto y una mejor relación costo-beneficio, procurando crear una responsabilidad individual y colectiva en el autocuidado de la salud bucal.

A nivel individual el instrumento preventivo más eficaz que tenemos es el reconocimiento odontológico. Con el determinaremos la aptitud dental que es un requisito de obligado cumplimiento, como lo son el reconocimiento médico y psicológico para el personal que va a ser desplegado o comisionado a TO La herramienta básica que se genera es la ficha odontológica, documento médicolegal de extraordinario valor que verifica la aptitud odontológica del sujeto y que puede llegar a servir como método de identificación ${ }^{31,68}$. 
La "aptitud dental" del personal militar la concederá el Oficial Odontólogo destinado o comisionado en la Base Militar durante las revisiones dentales (revisión ordinaria, previo misión, urgencia o realización de tratamientos). Serán considerados "aptos" aquellos militares en los cuales su estado oral no requerirá asistencia, o será improbable que necesite tratamiento de emergencia en los doce meses siguientes, con el fin de poder asegurar el correcto desarrollo de su actividad profesional ${ }^{17,31}$.

Con el fin de que nos demos cuenta de la extensión de este cometido del odontólogo, se indican las causas que motivan la pérdida de aptitud dental ${ }^{17,81}$ :

- Caries activas con cavitación que afectan a la dentina.

- Lesiones pulpares con signos y síntomas de irreversibilidad.

- Enfermedad periodontal en fase aguda o no controlada.

- Prótesis dentales insuficientemente retenidas o estables.

- Presencia de restos radiculares o de dientes incluidos con evidencia clínica o radiológica de patología.

- Presencia de fístulas de cualquier origen o condición.

- Episodios de pericoronaritis recurrente.

Lo que se busca es a que, poco a poco, la calidad de la salud oral de los contingentes desplegados sea mejor evitando con ello intervenciones profesionales en zona de operaciones (ZO). Para lograr este objetivo la función preventiva es fundamental.

A nivel colectivo es importante destacar el valor de las conferencias sanitarias donde se informa al contingente sobre los principales riesgos sanitarios y como realizar algunas técnicas de primeros auxilios y soporte vital básico $(\mathrm{SVB})^{57}$ y sobre las principales acciones de prevención ${ }^{57}$.

Estas medidas comunitarias se deben completar y potenciar con otras medidas específicas como las campañas de higiene oral o la fluoración del agua de consumo dentro del $\mathrm{TO}^{23,67,80}$. 
El esfuerzo de mantener la asistencia odontológica de calidad en toda la cadena logística, hace aconsejable incrementar las acciones preventivas en orden de disminuir la incidencia de nuevas patologías, y con ello la necesidad de nueva asistencia. Un porcentaje elevado de las emergencias en despliegues están ocasionadas por causas que pueden ser prevenibles ${ }^{82,83}$.

En la fase de concentración y una vez desplegado el contingente aparecen nuevos factores que alteran o modifican las rutinas adquiridas. Así, cabe destacar que a nivel odontológico, algo tan específicamente militar como el estrés de combate, puede desembocar en cuadros de patología oral. En el TO es frecuente que los hábitos de higiene oral se relajen, que se utilicen dietas desequilibradas con un exceso de carbohidratos en la alimentación o que se produzcan circunstancias que favorezcan el riesgo cariogénico y con él la aparición de patologías orales ${ }^{23}$.

Cuando se quieren hacer estudios comparativos se debe tener en cuenta que hay factores que van a condicionar la comparación de los diferentes índices de asistencia. Unos serían las variables sociodemográficas ${ }^{84,85}$ de la población desplegada (edad, sexo, país de nacimiento, tipo de población, nivel socioeconómico, nivel de estudios, etc.), otros las condiciones del despliegue donde el acceso a un servicio de salud oral no será fácil, además de los factores relacionados con las urgencias dentales ${ }^{17,83,86}$.

Por todos estos motivos se deben fomentar medidas de medicina preventiva encaminadas a reducir los factores de riesgo e incrementar el estado de salud y bienestar del personal militar. Se trata de disminuir la incidencia de enfermedades o lesiones que causan dolor, y/o malestar bucal, disminuir la necesidad de asistencia en operaciones y frenar o limitar las minusvalías. Todo esto instaurando programas de educación para la Salud Bucodental adecuados y de prevención continua.

\subsubsection{Competencias especificas de los cuerpos comunes de la defensa (cuerpo militar de sanidad). Especialidad complementaria: Odontología.}

Los oficiales odontólogos desplegados en Zona de Operaciones (ZO) deben estar preparados para realizar sus cometidos específicos con unos estándares de calidad equiparables a los existentes en tiempo de paz. 
El objetivo esencial de su actividad profesional en Territorio Nacional (TN) debe ser, por tanto, la de mantener actualizada su capacitación técnica ${ }^{17,66}$.

Las competencias específicas (CE) de los odontólogos (ODO) del cuerpo militar de sanidad son:

- Conocer los aspectos organizativos, económicos, de personal, documentales y de gestión de los servicios odontológicos en las FAS. Ejecutar a su nivel, la dirección y gestión de los órganos e instalaciones de los servicios Odontológicos de los ejércitos y órgano central. Conocer y aplicar a su nivel, los procedimientos para la gestión administrativa y logística de los recursos sanitarios Odontológicos ${ }^{71}$.

- Conocer, utilizar y mantener los equipos y material reglamentario de los servicios Odontológicos. Tanto en TN como en ZO. Conocer los diferentes tipos de instrumentos y materiales dentales que hay de dotación en las diferentes Unidades. Conocer y analizar los últimos avances en sistemas de odontología, instrumental y materiales tanto a nivel diagnostico como asistencial ${ }^{17,23,77}$.

- Conocer y saber utilizar de forma básica los principales métodos de desinfección y esterilización para aplicarlos de forma autónoma. Desarrollar diferentes hábitos y posturas acordes con los principios de prevención de riesgos laborales que sean congruentes con los principios de ergonomía aplicables tanto en TN como en $\mathrm{ZO}^{23,87}$.

- Identificar, diagnosticar y aplicar las medidas de prevención, control y tratamiento, de las patologías bucales más prevalentes en el seno de las FAS. Diseñar y dirigir programas integrales para prevención y cuidado de la Salud Oral tanto a nivel público como comunitario cuando se atiende a poblaciones en misiones de Coordinación Civil-Militar (CIMIC) ${ }^{17,88,89}$.

- Saber diagnosticar y tratar las patologías orales de mayor prevalencia y morbilidad en general y que sean causa de emergencias dentales y por tanto susceptibles de provocar más bajas. Conocer y dominar las técnicas tanto en el diagnostico como en el tratamiento de los traumatismos dentarios. Ser capaces de coordinar una evacuación por dichos motivos o 
realizar interconsulta con los medios propios de la TeleconsultaTelemedicina ${ }^{17,23,40,76}$.

- Conocer la actividad del odontólogo militar en campaña y las implicaciones de la odontología hiperbárica e hipobárica. Criterios de aptitud odontológica. Reconocimientos previos a la misión y normas de aplicación para la pérdida de aptitud en determinados ambientes: personal de vuelo, paracaidistas, personal de submarinos y personal con aptitud de buceo ${ }^{17,31,90,91,92}$.

- Conocer las principales acciones terapéuticas y preventivas ante el dolor, la infección y la hemorragia en el territorio estomatognático. Conocer, observar y aplicar los aspectos diferenciales del ejercicio de las competencias profesionales del apoyo Odontológico en el del marco de las operaciones militares nacionales e internacionales y saber de las estructuras sanitarias Odontológicas de los países aliados. Conocer los principios sanitarios de atención general ante emergencias, primeros auxilios y medidas de reducción en las fracturas de la cara y heridas por arma de fuego y ser capaces de aplicar la Reanimación Cardiopulmonar (RCP) básica y conocimientos sobre RCP avanzada en combate para coordinarse con los equipos sanitarios desplegados cuando se produzcan situaciones de Bajas Masivas (MASCAL) tanto en ambiente normal como en ambientes Nucleares, Biológicos, Químicos y Radiológicos $(\mathrm{NBQ}-\mathrm{R})^{17,24,76,93,94}$.

- Describir las implicaciones odontológicas en la determinación de la aptitud psicofísica para las diferentes misiones y conocer la documentación e informes odontológicos correspondientes que hay que redactar. Establecer las principales peritaciones odontológicas militares y saber de la importancia del odontólogo militar en la identificación legal de cadáveres ${ }^{17,67,74}$. 
3. Objetivos 
Estudio epidemiológico de la salud bucodental y ... 


\section{OBJETIVOS}

\subsection{Generales}

1. Conocer la prevalencia y analizar la distribución de las afecciones orales en la población militar, así como evaluar las necesidades de tratamiento.

2. Determinar el estado de Salud Bucodental y el Grado de Aptitud Dental de esta población, desde la primera revisión realizada y la última, con un período temporal de unos 9 años de diferencia entre una y otra y con los mismos sujetos.

3. Instaurar un programa de salud bucodental asociado a los Gabinetes de Odontología de las Bases Militares, establecer su eficiencia y aportar datos básicos para posteriores evaluaciones.

\subsection{Específicos}

1. Realizar una estimación que actualice el conocimiento sobre la prevalencia de la caries y conocer las necesidades de tratamiento odontológico en este colectivo. 
Estudio epidemiológico de la salud bucodental y ...

2. Conocer el estado periodontal y de la articulación temporomaxilar así como las anomalías dentofaciales, opacidades e hipoplasias del esmalte y el estado y situación de prótesis.

3. Valorar el efecto de la educación en salud oral de este colectivo, determinando la frecuencia de visitas al dentista, hábitos de cepillado y de tabaquismo.

4. Valorar la influencia del odontólogo y de las revisiones periódicas, en la reducción del numero de sujetos considerados "no aptos" para ir de misión. 
4. Material y Métodos 
Estudio epidemiológico de la salud bucodental y ... 


\section{MATERIAL Y MÉTODOS}

\subsection{Diseño y tipo de estudio}

Para alcanzar los objetivos planteados se ha procedido al diseño de un estudio cuasi-experimental de tipo serie temporal, pre-test y pos-test, usando el mismo grupo de militares, como control (antes de la intervención) y como experimental (después de la intervención). Con este tipo de diseño se describe el estado de la salud oral entre la población en un momento dado a través de la cuantificación de una serie de variables y se compara con la situación de la misma muestra en un segundo momento, separado del anterior por un período temporal dado, que en nuestro caso alcanzo un máximo de 9 años.

Para la elaboración del estudio hemos seguido las recomendaciones metodológicas propuestas en el manual de la Organización Mundial de la Salud (OMS) en su cuarta edición "Oral Health Surveys: Basic Methods"12, para la realización de estudios de salud oral, porque establece un esquema general que permite comparar fácilmente la realidad de la salud bucal entre diferentes poblaciones y conocer las necesidades de tratamiento odontológico de un paciente o de un grupo a partir de su estado de salud actual. 


\section{2. Ámbito y población}

La población objeto de estudio es personal militar de las Fuerzas Armadas destinado en una Base Militar perteneciente al Ejército de Tierra

\subsection{Muestreo}

\subsubsection{Duración y tamaño de la muestra}

La población diana estaba constituida por 780 militares, pertenecientes a diferentes Unidades y con edades comprendidas entre los 18 y 48 años. La muestra estudiada ha sido de 170 personas lo que representa el 21,79\%. Los miembros de la muestra acudieron al Gabinete del Oficial Odontólogo entre junio de 2006 y diciembre de 2008 en la primera visita y entre mayo de 2014 y a lo largo de 2015 en la segunda cita. En este segundo momento las edades estaban comprendidas entre los 26 y 56 años. Algunos sujetos nueve años más que en la primera visita.

\subsubsection{Técnica de muestreo}

Después de seleccionar las Unidades que entrarían a formar parte del estudio, se solicitó a cada una de ellas el listado de los militares que trabajan en la Base. Una vez determinado ese número total, que ha sido de 780 personas, se aplicó un muestreo sistemático de los militares que acudían al gabinete dental, en una primera cita, por alguna de las siguientes razones: revisión, cita previa para una misión, urgencia o realización de tratamientos y por revisión periódica, en una segunda cita. Todos los militares de las diferentes unidades contestaron al cuestionario y fueron examinados independientemente. Por tanto, dentro de cada una de las Unidades Militares resultantes, todos los individuos pertenecientes a 
una misma Unidad tuvieron la misma probabilidad de selección pero con probabilidades diferentes entre cada uno de los diferentes grupos.

\subsubsection{Criterios de inclusión y exclusión}

Los criterios de inclusión fueron:

- Ser militar.

- Estar destinado en la Base Militar de estudio.

Los criterios de exclusión fueron:

- Presentar odontalgia (que les impedía abrir la boca).

- Encontrarse de baja médica.

- Ausentes por alguna comisión de servicio.

- Cambio de destino fuera de la Base o finalización de contrato durante el proceso de inclusión.

\subsection{Datos recogidos}

Se utilizó como base el formulario propuesto por la $\mathrm{OMS}^{12,13}$ para estudios epidemiológicos. Dicho formulario fue modificado para adaptarlo a las necesidades de nuestro estudio. En la Figura del anexo de este capítulo se muestra la ficha odontológica.

\subsubsection{Variables sociodemográficas}

Edad

Sexo

País de nacimiento 
Tipo de población: La población de estudio estuvo constituida por personal militar.

Empleo militar: Desde soldado hasta coronel.

Escala militar: Se ha diferenciado en tres grupos: Tropa, Suboficiales y Oficiales.

Titularidad del centro: Las exploraciones bucodentales fueron realizadas en el Gabinete de Odontología de la Base.

\subsubsection{Variables de salud}

\section{Hábitos de comportamiento}

Cada uno de los sujetos estudiados fue preguntado por:

- El consumo de tabaco: Fumador, No Fumador o Ex Fumador.

- La frecuencia del cepillado: Nunca, a veces, 1 vez al día, 2 veces o 3 veces.

- El tipo de cepillo utilizado: Manual, eléctrico o ambos.

- La frecuencia de visitas al dentista: Nunca, solo con clínica (dolor o alguna molestia), esporádicamente o periódicamente.

\subsubsection{Evaluación clínica}

Se estudiaron las variables relacionadas con el estado de la salud dental de cada uno de los sujetos de la muestra, en el momento de su exploración y con sus necesidades terapéuticas. Y siguiendo las recomendaciones de la $\mathrm{OMS}^{12,13}$, se siguió un orden durante el examen clínico, para de este modo tener mayor seguridad de que todos los trastornos eran estudiados. Las líneas que siguen muestran los detalles del examen clínico. 


\section{Evaluación del estado de la articulación temporomaxilar}

En esta evaluación se utilizaron los siguientes códigos:

- Ausencia de signos y síntomas.

- Presencia de chasquido. Evaluamos directamente la presencia de un ruido agudo audible o por palpación de las articulaciones temporomaxilares.

- Dolor a la palpación. Este signo se evaluó por presión unilateral firme de los dos dedos, ejercida dos veces sobre la parte más voluminosa del músculo. Sólo lo registramos si a la palpación se provocó espontáneamente un reflejo de evitación.

- Movilidad reducida de la mandíbula. Medimos la distancia entre las puntas de los incisivos centrales de los maxilares superiores y de los incisivos de la mandíbula. Como orientación general, y por tratarse de adultos, la movilidad de la mandíbula se consideró reducida si el sujeto era incapaz de abrirla hasta una anchura de dos dedos (abertura $<30 \mathrm{~mm}$ ).

\section{Bruxismo}

Se valoró si el sujeto estudiado presentaba algún síntoma o signo de bruxismo según los criterios de Okeson ${ }^{98}$.

\section{Férulas oclusales}

Para el estudio se ha tenido en cuenta la siguiente clasificación en función de su utilización:

- No.

- De descarga.

- De mantenimiento. 


\section{Torus mandibular}

Lo indicamos cuando el sujeto estudiado presentó alguna prominencia ósea de este tipo.

\section{Opacidades e hipoplasias del esmalte}

Siguiendo las recomendaciones de la OMS se utilizó el índice de desarrollo de defectos del esmalte (DDE) modificado. Se observó visualmente la existencia de defectos en las superficies vestibulares, desde los bordes incisivos o las puntas de las cúspides hasta las encías y en las superficies oclusales de dientes posteriores. Basándose en su aspecto, las anomalías del esmalte se clasifican en tres tipos y varían en amplitud, localización en la superficie de los dientes y distribución dentro de la dentadura. El examen dental se realizó previa eliminación de cualquier placa gruesa o depósito de alimentos y los dientes se examinaron mientras estaban húmedos. Para incorporar al estudio estas anomalías o defectos del esmalte se utilizaron los siguientes códigos:

\section{- Normal.}

- Opacidad delimitada. En un esmalte de espesor normal y de superficie intacta, se observa una alteración de la translucidez del esmalte, de grado variable. Queda delimitada respecto al esmalte adyacente normal por un borde neto y claro, y puede ser blanca o de color crema, amarillo o pardo.

- Opacidad difusa. Comprende la alteración de la translucidez del esmalte, de grado variable y de aspecto blanco. No existe límite neto con el esmalte normal adyacente y la opacidad puede ser lineal o irregular o de distribución confluente.

- Hipoplasia. Es un defecto que afecta a la superficie del esmalte asociado con una disminución localizada de su espesor. Puede presentarse en forma de a) hoyos: únicos o múltiples, planos o profundos, dispersos o dispuestos en filas horizontales a través de la superficie dental; b) surcos: únicos o múltiples, estrechos o anchos ( 2 mm como máximo); o c) ausencia parcial o total de esmalte en 
una superficie considerable de la dentina. El esmalte afectado puede ser translúcido u opaco.

- Otros defectos. Aquellas alteraciones que no son fácilmente clasificables en los tres anteriores tipos básicos.

- Opacidad delimitada y difusa.

- Opacidad delimitada e hipoplasia.

- Opacidad difusa e hipoplasia.

- Las tres alteraciones.

Tinción por tetraciclinas

Lo indicamos si el sujeto estudiado presenta tinción, con independencia del grado y gravedad de la tinción dental.

\section{Evaluación del estado periodontal y necesidad de tratamiento.}

En la exploración se ha utilizado un espejo dental y una sonda ligera, especialmente diseñada para este fin. Comprende una punta esférica de $0,5 \mathrm{~mm}$, una banda blanca situada entre 3,5 y $5,5 \mathrm{~mm}$ y anillos situados a 8,5 y $11,5 \mathrm{~mm}$ de la punta esférica. La sonda no debe utilizarse con una fuerza superior a 20 gramos, si el paciente refiere dolor al efectuar el sondaje, esto indica que se emplea demasiada fuerza. Al introducir la sonda la punta esférica debe seguir la configuración anatómica de la superficie de la raíz dental introduciéndose suavemente en el surco o la bolsa gingival y debe explorarse en toda su extensión. Se ha seguido un procedimiento fijo para no olvidar ninguna superficie.

Al tratarse de adultos mayores de 20 años se han examinado los siguientes dientes indicadores: 1.7/1.6, 1.1, 2.6/2.7, 3.6/3.7, 3.1, 4.6/4.7. Sólo se ha examinado un sextante si contenía dos o más dientes en los que no está indicada la extracción. En caso de ausencia de diente indicador, se explorarían los dientes restantes del sextante, registrando el grado máximo como grado del sextante. 
Los tres indicadores del índice periodontal comunitario (IPC) utilizados en esta evaluación son: hemorragia gingival, cálculo y bolsas periodónticas. Se utilizaron los siguientes códigos:

- Sano.

- Hemorragia. Observada directamente o utilizando el espejo bucal, después de la exploración.

- Cálculo. Observado durante la exploración con la sonda, pero es visible toda la banda negra de la sonda.

- Bolsa de 4-5 mm (margen gingival dentro de la banda negra de la sonda).

- Bolsa de 6 mm o más (banda negra de la sonda invisible).

- Sextante excluido (existen menos de dos dientes).

- Según los datos obtenidos durante la exploración del estado periodontal se valoró la necesidad de tratamiento del mismo. Los códigos utilizados para determinar esta necesidad fueron los siguientes:

- Sano. No precisa tratamiento.

- Hemorragia. Precisa instrucciones de higiene oral.

- Cálculo. Además precisa tartrectomía.

- Bolsa de 4-5 mm. Además de todo lo anterior, requeriría hacer un raspado y alisado radicular.

- Bolsa de 6 mm o más. Precisa de otros tratamientos más complejos.

\section{Presencia de pendientes en lengua/labio}

Se anotó la presencia de pendientes cuando el sujeto estudiado presentó orificios que indicaban de su colocación y él confirmó su uso en el momento actual. 


\section{Evaluación del estado dental y necesidad de tratamiento}

- El examen dentario fue visual y se realizó empleando un espejo bucal plano. Se han tenido en cuenta las consideraciones que no recomiendan el uso de radiografías, ni de fibra óptica, por las frecuentes objeciones a la exposición radiológica y porque no es factible su uso en todas las situaciones, aun cuando se considera que esos medios de diagnóstico disminuirían la subestimación de las necesidades de tratamiento restaurador y las complicaciones adicionales ${ }^{12,100}$.

El examen se ha realizado de forma sistemática por cuadrantes procediendo ordenadamente de un diente a otro, pasando por el espacio interdental. Un diente fue considerado presente si cualquier parte de él era visible o podía ser tocado con la sonda sin desplazar indebidamente los tejidos blandos. Si un diente temporal y uno permanente ocupa el mismo espacio, sólo se anotó el espacio del permanente.

Se utilizó el siguiente código dental:

Sano. Un diente se consideró sano si no había evidencia clínica de caries ya fuese presente o tratada. Se excluyeron las caries incipientes, así como otros trastornos análogos a las fases iniciales de la caries, porque no se pueden diagnosticar de modo fiable. Así, por ejemplo, una corona que presenta los defectos que se indican a continuación, en ausencia de otros criterios positivos, debe codificarse como sana:

- manchas blancas o yesosas.

- manchas decoloradas o ásperas, que no resultan blandas al tacto con una sonda IPC metálica.

- hoyos o fisuras teñidos en el esmalte, que no presentan signos visuales de alteración del esmalte, ni ablandamiento del suelo o las paredes detectable con una sonda IPC.

- zonas oscuras, brillantes, duras o punteadas en el esmalte de un diente que presenta signos de fluorosis moderada a intensa.

- lesiones que, basándose en su distribución, sus antecedentes o el examen visual/táctil, parecen deberse a la abrasión. 
* Diente con caries. Se registró la presencia de caries cuando una lesión presente en un hoyo o fisura, o en una superficie dental lisa presentaba reblandecimiento del suelo o las paredes y socavamiento del esmalte. Los dientes con obturaciones temporales también se registraron como cariados. En caso de duda, la caries no fue registrada como presente.

Diente obturado con caries. Se consideró así al diente que portando una o más restauraciones permanentes tenía una o más zonas que estaban cariadas.

Diente obturado sin caries. Se registró así a un diente con una o más restauraciones permanentes y sin caries en la corona.

Diente ausente debido a caries. Este código se utilizó para los dientes permanentes o primarios que fueron extraídos debido a la presencia de caries.

* Diente ausente por otras causas. Se incluyeron en este código los dientes permanentes que se consideraron ausentes de modo congénito o que fueron extraídos por motivos ortodónticos, periodontopatías, traumatismos, etc.

Selladores de fisuras. Se utilizó este código para los dientes que presentaban un sellador en la superficie oclusal y en los que la fisura oclusal se ensanchó con una fresa redondeada o «en forma de llama», colocando un material compuesto.

- Soporte de puente, corona especial o funda. Se incluyeron en este código los dientes que forman parte de un puente fijo, es decir, que son soporte de puente. Y también se empleó para coronas o fundas colocadas por motivos distintos de la caries.

Diente sin erupcionar. Con esta clasificación se indicó el espacio de un diente permanente que no ha hecho erupción todavía, siempre que no esté el diente temporal. Los dientes clasificados como no erupcionados quedaron excluidos de todos los cálculos relativos a la caries dental.

Diente parcialmente erupcionado. Son los dientes que no han completado la erupción, independientemente de la causa. Se considera 
que la erupción termina cuando la pieza dentaria llega a oclusión o una posición funcional normal.

* Implantes. Se utilizó este código para indicar que existe un implante como soporte. Se anotaron los implantes observados en el maxilar superior y el inferior (mandíbula).

Seguidamente de anotar el estado de un diente, antes de pasar a valorar el siguiente, anotamos su necesidad de tratamiento dental. Todas las necesidades de tratamiento tuvieron como base el juicio clínico del examinador, basándose en lo que seria la asistencia probable y más conveniente para la persona media de la comunidad o el país, que en nuestro caso es una población militar española.

Los códigos y criterios para la necesidad de tratamiento que valoramos son:

- Ninguno. Se usa este código cuando se estima que el diente está sano.

- Obturación de una superficie.

\section{- Obturación de dos o más superficies.}

Estos códigos quedan a criterio del examinador y se deben usar cuando se requiera:

○ tratar la caries inicial, primaria o secundaria.

- tratar la decoloración del diente o un defecto de desarrollo.

- reparar lesiones producidas por traumatismo, erosión o abrasión.

- reparar obturaciones fracturadas o sueltas que permitan filtración a la dentina.

○ reemplazar obturaciones o sellados defectuosos.

- Corona o pilar de puente. Por cualquier motivo.

- Póntico (puente).

- Tratamiento pulpar (endodoncia) y restauración. Este código se utilizará para indicar que un diente necesita probablemente la realización de una endodoncia antes de la restauración con una 
obturación o una corona, debido a la presencia de una caries profunda y amplia, o a la mutilación o traumatismo del diente.

- Extracción. La indicación para la extracción dependerá de las posibilidades de tratamiento disponibles. Se indican los siguientes criterios:

- la caries ha destruido de tal forma el diente que no existe posibilidad de restauración.

- la caries ha avanzado tanto que se ha producido una exposición pulpar y no se puede restaurar el diente.

- debido al mal estado periodontal el diente está flojo, doloroso y no puede ser restaurado hasta una situación funcional.

- solo quedan restos radiculares (raíces retenidas).

- la extracción está indicada por motivos protésicos, ortodónticos, estéticos debido a la inclusión del diente y en dientes erupcionados parcialmente con episodios de pericoronaritis recurrente.

- Necesidad de otro tratamiento. El examinador deberá especificar en estos casos especiales, qué otro tratamiento llevarán.

\section{Indicadores epidemiológicos utilizados}

- Prevalencia total de caries: Se obtiene sumando los sujetos de la muestra estudiada que presentan una o más piezas careadas, obturadas o ausentes por caries y dividiéndolo después entre el número de sujetos examinados.

- Índice CAO-D (Índice de Piezas Definitivas Cariadas, Ausentes y Obturadas): se obtiene de dividir la suma del número de dientes permanentes cariados, ausentes por caries y obturados entre el número de sujetos explorados.

- Índice de Restauración dental en dentición definitiva (IR): proporción de piezas dentarias que han recibido atención 
conservadora (obturación) en relación al total del CAO-D. Nos proporciona información sobre la atención odontológica recibida y nos ayuda a estimar la dimensión de esta actividad restauradora sobre el conjunto de la patología detectada.

- Índice libre de caries: proporción de piezas dentarias sin presencia de caries evidente ni obturación ni perdida dentaria debida a caries.

\section{Situación de prótesis y necesidad de prótesis}

Se registró la presencia de prótesis en cada maxilar (superior e inferior/mandíbula). Para ello se han seguido los siguientes códigos:
○ Ninguna prótesis
○ Puente
○ Más de un puente
- Dentadura parcial removible.
○ Puentes y dentadura parcialmente movibles.
- Dentadura completa removible
○ Puentes con implantes.
○ Dentadura completa sobre implantes (removible).

Se registró para cada maxilar (superior e inferior/mandíbula) la necesidad de prótesis percibida por el examinador. Para ello se han utilizado los siguientes códigos:

- Ninguna prótesis necesaria.

○ Necesidad de prótesis unitaria (sustitución de un diente).

○ Necesidad de prótesis multiunitaria (sustitución de más de un diente).

- Necesidad de una combinación de prótesis unitaria y multiunitaria.

- Necesidad de una prótesis completa (sustitución de todos los dientes). 


\section{Presencia de Implantes}

Se anotaron los implantes observados en el maxilar superior y el inferior (mandíbula).

\section{Evaluación del estado oclusal (anomalías dentofaciales)}

Se registraron los siguientes códigos, según los criterios de la OMS en su $3^{\mathrm{a}}$ edicion:

- Ninguna. No hay anomalía o maloclusión.

- Anomalías leves como:

- Uno o más dientes rotados o inclinados.

- Apiñamiento o espaciamiento de un ancho no mayor que un premolar (segmento posterior) o de un incisivo lateral (segmentos anteriores).

- Anomalías moderadas/graves con la presencia de una o más de las siguientes condiciones:

- Apiñamientos o espaciamiento de mayor extensión que en las anomalías leves.

- Resalte maxilar en los cuatro incisivos anteriores de $9 \mathrm{~mm}$ o más.

- Resalte mandibular, mordida cruzada anterior de una anchura mayor que una corona.

○ Mordida abierta.

○ Desviación de la línea media de más de $4 \mathrm{~mm}$.

\section{Tratamiento de ortodoncia}

Se ha anotado si el sujeto estudiado es portador o no de ortodoncia, según la siguiente clasificación:

○ No.

○ Lleva fija. 
Llevó fija.
○ Llevó fija y lleva un retenedor.

$>$ Presencia de dientes parcialmente erupcionados

Se anotaron los dientes observados en el maxilar superior y el inferior (mandíbula) que se encontraban parcialmente erupcionados en el momento de la exploración.

\section{Evaluación de la necesidad de exodoncia de los terceros molares}

Se anotaron los terceros molares superiores e inferiores observados, que según el criterio del examinador requerían de exodoncia siguiendo las indicaciones para la extracción, según las posibilidades de tratamiento.

\section{$>$ Grado de aptitud dental}

El Grado de aptitud dental forma parte de los requisitos sanitarios exigibles ${ }^{31}$ al personal militar que va a participar en operaciones fuera del territorio nacional (TN).

Los grados de aptitud son a juicio clínico del odontólogo militar guiándose por las causas que motivan la pérdida de aptitud dental que están reflejadas en la Instrucción Técnica N³ de 13 de Mayo de 2014, de la Inspección General de Sanidad de la Defensa, sobre "Asistencia Odontológica en las Fuerzas Armadas".

Se utilizaron los siguientes códigos:

- Apto

- No Apto

\subsection{Programa de educación para la salud bucodental}

Se procedió a instaurar un programa de intervención educativa y preventiva sobre salud bucodental antes, durante y después de la revisión odontológica. 
En las visitas se les habló de temas generales sobre la boca, y se les mostraron algunas de las enfermedades y alteraciones que pueden afectar a la cavidad bucal (caries, gingivitis, periodontitis, problemas de oclusión, bruxismo, opacidades y tinciones dentales).

Asimismo se les explicó cómo prevenir esas enfermedades y los medios para hacerlo:

Se les indicó la necesidad de incrementar la frecuencia de cepillado (después de cada comida) y a realizarlo de forma más eficiente. Se les hizo una demostración de la técnica de cepillado manual (técnica de $\mathrm{BASS}^{65,99}$ ) con tipodonto.

Se les habló de la conveniencia, o no, del uso del cepillo eléctrico (en función del estado bucal y adaptación de cada uno) y a observar el estado del cepillo dental, indicándoles que, por norma general, no debe ser usado más de 3 meses.

Se les aconsejó sobre la importancia de las visitas periódicas al dentista, al menos una vez al año.

Por último, se les habló sobre la influencia de tener unos hábitos saludables para la salud general. Lo cual implicaría evitar el consumo del tabaco, alcohol e ingesta de azucares y esfuerzos o situaciones de estrés que lleven a un apretamiento de los dientes.

\subsection{Exploradores y Calibración}

El trabajo de campo lo realizó un solo odontólogo que también registró los datos e hizo el tratamiento de los mismos.

El reconocimiento odontológico se realizó en el Gabinete de Odontología de la Base Militar. El tiempo de exploración utilizado con cada paciente oscilaba entre los 10 y 15 minutos aproximadamente, con un máximo de 15 revisiones diarias entre cuadros de mando (oficiales y suboficiales) y tropa. 
La recogida de datos se realizó sobre la ficha odontológica (en papel) para después transferirlos a la base de datos creada para el efecto.

Las exploraciones se realizaron contando con los siguientes medios:

- Sillón con luz apropiada.

- Mascarilla.

- Guantes de exploración.

○ Espejos bucales planos del número 5.

- Sondas de exploración dental, doble terminación.

- Sonda periodontal tipo OMS.

- Jeringa de aire a presión del sillón, para secar el campo y eliminar los restos groseros.

- Seda dental.

- Batea con solución desinfectante.

- Autoclave.

\subsection{Análisis estadístico}

Las variables cuantitativas se presentan con la media y la desviación típica y las cualitativas según su distribución de frecuencias.

Mediante el test Chi-cuadrado de Pearson, se ha analizado la asociación de las variables cualitativas. En el caso de que el número de celdas con valores esperados menores de 5 sea mayor de un $20 \%$, se utilizará el test exacto de Fisher o el test Razón de verosimilitud para variables con más de dos categorías. Las comparaciones de los valores cuantitativos generados de distribución paramétrica se han realizado mediante la prueba $\mathrm{T}$ de Student para muestras independientes o la prueba $U$ de Mann Whitney, en el caso de variables no paramétricas.

Para las comparaciones en el tiempo se han empleado la prueba $\mathrm{T}$ de Student para muestras relacionadas, el test de McNemar y el de homogeneidad marginal, estos dos últimos utilizados para variables cualitativas. 
Estudio epidemiológico de la salud bucodental y ...

Los datos han sido analizados con el programa estadístico IBM SPSS Statistics versión 20.0 para Windows. Aquellos valores de $\mathrm{p}<0,05$ han sido considerados estadísticamente significativos. 


\section{ANEXO: Ficha dental}

FICHA ODONTOLÓGICA

\begin{tabular}{|c|c|c|c|c|}
\hline APELLIDOS & & NOMBRE & UNIDAD & GRADO APTITUD \\
\hline ARMA-CUERPO & EMPLEO & T.M.I. & FECHA NACIMIENTO & SEXO \\
\hline
\end{tabular}

PATOLOGÍAS PRESENTES (AUSENTES, CARIES, OBTURACIONES,...) Y TRATAMIENTOS REALIZADOS

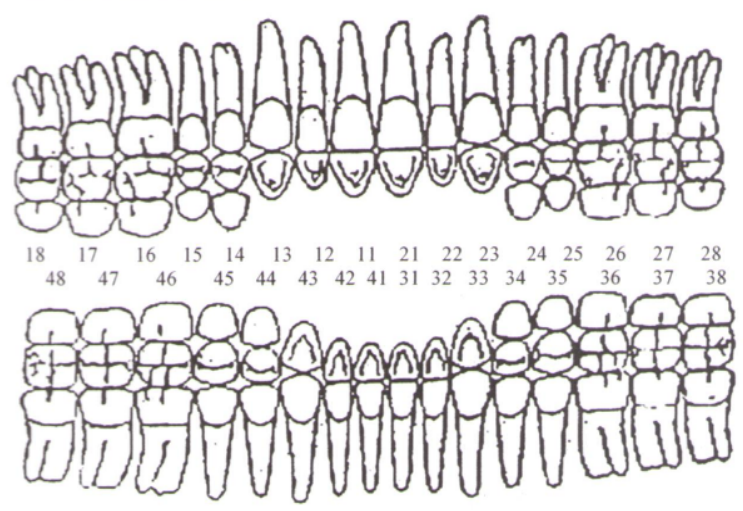

NUEVOS TRATAMIENTOS REALIZADOS
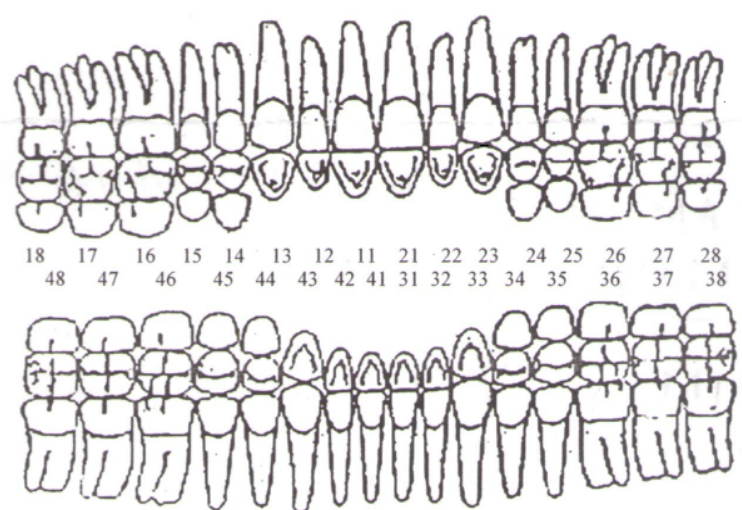

HISTORIA MÉDICA

ESTA BAJO ALGÚN TRATAMIENTO?

PROBLEMAS CON LA ANESTESTA LOCAL?

¿SANGRADO DESPI

EMBARAZO

¿TRATAMIENTO MEDDICO EN LOS UULTIMOS SEIS MESES

ENFERMEDADES DEL CORAZÓN,

HEPATITIS, DIABETES, HIPERTENSIÓN

HA SIDO RADIADO EN EL CUELIO $/$ CABEZA?

FIRMA Y FECHA DEL PACIENTE

\author{
COMENTARIOS: \\ PERIODONTALES \\ OCLUSALES \\ MUCOGINGIVALES \\ OTROS ..
}

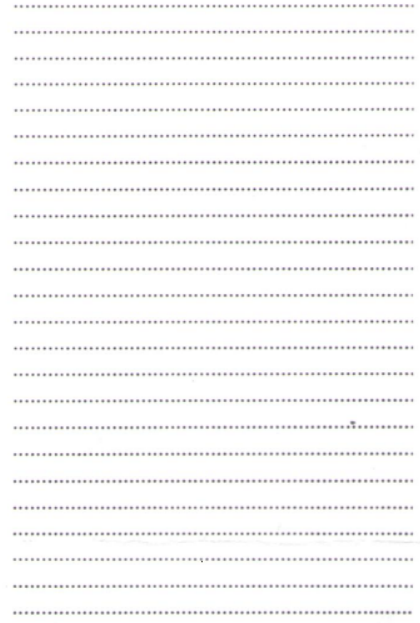

CENTRO DONDE SE REALIZA LA EXPLORACIÓN
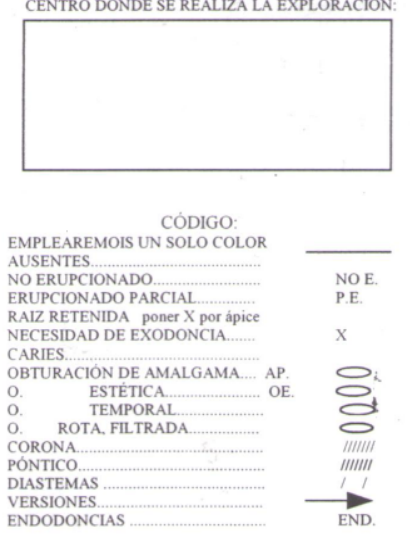

L OFICIAL ODONTÓLOGO / ESTOMATÓLOGO 
Estudio epidemiológico de la salud bucodental y ... 


\section{Resultados}


Estudio epidemiológico de la salud bucodental y ... 


\section{RESULTADOS}

La muestra estudiada no experimentó ninguna variación durante todo el estudio. En cuanto al sexo el $75,9 \%$ han sido varones. Respecto a la escala militar un $81,2 \%$ fue tropa (MPTM) y un 18,8\% oficiales y suboficiales (of/subof). El número de suboficiales se incrementó en 5 en la segunda visita debido a su paso de la escala MPTM a la de suboficiales. Las edades de los sujetos de la muestra en la primera visita estaban en un rango comprendido entre los 18 y los 48 años con 27,24 años de media, 26,50 de mediana y una desviación típica de 6,1. En la segunda visita, evidentemente, las edades se incrementaron en toda la muestra y pasaron a estar comprendidas entre los 26 y los 56 años con 35,44 años de media. En lo que respecta a la nacionalidad de los encuestados, el 3,5\% era distinta de la española, siendo el 2,9\% de Colombia y el resto de Ecuador. Debido a que es una proporción muy pequeña, este hecho no se ha tenido en cuenta en el análisis.

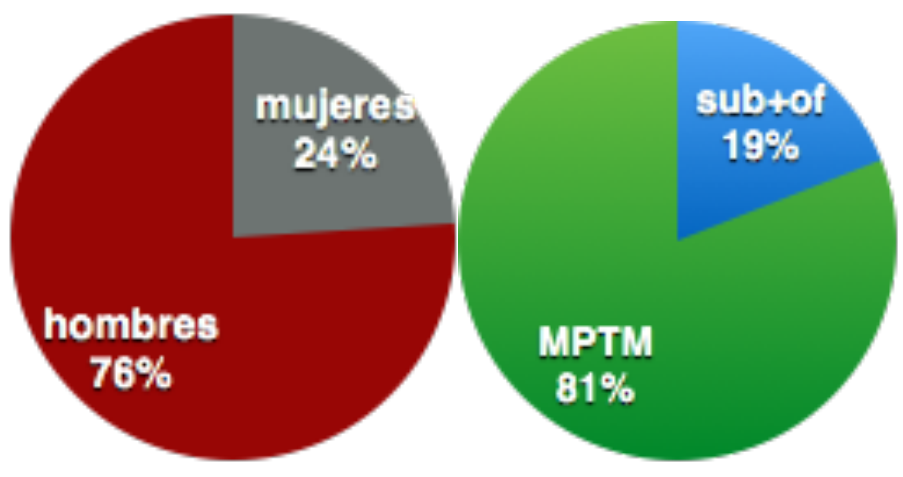

Figura 5.1. Distribución de la muestra por sexo y escala 
En la descripción de los resultados se presentan separadamente los de la primera y la segunda visita para cada uno de los factores analizados. Además, también se presentan separadamente, dentro de cada visita, los datos por sexo, escala y edad debido a que, para un importante número de factores, las diferencias entre ellos fueron estadísticamente significativas. Cada apartado se comienza con un comentario sobre los datos totales. Por ese motivo, al final del capitulo se adjunta un anexo en el que se muestran estos datos que, evidentemente, coinciden con la suma de los que aparecen en las tablas de edad, sexo y escala. Las Tablas del anexo se numeran 5.1.1a, 5.1.2a, 5.2.1a, 5.2.2a, 5.3.1a, ... El 5 es el capítulo, el 1,2,3,.., los distintos apartados el siguiente 1 y 2 la primera y segunda visita y la a del anexo. Este comentario inicial se justifica por el hecho de que en muchas de las referencias bibliográficas se habla de la población sin disgregar.

\subsection{Hábitos de cepillado, tabaquismo y frecuencia de visitas al dentista.}

\subsubsection{Visita 1}

Los datos totales de la distribución de la frecuencia diaria de cepillado de los sujetos estudiados se indican en la Tabla 5.1.1a del anexo. En la tabla se observa que los porcentajes más altos, 37,1 \%, corresponden a los que se cepillan una vez al día, mientras que un 35,9\% lo hacen 2 veces al día. Un $8 \%$ se cepilla solo a veces y un caso puntual no lo hace nunca. El tipo de cepillo más utilizado por los sujetos explorados fue el manual, con un porcentaje del 78,2\% por encima del eléctrico. El hábito de consumo de tabaco es de un 46,5\%, algo menor que el de los no fumadores que estaba en un 53,5\%. En lo referente a la frecuencia de visitas al dentista, el 32,4\% acude cuando tiene alguna molestia, mientras que $24,1 \%$ es el que acude periódicamente a revisiones. La mayoría de los explorados $(38,2 \%)$ lo hace de una forma esporádica: cuando se acuerdan y resulta que tienen tiempo libre en ese momento. Hay un $9 \%$ que no va nunca.

Cabe destacar (Tabla 5.1.1) que las mujeres son las que con más frecuencia se cepillan tres veces al día $(39,02 \%)$. En cuanto al tipo de cepillo, tanto hombres 
como mujeres usan en mayor medida el manual, pero son las mujeres las que más utilizan el eléctrico $(31,71 \%)$. El porcentaje de no fumadores respecto al de fumadores es mayor en ambos sexos, pero el porcentaje de hombres fumadores $(48,84 \%)$ es mayor que el de mujeres. Las revisiones en el dentista las hacen de forma periódica en mayor proporción las mujeres $(39,02 \%)$ que los hombres. Es más, los que no van nunca solo pertenecen al colectivo de hombres en una importante proporción $(6,98 \%)$.

Tabla 5.1.1. Resumen de los datos de hábitos de cepillado, tabaquismo y frecuencia de visitas al dentista, en función del sexo, para la primera visita.

\begin{tabular}{|c|c|c|c|c|c|c|c|}
\hline & & & \multicolumn{2}{|c|}{ Hombre } & \multicolumn{2}{|c|}{ Mujer } & \multirow{2}{*}{$\begin{array}{c}\text { p- } \\
\text { valor }\end{array}$} \\
\hline & & & $\mathbf{n}$ & $\%$ & $\mathbf{n}$ & $\%$ & \\
\hline \multirow{7}{*}{ Cepillado } & \multirow{5}{*}{ Frecuencia } & Nunca & 1 & $0,78 \%$ & 0 & $0,00 \%$ & \multirow{5}{*}{0,007} \\
\hline & & 1 vez día & 53 & $41,09 \%$ & 10 & $24,39 \%$ & \\
\hline & & 2 veces día & 46 & $35,66 \%$ & 15 & $36,59 \%$ & \\
\hline & & 3 veces día & 21 & $16,28 \%$ & 16 & $39,02 \%$ & \\
\hline & & 1 vez semana & 8 & $6,20 \%$ & 0 & $0,00 \%$ & \\
\hline & \multirow{2}{*}{ Tipo } & Manual & 105 & $81,40 \%$ & 28 & $68,29 \%$ & \multirow{2}{*}{0,077} \\
\hline & & Eléctrico & 24 & $18,60 \%$ & 13 & $31,71 \%$ & \\
\hline \multirow{2}{*}{\multicolumn{2}{|c|}{ Hábito de tabaquismo }} & No fumador & 66 & $51,16 \%$ & 25 & $60,98 \%$ & \multirow{2}{*}{0,272} \\
\hline & & Fumador & 63 & $48,84 \%$ & 16 & $39,02 \%$ & \\
\hline \multirow{4}{*}{\multicolumn{2}{|c|}{$\begin{array}{l}\text { Frecuencia de visitas } \\
\text { dentista }\end{array}$}} & Esporádicamente & 50 & $38,76 \%$ & 15 & $36,59 \%$ & \multirow{4}{*}{0,03} \\
\hline & & Nunca & 9 & $6,98 \%$ & 0 & $0,00 \%$ & \\
\hline & & Periódicamente & 25 & $19,38 \%$ & 16 & $39,02 \%$ & \\
\hline & & Sólo con clínica & 45 & $34,88 \%$ & 10 & $24,39 \%$ & \\
\hline
\end{tabular}

Si se analizan los parámetros por la escala (Tabla 5.1.2) la frecuencia con la que se cepillan los que lo hacen tres veces al día es ligeramente mayor en la tropa. Sin embargo, lo más común en las dos escalas son los que se cepillan una o dos veces diarias. Ambas escalas utilizan mayoritariamente el cepillo manual, pero son los de tropa los que más usan el eléctrico. En la escala de of/subof el porcentaje de no fumadores dobla a los que fuman habitualmente, mientras que en la tropa están a la par los que fuman y los que no lo hacen. En cuanto a las revisiones de boca los of/subof acuden todos al dentista pero la mayoría lo hace de forma esporádica. Los de tropa, mayoritariamente, acuden más al dentista cuando tienen alguna molestia y hay un porcentaje, sin significación estadística, que no va nunca. 
Estudio epidemiológico de la salud bucodental y ...

Tabla 5.1.2. Resumen de los datos de hábitos de cepillado, tabaquismo y frecuencia de visitas al dentista, por escala, para la primera visita.

\begin{tabular}{|c|c|c|c|c|c|c|c|}
\hline & & & \multicolumn{4}{|c|}{ ESCALA } & \multirow{3}{*}{$\begin{array}{c}p- \\
\text { valor }\end{array}$} \\
\hline & & & \multicolumn{2}{|c|}{ MPTM } & \multicolumn{2}{|c|}{$\begin{array}{c}\text { Suboficiales } \\
+ \text { Oficiales }\end{array}$} & \\
\hline & & & $\mathbf{n}$ & $\%$ & $\mathbf{n}$ & $\%$ & \\
\hline \multirow{7}{*}{ Cepillado } & \multirow{5}{*}{ Frecuencia } & Nunca & 1 & $0,72 \%$ & 0 & $0,00 \%$ & \multirow{5}{*}{0,913} \\
\hline & & 1 vez día & 50 & $36,23 \%$ & 13 & $40,63 \%$ & \\
\hline & & 2 veces día & 49 & $35,51 \%$ & 12 & $37,50 \%$ & \\
\hline & & 3 veces día & 31 & $22,46 \%$ & 6 & $18,75 \%$ & \\
\hline & & 1 vez semana & 7 & $5,07 \%$ & 1 & $3,13 \%$ & \\
\hline & \multirow{2}{*}{ Tipo } & Manual & 112 & $81,16 \%$ & 21 & $65,63 \%$ & \multirow{2}{*}{0,055} \\
\hline & & Eléctrico & 26 & $18,84 \%$ & 11 & $34,38 \%$ & \\
\hline \multirow{2}{*}{\multicolumn{2}{|c|}{ Hábito de tabaquismo }} & No fumador & 69 & $50,00 \%$ & 22 & $68,75 \%$ & \multirow{2}{*}{0,055} \\
\hline & & Fumador & 69 & $50,00 \%$ & 10 & $31,25 \%$ & \\
\hline \multirow{4}{*}{\multicolumn{2}{|c|}{$\begin{array}{l}\text { Frecuencia de visitas } \\
\text { dentista }\end{array}$}} & Esporádicamente & 49 & $35,51 \%$ & 16 & $50,00 \%$ & \multirow{4}{*}{0,003} \\
\hline & & Nunca & 9 & $6,52 \%$ & 0 & $0,00 \%$ & \\
\hline & & Periódicamente & 29 & $21,01 \%$ & 12 & $37,50 \%$ & \\
\hline & & Sólo con clínica & 51 & $36,96 \%$ & 4 & $12,50 \%$ & \\
\hline
\end{tabular}

Tabla 5.1.3. Resumen de los datos de hábitos de cepillado, tabaquismo y frecuencia de visitas al dentista, por edad, para la primera visita.

\begin{tabular}{|c|c|c|c|c|c|c|c|}
\hline & & & \multicolumn{4}{|c|}{ Grupos de Edad } & \multirow{3}{*}{ p-valor } \\
\hline & & & \multicolumn{2}{|c|}{$\leq 27$} & \multicolumn{2}{|c|}{$>27$} & \\
\hline & & & $\mathbf{n}$ & $\%$ & $\mathbf{n}$ & $\%$ & \\
\hline \multirow{7}{*}{ Cepillado } & \multirow{5}{*}{ Frecuencia } & Nunca & 1 & $1,00 \%$ & 0 & $0,00 \%$ & \multirow{5}{*}{0,402} \\
\hline & & 1 vez día & 31 & $31,60 \%$ & 32 & $44,40 \%$ & \\
\hline & & 2 veces día & 37 & $37,80 \%$ & 24 & $33,30 \%$ & \\
\hline & & 3 veces día & 24 & $24,50 \%$ & 13 & $18,10 \%$ & \\
\hline & & $1 \mathrm{vez}$ semana & 5 & $5,10 \%$ & 3 & $4,20 \%$ & \\
\hline & \multirow{2}{*}{ Tipo } & Manual & 78 & $79,60 \%$ & 55 & $76,40 \%$ & \multirow{2}{*}{0,617} \\
\hline & & Eléctrico & 20 & $20,40 \%$ & 17 & $23,60 \%$ & \\
\hline \multirow{2}{*}{\multicolumn{2}{|c|}{ Hábito de tabaquismo }} & No fumador & 45 & $45,90 \%$ & 46 & $63,90 \%$ & \multirow{2}{*}{0,02} \\
\hline & & Fumador & 53 & $54,10 \%$ & 26 & $36,10 \%$ & \\
\hline \multirow{4}{*}{\multicolumn{2}{|c|}{$\begin{array}{c}\text { Frecuencia de visitas } \\
\text { dentista }\end{array}$}} & Esporádicamente & 35 & $35,70 \%$ & 30 & $41,70 \%$ & \multirow{4}{*}{0,197} \\
\hline & & Nunca & 8 & $8,20 \%$ & 1 & $1,40 \%$ & \\
\hline & & Periódicamente & 23 & $23,50 \%$ & 18 & $25,00 \%$ & \\
\hline & & Sólo con clínica & 32 & $32,70 \%$ & 23 & $31,90 \%$ & \\
\hline
\end{tabular}

La Tabla 5.1.3 indica que la edad juega un importante papel. Los menores de 27 años son los que con mayor frecuencia se cepillan tres veces al día, siendo lo 
más habitual en los dos rangos de edad un cepillado de una o dos veces al día. El cepillo usual en ambas edades es el manual, siendo, ligeramente mayor, el uso del eléctrico en los mayores de 27 años. El porcentaje de no fumadores es más elevado para los mayores de 27 años. Las visitas al dentista las realizan los dos grupos de edad, sobre todo, cuando tienen alguna molestia y ambos grupos acuden, más, de forma esporádica

\subsubsection{Visita 2}

En esta visita se han producido notables cambios respecto a la anterior. De acuerdo con la Tabla 5.1.2a del anexo, los porcentajes más altos $(42,9 \%)$ corresponden a los que se cepillan dos veces al día mientras que un $34,1 \%$ lo hacen tres veces, un 21,8\% lo hace una vez al día y hay un par de casos que solo se cepillan a veces. El tipo de cepillo más utilizado sigue siendo el manual con un porcentaje del $62,4 \%$ sobre el uso del eléctrico. Es interesante reseñar que un $14,7 \%$ alterna los dos tipos. Un resultado llamativo es que el porcentaje de fumadores ha disminuido a un $30,6 \%$; debido a esto en la tabla se ha incorporado un nuevo parámetro: el grupo de ex-fumadores con un porcentaje del 15,3\%. Este grupo incrementa notablemente el anterior número de no fumadores. En lo referente a la frecuencia de visitas al dentista, el 55,9\% acude de forma periódica, seguido de un $27,1 \%$ de aquellos que lo hacen esporádicamente y de un $15,9 \%$ que acude solamente cuando tiene molestias. Sigue existiendo un par de casos que no van nunca al dentista.

En la muestra estudiada en la segunda visita cabe destacar que, si analizamos la muestra por sexo (Tabla 5.1.4), las mujeres son las que con más frecuencia se cepillan 3 veces al día. En cuanto al tipo de cepillo, tanto hombres como mujeres utilizan mayoritariamente el manual, sin embargo, son los hombres los que más usan el eléctrico aunque es mayor el porcentaje de mujeres que combinan los dos tipos de cepillos. En ambos sexos hay más sujetos que no fuman, siendo el porcentaje de mujeres no fumadoras mayor. Aunque, sorprendentemente, existe un mayor número de hombres que ha dejado de fumar desde la primera visita. Las revisiones periódicas en el dentista se han incrementado en ambos sexos. Sin embargo sigue siendo mayor el porcentaje de mujeres que las realizan, así como sigue siendo mayor el número de hombres que va solo cuando tiene alguna molestia. Sigue existiendo un pequeño número que no van nunca. 
Estudio epidemiológico de la salud bucodental y ...

Tabla 5.1.4. Resumen de los datos de hábitos de cepillado, tabaquismo y frecuencia de visitas al dentista, en función del sexo, para la segunda visita.

\begin{tabular}{|c|c|c|c|c|c|c|c|}
\hline & & \multicolumn{2}{|c|}{ Hombre } & \multicolumn{2}{|c|}{ Mujer } & \multirow[t]{2}{*}{ p-valor } \\
\hline & & & $\mathbf{n}$ & $\%$ & $\mathbf{n}$ & $\%$ & \\
\hline \multirow{8}{*}{ Cepillado } & \multirow{5}{*}{ Frecuencia } & Nunca & 0 & $0,00 \%$ & 0 & $0,00 \%$ & \multirow{5}{*}{0,18} \\
\hline & & 1 vez al día & 31 & $24,03 \%$ & 6 & $14,63 \%$ & \\
\hline & & 2 veces al día & 57 & $44,19 \%$ & 16 & $39,02 \%$ & \\
\hline & & 3 veces al día & 39 & $30,23 \%$ & 19 & $46,34 \%$ & \\
\hline & & 1 vez a la semana & 2 & $1,55 \%$ & 0 & $0,00 \%$ & \\
\hline & \multirow{3}{*}{ Tipo } & Manual & 80 & $62,02 \%$ & 26 & $63,41 \%$ & \multirow{3}{*}{0,782} \\
\hline & & Eléctrico & 31 & $24,03 \%$ & 8 & $19,51 \%$ & \\
\hline & & Ambos & 18 & $13,95 \%$ & 7 & $17,07 \%$ & \\
\hline \multirow{3}{*}{\multicolumn{2}{|c|}{ Hábito de tabaquismo }} & No Fumador & 66 & $51,16 \%$ & 26 & $63,41 \%$ & \multirow{3}{*}{0,334} \\
\hline & & Ex-fumador & 22 & $17,05 \%$ & 4 & $9,76 \%$ & \\
\hline & & Fumador & 41 & $31,78 \%$ & 11 & $26,83 \%$ & \\
\hline \multirow{4}{*}{\multicolumn{2}{|c|}{$\begin{array}{l}\text { Frecuencia de visitas } \\
\text { dentista }\end{array}$}} & Esporádicamente & 36 & $27,91 \%$ & 10 & $24,39 \%$ & \multirow{4}{*}{0,132} \\
\hline & & Nunca & 2 & $1,55 \%$ & 0 & $0,00 \%$ & \\
\hline & & Periódicamente & 67 & $51,94 \%$ & 28 & $68,29 \%$ & \\
\hline & & Sólo con clínica & 24 & $18,60 \%$ & 3 & $7,32 \%$ & \\
\hline
\end{tabular}

Tabla 5.1.5. Resumen de los datos de hábitos de cepillado, tabaquismo y frecuencia de visitas al dentista, en función de la escala, para la segunda visita.

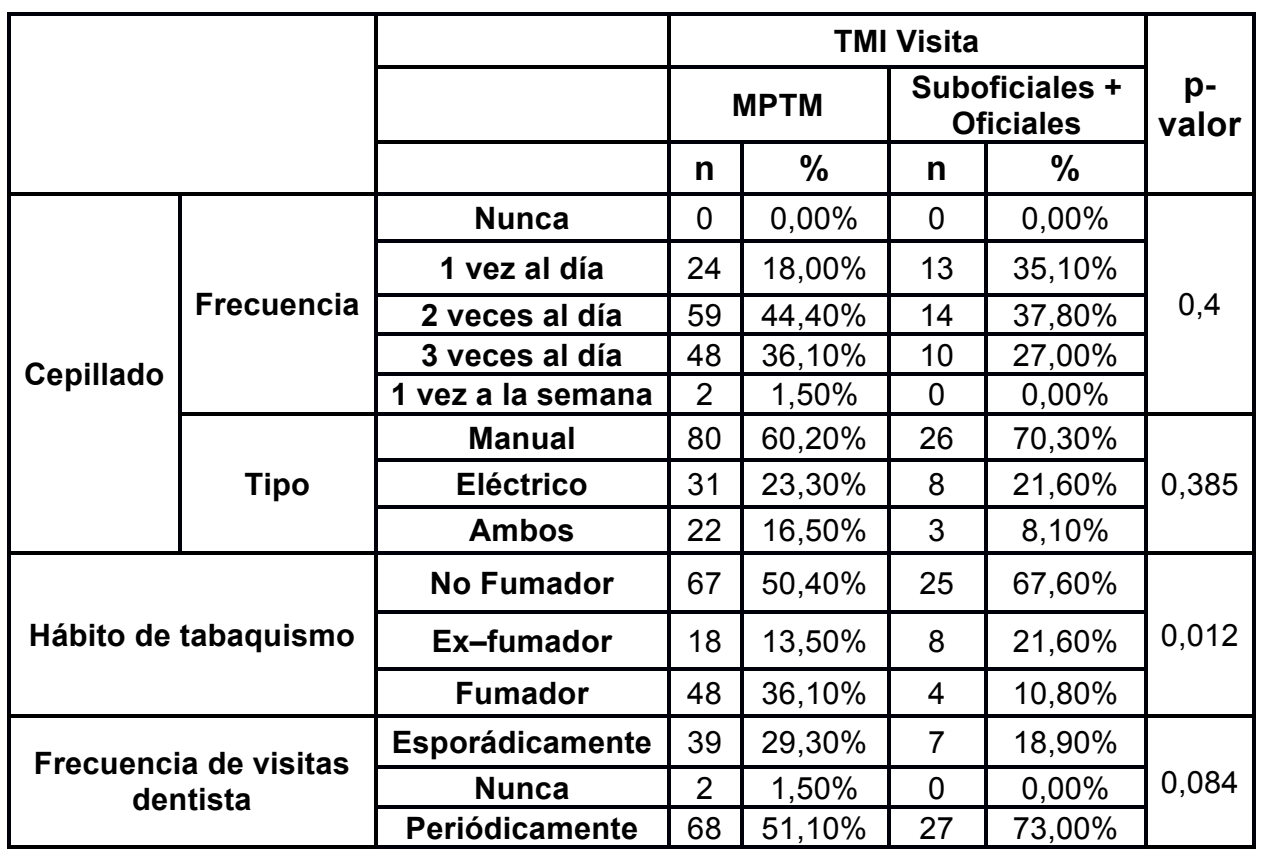

En las dos escalas en las que se ha dividido la muestra (Tabla 5.1.5) sigue siendo el porcentaje más alto el de los que se cepillan dos veces al día. Sin embargo, en 
contra de lo que cabría esperar, la tropa se cepilla tres veces diarias con más frecuencia que la escala de of/subof. En cuanto al tipo de cepillo utilizado, en ambas escalas el más utilizado es el manual. El eléctrico lo utilizan casi en el mismo porcentaje unos y otros, pero son los de tropa los que más combinan el uso de los dos tipos. El porcentaje de no fumadores con respecto a los que si fuman es mayor en las dos escalas pero es más elevado entre los of/subof en los que hay, además, más ex-fumadores. Como era de esperar por el comentario del párrafo anterior, las revisiones en el dentista las hacen de forma periódica las dos escalas en la mayoría de los casos, aunque es mayor el porcentaje en la de los of/subof. En este tópico, en lo que se refiere a ir al dentista solo cuando hay molestias, el porcentaje es mayor para el personal de tropa. Incluso hay un pequeño porcentaje que ni siquiera acude.

Tabla 5.1.6. Resumen de los datos de hábitos de cepillado, tabaquismo y frecuencia de visitas al dentista, en función de la edad, para la segunda visita.

\begin{tabular}{|c|c|c|c|c|c|c|c|}
\hline & & \multicolumn{4}{|c|}{ Grupos de Edad } & \multirow{3}{*}{$\begin{array}{c}\text { p- } \\
\text { valor }\end{array}$} \\
\hline & & & \multicolumn{2}{|r|}{$\leq 27$} & \multicolumn{2}{|r|}{$>27$} & \\
\hline & & & $\mathbf{n}$ & $\%$ & $\mathbf{n}$ & $\%$ & \\
\hline \multirow{8}{*}{ Cepillado } & \multirow{5}{*}{ Frecuencia } & Nunca & 0 & $0,00 \%$ & 0 & $0,00 \%$ & \multirow{5}{*}{0,113} \\
\hline & & 1 vez al día & 19 & $19,40 \%$ & 18 & $25,00 \%$ & \\
\hline & & 2 veces al día & 38 & $38,80 \%$ & 35 & $48,60 \%$ & \\
\hline & & 3 veces al día & 39 & $39,80 \%$ & 19 & $26,40 \%$ & \\
\hline & & $\begin{array}{c}1 \text { vez a la } \\
\text { semana }\end{array}$ & 2 & $2,00 \%$ & 0 & $0,00 \%$ & \\
\hline & \multirow{3}{*}{ Tipo } & Manual & 65 & $66,30 \%$ & 41 & $56,90 \%$ & \multirow{3}{*}{0,413} \\
\hline & & Eléctrico & 21 & $21,40 \%$ & 18 & $25,00 \%$ & \\
\hline & & Ambos & 12 & $12,20 \%$ & 13 & $18,10 \%$ & \\
\hline \multirow{3}{*}{\multicolumn{2}{|c|}{ Hábito de tabaquismo }} & No Fumador & 46 & $46,90 \%$ & 46 & $63,90 \%$ & \multirow{3}{*}{0,078} \\
\hline & & Exfumador & $\overline{15}$ & $15,30 \%$ & 11 & $15,30 \%$ & \\
\hline & & Fumador & 37 & $37,80 \%$ & 15 & $20,80 \%$ & \\
\hline \multirow{4}{*}{\multicolumn{2}{|c|}{$\begin{array}{l}\text { Frecuencia de visitas } \\
\text { dentista }\end{array}$}} & Esporádicamente & 30 & $30,60 \%$ & 16 & $22,20 \%$ & \multirow{4}{*}{0,261} \\
\hline & & Nunca & 2 & $2,00 \%$ & 0 & $0,00 \%$ & \\
\hline & & Periódicamente & 52 & $53,10 \%$ & 43 & $59,70 \%$ & \\
\hline & & Sólo con clínica & 14 & $14,30 \%$ & 13 & $18,10 \%$ & \\
\hline
\end{tabular}

En función de la edad (Tabla 5.1.6), siguen siendo los menores de 27 años los que con mayor frecuencia se cepillan tres veces al día. Sin embargo, el hábito de cepillado de dos veces al día sigue siendo la tónica general para los mayores de 27 años. En cuanto al tipo de cepillo utilizado sigue siendo el manual el más frecuente para todas las edades. El uso del eléctrico sigue siendo más elevado en los mayores de 27 años los cuales también combinan, más a menudo, los dos tipos de cepillos. Los mayores de 27 siguen teniendo un mayor porcentaje de no fumadores, sin embargo el número de ex-fumadores es igual en los dos grupos de edad. Se ha incrementado la frecuencia de visitas al dentista, la cual es 
realizada por los dos grupos de edad de forma bastante periódica. En cuanto a los que acuden solo cuando tienen alguna molestia siguen teniendo los mayores de 27 años un porcentaje ligeramente mayor. Sigue existiendo un pequeño porcentaje de los menores de 27 años que no va nunca.

\subsection{Estado de la articulación témporo-mandibular, presencia de bruxismo, utilización de férulas oclusales y presencia de torus mandibulares.}

\subsubsection{Visita 1}

De acuerdo con la Tabla 5.2.1a del anexo, los datos del estado de la ATM (articulación témporo-mandibular) de los sujetos estudiados indican que solo el $9 \%$ presentaba algún signo, de los cuales los más frecuentes son los chasquidos $(8,20 \%)$. Es de reseñar que solo el 7,6\% de los estudiados presenta bruxismo sin detallar su manifestación nocturna o diurna. Alrededor de un $2 \%$ de los sujetos estudiados utilizan férulas oclusales siendo mayor la prevalencia de las de mantenimiento. Por último es de reseñar que alrededor de un $8 \%$ de sujetos presenta torus mandibulares.

En los datos de la ATM para ambos sexos (Tabla 5.2.1) lo que más abunda es la ausencia de signos y síntomas. La presencia de chasquidos es el signo más frecuente, tanto en hombres como mujeres, siendo ligeramente mayor en ellas. En cuanto al bruxismo, la proporción es pequeña pero aquí si hay diferencia entre hombres y mujeres. El porcentaje de casos encontrados en los hombres dobla al de mujeres. El uso de férulas es igual en ambos sexos. Las mujeres usan más las de mantenimiento. La presencia de torus mandibulares se ha encontrado, casi en su totalidad, en los hombres.

En las dos escalas en las que se ha dividido la muestra (Tabla 5.2.2) la ausencia de signos y síntomas relacionados con la ATM es muy alta. De acuerdo con el párrafo anterior el chasquido es el signo más presente en los dos grupos, pero más frecuente entre of/subof. En cuanto al bruxismo, también es mayor el porcentaje en la escala de of/subof. La utilización de férulas, todas ellas de mantenimiento, es mayor en la tropa. La presencia de torus mandibulares se ha encontrado en mayor porcentaje en la tropa. 
Tabla 5.2.1. Resumen del estado de la articulación témporo-mandibular, presencia de bruxismo, utilización de férulas oclusales y presencia de torus mandibulares, en función del sexo, en la primera visita.

\begin{tabular}{|c|c|c|c|c|c|c|}
\hline & & \multicolumn{2}{|c|}{ Hombre } & \multicolumn{2}{|c|}{ Mujer } & \multirow{2}{*}{$\begin{array}{c}p- \\
\text { valor }\end{array}$} \\
\hline & & $\mathbf{n}$ & $\%$ & $\mathbf{n}$ & $\%$ & \\
\hline \multirow{3}{*}{$\begin{array}{l}\text { Estado de la } \\
\text { ATM }\end{array}$} & $\begin{array}{c}\text { Ausencia de signos y } \\
\text { síntomas }\end{array}$ & 118 & $91,50 \%$ & 37 & $90,20 \%$ & \multirow{3}{*}{0,704} \\
\hline & Presencia de chasquidos & 10 & $7,80 \%$ & 4 & $9,80 \%$ & \\
\hline & Dolor a la palpación & 1 & $0,80 \%$ & 0 & $0,00 \%$ & \\
\hline \multirow{2}{*}{ Bruxismo } & NO & 118 & $91,50 \%$ & 39 & $95,10 \%$ & \multirow{2}{*}{0,736} \\
\hline & SI & 11 & $8,50 \%$ & 2 & $4,90 \%$ & \\
\hline \multirow{3}{*}{$\begin{array}{l}\text { Férulas } \\
\text { Oclusales }\end{array}$} & NO & 127 & $98,40 \%$ & 39 & $95,10 \%$ & \multirow{3}{*}{0,222} \\
\hline & De mantenimiento & 1 & $0,80 \%$ & 2 & $4,90 \%$ & \\
\hline & De descarga & 1 & $0,80 \%$ & 0 & $0,00 \%$ & \\
\hline \multirow{2}{*}{$\begin{array}{c}\text { Torus } \\
\text { mandibulares }\end{array}$} & NO & 117 & $90,70 \%$ & 40 & $97,60 \%$ & \multirow{2}{*}{0,193} \\
\hline & SI & 12 & $9,30 \%$ & 1 & $2,40 \%$ & \\
\hline
\end{tabular}

Tabla 5.2.2. Resumen del estado de la articulación témporo-mandibular, presencia de bruxismo, utilización de férulas oclusales y presencia de torus mandibulares, en función de la escala, en la primera visita.

\begin{tabular}{|c|c|c|c|c|c|c|}
\hline & & \multicolumn{2}{|c|}{ MPTM } & \multicolumn{2}{|c|}{$\begin{array}{c}\text { Suboficiales + } \\
\text { Oficiales }\end{array}$} & \multirow[t]{2}{*}{ p-valor } \\
\hline & & $n$ & $\%$ & $\mathbf{n}$ & $\%$ & \\
\hline \multirow{3}{*}{ Estado de la ATM } & $\begin{array}{l}\text { Ausencia de } \\
\text { signos y } \\
\text { síntomas }\end{array}$ & 129 & $93,50 \%$ & 26 & $81,30 \%$ & \multirow{3}{*}{0,05} \\
\hline & $\begin{array}{l}\text { Presencia de } \\
\text { chasquidos }\end{array}$ & 9 & $6,50 \%$ & 5 & $15,60 \%$ & \\
\hline & $\begin{array}{l}\text { Dolor a la } \\
\text { palpación }\end{array}$ & 0 & $0,00 \%$ & 1 & $3,10 \%$ & \\
\hline \multirow{2}{*}{ Bruxismo } & NO & 128 & $92,80 \%$ & 29 & $90,60 \%$ & \multirow{2}{*}{0,713} \\
\hline & SI & 10 & $7,20 \%$ & 3 & $9,40 \%$ & \\
\hline \multirow{3}{*}{$\begin{array}{l}\text { Férulas } \\
\text { Oclusales }\end{array}$} & NO & 135 & $97,80 \%$ & 31 & $96,90 \%$ & \multirow{3}{*}{0,101} \\
\hline & $\begin{array}{c}\mathrm{De} \\
\text { mantenimiento }\end{array}$ & 3 & $2,20 \%$ & 0 & $0,00 \%$ & \\
\hline & De descarga & 0 & $0,00 \%$ & 1 & $3,10 \%$ & \\
\hline \multirow{2}{*}{$\begin{array}{c}\text { Torus } \\
\text { mandibulares }\end{array}$} & NO & 127 & $92,00 \%$ & 30 & $93,80 \%$ & \multirow{2}{*}{1} \\
\hline & SI & 11 & $8,00 \%$ & 2 & $6,30 \%$ & \\
\hline
\end{tabular}

En lo que se refiere a las edades (Tabla 5.2.3) se constata el mismo resultado: ausencia de signos y síntomas del ATM, siendo, de todos los signos, la presencia 
de chasquidos el signo más abundante, el cual es más frecuente en menores de 27 años. En cuanto al bruxismo, es mayor el porcentaje en los mayores de 27 años. El uso de férulas es igual en ambos grupos de edad, pero son los menores de 27 años los mayoritarios en las de mantenimiento. La presencia de torus mandibulares se ha encontrado en mayor porcentaje en menores de 27 años.

Tabla 5.2.3. Resumen del estado de la articulación témporo-mandibular, presencia de bruxismo, utilización de férulas oclusales y presencia de torus mandibulares, en función de la edad, en la primera visita.

\begin{tabular}{|c|c|c|c|c|c|c|}
\hline & & \multicolumn{2}{|c|}{$\leq 27$} & \multicolumn{2}{|c|}{$>27$} & \multirow[t]{2}{*}{ p-valor } \\
\hline & & $\mathbf{n}$ & $\%$ & $\mathbf{n}$ & $\%$ & \\
\hline \multirow{3}{*}{$\begin{array}{c}\text { Estado de la } \\
\text { ATM }\end{array}$} & $\begin{array}{c}\text { Ausencia de } \\
\text { signos y } \\
\text { síntomas } \\
\end{array}$ & 89 & $90,80 \%$ & 66 & $91,70 \%$ & \multirow{3}{*}{0,372} \\
\hline & $\begin{array}{l}\text { Presencia de } \\
\text { chasquidos }\end{array}$ & 9 & $9,20 \%$ & 5 & $6,90 \%$ & \\
\hline & $\begin{array}{l}\text { Dolor a la } \\
\text { palpación }\end{array}$ & 0 & $0,00 \%$ & 1 & $1,40 \%$ & \\
\hline \multirow{2}{*}{ Bruxismo } & NO & 93 & $94,90 \%$ & 64 & $88,90 \%$ & \multirow{2}{*}{0,145} \\
\hline & SI & 5 & $5,10 \%$ & 8 & $11,10 \%$ & \\
\hline \multirow{3}{*}{$\begin{array}{l}\text { Férulas } \\
\text { Oclusales }\end{array}$} & NO & 96 & $98,00 \%$ & 70 & $97,20 \%$ & \multirow{3}{*}{0,402} \\
\hline & $\begin{array}{c}\mathrm{De} \\
\text { mantenimiento }\end{array}$ & 2 & $2,00 \%$ & 1 & $1,40 \%$ & \\
\hline & De descarga & 0 & $0,00 \%$ & 1 & $1,40 \%$ & \\
\hline \multirow{2}{*}{$\begin{array}{c}\text { Torus } \\
\text { mandibulares }\end{array}$} & NO & 89 & $90,80 \%$ & 68 & $94,40 \%$ & \multirow{2}{*}{0,379} \\
\hline & SI & 9 & $9,20 \%$ & 4 & $5,60 \%$ & \\
\hline
\end{tabular}

\subsubsection{Visita 2}

En la segunda visita (Tabla 5.2.2a del anexo) solo alrededor de un 9\% presentaba algún signo en el estado de la ATM, siendo los chasquidos el más frecuente. En cuanto a la presencia de bruxismo se sigue manteniendo la misma proporción que en la primera visita $(7,6 \%)$. Algo más de un $4 \%$ son los sujetos que utilizan férulas oclusales y solo alrededor de un $8 \%$ de sujetos presenta torus mandibulares.

El estado de la ATM en ambos sexos (Tabla 5.2.4) no experimentó ninguna variación notable respecto a la primera visita. Por tanto, sigue siendo el síntoma más abundante (casi único) la presencia de chasquidos tanto hombres como mujeres, en las que el porcentaje es ligeramente mayor. En cuanto al bruxismo, 
el porcentaje observado en los hombres sigue siendo casi el doble que el detectado en mujeres. El uso de férulas es mayor en los hombres que son los que únicamente usan las de descarga y los torus mandibulares se han encontrado, casi en su totalidad, en los hombres.

Tabla 5.2.4. Resumen del estado de la articulación témporo-mandibular, presencia de bruxismo, utilización de férulas oclusales y presencia de torus mandibulares, en función del sexo, en la segunda visita.

\begin{tabular}{|c|c|c|c|c|c|c|}
\hline & & \multicolumn{2}{|c|}{ Hombre } & \multicolumn{2}{|c|}{ Mujer } & \multirow[t]{2}{*}{ p-valor } \\
\hline & & $\mathbf{n}$ & $\%$ & $\mathbf{n}$ & $\%$ & \\
\hline \multirow{4}{*}{$\begin{array}{c}\text { Estado de la } \\
\text { ATM }\end{array}$} & $\begin{array}{c}\text { Ausencia de } \\
\text { signos y } \\
\text { síntomas } \\
\end{array}$ & 119 & $92,20 \%$ & 36 & $87,80 \%$ & \multirow{4}{*}{0,288} \\
\hline & $\begin{array}{l}\text { Presencia de } \\
\text { chasquidos }\end{array}$ & 9 & $7,00 \%$ & 4 & $9,80 \%$ & \\
\hline & $\begin{array}{l}\text { Dolor a la } \\
\text { palpación }\end{array}$ & 0 & $0,00 \%$ & 1 & $2,40 \%$ & \\
\hline & $\begin{array}{l}\text { Movilidad } \\
\text { reducida de la } \\
\text { mandíbula }\end{array}$ & 1 & $0,80 \%$ & 0 & $0,00 \%$ & \\
\hline \multirow{2}{*}{ Bruxismo } & NO & 118 & $91,50 \%$ & 39 & $95,10 \%$ & \multirow{2}{*}{0,736} \\
\hline & SI & 11 & $8,50 \%$ & 2 & $4,90 \%$ & \\
\hline \multirow{3}{*}{$\begin{array}{l}\text { Férulas } \\
\text { Oclusales }\end{array}$} & NO & 124 & $96,10 \%$ & 39 & $95,10 \%$ & \multirow{3}{*}{0,234} \\
\hline & $\begin{array}{c}\mathrm{De} \\
\text { mantenimiento }\end{array}$ & 2 & $1,60 \%$ & 2 & $4,90 \%$ & \\
\hline & De descarga & 3 & $2,30 \%$ & 0 & $0,00 \%$ & \\
\hline \multirow{2}{*}{$\begin{array}{c}\text { Torus } \\
\text { mandibulares }\end{array}$} & NO & 117 & $90,70 \%$ & 40 & $97,60 \%$ & \multirow{2}{*}{0,193} \\
\hline & SI & 12 & $9,30 \%$ & 1 & $2,40 \%$ & \\
\hline
\end{tabular}

Con las escalas (Tabla 5.2.5) ocurre lo mismo, se repiten los datos de la primera visita: ausencia, en ambas escalas de signos y síntomas de alteración en el estado de la ATM. Solo la presencia de chasquidos siendo mayor el porcentaje en la escala de of/subof. En cuanto al bruxismo el porcentaje también es mayor en la escala de of/subof. El uso de férulas es mayor en la tropa, con predominio de las de mantenimiento que a su vez son los únicos que usan este tipo. Como en la visita 1 la presencia de torus mandibulares se ha encontrado en mayor porcentaje en la tropa.

Con la distribución de síntomas en función de las edades (Tabla 5.2.6) ocurre lo mismo que en la visita 1. Ausencia de signos y síntomas en el estado de la ATM. Solo la presencia de chasquidos (en pequeña proporción) el cual es más frecuente en menores de 27 años. En cuanto al bruxismo, es mayor el porcentaje en los mayores de 27 años. El porcentaje de uso de férulas, es ligeramente superior en los mayores de 27 años, que usan en un caso más la de descarga. La 
Estudio epidemiológico de la salud bucodental y ...

presencia de torus mandibulares se ha encontrado en mayor porcentaje en menores de 27 años.

Tabla 5.2.5. Resumen del estado de la articulación témporo-mandibular, presencia de bruxismo, utilización de férulas oclusales y presencia de torus mandibulares, en función de la escala, en la segunda visita.

\begin{tabular}{|c|c|c|c|c|c|c|}
\hline & & \multicolumn{2}{|c|}{ MPTM } & \multicolumn{2}{|c|}{$\begin{array}{l}\text { Suboficiales + } \\
\text { Oficiales }\end{array}$} & \multirow[t]{2}{*}{$\begin{array}{c}\text { p- } \\
\text { valor }\end{array}$} \\
\hline & & $\mathbf{n}$ & $\%$ & $\mathbf{n}$ & $\%$ & \\
\hline \multirow{4}{*}{$\begin{array}{c}\text { Estado de la } \\
\text { ATM }\end{array}$} & $\begin{array}{l}\text { Ausencia de } \\
\text { signos y } \\
\text { síntomas }\end{array}$ & 122 & $91,70 \%$ & 33 & $89,20 \%$ & \multirow{4}{*}{0,378} \\
\hline & $\begin{array}{l}\text { Presencia de } \\
\text { chasquidos }\end{array}$ & 9 & $6,80 \%$ & 4 & $10,80 \%$ & \\
\hline & $\begin{array}{l}\text { Dolor a la } \\
\text { palpación }\end{array}$ & 1 & $0,80 \%$ & 0 & $0,00 \%$ & \\
\hline & $\begin{array}{c}\text { Movilidad } \\
\text { reducida de la } \\
\text { mandíbula }\end{array}$ & 1 & $0,80 \%$ & 0 & $0,00 \%$ & \\
\hline \multirow{2}{*}{ Bruxismo } & NO & 124 & $93,20 \%$ & 33 & $89,20 \%$ & \multirow{2}{*}{0,145} \\
\hline & SI & 9 & $6,80 \%$ & 4 & $10,80 \%$ & \\
\hline \multirow{3}{*}{$\begin{array}{l}\text { Férulas } \\
\text { Oclusales }\end{array}$} & NO & 127 & $95,50 \%$ & 36 & $97,30 \%$ & \multirow{3}{*}{0,657} \\
\hline & $\begin{array}{c}\mathrm{De} \\
\text { mantenimiento }\end{array}$ & 4 & $3,00 \%$ & 0 & $0,00 \%$ & \\
\hline & De descarga & 2 & $1,50 \%$ & 1 & $2,70 \%$ & \\
\hline \multirow{2}{*}{$\begin{array}{c}\text { Torus } \\
\text { mandibulares }\end{array}$} & NO & 122 & $91,70 \%$ & 35 & $94,60 \%$ & \multirow{2}{*}{0,379} \\
\hline & SI & 11 & $8,30 \%$ & 2 & $5,40 \%$ & \\
\hline
\end{tabular}

Tabla 5.2.6. Resumen del estado de la articulación témporo-mandibular, presencia de bruxismo, utilización de férulas oclusales y presencia de torus mandibulares, en función de la edada, en la segunda visita.

\begin{tabular}{|c|c|c|c|c|c|c|}
\hline & \multicolumn{2}{|c|}{$\leq 27$} & \multicolumn{2}{|c|}{$>27$} & \multirow{2}{*}{$\begin{array}{c}\text { p- } \\
\text { valor }\end{array}$} \\
\hline & & $\mathbf{n}$ & $\%$ & $\mathbf{n}$ & $\%$ & \\
\hline \multirow{4}{*}{$\begin{array}{c}\text { Estado de la } \\
\text { ATM }\end{array}$} & $\begin{array}{c}\text { Ausencia de } \\
\text { signos y } \\
\text { síntomas }\end{array}$ & 87 & $88,80 \%$ & 68 & $94,40 \%$ & \multirow{4}{*}{0,378} \\
\hline & $\begin{array}{c}\text { Presencia de } \\
\text { chasquidos }\end{array}$ & 9 & $9,20 \%$ & 4 & $5,60 \%$ & \\
\hline & $\begin{array}{l}\text { Dolor a la } \\
\text { palpación }\end{array}$ & 1 & $1,00 \%$ & 0 & $0,00 \%$ & \\
\hline & $\begin{array}{c}\text { Movilidad } \\
\text { reducida de la } \\
\text { mandíbula }\end{array}$ & 1 & $1,00 \%$ & 0 & $0,00 \%$ & \\
\hline \multirow{2}{*}{ Bruxismo } & NO & 93 & $94,90 \%$ & 64 & $88,90 \%$ & \multirow{2}{*}{0,145} \\
\hline & $\mathrm{SI}$ & 5 & $5,10 \%$ & 8 & $11,10 \%$ & \\
\hline \multirow{3}{*}{$\begin{array}{l}\text { Férulas } \\
\text { Oclusales }\end{array}$} & NO & 95 & $96,90 \%$ & 68 & $94,40 \%$ & \multirow{3}{*}{0,657} \\
\hline & $\begin{array}{c}\mathrm{De} \\
\text { mantenimiento }\end{array}$ & 2 & $2,00 \%$ & 2 & $2,80 \%$ & \\
\hline & De descarga & 1 & $1,00 \%$ & 2 & $2,80 \%$ & \\
\hline \multirow{2}{*}{$\begin{array}{c}\text { Torus } \\
\text { mandibulares }\end{array}$} & NO & 89 & $90,80 \%$ & 68 & $94,40 \%$ & \multirow{2}{*}{0,379} \\
\hline & SI & 9 & $9,20 \%$ & 4 & $5,60 \%$ & \\
\hline
\end{tabular}




\subsection{Opacidades e hipoplasias del esmalte y tinción por tetraciclinas}

\subsubsection{Visita 1}

En cuanto a la distribución de las opacidades/hipoplasias del esmalte de los sujetos estudiados en la primera visita, de acuerdo con la Tabla 5.3.1a del anexo, los porcentajes más altos, con valores del 88,8\%, corresponden a los sujetos que no presentan ningún defecto del esmalte. Apareciendo como lo más prevalente, las opacidades difusas en $4,1 \%$ seguido de la opacidad delimitada e hipoplasia con $2,4 \%$ y otros defectos en $1,8 \%$ de los casos. La presencia de tinciones por tetraciclinas solo se observó en un $2,4 \%$ de los sujetos estudiados.

En ambos sexos (Tabla 5.3.1) lo que más abunda es la ausencia de defectos del esmalte, siendo ligeramente mayor el porcentaje en los hombres $(89,1 \%)$. Las opacidades difusas es la alteración mas prevalente en los dos sexos, apareciendo con mayor porcentaje en mujeres $(4,9 \%)$ mientras que otros defectos se observan únicamente en hombres $(2,3 \%)$. En cuanto a la tinción por tetraciclinas, todos los casos observados corresponden a los hombres.

Tabla 5.3.1, Resumen de las opacidades e hipoplasias del esmalte y tinción por tetraciclinas, en función del sexo, en la primera visita.

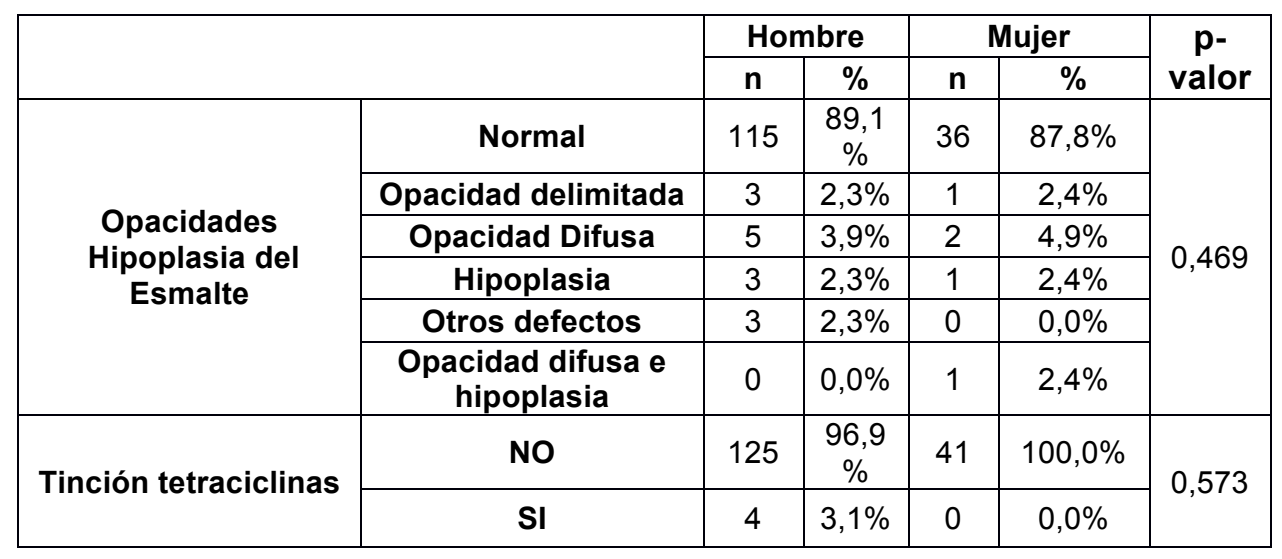


En las dos escalas (Tabla 5.3.2) el dato predominante es la ausencia de defectos del esmalte, que es algo mayor en porcentaje en la tropa $(89,1 \%)$. Las opacidades difusas se observan sobre todo en la tropa $(4,3 \%)$, en la cual aparecen exclusivamente los casos de opacidad delimitada. Las hipoplasias $(3,1 \%)$ y otros defectos $(6,3 \%)$ aparecen con mayor porcentaje en of/subof. En cuanto a la tinción por tetraciclinas, todos los casos observados corresponden a la tropa.

Tabla 5.3.2. Resumen de las opacidades e hipoplasias del esmalte y tinción por tetraciclinas, en función del sexo, en la primera visita.

\begin{tabular}{|c|c|c|c|c|c|c|}
\hline \multirow{2}{*}{} & \multicolumn{2}{|c|}{ MPTM } & \multicolumn{2}{c|}{$\begin{array}{c}\text { Suboficiales + } \\
\text { Oficiales }\end{array}$} & \multirow{2}{*}{$\begin{array}{c}\text { p- } \\
\text { valor }\end{array}$} \\
\cline { 3 - 6 } & Normal & $\mathbf{n}$ & $\%$ & $\mathbf{n}$ & $\%$ & \\
\hline \multirow{4}{*}{$\begin{array}{c}\text { Opacidades } \\
\text { Hipoplasias del } \\
\text { Esmalte }\end{array}$} & $\begin{array}{c}\text { Opacidad } \\
\text { delimitada }\end{array}$ & 4 & $2,9 \%$ & 0 & $0,0 \%$ & \\
\cline { 2 - 6 } & Opacidad Difusa & 6 & $4,3 \%$ & 1 & $3,1 \%$ & \multirow{2}{*}{0,351} \\
\cline { 2 - 6 } & Hipoplasia & 3 & $2,2 \%$ & 1 & $3,1 \%$ & \\
\cline { 2 - 6 } & Otros defectos & 1 &, $7 \%$ & 2 & $6,3 \%$ & \\
\cline { 2 - 6 } & $\begin{array}{c}\text { Opacidad difusa e } \\
\text { hipoplasia }\end{array}$ & 1 &, $7 \%$ & 0 & $0,0 \%$ & \\
\hline \multirow{2}{*}{$\begin{array}{c}\text { Tinción } \\
\text { tetraciclinas }\end{array}$} & NO & 134 & $97,1 \%$ & 32 & $100,0 \%$ & \multirow{2}{*}{1} \\
\cline { 2 - 6 } & SI & 4 & $2,9 \%$ & 0 & $0,0 \%$ & \\
\hline
\end{tabular}

En los dos grupos de edad en los que se distribuyó la muestra, lo mismo que en los grupos anteriores, predomina, muy mayoritariamente, la ausencia de defectos del esmalte que es algo mayor en porcentaje en los menores de 27 años $(90,8 \%)$ (Tabla 5.3.3).

Tabla 5.3.3. Resumen de las opacidades e hipoplasias del esmalte y tinción por tetraciclinas, en función de la edad, en la primera visita.

\begin{tabular}{|c|c|c|c|c|c|c|}
\hline & & \multicolumn{2}{|c|}{$\leq 27$} & \multicolumn{2}{|c|}{$>27$} & \multirow{2}{*}{$\begin{array}{c}\text { p- } \\
\text { valor }\end{array}$} \\
\hline & & $\mathbf{n}$ & $\%$ & $\mathbf{n}$ & $\%$ & \\
\hline \multirow{6}{*}{$\begin{array}{c}\text { Opacidades } \\
\text { Hipoplasia del } \\
\text { Esmalte }\end{array}$} & Normal & 89 & $90,8 \%$ & 62 & $\begin{array}{c}86,1 \\
\%\end{array}$ & \multirow{6}{*}{0,256} \\
\hline & Opacidad delimitada & 2 & $2,0 \%$ & 2 & $2,8 \%$ & \\
\hline & Opacidad Difusa & 4 & $4,1 \%$ & 3 & $4,2 \%$ & \\
\hline & Hipoplasia & 2 & $2,0 \%$ & 2 & $2,8 \%$ & \\
\hline & Otros defectos & 0 & $0,0 \%$ & 3 & $4,2 \%$ & \\
\hline & $\begin{array}{c}\text { Opacidad difusa e } \\
\text { hipoplasia }\end{array}$ & 1 & $1,0 \%$ & 0 & $0,0 \%$ & \\
\hline \multirow{2}{*}{ Tinción tetraciclinas } & NO & 98 & $100 \%$ & 68 & $\begin{array}{c}94,4 \\
\%\end{array}$ & \multirow{2}{*}{0,031} \\
\hline & SI & 0 & $0,0 \%$ & 4 & $5,6 \%$ & \\
\hline
\end{tabular}


En cuanto a las opacidades difusas es la alteración que más aparece con el mismo porcentaje en ambas edades. Los casos de opacidad delimitada $(2,8 \%)$ e hipoplasia $(2,8 \%)$ se observan en mayor porcentaje en mayores de 27 años, apareciendo exclusivamente los otros defectos solo en este grupo. En cuanto a la tinción por tetraciclinas, todos los casos observados corresponden a los mayores de 27 años.

\subsubsection{Visita 2}

La distribución de las opacidades/hipoplasias del esmalte en la segunda visita (Tabla 5.3.2a del anexo) fue coincidente con la de la primera visita. En la tabla se observa que los porcentajes más altos son de un $88,8 \%$ de los que no presentan ningún defecto del esmalte. Apareciendo como lo más prevalente, las opacidades difusas en un $4,1 \%$ seguido de la opacidad delimitada e hipoplasia con $2,4 \%$ y otros defectos en un $1,8 \%$ de los casos. Lo mismo ocurre con la presencia de tinciones por tetraciclinas que se observó en un $2,4 \%$ de los sujetos estudiados.

En ambos sexos los resultados coinciden, prácticamente, con la primera visita (Tabla 5.3.4). Es predominante la ausencia de defectos del esmalte, siendo ligeramente mayor el porcentaje en los hombres $(89,1 \%)$. Las opacidades difusas son la alteración más prevalente en los dos sexos, apareciendo con mayor porcentaje en mujeres $(4,9 \%)$ mientras que otros defectos se observan únicamente en hombres $(2,3 \%)$. En cuanto a la tinción por tetraciclinas, todos los casos observados corresponden a los hombres.

Tabla 5.3.4, Resumen de las opacidades e hipoplasias del esmalte y tinción por tetraciclinas, en función del sexo, en la segunda visita.

\begin{tabular}{|c|c|c|c|c|c|c|}
\hline \multirow{2}{*}{} & \multicolumn{2}{|c|}{ Hombre } & \multicolumn{2}{c|}{ Mujer } & \multirow{2}{*}{$\begin{array}{c}\text { p- } \\
\text { valor }\end{array}$} \\
\cline { 2 - 6 } & Normal & 115 & $89,1 \%$ & 36 & $\begin{array}{c}87,8 \\
\%\end{array}$ & \\
\cline { 2 - 6 } & $\begin{array}{c}\text { Opacidad } \\
\text { delimitada }\end{array}$ & 3 & $2,3 \%$ & 1 & $2,4 \%$ & \\
\cline { 2 - 6 } $\begin{array}{c}\text { Opacidades } \\
\text { Hipoplasias del } \\
\text { Esmalte }\end{array}$ & Opacidad Difusa & 5 & $3,9 \%$ & 2 & $4,9 \%$ & \multirow{2}{*}{0,469} \\
\cline { 2 - 6 } & Hipoplasia & 3 & $2,3 \%$ & 1 & $2,4 \%$ & \\
\cline { 2 - 6 } & Otros defectos & 3 & $2,3 \%$ & 0 & $0,0 \%$ & \\
\cline { 2 - 5 } & $\begin{array}{c}\text { Opacidad difusa e } \\
\text { hipoplasia }\end{array}$ & 0 & $0,0 \%$ & 1 & $2,4 \%$ & \\
\hline \multirow{2}{*}{$\begin{array}{c}\text { Tinción } \\
\text { tetraciclinas }\end{array}$} & No & 125 & $96,9 \%$ & 41 & $\begin{array}{c}100,0 \\
\%\end{array}$ & \multirow{2}{*}{0,573} \\
\cline { 2 - 6 } & SI & 4 & $3,1 \%$ & 0 & $0,0 \%$ & \\
\hline
\end{tabular}


Como tenía que ser, tampoco los datos referidos a la escala experimentan variaciones notables (Tabla 5.3.5). Predomina, muy mayoritariamente, la ausencia de defectos del esmalte en ambas escalas, aunque es algo mayor en porcentaje en of/subof $(89,2 \%)$. Las opacidades difusas se observan sobre todo en la tropa $(4,5 \%)$, en la cual aparecen exclusivamente los casos de opacidad delimitada. Las hipoplasias $(2,7 \%)$ y otros defectos $(5,4 \%)$ aparecen con mayor porcentaje en of/subof. En cuanto a la tinción por tetraciclinas, como en la primera visita, todos los casos observados corresponden a la tropa.

Tabla 5.3.5, Resumen de las opacidades e hipoplasias del esmalte y tinción por tetraciclinas, en función de la escala, en la segunda visita.

\begin{tabular}{|c|c|c|c|c|c|c|}
\hline \multirow{2}{*}{} & \multicolumn{2}{|c|}{ MPTM } & $\begin{array}{c}\text { Suboficiales } \\
\text { + Oficiales }\end{array}$ & \multirow{2}{*}{ p-valor } \\
\cline { 2 - 6 } & \multicolumn{2}{|c|}{$\mathbf{n}$} & $\%$ & $\mathbf{n}$ & $\%$ & \\
\hline \multirow{4}{*}{$\begin{array}{c}\text { Opocidades } \\
\text { Hipoplasias del } \\
\text { Esmalte }\end{array}$} & Opacidad delimitada & 4 & $3,0 \%$ & 0 & $0,0 \%$ & \\
\cline { 2 - 6 } & Opacidad Difusa & 6 & $4,5 \%$ & 1 & $2,7 \%$ & \multirow{2}{*}{0,256} \\
\cline { 2 - 6 } & Hipoplasia & 3 & $2,3 \%$ & 1 & $2,7 \%$ & \\
\cline { 2 - 6 } & Otros defectos & 1 &, $8 \%$ & 2 & $5,4 \%$ & \\
\cline { 2 - 6 } $\begin{array}{c}\text { Opacidad difusa e } \\
\text { hipoplasia }\end{array}$ & 1 &, $8 \%$ & 0 & $0,0 \%$ & \\
\hline Tinción & No & 129 & $97,0 \%$ & 37 & $\begin{array}{c}100,0 \\
\%\end{array}$ & \multirow{2}{*}{0,031} \\
\cline { 2 - 6 } & SI & 4 & $3,0 \%$ & 0 & $0,0 \%$ & \\
\hline
\end{tabular}

Tabla 5.3.6, Resumen de las opacidades e hipoplasias del esmalte y tinción por tetraciclinas, en función de la escala, en la segunda visita.

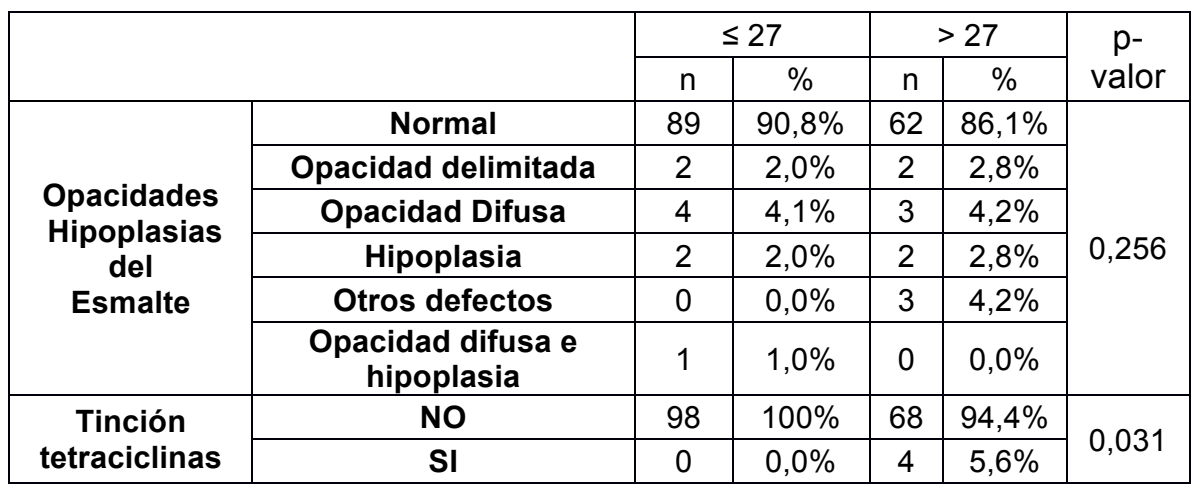

Como se ve en la Tabla 5.3.6 en ambos grupos de edad vuelven a repetirse los datos de la primera visita. Por ejemplo, la ausencia de defectos del esmalte sigue siendo algo mayor en porcentaje en los menores de 27 años $(90,8 \%)$. Las opacidades difusas siguen siendo la alteración que más aparece, pero con el 
mismo porcentaje en ambas edades. Los casos de opacidad delimitada $(2,8 \%)$ e hipoplasia $(2,8 \%)$ se observan en mayor porcentaje en mayores de 27 años, apareciendo exclusivamente los otros defectos solo en este grupo. En cuanto a la tinción por tetraciclinas, todos los casos observados corresponden a los mayores de 27 años.

\subsection{Estado periodontal y la necesidad de tratamiento, y presencia de pendientes en labios y lengua.}

\subsubsection{Visita 1}

La Tabla 5.4.1a del anexo indica el estado periodontal de los sujetos estudiados, solo un 14,7\% no presentó ninguno de los 3 indicadores utilizados. En el 72\% de los estudiados se observó durante la exploración que presentaban cálculo. En el 9,4\% se apreciaron bolsas de 4-5 mm y en el 3,5\% de los sujetos se observó hemorragia, directamente o ayudados con el espejo bucal durante la exploración. La necesidad de tratamiento periodontal, que viene determinada por la mayor afectación gingival o periodontal, en nuestra población en la primera visita lo mas prevalente es la tartrectomia, alrededor de un $76 \%$. Un 11,8\% no requeriría ningún tratamiento, mientras que el 9,4\% debería realizarse un raspado y alisado radicular. Un 2,9\% necesitaría mejorar sus hábitos de higiene con unas instrucciones. Un 6,5\% de los sujetos explorados presentaba un orificio para el uso de pendientes en la lengua y un $2,9 \%$ de los sujetos explorados presentaba orificios para el uso de pendientes en el labio. En todos los casos confirmaron que los usaban.

Entre los sujetos sanos, según el estado periodontal, el porcentaje mayor es de mujeres $(31,7 \%)$ (Tabla 5.4.1). Como consecuencia, los hombres dan un mayor porcentaje en los indicadores de cálculo, de bolsas de 4-5mm y de hemorragia. Las mujeres no precisan ningún tratamiento periodontal en el 29,3\% de los casos a diferencia de los hombres que solo son un 6,2\%. El tratamiento mas requerido, en ambos sexos, es la tartrectomia, siendo en mayor porcentaje en los hombres, al igual que el raspado y alisado radicular e, incluso, en instrucciones de higiene oral. 
Estudio epidemiológico de la salud bucodental y ...

Tabla 5.4.1. Resumen del estado periodontal, necesidad de tratamiento y utilización de pendientes en labios y lengua, en función del sexo, en la primera visita.

\begin{tabular}{|c|c|c|c|c|c|c|}
\hline & \multicolumn{2}{|c|}{ Hombre } & \multicolumn{2}{|c|}{ Mujer } & \multirow{2}{*}{ p-valor } \\
\hline & & $\mathbf{n}$ & $\%$ & $\mathbf{n}$ & $\%$ & \\
\hline \multirow{4}{*}{ Estado Periodontal } & Sano & 12 & $9,3 \%$ & 13 & $31,7 \%$ & \multirow{4}{*}{0,012} \\
\hline & Hemorragia & 5 & $3,9 \%$ & 1 & $2,4 \%$ & \\
\hline & Cálculo & 99 & $76,7 \%$ & 24 & $58,5 \%$ & \\
\hline & Bolsa 4-5 mm & 13 & $10,1 \%$ & 3 & $7,3 \%$ & \\
\hline \multirow{4}{*}{$\begin{array}{l}\text { Necesidad de } \\
\text { Tratamiento } \\
\text { Periodontal }\end{array}$} & $\begin{array}{c}\text { Instrucciones de } \\
\text { higiene }\end{array}$ & 4 & $3,1 \%$ & 1 & $2,4 \%$ & \multirow{4}{*}{0,003} \\
\hline & No precisa & 8 & $6,2 \%$ & 12 & $29,3 \%$ & \\
\hline & $\begin{array}{c}\text { Raspado y alisado } \\
\text { radicular }\end{array}$ & 13 & $10,1 \%$ & 3 & $7,3 \%$ & \\
\hline & Tartrectomía & 104 & $80,6 \%$ & 25 & $61,0 \%$ & \\
\hline \multirow{2}{*}{ Pendiente en lengua } & NO & 123 & $95,3 \%$ & 36 & $87,8 \%$ & \multirow{2}{*}{0,137} \\
\hline & SI & 6 & $4,7 \%$ & 5 & $12,2 \%$ & \\
\hline \multirow{2}{*}{ Pendiente en labio } & NO & 126 & $97,7 \%$ & 39 & $95,1 \%$ & \multirow{2}{*}{0,595} \\
\hline & SI & 3 & $2,3 \%$ & 2 & $4,9 \%$ & \\
\hline
\end{tabular}

En cuanto a los resultados del estado periodontal en función de la escala (Tabla 5.4.2) observamos que el porcentaje de sujetos sanos son prácticamente los mismos en una y otra escala.

Tabla 5.4.2: Resumen del estado periodontal, necesidad de tratamiento y utilización de pendientes en labios y lengua, en función de la escala, en la primera visita.

\begin{tabular}{|c|c|c|c|c|c|c|}
\hline & \multicolumn{2}{|c|}{ MPTM } & \multicolumn{2}{|c|}{$\begin{array}{c}\text { Suboficiales + } \\
\text { Oficiales }\end{array}$} & \multirow[t]{2}{*}{ p-valor } \\
\hline & & $\mathbf{n}$ & $\%$ & $\mathbf{n}$ & $\%$ & \\
\hline \multirow{4}{*}{$\begin{array}{c}\text { Estado } \\
\text { Periodontal }\end{array}$} & Sano & 20 & $14,5 \%$ & 5 & $15,6 \%$ & \multirow{4}{*}{0,192} \\
\hline & Hemorragia & 4 & $2,9 \%$ & 2 & $6,3 \%$ & \\
\hline & Cálculo & 104 & $75,4 \%$ & 19 & $59,4 \%$ & \\
\hline & Bolsa 4-5 mm & 10 & $7,2 \%$ & 6 & $18,8 \%$ & \\
\hline \multirow{4}{*}{$\begin{array}{l}\text { Necesidad de } \\
\text { Tratamiento } \\
\text { Periodontal }\end{array}$} & $\begin{array}{c}\text { Instrucciones de } \\
\text { higiene }\end{array}$ & 5 & $3,6 \%$ & 0 & $0,0 \%$ & \multirow{4}{*}{0,104} \\
\hline & No precisa & 15 & $10,9 \%$ & 5 & $15,6 \%$ & \\
\hline & $\begin{array}{c}\text { Raspado y } \\
\text { alisado radicular }\end{array}$ & 10 & $7,2 \%$ & 6 & $18,8 \%$ & \\
\hline & Tartrectomía & 108 & $78,3 \%$ & 21 & $65,6 \%$ & \\
\hline \multirow{2}{*}{$\begin{array}{c}\text { Pendiente en } \\
\text { lengua }\end{array}$} & NO & 127 & $92,0 \%$ & 32 & $100,0 \%$ & \multirow{2}{*}{0,128} \\
\hline & SI & 11 & $8,0 \%$ & 0 & $0,0 \%$ & \\
\hline \multirow{2}{*}{ Pendiente en labio } & NO & 133 & $96,4 \%$ & 32 & $100,0 \%$ & \multirow{2}{*}{0,585} \\
\hline & SI & 5 & $3,6 \%$ & 0 & $0,0 \%$ & \\
\hline
\end{tabular}


En ambos grupos el indicador mas prevalente es el cálculo, siendo mayor el porcentaje en la tropa $(75,4 \%)$, mientras que el porcentaje de los indicadores de bolsas de $4-5 \mathrm{~mm}(18,8 \%)$ y hemorragia $(6,3 \%)$ son el doble para los of/subof.

La mayor necesidad de tratamiento periodontal para las 2 escalas es la tartrectomia, siendo en mayor porcentaje en la tropa, la cual también requiere mas instrucciones de higiene bucal $(3,6 \%)$. El porcentaje de of/subof que no precisa ningún tratamiento $(15,6 \%)$ es mayor que en la tropa $(10,9 \%)$, pero van a requerir realizarse un raspado y alisado radicular en mayor porcentaje $(18,8 \%)$. La totalidad de los sujetos estudiados que presenten un orificio para el uso de pendientes en la lengua y/o labios son de la escala de tropa.

Tabla 5.4.3: Resumen del estado periodontal, necesidad de tratamiento y utilización de pendientes en labios y lengua, en función de la edad, en la primera visita.

\begin{tabular}{|c|c|c|c|c|c|c|}
\hline & & \multicolumn{2}{|c|}{$\leq 27$} & \multicolumn{2}{|r|}{$>27$} & \multirow{2}{*}{ p-valor } \\
\hline & & $\mathbf{n}$ & $\%$ & $\mathbf{n}$ & $\%$ & \\
\hline \multirow{4}{*}{ Estado Periodontal } & Sano & 14 & $14,3 \%$ & 11 & $15,3 \%$ & \multirow{4}{*}{0,175} \\
\hline & Hemorragia & 2 & $2,0 \%$ & 4 & $5,6 \%$ & \\
\hline & Cálculo & 76 & $77,6 \%$ & 47 & $65,3 \%$ & \\
\hline & Bolsa 4-5 mm & 6 & $6,1 \%$ & 10 & $13,9 \%$ & \\
\hline \multirow{4}{*}{$\begin{array}{l}\text { Necesidad de } \\
\text { Tratamiento } \\
\text { Periodontal }\end{array}$} & $\begin{array}{c}\text { Instrucciones de } \\
\text { higiene }\end{array}$ & 3 & $3,1 \%$ & 2 & $2,8 \%$ & \multirow{4}{*}{0,374} \\
\hline & No precisa & 11 & $11,2 \%$ & 9 & $12,5 \%$ & \\
\hline & $\begin{array}{l}\text { Raspado y alisado } \\
\text { radicular }\end{array}$ & 6 & $6,1 \%$ & 10 & $13,9 \%$ & \\
\hline & Tartrectomía & 78 & $79,6 \%$ & 51 & $70,8 \%$ & \\
\hline \multirow{2}{*}{ Pendiente en lengua } & NO & 87 & $88,8 \%$ & 72 & $100,0 \%$ & \multirow{2}{*}{0,003} \\
\hline & SI & 11 & $11,2 \%$ & 0 & $0,0 \%$ & \\
\hline \multirow{2}{*}{ Pendiente en labio } & NO & 95 & $96,9 \%$ & 70 & $97,2 \%$ & \multirow{2}{*}{1} \\
\hline & SI & 3 & $3,1 \%$ & 2 & $2,8 \%$ & \\
\hline
\end{tabular}

En cuanto a la edad (Tabla 5.4.3), el porcentaje de sujetos sanos según el estado periodontal es prácticamente el mismo en los dos grupos de edad y en ambos grupos observamos que el indicador más frecuente del estado periodontal es el cálculo, siendo mayor en los menores de 27 años $(77,6 \%)$, mientras que los indicadores de bolsas de $4-5 \mathrm{~mm}$ y de hemorragia son algo más del doble, en porcentaje, en los mayores de 27 años. El porcentaje en los mayores de 27 para los que no precisan ningún tratamiento periodontal (12,5\%) ysin embargo, en ambos grupos, es parecido el porcentaje de los que requieren instrucciones de higiene. La mayor necesidad de tratamiento periodontal para los dos grupos de 
edad es la tartrectomia siendo mayor el porcentaje en los menores de 27 años $(79,6 \%)$, mientras que el raspado y alisado radicular es doblemente necesario, en porcentaje $(13,9 \%)$, en los mayores de 27 años con respecto a la tropa. La totalidad de los sujetos estudiados que presenten un orificio para el uso de pendientes en la lengua, son menores de 27 años. Los casos que presentan un orificio para el uso de pendientes en el labio, están repartidos entre los dos grupos de edad, ligeramente mayor en los menores de 27 años.

\subsubsection{Visita 2}

En cuanto al estado periodontal de los sujetos estudiados en la segunda visita, de acuerdo con la Tabla 5.4.2a del anexo, los datos son muy parecidos a la primera visita. Un 35,9\% no presento ninguno de los 3 indicadores del estado periodóntico utilizados. En el $44,7 \%$ de los estudiados se observó durante la exploración que tenían cálculo. En el 15,3\% se apreciaron bolsas de 4-5 mm y en el $4,1 \%$ de los sujetos, se observó hemorragia directamente o ayudados con el espejo bucal durante la exploración. La necesidad de tratamiento periodontal, que viene determinada por la mayor afectación gingival o periodontal, es en esta segunda visita, la tartrectomia en un 45,9\% de los casos. Un $23,5 \%$ no requeriría ningún tratamiento, mientras que el $15,3 \%$ debería realizarse un raspado y alisado radicular, el mismo porcentaje de aquellos que necesitarían mejorar sus hábitos de higiene bucal con unas instrucciones. Un 5,9\% de los sujetos explorados presentaba un orificio para el uso de pendientes en la lengua, ligeramente inferior al de la primera visita, mientras que los orificios en el labio seguía siendo los mismos.

El número de sujetos sanos, según el estado periodontal, en la segunda visita sigue siendo mayor entre las mujeres $(56,1 \%)$ mientras que en los indicadores de cálculo, de bolsas de 4-5mm y de hemorragia es mayor el mayor porcentaje entre los hombres (Tabla 5.4.4). Las mujeres no precisan ningún tratamiento periodontal en el $46,3 \%$ de los casos a diferencia de los hombres que no lo necesita solo un 16,3\%. El tratamiento mas requerido, es en ambos sexos, es la tartrectomia, siendo en mayor porcentaje en los hombres, al igual que el raspado y alisado radicular e instrucciones de higiene oral. También es algo mayor el porcentaje de mujeres $(12,2 \%)$ que presenten un orificio para el uso de pendientes en la lengua y el de mujeres $(4,9 \%)$ que presenten un orificio para el uso de pendientes en el labio. 
Tabla 5.4.4. Resumen del estado periodontal, necesidad de tratamiento y utilización de pendientes en labios y lengua, en función del sexo, en la segunda visita.

\begin{tabular}{|c|c|c|c|c|c|c|}
\hline & \multicolumn{2}{|c|}{ Hombre } & \multicolumn{2}{|c|}{ Mujer } & \multirow{2}{*}{ p-valor } \\
\hline & & $\mathbf{n}$ & $\%$ & $\mathbf{n}$ & $\%$ & \\
\hline \multirow{4}{*}{ Estado Periodontal } & Sano & 38 & $29,5 \%$ & 23 & $56,1 \%$ & \multirow{4}{*}{0,01} \\
\hline & Hemorragia & 7 & $5,4 \%$ & 0 & $0,0 \%$ & \\
\hline & Cálculo & 64 & $49,6 \%$ & 12 & $29,3 \%$ & \\
\hline & Bolsa 4-5 mm & 20 & $15,5 \%$ & 6 & $14,6 \%$ & \\
\hline \multirow{4}{*}{$\begin{array}{l}\text { Necesidad de } \\
\text { Tratamiento } \\
\text { Periodontal }\end{array}$} & $\begin{array}{l}\text { Instrucciones de } \\
\text { higiene }\end{array}$ & 22 & $17,1 \%$ & 4 & $9,8 \%$ & \multirow{4}{*}{0,001} \\
\hline & No precisa & 21 & $16,3 \%$ & 19 & $46,3 \%$ & \\
\hline & $\begin{array}{c}\text { Raspado y alisado } \\
\text { radicular }\end{array}$ & 20 & $15,5 \%$ & 6 & $14,6 \%$ & \\
\hline & Tartrectomía & 66 & $51,2 \%$ & 12 & $29,3 \%$ & \\
\hline \multirow{2}{*}{$\begin{array}{l}\text { Pendiente en } \\
\text { lengua }\end{array}$} & NO & 124 & $96,1 \%$ & 36 & $87,8 \%$ & \multirow{2}{*}{0,062} \\
\hline & SI & 5 & $3,9 \%$ & 5 & $12,2 \%$ & \\
\hline \multirow{2}{*}{ Pendiente en labio } & NO & 126 & $97,7 \%$ & 39 & $95,1 \%$ & \multirow{2}{*}{0,595} \\
\hline & SI & 3 & $2,3 \%$ & 2 & $4,9 \%$ & \\
\hline
\end{tabular}

También se observa que en relación con el estado periodontal el porcentaje de sujetos sanos es mayor entre los of/subof $(43,2 \%$ ) (Tabla 5.4.5). En las dos escalas el indicador mas prevalente es el cálculo, siendo mayor el porcentaje en la tropa $(48,9 \%)$, mientras que los indicadores de bolsas de $4-5 \mathrm{~mm}(18,9 \%)$ y hemorragia $(8,1 \%)$ presentan un mayor en porcentaje entre los of/subof. El porcentaje de tropa $(24,8 \%)$ que no precisa ningún tratamiento es mayor que en of/subof $(18,9 \%)$. La mayor necesidad de tratamiento periodontal para las 2 escalas es la tartrectomia. En este caso es mayor la necesidad en la tropa $(49,6 \%)$. Sin embargo el porcentaje de of/subof que requieren un raspado y alisado radicular $(18,9 \%)$ es mayor. Esta escala precisa también mas instrucciones de higiene bucal (29,7\%). Casi la totalidad de los sujetos estudiados que presenten un orificio para el uso de pendientes en la lengua y/o boca, son de la escala de tropa.

En las dos escalas el indicador mas prevalente es el cálculo, siendo mayor el porcentaje en la tropa $(48,9 \%)$, mientras que los indicadores de bolsas de 4$5 \mathrm{~mm}(18,9 \%)$ y hemorragia $(8,1 \%)$ presentan un mayor en porcentaje entre los of/subof. El porcentaje de tropa $(24,8 \%)$ que no precisa ningún tratamiento es mayor que en of/subof $(18,9 \%)$. La mayor necesidad de tratamiento periodontal para las 2 escalas es la tartrectomia. En este caso es mayor la necesidad en la tropa $(49,6 \%)$. Sin embargo el porcentaje de of/subof que requieren un raspado y 
alisado radicular $(18,9 \%)$ es mayor. Esta escala precisa también mas instrucciones de higiene bucal $(29,7 \%)$. Casi la totalidad de los sujetos estudiados que presenten un orificio para el uso de pendientes en la lengua y/o boca, son de la escala de tropa.

Tabla 5.4.5. Resumen del estado periodontal, necesidad de tratamiento y utilización de pendientes en labios y lengua, en función de la escala, en la segunda visita.

\begin{tabular}{|c|c|c|c|c|c|c|}
\hline & \multicolumn{2}{|c|}{ MPTM } & \multicolumn{2}{|c|}{$\begin{array}{c}\text { Suboficiales + } \\
\text { Oficiales }\end{array}$} & \multirow{2}{*}{$\begin{array}{c}\text { p- } \\
\text { valor }\end{array}$} \\
\hline & & $\mathbf{n}$ & $\%$ & $\mathbf{n}$ & $\%$ & \\
\hline \multirow{4}{*}{ Estado Periodontal } & Sano & 45 & $33,8 \%$ & 16 & $43,2 \%$ & \multirow{4}{*}{0,019} \\
\hline & Hemorragia & 4 & $3,0 \%$ & 3 & $8,1 \%$ & \\
\hline & Cálculo & 65 & $48,9 \%$ & 11 & $29,7 \%$ & \\
\hline & Bolsa 4-5 mm & 19 & $14,3 \%$ & 7 & $18,9 \%$ & \\
\hline \multirow{4}{*}{$\begin{array}{l}\text { Necesidad de } \\
\text { Tratamiento } \\
\text { Periodontal }\end{array}$} & $\begin{array}{c}\text { Instrucciones } \\
\text { de higiene }\end{array}$ & 15 & $11,3 \%$ & 11 & $29,7 \%$ & \multirow{4}{*}{0,076} \\
\hline & No precisa & 33 & $24,8 \%$ & 7 & $18,9 \%$ & \\
\hline & $\begin{array}{c}\text { Raspado y } \\
\text { alisado } \\
\text { radicular }\end{array}$ & 19 & $14,3 \%$ & 7 & $18,9 \%$ & \\
\hline & Tartrectomía & 66 & $49,6 \%$ & 12 & $32,4 \%$ & \\
\hline \multirow{2}{*}{$\begin{array}{l}\text { Pendiente en } \\
\text { lengua }\end{array}$} & NO & 124 & $93,2 \%$ & 36 & $97,3 \%$ & \multirow{2}{*}{0,005} \\
\hline & SI & 9 & $6,8 \%$ & 1 & $2,7 \%$ & \\
\hline \multirow{2}{*}{ Pendiente en labio } & NO & 128 & $96,2 \%$ & 37 & $100,0 \%$ & \multirow{2}{*}{1} \\
\hline & SI & 5 & $3,8 \%$ & 0 & $0,0 \%$ & \\
\hline
\end{tabular}

El porcentaje de sujetos sanos según el estado periodontal es mayor en los menores de 27 años $(39,8 \%$ ) (Tabla 5.4.6). En ambos grupos de edad observamos que el indicador más frecuente del estado periodontal es el cálculo, siendo mayor en los menores de 27 años $(49,0 \%)$, mientras que los indicadores de bolsas de 4-5mm y de hemorragia son algo más del doble en porcentaje, en los mayores de 27 años. Es algo mayor el porcentaje en los menores de 27 años para los que no precisan ningún tratamiento periodontal $(24,5 \%)$,para los que solo requieren de instrucciones de higiene bucal $(17,3 \%)$ y para los que necesitan realizarse tartrectomia que es el tratamiento mas prevalente en los dos grupos pero en mayor porcentaje en los menores de 27 (49\%). El raspado y alisado radicular es doblemente necesario en porcentajes $(23,6 \%)$ en los mayores de 27 años con respecto a la tropa. La totalidad de los sujetos estudiados que presenten un orificio para el uso de pendientes en la lengua, son menores de 27 años. Los casos que presentan un orificio para el uso de pendientes en el labio, están repartidos por igual entre los dos grupos de edad, ligeramente mayor en los menores de 27 años. 
Tabla 5.4.6. Resumen del estado periodontal, necesidad de tratamiento y utilización de pendientes en labios y lengua, en función de la edad, en la segunda visita.

\begin{tabular}{|c|c|c|c|c|c|c|}
\hline & & \multicolumn{2}{|c|}{$\leq 27$} & \multicolumn{2}{|c|}{$>27$} & \multirow[t]{2}{*}{$\begin{array}{c}\text { p- } \\
\text { valor }\end{array}$} \\
\hline & & $\mathbf{n}$ & $\%$ & $\mathbf{n}$ & $\%$ & \\
\hline \multirow{4}{*}{ Estado Periodontal } & Sano & 39 & $39,8 \%$ & 22 & $30,6 \%$ & \multirow{4}{*}{0,019} \\
\hline & Hemorragia & 2 & $2,0 \%$ & 5 & $6,9 \%$ & \\
\hline & Cálculo & 48 & $49,0 \%$ & 28 & $38,9 \%$ & \\
\hline & Bolsa 4-5 mm & 9 & $9,2 \%$ & 17 & $23,6 \%$ & \\
\hline \multirow{4}{*}{$\begin{array}{c}\text { Necesidad de } \\
\text { Tratamiento Periodontal }\end{array}$} & $\begin{array}{c}\text { Instrucciones de } \\
\text { higiene }\end{array}$ & 17 & $17,3 \%$ & 9 & $12,5 \%$ & \multirow{4}{*}{0,076} \\
\hline & No precisa & 24 & $24,5 \%$ & 16 & $22,2 \%$ & \\
\hline & $\begin{array}{l}\text { Raspado y alisado } \\
\text { radicular }\end{array}$ & 9 & $9,2 \%$ & 17 & $23,6 \%$ & \\
\hline & Tartrectomía & 48 & $49,0 \%$ & 30 & $41,7 \%$ & \\
\hline \multirow{2}{*}{ Pendiente en lengua } & NO & 88 & $89,8 \%$ & 72 & $100 \%$ & \multirow{2}{*}{0,005} \\
\hline & SI & 10 & $10,2 \%$ & 0 & $0,0 \%$ & \\
\hline \multirow{2}{*}{ Pendiente en labio } & NO & 95 & $96,9 \%$ & 70 & $97,2 \%$ & \multirow{2}{*}{1} \\
\hline & SI & 3 & $3,1 \%$ & 2 & $2,8 \%$ & \\
\hline
\end{tabular}

\section{5. Índice CAO-D y componentes, necesidades de tratamiento}

En este apartado se presentan los resultados relacionados con el estudio del índice CAO-D (media y desviación típica) para el cual se valoraron los índices de caries (C), ausentes por caries (A) y obturados (O) por diente permanente (CAO-D). También, se presentan, en porcentajes, el índice de restauración (IR) y el índice libre de caries.

\subsubsection{Visita 1}

En la primera visita la muestra analizada presentó un índice CAO-D de 7,59 y, al analizar sus componentes (Tabla 5.5.1), la mayor parte del índice lo constituían las piezas obturadas $(\mathrm{O})$ con un valor 3,78. En segundo lugar las 
piezas careadas $(\mathrm{C})$ con un valor de 2,75 siendo las piezas ausentes por caries (A) igual a 1,07 .

Tabla 5.5.1.Índice CAO-D y sus componentes de la primera visita.

\begin{tabular}{|c|c|c|}
\hline \multirow{2}{*}{} & \multicolumn{2}{|c|}{ Visita 1 } \\
\cline { 2 - 3 } & Media & Desviación típica \\
\hline Edad & 27,24 & 6,12 \\
\hline Índice caries (C) & 2,75 & 3,06 \\
\hline Índice Obturación (O) & 3,78 & 3,62 \\
\hline Índice Ausentes (A) & 1,07 & 1,81 \\
\hline Índice CAOD & 7,59 & 4,45 \\
\hline
\end{tabular}

Como se puede ver en la tabla 5.5.2 el valor del índice CAO-D de las mujeres, 7,76 , es más elevado que el de los hombres. Aunque los hombres han dado para los índices $\mathrm{C}$ y A valores superiores a las mujeres, es el valor del índice $\mathrm{O}$ de las mujeres (caries tratadas con obturaciones) el que determina que el índice CAO$\mathrm{D}$ de las mujeres sea superior al de los hombres. La tabla indica que las mujeres presentan un mayor porcentaje de restauración (IR), 58,76\% así como, mayor porcentaje libre de caries $(34,9 \%)$.

Tabla 5.5.2.Resultados, de la primera visita, del índice CAO-D y sus componentes. Distribución por grupos.

\begin{tabular}{|l|l|l|l|l|l|l|l|}
\hline & & C & A & O & CA0-D & IR & $\begin{array}{l}\text { Sin } \\
\text { caries }\end{array}$ \\
\hline \multirow{4}{*}{ Edad } & $<=27$ & 3,02 & 0,55 & 3,13 & 6,70 & $46,71 \%$ & $28,6 \%$ \\
& & $(2,88)$ & $(0,81)$ & $(3,65))$ & $(4,49)$ & & \\
\cline { 2 - 8 } & $>\mathbf{2 7}$ & 2,38 & 1,78 & 4,65 & 8,81 & $52,78 \%$ & $41,7 \%$ \\
& & $(3,28)$ & $(2,45)$ & $(3,42)$ & $(4,12)$ & & \\
\hline \multirow{5}{*}{ Escala } & Tropa & 2,92 & 0,87 & 3,42 & 7,21 & $47,43 \%$ & $31,9 \%$ \\
& & $(3,02)$ & $(1,34)$ & $(3,71)$ & $(4,55)$ & & \\
\cline { 2 - 8 } & Oficiales y & 2,00 & 1,94 & 5,31 & 9,25 & $57,40 \%$ & $43,8 \%$ \\
& Suboficiales & $(3,16)$ & $(2,98)$ & $(2,79)$ & $(3,57)$ & & \\
\hline \multirow{5}{*}{ Sexo } & Hombre & 2,84 & 1,17 & 3,53 & 7,54 & $46,81 \%$ & $31,7 \%$ \\
& & $(3,19)$ & $(1,95)$ & $(3,57)$ & $(4,58)$ & & \\
\cline { 2 - 8 } & Mujer & 2,44 & 0,76 & 4,56 & 7,76 & $58,76 \%$ & $34,9 \%$ \\
& & $(2,63)$ & $(1,22)$ & $(3,70)$ & $(4,06)$ & & \\
\hline
\end{tabular}

Analizando los resultados por la escala, es la escala of/subof la que presenta el índice CAO-D mas elevado, 9,25. Esto es debido a que la ausencia de caries 
(índice A) y la presencia de obturaciones por caries (índice O) es mayor en esta escala que en la MPTM. Sin embargo, es la tropa la que tiene mas elevado el índice $\mathrm{C}$ con un valor de 2,92. La escala of/subof es la que presenta un mayor porcentaje de restauración ( $\mathrm{IR}=57,40 \%$ ) y también, un mayor porcentaje de sujetos sin caries $(43,8 \%)$.

La tabla indica que el índice CAO-D más alto, 8,81, corresponde al grupo de más edad. Grupo para el que los valores de los índices A y O son más elevados que los de los más jóvenes. Es interesante indicar que es el grupo de los mas jóvenes el que tiene mas elevado el índice de caries (C) con un valor de 3,02. En coherencia con el resultados anterior, el valor más elevado del índice de restauración (IR) corresponde al grupo de mayor edad. Grupo que también contiene el mayor porcentaje de sujetos libres de caries $(41,7 \%)$.

Seguidamente de valorar el estado dental realizamos el análisis de la necesidad de tratamiento por caries. La Tabla 5.5.3 indica que la mayor prevalencia corresponde a las obturaciones simples $(61,2 \%)$ seguido de las compuestas o complejas (que abarcan dos o mas superficies) con el 34,7\%. La necesidad de exodoncia se observo en el $23,5 \%$ y los tratamientos pulpares con su respectiva restauración la encontramos en el 16,5\% de los casos.

Tabla 5.5.3.Necesidades de tratamiento por caries en la primera visita.

\begin{tabular}{|c|c|c|c|c|c|c|c|c|c|}
\hline & $\mathbf{n}$ & $\%$ & Media & $\begin{array}{c}\text { Desviación } \\
\text { típica }\end{array}$ & Mínimo & Máximo & Mediana & $\begin{array}{c}\text { Percentil } \\
\mathbf{7 5}\end{array}$ & $\begin{array}{c}\text { Percentil } \\
\mathbf{2 5}\end{array}$ \\
\hline Ninguno & 86 & $50,6 \%$ & 29,0 & 3,4 & 16,0 & 34,0 & 30,0 & 32,0 & 27,0 \\
\hline $\begin{array}{c}\text { Obturación } \\
\text { de una } \\
\text { superficie }\end{array}$ & 104 & $61,2 \%$ & 3,3 & 2,5 & 1,0 & 13,0 & 3,0 & 4,0 & 1,0 \\
\hline $\begin{array}{c}\text { Obturación } \\
\text { de dos ó } \\
\text { más } \\
\text { superficies }\end{array}$ & 59 & $34,7 \%$ & 1,7 & 1,0 & 1,0 & 4,0 & 1,0 & 2,0 & 1,0 \\
\hline $\begin{array}{c}\text { Tratamiento } \\
\text { pulpar y } \\
\text { restauración }\end{array}$ & 28 & $16,5 \%$ & 1,3 & 0,5 & 1,0 & 3,0 & 1,0 & 2,0 & 1,0 \\
\hline Extracción & 40 & $23,5 \%$ & 2,0 & 1,2 & 1,0 & 6,0 & 2,0 & 2,0 & 1,0 \\
\hline
\end{tabular}

\subsubsection{Visita 2}

En la segunda visita el índice CAO-D presenta un valor de 7,99 (Tabla 5.5.4). Al analizar sus componentes se observa que la mayor contribución al valor del 
índice lo constituían las piezas obturadas $(\mathrm{O})$ que aumento notablemente y paso a ser de 5,36. Mientras que el índice piezas careadas (C) disminuye a mas de la mitad su valor pasando a ser de 1,11 y las ausencias por caries (A) aumentan ligeramente su valor $(1,52)$.

Tabla 5.5.4. Índice CAO-D y sus componentes de la segunda visita.

\begin{tabular}{|c|c|c|}
\hline \multirow{2}{*}{} & \multicolumn{2}{|c|}{ Visita 2 } \\
\cline { 2 - 3 } & Media & Desviación típica \\
\hline Edad & 35,44 & 6,20 \\
\hline Índice caries (C) & 1,11 & 1,82 \\
\hline Índice Obturación (O) & 5,36 & 3,86 \\
\hline Índice Ausentes (A) & 1,52 & 2,02 \\
\hline Índice CAOD & 7,99 & 4,65 \\
\hline
\end{tabular}

Como se resume en la Tabla 5.5.5, en la segunda visita según el sexo, el índice CAO-D de los hombres $(8,02)$ pasó a ser ligeramente superior al de las mujeres $(7,93)$. Los hombres siguen teniendo un mayor índice de caries $(C)(1,20)$ y de ausencias por caries (A) $(1,70)$ mientras que las mujeres tienen un mayor índice por obturaciones. Las mujeres siguen teniendo un mayor porcentaje de restauración ( $\mathrm{IR}=77,17 \%$ ) y también un mayor porcentaje de sujetos sin caries $(61,0 \%)$.

Tabla 5.5.5.Resultados, de la segunda visita, del índice CAO-D y de sus componentes. Distribución por grupos.

\begin{tabular}{|l|c|c|c|c|c|c|c|}
\hline & & C & A & O & CAO-D & IR & $\begin{array}{c}\text { Sin } \\
\text { caries }\end{array}$ \\
\hline \multirow{4}{*}{ Edad } & $<=27$ & 1,22 & 1,10 & 4,76 & 7,08 & $67,23 \%$ & $54,1 \%$ \\
& $>\mathbf{2 7}$ & 0,96 & $(1,69)$ & $(3,92)$ & $(7,46)$ & & \\
\cline { 2 - 8 } & & 2,10 & 6,19 & 9,25 & $66,91 \%$ & $62,5 \%$ \\
& Tropa & $1,22)$ & $(2,28)$ & $(3,64)$ & $(6,76)$ & & \\
\hline \multirow{4}{*}{ Escala } & & $(1,91)$ & $(1,95)$ & 5,01 & 7,64 & $65,57 \%$ & $54,9 \%$ \\
& Oficiales y & 0,66 & 2,00 & 6,91 & 9,57 & $72,20 \%$ & $67,6 \%$ \\
& Suboficiales & $(1,29)$ & $(2,24)$ & $(3,39)$ & $(6,49)$ & & \\
\hline \multirow{4}{*}{ Sexo } & Hombre & 1,20 & 1,70 & 5,12 & 8.02 & $63,84 \%$ & $56,6 \%$ \\
& & $(1,95)$ & $(2,15)$ & $(3,90)$ & $(7,29)$ & & \\
\cline { 2 - 8 } & Mujer & 0,83 & 0,98 & 6,12 & 7,93 & $77,17 \%$ & $61,0 \%$ \\
& & $(1,32)$ & $(1,41)$ & $(3,70)$ & $(7,13)$ & & \\
\hline
\end{tabular}


Analizando los resultados por la escala militar en esta segunda visita el índice CAO-D mas elevado lo presenta la escala of/subof $(9,57)$ los cuales muestran una mayor presencia de obturaciones (O) con 6,91 y de ausencias por caries (A) con 2,00. La tropa tiene un índice de caries de 1,22 que es más elevado que el de la escala sub-of. La escala sub-of también presenta un mayor porcentaje de restauración ( $\mathrm{IR}=72,20 \%)$ y un mayor porcentaje de sujetos sin caries $(67,6 \%)$.

En el análisis por edades, observamos que el grupo de mayor edad, tiene el índice CAOD mas elevado $(9,25)$ con una mayor presencia de ausencias por caries (A) con 2,10 y de obturaciones por caries (O) con 6,19. El grupo de los mas jóvenes presento mas elevado el índice de caries (C) con 1,22. El grupo de más edad presento ligeramente un menor índice de restauración (IR) $(66,91 \%)$ y un mayor porcentaje de sujetos libres de caries $(62,5 \%)$.

La tabla 5.5.6 indica que en la segunda visita, la necesidad de tratamiento por caries, tiene mayor prevalencia en las obturaciones simples $(39,41 \%)$ seguido de las que abarcan dos o mas superficies $(17,65 \%)$. La necesidad de exodoncia se observo en el $12,35 \%$ y los tratamientos pulpares con su respectiva restauración la encontramos en un solo caso.

Tabla 5.5.6.Necesidades de tratamiento por caries en la segunda visita.

\begin{tabular}{|c|c|c|c|c|c|c|c|c|c|}
\hline & $\mathbf{n}$ & $\%$ & Media & $\begin{array}{c}\text { Desviación } \\
\text { típica }\end{array}$ & Mínimo & Máximo & Mediana & $\begin{array}{c}\text { Percentil } \\
\mathbf{7 5}\end{array}$ & $\begin{array}{c}\text { Percentil } \\
\mathbf{2 5}\end{array}$ \\
\hline $\begin{array}{c}\text { Ninguno } \\
\text { Obturación } \\
\text { de una } \\
\text { superficie }\end{array}$ & 128 & $75,3 \%$ & 31,1 & 2,4 & 17,0 & 36,0 & 32,0 & 32,0 & 30,0 \\
\hline $\begin{array}{c}\text { Obturación } \\
\text { de dos ó } \\
\text { más } \\
\text { superficies }\end{array}$ & 30 & $17,7 \%$ & 1,3 & 0,6 & 1,0 & 3,0 & 1,0 & 1,0 & 1,0 \\
\hline $\begin{array}{c}\text { Tratamiento } \\
\text { pulpar y } \\
\text { restauración }\end{array}$ & 1 & $0,59 \%$ & 1,0 & 0,1 & 1,0 & 1,0 & 1,0 & 1,0 & 1,0 \\
\hline Extracción & 21 & $12,4 \%$ & 1,8 & 1,4 & 1,0 & 7,0 & 1,0 & 2,0 & 1,0 \\
\hline
\end{tabular}




\subsection{Estado de prótesis, necesidad de tratamiento y presencia de implantes.}

\subsubsection{Visita 1}

De acuerdo con el resumen que aparece en la tabla 5.6.1a del anexo, en esta primera visita de los sujetos estudiados, un 92,9\% no tienen ninguna prótesis superior. Observamos que lo más frecuente, un 5,3\% de los sujetos, son los que tienen un puente. Solo un $1,2 \%$ tienen más de un puente y solo un sujeto presenta un parcial removible. Un 97,6\% no presenta ninguna prótesis inferior y se observa que lo más prevalente es la utilización de un parcial removible $(1,2 \%)$. Hay solo un sujeto que presenta un puente y otro que presenta más de un puente.

En cuanto a la necesidad de prótesis, un $73,5 \%$ de los sujetos estudiados no precisa ninguna prótesis superior pero se observa que un $22,4 \%$ necesita una prótesis unitaria y un 3,5\% una prótesis multiunitaria. Solo se ha observado un caso que requeriría una combinación de prótesis unitaria y multiunitaria. Un $68,8 \%$ de los sujetos estudiados no necesitaban una prótesis inferior. Un 22,9\% requeria una prótesis unitaria y el $8,2 \%$ una prótesis multiunitaria.

En lo que hace referencia al sexo (Tabla 5.6.1) en el estado de la prótesis superior la presencia de "un puente" es algo mayor en los hombres $(5,4 \%)$ mientras que la presencia de "más de un puente" lo es en las mujeres $(2,4 \%)$. Entre los hombres aparece un caso que porta un "puente con parcial removible". En cuanto al estado de prótesis inferior las mujeres no presentan ninguna prótesis mientras que, entre los hombres, llevan prótesis alrededor de un $3 \%$. Aquí tenemos los que usan un parcial removible $(1,6 \%)$ y un sujeto que presenta un puente y otro que lleva más de un puente. En cuanto a la necesidad de prótesis superior observamos que el porcentaje $(75,6 \%)$ de mujeres que no requieren protesis es mayor que el porcentaje de hombres $(72,9 \%)$. La necesidad de prótesis unitaria es la más alta para ambos sexos $(22,0 \%)$, mientras que las prótesis multiunitarias las necesitarían solo el $4,7 \%$ de los hombres. Solo un caso femenino requiere una combinación de prótesis unitaria y multiunitaria. En cuanto a la necesidad de prótesis inferior también se observa que el porcentaje de mujeres que no requieren protesis $(75,6 \%)$ es mayor que el porcentaje de hombres $(66,7 \%)$. La necesidad de prótesis unitaria $(24,0 \%)$ y multiunitaria 
$(9,3 \%)$ es más alta para los hombres siendo el porcentaje de necesidad de la multiunitaria casi el doble que el de las mujeres $(4,9 \%)$.

Tabla 5.6.1: Resumen del estado de las prótesis, necesidad de tratamiento y presencia de implantes, en función del sexo, en la primera visita.

\begin{tabular}{|c|c|c|c|c|c|c|}
\hline & & \multicolumn{2}{|c|}{ Hombre } & \multicolumn{2}{|c|}{ Mujer } & \multirow{2}{*}{ p-valor } \\
\hline & & $n$ & $\%$ & $\mathbf{n}$ & $\%$ & \\
\hline \multirow{4}{*}{$\begin{array}{l}\text { Estado Prótesis } \\
\text { Superior }\end{array}$} & Ninguna & 120 & $93,0 \%$ & 38 & $92,7 \%$ & \multirow{4}{*}{0,754} \\
\hline & $\begin{array}{l}\text { Puente } \\
\end{array}$ & 7 & $5,4 \%$ & 2 & $4,9 \%$ & \\
\hline & Más de un puente & 1 &, $8 \%$ & 1 & $2,4 \%$ & \\
\hline & $\begin{array}{l}\text { Puentes y parcial } \\
\text { removible }\end{array}$ & 1 & ,8\% & 0 & $0,0 \%$ & \\
\hline \multirow{4}{*}{$\begin{array}{l}\text { Estado Prótesis } \\
\text { Inferior }\end{array}$} & Ninguna & 125 & $96,9 \%$ & 41 & $100,0 \%$ & \multirow{4}{*}{0,524} \\
\hline & Puente & 1 &, $8 \%$ & 0 & $0,0 \%$ & \\
\hline & Más de un puente & 1 &, $8 \%$ & 0 & $0,0 \%$ & \\
\hline & Parcial removible & 2 & $1,6 \%$ & 0 & $0,0 \%$ & \\
\hline \multirow{4}{*}{$\begin{array}{c}\text { Necesidad de } \\
\text { Prótesis Superior }\end{array}$} & Ninguna & 94 & $72,9 \%$ & 31 & $75,6 \%$ & \multirow{4}{*}{0,103} \\
\hline & Prótesis Unitaria & 29 & $22,5 \%$ & 9 & $22,0 \%$ & \\
\hline & $\begin{array}{c}\text { Prótesis } \\
\text { multiunitaria }\end{array}$ & 6 & $4,7 \%$ & 0 & $0,0 \%$ & \\
\hline & $\begin{array}{c}\text { Combinación de } \\
\text { prótesis unitaria y } \\
\text { multiunitaria }\end{array}$ & 0 & $0,0 \%$ & 1 & $2,4 \%$ & \\
\hline \multirow{3}{*}{$\begin{array}{l}\text { Necesidad de } \\
\text { Prótesis } \\
\text { Inferior }\end{array}$} & Ninguna & 86 & $66,7 \%$ & 31 & $75,6 \%$ & \multirow{3}{*}{0,502} \\
\hline & Prótesis Unitaria & 31 & $24,0 \%$ & 8 & $19,5 \%$ & \\
\hline & $\begin{array}{c}\text { Prótesis } \\
\text { multiunitaria }\end{array}$ & 12 & $9,3 \%$ & 2 & $4,9 \%$ & \\
\hline \multirow[b]{2}{*}{ Implantes } & Inferiores & 3 & $50 \%$ & 0 & $0,0 \%$ & \multirow{2}{*}{---- } \\
\hline & Superiores & 3 & $50 \%$ & 0 & $0,0 \%$ & \\
\hline
\end{tabular}

Los resultados del estado de la prótesis superior referido a la escala (Tabla 5.6.2) indican que la presencia de un puente solo aparece en la tropa $(6,5 \%)$ Sin embargo, la presencia de más de un puente y puente con parcial removible solo se aprecia en el 3,1\% de la escala de of/subof. En cuanto al estado de la prótesis inferior observamos que casi el $99 \%$ de la tropa no presenta ninguna mientras que están presentes en el $6 \%$ de la escala of/subof en la que un 3,1\% presenta mas de un puente y otro 3,1\% un parcial removible. En la tropa solo hay un caso con un puente. En cuanto a la necesidad de prótesis superior se observa que en ambas escalas es mayoritaria la no necesidad de ningún tipo de prótesis. La necesidad de prótesis unitaria es la más alta para ambas escalas siendo mayor el porcentaje de los que la necesitan en la escala of/subof (34,4\%). Sin embargo, las prótesis multiunitarias las necesitan en similares porcentajes ambas escalas, alrededor del 3\%. Aparece un caso de tropa que requiere de una combinación de prótesis unitaria y multiunitaria. En cuanto a la prótesis inferior, en ambas escalas, el porcentaje que las necesita es del orden del 30\%. La necesidad de 
prótesis unitaria y multiunitaria es las más requerida para ambas escalas siendo algo mayor en la escala de of/subof.

Tabla 5.6.2: Resumen del estado de las prótesis, necesidad de tratamiento y presencia de implantes, en función de la escala, en la primera visita.

\begin{tabular}{|c|c|c|c|c|c|c|}
\hline & \multicolumn{2}{|c|}{ MPTM } & \multicolumn{2}{|c|}{$\begin{array}{c}\text { Suboficiales + } \\
\text { Oficiales }\end{array}$} & \multirow[t]{2}{*}{ p-valor } \\
\hline & & $\mathbf{n}$ & $\%$ & $\mathbf{n}$ & $\%$ & \\
\hline \multirow{4}{*}{$\begin{array}{l}\text { Estado Prótesis } \\
\text { Superior }\end{array}$} & Ninguna & 128 & $92,8 \%$ & 30 & $93,8 \%$ & \multirow{4}{*}{0,044} \\
\hline & Puente & 9 & $6,5 \%$ & 0 & $0,0 \%$ & \\
\hline & Más de un puente & 1 &, $7 \%$ & 1 & $3,1 \%$ & \\
\hline & $\begin{array}{c}\text { Puentes y parcial } \\
\text { removible }\end{array}$ & 0 & $0,0 \%$ & 1 & $3,1 \%$ & \\
\hline \multirow{4}{*}{$\begin{array}{l}\text { Estado Prótesis } \\
\text { Inferior }\end{array}$} & Ninguna & 136 & $98,6 \%$ & 30 & $93,8 \%$ & \multirow{4}{*}{0,187} \\
\hline & Puente & 1 &, $7 \%$ & 0 & $0,0 \%$ & \\
\hline & Más de un puente & 0 & $0,0 \%$ & 1 & $3,1 \%$ & \\
\hline & Parcial removible & 1 &, $7 \%$ & 1 & $3,1 \%$ & \\
\hline \multirow{4}{*}{$\begin{array}{l}\text { Necesidad de } \\
\text { Prótesis } \\
\text { Superior }\end{array}$} & Ninguna & 105 & $76,1 \%$ & 20 & $62,5 \%$ & \multirow{4}{*}{0,335} \\
\hline & Prótesis Unitaria & 27 & $19,6 \%$ & 11 & $34,4 \%$ & \\
\hline & $\begin{array}{c}\text { Prótesis } \\
\text { multiunitaria }\end{array}$ & 5 & $3,6 \%$ & 1 & $3,1 \%$ & \\
\hline & $\begin{array}{l}\text { Combinación de } \\
\text { prótesis unitaria } \\
\text { y multiunitaria }\end{array}$ & 1 &, $7 \%$ & 0 & $0,0 \%$ & \\
\hline \multirow{3}{*}{$\begin{array}{l}\text { Necesidad de } \\
\text { Prótesis Inferior }\end{array}$} & Ninguna & 97 & $70,3 \%$ & 20 & $62,5 \%$ & \multirow{3}{*}{0,686} \\
\hline & Prótesis Unitaria & 30 & $21,7 \%$ & 9 & $28,1 \%$ & \\
\hline & $\begin{array}{c}\text { Prótesis } \\
\text { multiunitaria }\end{array}$ & 11 & $8,0 \%$ & 3 & $9,4 \%$ & \\
\hline \multirow[b]{2}{*}{ Implantes } & Inferiores & 3 & $60 \%$ & 0 & $0,0 \%$ & \multirow[b]{2}{*}{1,000} \\
\hline & Superiores & 2 & $40 \%$ & 1 & $100 \%$ & \\
\hline
\end{tabular}

De acuerdo con la Tabla 5.6.3 alrededor del 97\% de los menores de 27 años no presenta ninguna prótesis superior. Son los mayores de 27 años quienes presentan un mayor porcentaje con un puente $(8,3 \%)$ y los únicos que presentan mas de un puente $(2,8 \%)$ y puentes y parcial removible $(1,4 \%)$. Observamos que la proporción de los que no tienen prótesis inferior es muy alta. Del $100 \%$ en los menores de 27 años. Del casi 6\% de mayores de 27 años que presentan prótesis inferior, un $2,8 \%$ lleva parcial removible, un $1,4 \%$ presenta un puente y un $1,4 \%$ mas de un puente. La proporción de sujetos que no necesitan prótesis superior es muy alta. Por ejemplo del 80,6\% en los menores de 27 años. La necesidad de prótesis unitaria es la más alta para todas las edades con un porcentaje más elevado para los mayores de 27 años $(27,8 \%)$. Éstos, también requerirán en mayor porcentaje prótesis multiunitarias $(6,9 \%)$ y una combinación de prótesis unitaria y multiunitaria $(1,4 \%)$. En cuanto a la necesidad de prótesis inferior el resultado es similar al anterior. Por ejemplo el porcentaje de menores de 27 años que no la necesitan es del 74,5\%. Las dos prótesis más requeridas para todas alas edades son la unitaria $(23,6 \%)$ y la multiunitaria $(15,3 \%)$. Pero de nuevo el 
porcentaje de los sujetos que la necesitan es más elevado para los mayores de 27 años.

Tabla 5.6.3. Resumen del estado de las prótesis, necesidad de tratamiento y presencia de implantes, en función de la edad, en la primera visita.

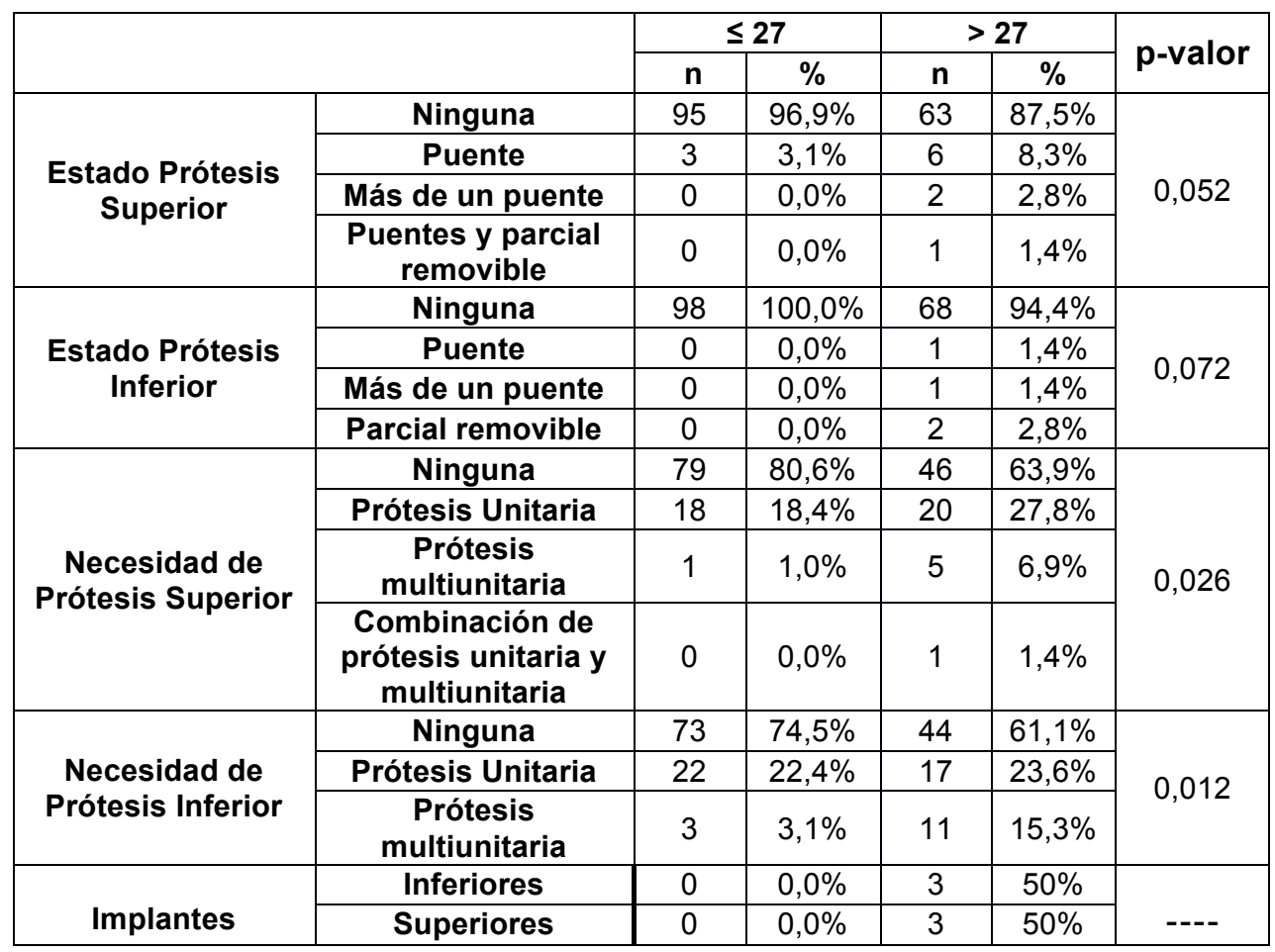

\subsubsection{Visita 2}

En la segunda visita los datos han variado muy poco (Ver Tablas 5.6.1a y 5.6.2a del anexo). Un 91,2\% de la muestra estudiada no presentan ninguna prótesis superior. Lo más frecuente son los puentes en un 5,9\% de los casos, seguido de los que presentan más de un puente con $1,8 \%$ y un caso que presenta un parcial removible y otro puentes con implantes. Un $97,6 \%$ no presenta ninguna prótesis inferior y observamos cuatro sujetos que presentan prótesis que se reparten con igual porcentaje entre la utilización de un parcial removible, un puente, más de un puente y puentes con implantes. Un $62,9 \%$ de los sujetos estudiados no precisa ninguna prótesis superior, un $28,8 \%$ necesita una prótesis unitaria y un $7,6 \%$ una prótesis multiunitaria. Solo un caso requeriría una combinación de prótesis unitaria y multiunitaria. Un $62,4 \%$ no precisaban ninguna prótesis 
inferior, un $24,7 \%$ requería una prótesis unitaria y el $12,9 \%$ una prótesis multiunitaria.

Tabla 5.6.4. Resumen del estado de las prótesis, necesidad de tratamiento y presencia de implantes, en función del sexo, en la segunda visita.

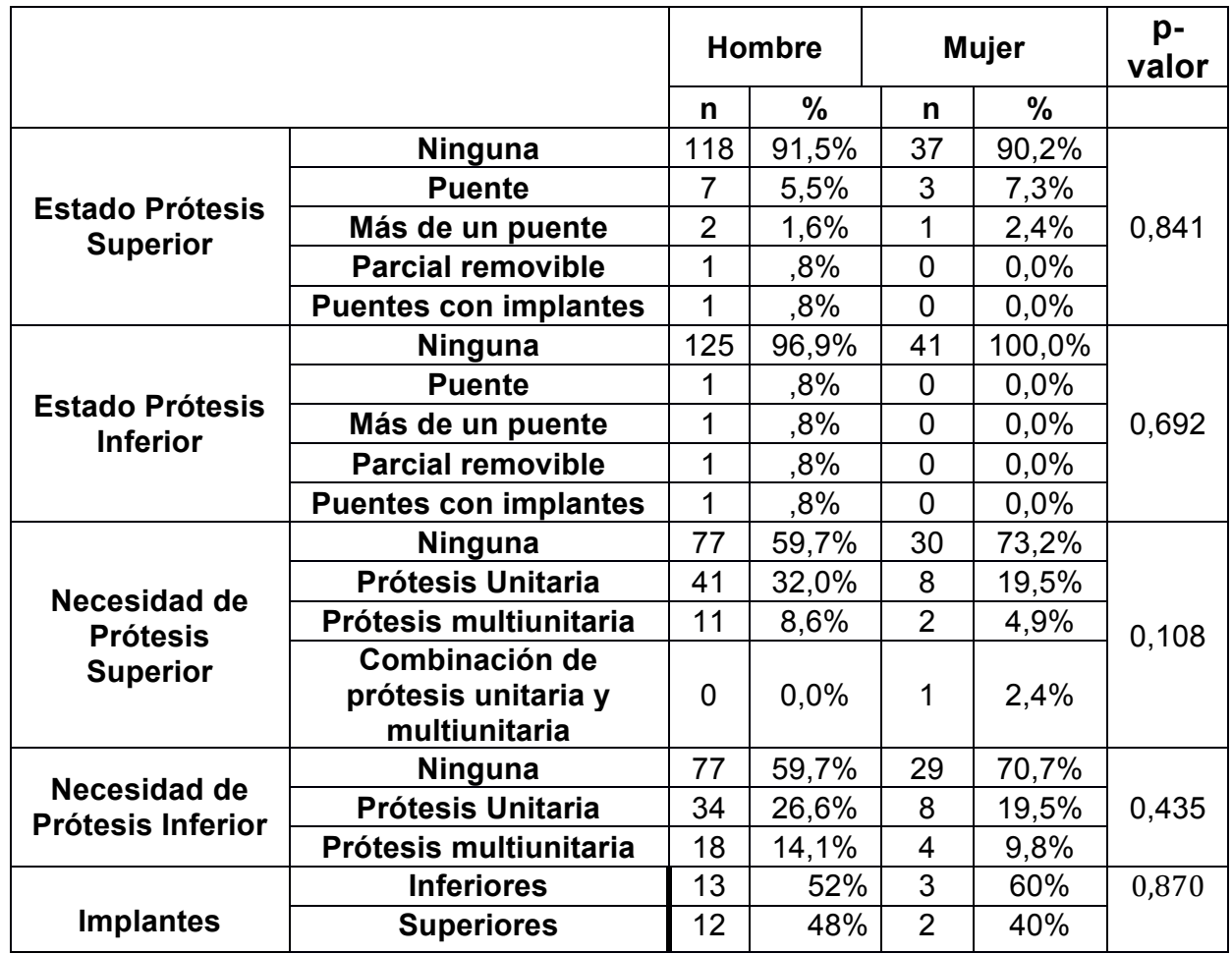

El $91 \%$ de los sujetos estudiados de ambos sexos, en lo que se refiere al estado de prótesis superior, no presentan ninguna prótesis (Tabla 5.6.4). El porcentaje de presencia de "un puente" $(7,3 \%)$ y el de "más de un puente" $(2,4 \%)$ es mayor en las mujeres. Apareciendo en los hombres un caso que utiliza "parcial removible" y otro "puentes con implantes". En cuanto al estado de prótesis inferior las mujeres no presentan ninguna prótesis, mientras que los hombres, en una proporción del 3\%, muestran un "parcial removible", un "puente", otro sujeto que presenta "más de un puente" y otro con "puentes con implantes", repartidos en el mismo porcentaje. En cuanto a la necesidad de prótesis superior el resultado del examen dio que el porcentaje de mujeres que no requieren prótesis $(73,2 \%)$ es mayor que el de los hombres $(59,7 \%)$. Las prótesis unitarias son las que más necesitan ambos sexos, siendo mayor el porcentaje de necesidad para los hombres $(32,0 \%)$. Lo mismo ocurre con las prótesis multiunitarias $(4,9 \%)$. Se encontró un caso femenino que requiere de una combinación de prótesis unitaria y multiunitaria. En cuanto a la necesidad de 
prótesis inferior también se observa que el porcentaje de necesidad para las mujeres $(29,3 \%)$ es menor que para los hombres $(40,3 \%)$. La necesidad de prótesis unitaria $(26,6 \%)$ y multiunitaria $(14,1 \%)$ es más alta para los hombres.

Tabla 5.6.5. Resumen del estado de las prótesis, necesidad de tratamiento y presencia de implantes, en función de la escala, en la segunda visita.

\begin{tabular}{|c|c|c|c|c|c|c|}
\hline & & \multicolumn{2}{|c|}{ MPTM } & \multicolumn{2}{|c|}{$\begin{array}{c}\text { Suboficiales + } \\
\text { Oficiales }\end{array}$} & \multirow{2}{*}{$\begin{array}{l}p- \\
\text { valor }\end{array}$} \\
\hline & & $\mathbf{n}$ & $\%$ & $\mathbf{n}$ & $\%$ & \\
\hline \multirow{5}{*}{$\begin{array}{l}\text { Estado } \\
\text { Prótesis } \\
\text { Superior }\end{array}$} & Ninguna & 120 & $90,2 \%$ & 35 & $94,6 \%$ & \multirow{5}{*}{0,068} \\
\hline & Puente & 10 & $7,5 \%$ & 0 & $0,0 \%$ & \\
\hline & Más de un puente & 2 & $1,5 \%$ & 1 & $2,7 \%$ & \\
\hline & Parcial removible & 1 &, $8 \%$ & 0 & $0,0 \%$ & \\
\hline & Puentes con implantes & 0 & $0,0 \%$ & 1 & $2,7 \%$ & \\
\hline \multirow{5}{*}{$\begin{array}{l}\text { Estado } \\
\text { Prótesis } \\
\text { Inferior }\end{array}$} & Ninguna & 131 & $98,5 \%$ & 35 & $94,6 \%$ & \multirow{5}{*}{0,129} \\
\hline & Puente & 1 &, $8 \%$ & 0 & $0,0 \%$ & \\
\hline & Más de un puente & 0 & $0,0 \%$ & 1 & $2,7 \%$ & \\
\hline & Parcial removible & 1 &, $8 \%$ & 0 & $0,0 \%$ & \\
\hline & Puentes con implantes & 0 & $0,0 \%$ & 1 & $2,7 \%$ & \\
\hline \multirow{4}{*}{$\begin{array}{l}\text { Necesidad } \\
\text { de Prótesis } \\
\text { Superior }\end{array}$} & Ninguna & 88 & $66,2 \%$ & 19 & $51,4 \%$ & \multirow{4}{*}{0,174} \\
\hline & Prótesis Unitaria & 33 & $24,8 \%$ & 16 & $43,2 \%$ & \\
\hline & Prótesis multiunitaria & 11 & $8,3 \%$ & 2 & $5,4 \%$ & \\
\hline & $\begin{array}{l}\text { Combinación de } \\
\text { prótesis unitaria y } \\
\text { multiunitaria }\end{array}$ & 1 &, $8 \%$ & 0 & $0,0 \%$ & \\
\hline \multirow{3}{*}{$\begin{array}{c}\text { Necesidad } \\
\text { de Prótesis } \\
\text { Inferior }\end{array}$} & Ninguna & 84 & $63,2 \%$ & 22 & $59,5 \%$ & \multirow{3}{*}{0,076} \\
\hline & Prótesis Unitaria & 31 & $23,3 \%$ & 11 & $29,7 \%$ & \\
\hline & Prótesis multiunitaria & 18 & $13,5 \%$ & 4 & $10,8 \%$ & \\
\hline \multirow[b]{2}{*}{ Implantes } & Inferiores & 9 & $69,2 \%$ & 7 & $41,2 \%$ & \multirow[t]{2}{*}{0,247} \\
\hline & Superiores & 4 & $30,8 \%$ & 10 & $58,8 \%$ & \\
\hline
\end{tabular}

En ambas escalas, MPTM y of/subof, es muy elevado el número de sujetos que no presentan prótesis superior (Tabla 5.6.5). Por ejemplo el 94,6\% para la escala de of/subof. Los sujetos con un puente solo aparecen en la tropa (7,5\%) y más de un puente se aprecia en el 2,7\% de los of/subof. Siguen los dos casos únicos; un caso en tropa que presenta "parcial removible" y un caso en la escala de of/subof que tiene "puente con implantes". El 98,5\% de la tropa no presenta ninguna prótesis inferior y solo aparecen dos casos a reseñar, uno con un "puente" y otro con un "parcial removible". Aquí hay una diferencia a tener en cuenta con la escala de of/subof en la cual un $2,7 \%$ presentan "mas de un puente" y otro $2,7 \%$ tienen "puentes con implantes". El 66,2\% del personal de tropa no necesita prótesis superior, siendo este porcentaje un poco más bajo en la escala of/subof. Entre los que necesitan prótesis, la unitaria es la predominante en ambas escalas, aunque el porcentaje es más alto $(43,2 \%)$ para la escala of/subof. Sin embargo con la necesidad de prótesis multiunitarias ocurre al revés, es mayor el porcentaje del personal de tropa $(8,3 \%)$ que la necesita. Se reseña que solamente 
un caso del MPTM requiere una combinación de prótesis unitaria y multiunitaria. En cuanto a la necesidad de prótesis inferior se observa el mismo comportamiento que con la superior. Sin embargo el porcentaje del personal de tropa que la necesita, $63,2 \%$, es mayor que el de la escala of/subof. La necesidad de prótesis unitaria es mayor en la escala de of/subof $(29,7 \%)$ mientras que la multiunitaria es más requerida por la tropa $(13,5 \%)$.

Tabla 5.6.5. Resumen del estado de las prótesis, necesidad de tratamiento y presencia de implantes, en función de la edad, en la segunda visita.

\begin{tabular}{|c|c|c|c|c|c|c|}
\hline & \multicolumn{2}{|c|}{$\leq 27$} & \multicolumn{2}{|c|}{$>27$} & \multirow{2}{*}{$\begin{array}{c}p- \\
\text { valor }\end{array}$} \\
\hline & & $\mathbf{n}$ & $\%$ & $\mathbf{n}$ & $\%$ & \\
\hline \multirow{5}{*}{$\begin{array}{l}\text { Estado Prótesis } \\
\text { Superior }\end{array}$} & Ninguna & 92 & $93,9 \%$ & 63 & $87,5 \%$ & \multirow{5}{*}{0,289} \\
\hline & Puente & 4 & $4,1 \%$ & 6 & $8,3 \%$ & \\
\hline & Más de un puente & 1 & $1,0 \%$ & 2 & $2,8 \%$ & \\
\hline & Parcial removible & 1 & $1,0 \%$ & 0 & $0,0 \%$ & \\
\hline & Puentes con implantes & 0 & $0,0 \%$ & 1 & $1,4 \%$ & \\
\hline \multirow{5}{*}{$\begin{array}{l}\text { Estado Prótesis } \\
\text { Inferior }\end{array}$} & Ninguna & 98 & $\begin{array}{c}100,0 \\
\%\end{array}$ & 68 & $94,4 \%$ & \multirow{5}{*}{0,136} \\
\hline & Puente & 0 & $0,0 \%$ & 1 & $1,4 \%$ & \\
\hline & Más de un puente & 0 & $0,0 \%$ & 1 & $1,4 \%$ & \\
\hline & Parcial removible & 0 & $0,0 \%$ & 1 & $1,4 \%$ & \\
\hline & Puentes con implantes & 0 & $0,0 \%$ & 1 & $1,4 \%$ & \\
\hline \multirow{4}{*}{$\begin{array}{l}\text { Necesidad de } \\
\text { Prótesis } \\
\text { Superior }\end{array}$} & Ninguna & 65 & $66,3 \%$ & 42 & $58,3 \%$ & \multirow{4}{*}{0,253} \\
\hline & Prótesis Unitaria & 28 & $28,6 \%$ & 21 & $29,2 \%$ & \\
\hline & Prótesis multiunitaria & 5 & $5,1 \%$ & 8 & $11,1 \%$ & \\
\hline & $\begin{array}{c}\text { Combinación de } \\
\text { prótesis unitaria y } \\
\text { multiunitaria }\end{array}$ & 0 & $0,0 \%$ & 1 & $1,4 \%$ & \\
\hline \multirow{3}{*}{$\begin{array}{c}\text { Necesidad de } \\
\text { Prótesis Inferior }\end{array}$} & Ninguna & 68 & $69,4 \%$ & 38 & $52,8 \%$ & \multirow{3}{*}{0,068} \\
\hline & Prótesis Unitaria & 21 & $21,6 \%$ & 21 & $29,2 \%$ & \\
\hline & Prótesis multiunitaria & 9 & $9,2 \%$ & 13 & $18,1 \%$ & \\
\hline \multirow[b]{2}{*}{ Implantes } & Inferiores & 2 & $40 \%$ & 14 & $56 \%$ & \multirow[b]{2}{*}{0,870} \\
\hline & Superiores & 3 & $60 \%$ & 11 & $44 \%$ & \\
\hline
\end{tabular}

Si nos fijamos en el estado de la prótesis superior en función de la edad (Tabla 5.30a) se observa que alrededor del $94 \%$ de los menores de 27 años no presenta ninguna prótesis. Son los mayores de 27 años quienes presentan mayor porcentaje de sujetos con "un puente" $(8,3 \%)$ y con "mas de un puente" $(2,8 \%)$. En este grupo se ubica el caso con "puentes con implantes" mientras que el caso con "parcial removible" se ubica en el grupo de los menores de 27 años. Observamos que en los menores de 27 años no se ha registrado la presencia de ninguna prótesis inferior. Además, es de reseñar que entre los mayores de 27 años cerca del $6 \%$ presentan prótesis inferior. Estas se reparten con el mismo porcentaje $(1,4 \%)$ entre: un "parcial removible", un "puente", un sujeto que 
presenta "más de un puente" y otro con "puentes con implantes". En cuanto a la necesidad de prótesis superior es mayor el porcentaje de los que no la necesitan. Dicho porcentaje es mayor en en el grupo de edad menor de 27 años(66,3\%). En cuanto al tipo de prótesis la unitaria es la que más se necesita, alrededor del $29 \%$,para ambos grupos. Un poco más alto para los mayores de 27 años que también, requerirán en mayor porcentaje de prótesis multiunitarias $(11,1 \%)$ y una combinación de prótesis unitaria y multiunitaria en un 1,4\%. En cuanto a la necesidad de prótesis inferior los datos son cercanos a los de la superior. En este caso, un 69,4\% de los menores de 27 años no la necesitan. Las prótesis unitaria $(29,2 \%)$ y multiunitaria $(18,1 \%)$ son las más necesarias para ambas edades, siendo ligeramente mayor el porcentaje en los mayores de 27 años.

\subsection{Estado oclusal (anomalías dentofaciales), presencia de tratamientos ortodóncicos, presencia de dientes parcialmente erupcionados y necesidad de exodoncia de los terceros molares.}

\subsubsection{Visita 1}

En este apartado se han analizado cuatro factores muy determinantes en el análisis de la salud oral en relaciones con las misiones. En el análisis del estado oclusal correspondiente a la primera visita se encontró (Tabla 5.7.1a) que, aproximadamente, el $54 \%$ de la muestra presento alguna anomalía. En una escala de "leves - graves" se distribuyen de la forma siguiente: Un 28,8\% de sujetos perentan anomalías leves y un $24,7 \%$ moderadas/graves. Por otra parte se registró que el 7,1\% había sido tratado con ortodoncia fija y un 2,9\% llevaba un retenedor. Además, casi el $2 \%$ de los explorados llevaban ortodoncia en ese momento.

De acuerdo con lo anterior, en ambos sexos lo que más abunda es la ausencia de anomalías, siendo mayor el porcentaje en mujeres (51,2\%) (Tabla 5.7.1). El porcentaje de anomalías leves es mayor en los hombres (31\%) y las moderadas/graves en las mujeres $(26,8 \%)$. En cuanto a los tratamientos de ortodoncia el $20 \%$ de las mujeres tiene o ha tenido algún tratamiento, por solo el $10 \%$ de los hombres; También, son precisamente las mujeres las que mayor 
Estudio epidemiológico de la salud bucodental y ...

porcentaje de fija llevan en esta primera visita (4,9\%). También son las mujeres las que han llevado ortodoncia fija alrededor de un 15\%, de las cuales casi un 5\% llevan un retenedor.

Tabla 5.7.1. Resumen del estado oclusal, presencia de tratamientos ortodoncicos, presencia de dientes parcialmente erupcionados y necesidad de exodoncia de los $3^{\circ}$ molares, de la primera visita en función del sexo.

\begin{tabular}{|c|c|c|c|c|c|c|}
\hline & \multicolumn{2}{|c|}{ Hombre } & \multicolumn{2}{|c|}{ Mujer } & \multirow{2}{*}{ p-valor } \\
\hline & & $\mathbf{n}$ & $\%$ & $\mathbf{n}$ & $\%$ & \\
\hline \multirow{3}{*}{ Estado Oclusal } & Ninguna & 58 & $45,0 \%$ & 21 & $51,2 \%$ & \multirow{3}{*}{0,536} \\
\hline & Leve & 40 & $31,0 \%$ & 9 & $22,0 \%$ & \\
\hline & Moderada-Grave & 31 & $24,0 \%$ & 11 & $26,8 \%$ & \\
\hline \multirow{4}{*}{$\begin{array}{l}\text { Tratamiento } \\
\text { Ortodoncia }\end{array}$} & No & 117 & $90,7 \%$ & 33 & $80,5 \%$ & \multirow{4}{*}{0,269} \\
\hline & Llevó fija & 8 & $6,2 \%$ & 4 & $9,8 \%$ & \\
\hline & Lleva fija & 1 &, $8 \%$ & 2 & $4,9 \%$ & \\
\hline & $\begin{array}{l}\text { Llevó fija (y lleva } \\
\text { un retenedor) }\end{array}$ & 3 & $2,3 \%$ & 2 & $4,9 \%$ & \\
\hline \multirow[b]{2}{*}{ Erupcionado parcial } & Inferiores & 39 & $84,8 \%$ & 12 & $85,7 \%$ & \multirow[b]{2}{*}{0,732} \\
\hline & Superiores & 7 & $15,2 \%$ & 2 & $14,3 \%$ & \\
\hline \multirow[b]{2}{*}{$\begin{array}{l}\text { Necesidad de } \\
\text { Exodoncia }\end{array}$} & Inferiores & 40 & $80,0 \%$ & 10 & $20,0 \%$ & \multirow[b]{2}{*}{0,607} \\
\hline & Superiores & 21 & $75,0 \%$ & 7 & $25,0 \%$ & \\
\hline
\end{tabular}

Tabla 5.7.2. Resumen del estado oclusal, presencia de tratamientos ortodoncicos, presencia de dientes parcialmente erupcionados y necesidad de exodoncia de los $3^{\circ}$ molares, de la primera visita en función de la escala.

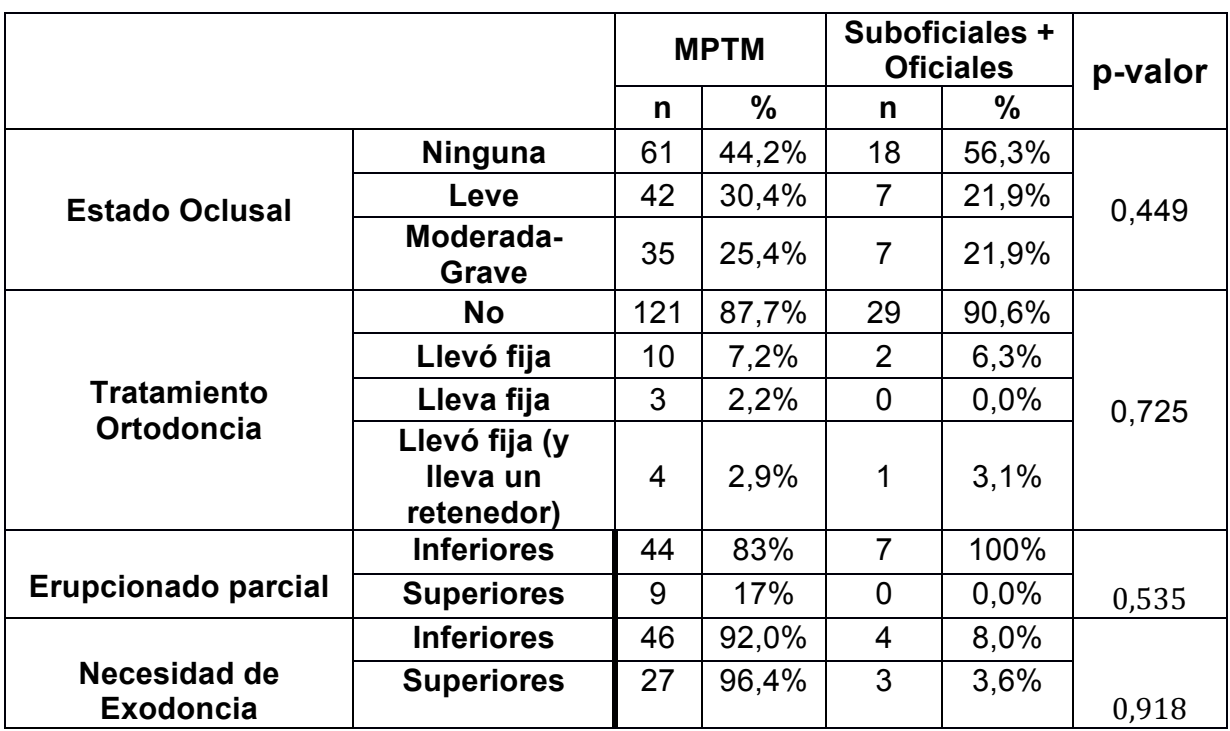


En ambas escalas la ausencia de anomalías supera el 50\%, aunque el porcentaje es más elevado para la escala of/subof (56,3\%) (Tabla 5.7.2). Sin embargo, en este caso, tanto las anomalías leves como las moderadas/graves son más prevalentes en la tropa con un $30,4 \%$ y un $25 \%$ respectivamente. En cuanto a los tratamientos de ortodoncia, el porcentaje de sujetos que llevo ortodoncia fija es similar para ambas escalas, alrededor del 10\%, aunque ligeramente mayor en la tropa que son los únicos que presentan tratamiento en la exploración de la primera visita. El porcentaje de los que han llevado ortodoncia fija es casi igual para ambas escalas, alrededor de un 10\% del cual, un 3\%, lleva un retenedor.

En cuanto a la edad, el mayor porcentaje de sujetos sin anomalías corresponde a los mayores de 27 años $(54,2 \%)$ (Tabla 5.7.3). Tanto las anomalías leves como las moderadas/graves son más prevalentes en los menores de 27 años con un $32,7 \%$ y un $26,5 \%$ respectivamente. En cuanto a los tratamientos de ortodoncia, de los sujetos estudiados son los menores de 27 años los que presentan un ligero mayor porcentaje $(2,0 \%)$ de tratamiento en el momento de la exploración de la primera visita. También, para este grupo de edad es mayor el porcentaje de los que llevaron ortodoncia fija $(8,2 \%)$ y todos los casos que presentaban un retenedor $(5,1 \%)$.

Tabla 5.7.3. Resumen del estado oclusal, presencia de tratamientos ortodoncicos, presencia de dientes parcialmente erupcionados y necesidad de exodoncia de los $3^{\circ}$ molares, de la primera visita en función de la edad.

\begin{tabular}{|c|c|c|c|c|c|c|}
\hline & \multicolumn{2}{|c|}{$\leq 27$} & \multicolumn{2}{|c|}{$>27$} & \multirow{2}{*}{$\begin{array}{c}p- \\
\text { valor }\end{array}$} \\
\hline & & $\mathbf{n}$ & $\%$ & $\mathbf{n}$ & $\%$ & \\
\hline \multirow{3}{*}{ Estado Oclusal } & Ninguna & 40 & $40,8 \%$ & 39 & $54,2 \%$ & \multirow{3}{*}{0,214} \\
\hline & Leve & 32 & $32,7 \%$ & 17 & $23,6 \%$ & \\
\hline & Moderada-Grave & 26 & $26,5 \%$ & 16 & $22,2 \%$ & \\
\hline \multirow{4}{*}{$\begin{array}{l}\text { Tratamiento } \\
\text { Ortodoncia }\end{array}$} & No & 83 & $84,7 \%$ & 67 & $93,1 \%$ & \multirow{4}{*}{0,096} \\
\hline & Llevó fija & 8 & $8,2 \%$ & 4 & $5,6 \%$ & \\
\hline & Lleva fija & 2 & $2,0 \%$ & 1 & $1,4 \%$ & \\
\hline & $\begin{array}{l}\text { Llevó fija (y } \\
\text { lleva un } \\
\text { retenedor) }\end{array}$ & 5 & $5,1 \%$ & 0 & $0,0 \%$ & \\
\hline \multirow[b]{2}{*}{ Erupcionado parcial } & Inferiores & 35 & $87,5 \%$ & 16 & $80 \%$ & \multirow[b]{2}{*}{0,701} \\
\hline & Superiores & 5 & $12,5 \%$ & 4 & $20 \%$ & \\
\hline \multirow[b]{2}{*}{$\begin{array}{l}\text { Necesidad de } \\
\text { Exodoncia }\end{array}$} & Inferiores & 34 & $68,0 \%$ & 16 & $32,0 \%$ & \multirow[b]{2}{*}{0,738} \\
\hline & Superiores & 18 & $64,3 \%$ & 10 & $35,7 \%$ & \\
\hline
\end{tabular}




\subsubsection{Visita 2}

En cuanto al estado oclusal en la segunda visita (Tabla 5.7.2a del anexo) se sigue manteniendo la misma proporción de sujetos que presentan alguna anomalía, aproximadamente el $53 \%$ de la muestra estudiada. Lo mismo ocurre con su distribución; las leves afectaban a un 29,4\% y las moderadas/graves a un 23,5\%. También se mantenían las proporciones de los otros factores: el 8,2\% había sido tratado con ortodoncia fija, un $2,9 \%$ llevaba un retenedor y solo un caso de los explorados llevaba ortodoncia en ese momento. También se repiten los resultados referidos a sexo, escala y edad.

Tabla 5.7.4. Resumen del estado oclusal, presencia de tratamientos ortodoncicos, presencia de dientes parcialmente erupcionados y necesidad de exodoncia de los $3^{\circ}$ molares, de la segunda visita en función del sexo.

\begin{tabular}{|c|c|c|c|c|c|c|}
\hline & \multicolumn{2}{|c|}{ Hombre } & \multicolumn{2}{|c|}{ Mujer } & \multirow[t]{2}{*}{ p-valor } \\
\hline & & $n$ & $\%$ & $\mathrm{n}$ & $\%$ & \\
\hline \multirow{3}{*}{ Estado Oclusal } & Ninguna & 59 & $\begin{array}{c}45,7 \\
\%\end{array}$ & 21 & $51,2 \%$ & \multirow{3}{*}{0,712} \\
\hline & Leve & 40 & $\begin{array}{c}31,0 \\
\%\end{array}$ & 10 & $24,4 \%$ & \\
\hline & Moderada-Grave & 30 & $\begin{array}{c}23,3 \\
\%\end{array}$ & 10 & $24,4 \%$ & \\
\hline \multirow{4}{*}{$\begin{array}{l}\text { Tratamiento } \\
\text { Ortodoncia }\end{array}$} & No & 118 & $\begin{array}{c}91,5 \\
\%\end{array}$ & 32 & $78,0 \%$ & \multirow{4}{*}{0,062} \\
\hline & Llevó fija & 9 & $7,0 \%$ & 5 & $12,2 \%$ & \\
\hline & Lleva fija & 0 & $0,0 \%$ & 1 & $2,4 \%$ & \\
\hline & $\begin{array}{l}\text { Llevó fija (y lleva } \\
\text { un retenedor) }\end{array}$ & 2 & $1,6 \%$ & 3 & $7,3 \%$ & \\
\hline \multirow[t]{2}{*}{ Erupcionado parcial } & Inferiores & 37 & $\begin{array}{c}77,1 \\
\%\end{array}$ & 6 & $85,7 \%$ & \multirow[b]{2}{*}{0,978} \\
\hline & Superiores & 11 & $\begin{array}{c}22,9 \\
\%\end{array}$ & 1 & $14,3 \%$ & \\
\hline \multirow{2}{*}{$\begin{array}{l}\text { Necesidad de } \\
\text { Exodoncia }\end{array}$} & Inferiores & 14 & $\begin{array}{c}87,5 \\
\%\end{array}$ & 2 & $12,5 \%$ & \multirow[b]{2}{*}{0,701} \\
\hline & Superiores & 19 & $\begin{array}{c}86,4 \\
\%\end{array}$ & 3 & $13,6 \%$ & \\
\hline
\end{tabular}

Así, en ambos sexos (Tabla 5.7.4) sigue la misma proporción de los que no presentan anomalías, con un mayor porcentaje en mujeres $(51,2 \%)$. Sin embargo sigue siendo el porcentaje de anomalías leves mayor en los hombres (31\%) y las moderadas/graves en las mujeres $(24,4 \%)$. En cuanto a los tratamientos de 
ortodoncia las mujeres que tienen o han tenido algún tratamiento se ha incrementado un poco alcanzando el $22 \%$ por casi el $9 \%$ de los hombres. También ellas seguían llevado ortodoncia fija en mayor porcentaje, alrededor de un $20 \%$, de las cuales un $7 \%$ llevan un retenedor. Y el único caso que presenta tratamiento de ortodoncia fija en el momento de la exploración en la segunda visita, es mujer.

Tabla 5.7.5. Resumen del estado oclusal, presencia de tratamientos ortodoncicos, presencia de dientes parcialmente erupcionados y necesidad de exodoncia de los $3^{\circ}$ molares, de la segunda visita en función de la escala.

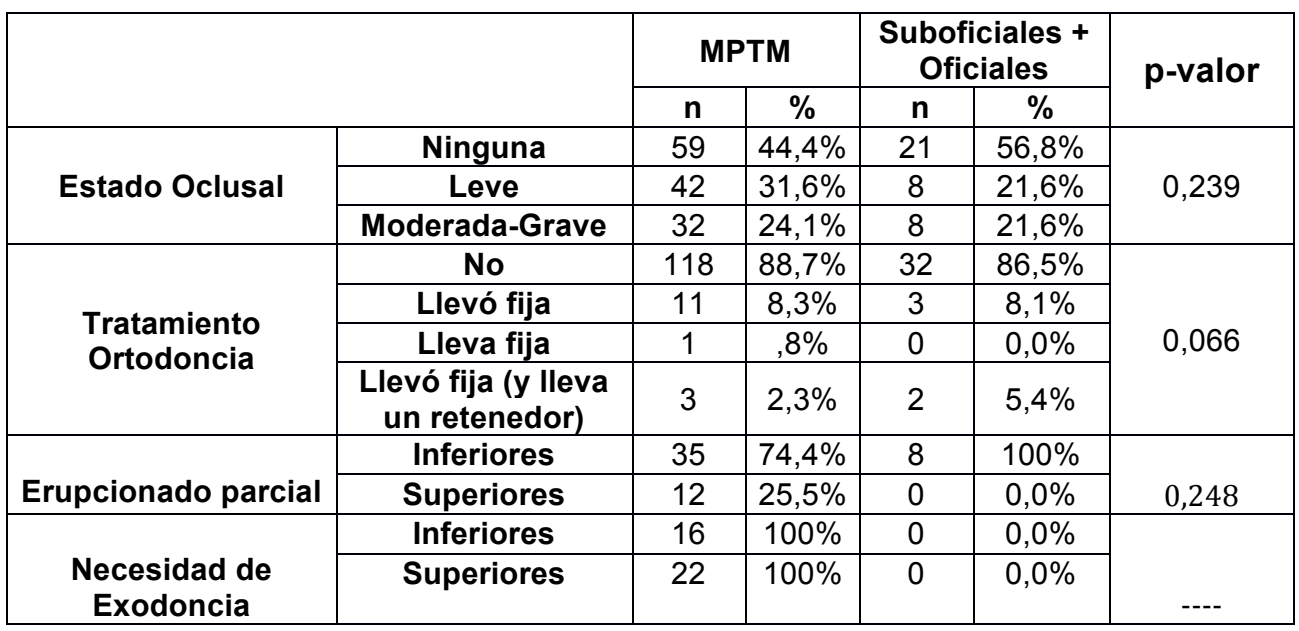

Evidentemente ocurre algo parecido con los resultados referidos a la escala (Tabla 5.7.5). El mayor porcentaje de ausencia de anomalías sigue teniéndola la escala de los of/subof $(56,8 \%)$. En cuanto a las anomalías siguen siendo mayoritarias en la tropa con un $31,6 \%$ de leves y un $24,1 \%$ de moderadas/graves. En cuanto a los tratamientos de ortodoncia, el porcentaje de sujetos que llevaba ortodoncia fija en la segunda visita seguía siendo similar para ambas escalas, alrededor de un $8 \%$ ligeramente mayor en la tropa que, además, es donde se presentó el único caso con tratamiento ortodoncico en la exploración. El porcentaje de los que han llevado ortodoncia fija y tienen un retenedor sigue siendo mayor en la escala de of/subof $(5,4 \%)$.

También, referidos a las edades (Tabla 5.7.6) los resultados seguían siendo los mismos. Los sujetos con ausencia de anomalías siguen siendo mayoritarios. También, en este caso, sigue siendo mayor el porcentaje en los mayores de 27 años $(54,2 \%)$. En cuanto a las anomalías, leves o moderadas/graves, son más prevalentes en los menores de 27 con un $33,7 \%$ y un $24,5 \%$ respectivamente. El 
único caso, en la segunda visita, que presenta tratamiento de ortodoncia fija en el momento de la exploración es menor de 27 años, grupo de edad que también han llevado ortodoncia fija en mayor porcentaje $(9,2 \%)$ y al que pertenece el total de los casos que presentaban un retenedor $(5,1 \%)$.

Tabla 5.7.3. Resumen del estado oclusal, presencia de tratamientos ortodoncicos, presencia de dientes parcialmente erupcionados y necesidad de exodoncia de los $3^{\circ}$ molares, de la segundaa visita en función de la edad.

\begin{tabular}{|c|c|c|c|c|c|c|}
\hline & \multicolumn{2}{|c|}{$\leq 27$} & \multicolumn{2}{|c|}{$>27$} & \multirow{2}{*}{$\begin{array}{c}\text { p- } \\
\text { valor }\end{array}$} \\
\hline & & n & $\%$ & $\mathbf{n}$ & $\%$ & \\
\hline \multirow{3}{*}{ Estado Oclusal } & Ninguna & 41 & $41,8 \%$ & 39 & $54,2 \%$ & \multirow{3}{*}{0,239} \\
\hline & $\begin{array}{l}\text { Leve } \\
\end{array}$ & 33 & $33,7 \%$ & 17 & $23,6 \%$ & \\
\hline & Moderada-Grave & 24 & $24,5 \%$ & 16 & $22,2 \%$ & \\
\hline \multirow{4}{*}{$\begin{array}{l}\text { Tratamiento } \\
\text { Ortodoncia }\end{array}$} & No & 83 & $84,7 \%$ & 67 & $93,1 \%$ & \multirow{4}{*}{0,066} \\
\hline & Llevó fija & 9 & $9,2 \%$ & 5 & $6,9 \%$ & \\
\hline & Lleva fija & 1 & $1,0 \%$ & 0 & $0,0 \%$ & \\
\hline & $\begin{array}{l}\text { Llevó fija (y lleva } \\
\text { un retenedor) }\end{array}$ & 5 & $5,1 \%$ & 0 & $0,0 \%$ & \\
\hline \multirow[b]{2}{*}{$\begin{array}{l}\text { Erupcionado } \\
\text { parcial }\end{array}$} & Inferiores & 28 & $73,7 \%$ & 15 & $88,2 \%$ & \multirow[b]{2}{*}{0,393} \\
\hline & Superiores & 10 & $26,3 \%$ & 2 & $11,8 \%$ & \\
\hline \multirow[b]{2}{*}{$\begin{array}{l}\text { Necesidad de } \\
\text { Exodoncia }\end{array}$} & Inferiores & 12 & $75,0 \%$ & 4 & $25,0 \%$ & \multirow[b]{2}{*}{0,222} \\
\hline & Superiores & 11 & $50,0 \%$ & 11 & $50,0 \%$ & \\
\hline
\end{tabular}

\subsection{Análisis por el grado de aptitud dental}

\subsubsection{Visita 1}

Un dato muy relevante para el colectivo estudiado en este trabajo es el que indica que de los 170 militares a los que se les realizo la revisión dental en la primera visita, al 30\% se le consideró "no apto". Dato fundamental cuando se traslada a la selección de los miembros de las fuerzas armadas para una misión.

Tabla 5.8.1. Resultados del Grado de Aptitud Dental, en la primera visita

\begin{tabular}{|l|l|r|r|}
\hline \multicolumn{2}{|c|}{} & \multicolumn{1}{|c|}{ n } & \multicolumn{1}{c|}{$\%$} \\
\hline \multirow{3}{*}{ Visita 1 } & Apto & 119 & $70,0 \%$ \\
\cline { 2 - 4 } & No apto & 51 & $30,0 \%$ \\
\hline
\end{tabular}




\subsubsection{Visita 2}

El análisis realizado permitió determinar cuantos sujetos del colectivo estudiado eran no aptos. Se ha constatado que su porcentaje se redujo de un $30,0 \%$ a un $8.2 \%$. Dato de gran interés y que es analizado con más detalle, por sexo, escala y edad, en la discusión de este trabajo.

Tabla 5.8.2. Resultados del Grado de Aptitud Dental, en la segunda visita

\begin{tabular}{|l|l|r|r|}
\hline \multicolumn{2}{|c|}{} & \multicolumn{1}{c|}{$\mathbf{n}$} & \multicolumn{1}{c|}{$\%$} \\
\hline \multirow{3}{*}{ Visita 2 } & Apto & 156 & $91,8 \%$ \\
\cline { 2 - 4 } & No apto & 14 & $8,2 \%$ \\
\hline
\end{tabular}


Estudio epidemiológico de la salud bucodental y ...

\section{ANEXO}

El anexo muestra las tablas que contienen todos los datos totales relevantes de las visitas 1 y 2 . Estas tablas son comentadas en los capítulos de resultados y discusión de la presente memoria.

\section{Relativas al cepillado, tabaquismo y frecuencia de visitas al dentista.}

Tabla 5.1.1a Resumen de los datos de hábitos de cepillado, tabaquismo y frecuencia de visitas al dentista para la visita 1.

\begin{tabular}{|c|c|c|c|c|}
\hline & & & $\mathbf{n}$ & $\%$ \\
\hline \multirow{7}{*}{ CEPILLADO } & \multirow{5}{*}{$\begin{array}{l}\text { Frecuencia de } \\
\text { cepillado }\end{array}$} & Nunca & 1 & $6 \%$ \\
\hline & & 1 vez día & 63 & $37,1 \%$ \\
\hline & & 2 veces día & 61 & $35,9 \%$ \\
\hline & & 3 veces día & 37 & $21,8 \%$ \\
\hline & & 1 vez semana & 8 & $4,7 \%$ \\
\hline & \multirow{2}{*}{ Tipo de cepillo } & Manual & 133 & $78,2 \%$ \\
\hline & & Eléctrico & 37 & $21,8 \%$ \\
\hline \multirow{2}{*}{\multicolumn{2}{|c|}{ HABITO DE TABAQUISMO }} & No fumador & 91 & $53,5 \%$ \\
\hline & & Fumador & 79 & $46,5 \%$ \\
\hline \multirow{4}{*}{\multicolumn{2}{|c|}{$\begin{array}{c}\text { FRECUENCIA DE VISITAS AL } \\
\text { DENTISTA }\end{array}$}} & Esporádicamente & 65 & $38,2 \%$ \\
\hline & & Nunca & 9 & $5,3 \%$ \\
\hline & & Periódicamente & 41 & $24,1 \%$ \\
\hline & & Solo con clínica & 55 & $32,4 \%$ \\
\hline
\end{tabular}

Tabla 5.1.2a. Resumen de los datos de hábitos de cepillado, tabaquismo y frecuencia de visitas al dentista para la visita 2.

\begin{tabular}{|c|c|c|c|c|}
\hline & & & $\mathbf{n}$ & $\%$ \\
\hline \multirow{8}{*}{ CEPILLADO } & \multirow{5}{*}{$\begin{array}{l}\text { Frecuencia de } \\
\text { cepillado }\end{array}$} & Nunca & 0 & $0,0 \%$ \\
\hline & & 1 vez al día & 37 & $21,8 \%$ \\
\hline & & 2 veces al día & 73 & $42,9 \%$ \\
\hline & & 3 veces al día & 58 & $34,1 \%$ \\
\hline & & $1 \mathrm{vez}$ a la semana & 2 & $1,2 \%$ \\
\hline & \multirow{3}{*}{ Tipo de cepillo } & Manual & 106 & $62,4 \%$ \\
\hline & & Eléctrico & 39 & $22,9 \%$ \\
\hline & & Ambos & 25 & $14,7 \%$ \\
\hline \multirow{3}{*}{\multicolumn{2}{|c|}{ HÁBITO DE TABAQUISMO }} & No Fumador & 92 & $54,1 \%$ \\
\hline & & Ex-fumador & 26 & $15,3 \%$ \\
\hline & & Fumador & 52 & $30,6 \%$ \\
\hline \multirow{4}{*}{\multicolumn{2}{|c|}{$\begin{array}{c}\text { FRECUENCIA DE VISITAS } \\
\text { DENTISTA }\end{array}$}} & Esporádicamente & 46 & $27,1 \%$ \\
\hline & & Nunca & 2 & $1,2 \%$ \\
\hline & & Periódicamente & 95 & $55,9 \%$ \\
\hline & & Sólo con clínica & 27 & $15,9 \%$ \\
\hline
\end{tabular}


Relativas a la articulación témporo-mandibular, bruxismo, utilización de férulas oclusales y presencia de torus mandibulares.

Tabla 5.2.1a. Resumen del estado de la articulación témporo-mandibular, presencia de bruxismo, utilización de férulas oclusales y presencia de torus mandibulares de la muestra estudiada en su primera visita.

\begin{tabular}{|c|c|c|c|}
\hline \multicolumn{2}{|c|}{} & $\mathbf{n}$ & $\%$ \\
\hline \multirow{2}{*}{ ESTADO DE LA ATM } & $\begin{array}{c}\text { Ausencia de signos } \\
\text { y síntomas }\end{array}$ & 155 & $91,20 \%$ \\
\cline { 2 - 4 } & $\begin{array}{c}\text { Presencia de } \\
\text { chasquidos }\end{array}$ & 14 & $8,20 \%$ \\
\cline { 2 - 4 } & Dolor a la palpación & 1 & $0,60 \%$ \\
\hline \multirow{2}{*}{ BRUXISMO } & NO & 157 & $92,40 \%$ \\
\cline { 2 - 4 } & SI & 13 & $7,60 \%$ \\
\hline \multirow{2}{*}{ FÉRULAS OCLUSALES } & NO & 166 & $97,6 \%$ \\
\cline { 2 - 4 } & De mantenimiento & 3 & $1,8 \%$ \\
\cline { 2 - 4 } & De descarga & 1 & $0.6 \%$ \\
\hline \multirow{2}{*}{ TORUS MANDIBULARES } & NO & 157 & $92,40 \%$ \\
\cline { 2 - 4 } & SI & 13 & $7,60 \%$ \\
\hline
\end{tabular}

Tabla 5.2.2a. Resumen del estado de la articulación témporo-mandibular, presencia de bruxismo, utilización de férulas oclusales y presencia de torus mandibulares de la muestra estudiada en su segunda visita.

\begin{tabular}{|c|c|c|c|}
\hline & & $\mathbf{n}$ & $\%$ \\
\hline \multirow{4}{*}{ ESTADO DE LA ATM } & $\begin{array}{c}\text { Ausencia de signos y } \\
\text { síntomas }\end{array}$ & 155 & $91,20 \%$ \\
\hline & $\begin{array}{c}\text { Presencia de } \\
\text { chasquidos }\end{array}$ & 13 & $7,60 \%$ \\
\hline & Dolor a la palpación & 1 & $0,60 \%$ \\
\hline & $\begin{array}{c}\text { Movilidad reducida de la } \\
\text { mandíbula }\end{array}$ & 1 & $0,60 \%$ \\
\hline \multirow{2}{*}{ BRUXISMO } & NO & 157 & $92,40 \%$ \\
\hline & SI & 13 & $7,60 \%$ \\
\hline \multirow{3}{*}{ FÉRULAS OCLUSALES } & NO & 163 & $95,90 \%$ \\
\hline & De mantenimiento & 4 & $2,35 \%$ \\
\hline & De descarga & 3 & $1,76 \%$ \\
\hline \multirow{2}{*}{ TORUS MANDIBULARES } & NO & 157 & $92,40 \%$ \\
\hline & SI & 13 & $7,60 \%$ \\
\hline
\end{tabular}


Estudio epidemiológico de la salud bucodental y ...

\section{Relativas a las opacidades e hipoplasias del esmalte y a la tinción por tetraciclinas.}

Tabla 5.3.1a. Resumen de las opacidades e hipoplasias del esmalte y tinción por tetraciclinas de la muestra estudiada en su primera visita.

\begin{tabular}{|c|c|c|c|}
\hline \multirow{4}{*}{$\begin{array}{c}\text { Normal } \\
\text { OPACIDADES/HIPOPLASIA DEL } \\
\text { ESMALTE }\end{array}$} & $\mathbf{n}$ & $\boldsymbol{\%}$ \\
\cline { 2 - 4 } & Opacidad delimitada & 4 & \multicolumn{1}{|c|}{$2,4 \%$} \\
\cline { 2 - 4 } & Opacidad Difusa & 7 & $4,1 \%$ \\
\cline { 2 - 4 } & Hipoplasia & 4 & $2,4 \%$ \\
\cline { 2 - 4 } & Otros defectos & 3 & $1,8 \%$ \\
\cline { 2 - 4 } & $\begin{array}{c}\text { Opacidad difusa e } \\
\text { hipoplasia }\end{array}$ & 1 &, $6 \%$ \\
\hline \multirow{2}{*}{ TINCIÓN TETRACICLINAS } & NO & 166 & $97,6 \%$ \\
\cline { 2 - 4 } & SI & 4 & $2,4 \%$ \\
\hline
\end{tabular}

Tabla 5.3.2a, Resumen de las opacidades e hipoplasias del esmalte y tinción por tetraciclinas de la muestra estudiada en su segunda visita.

\begin{tabular}{|c|c|c|c|}
\hline \multicolumn{2}{|c|}{} & $\mathbf{n}$ & $\mathbf{\%}$ \\
\hline \multirow{4}{*}{$\begin{array}{c}\text { OPACIDADES/HIPOPLASIA DEL } \\
\text { ESMALTE }\end{array}$} & Normal & 151 & $88,8 \%$ \\
\cline { 2 - 4 } & $\begin{array}{c}\text { Opacidad } \\
\text { delimitada }\end{array}$ & 4 & $2,4 \%$ \\
\cline { 2 - 4 } & Opacidad Difusa & 7 & $4,1 \%$ \\
\cline { 2 - 4 } & Hipoplasia & 4 & $2,4 \%$ \\
\cline { 2 - 4 } & Otros defectos & 3 & $1,8 \%$ \\
\cline { 2 - 4 } & $\begin{array}{c}\text { Opacidad difusa e } \\
\text { hipoplasia }\end{array}$ & 1 &, $6 \%$ \\
\hline \multirow{2}{*}{ TINCIÓN TETRACICLINAS } & NO & 166 & $97,6 \%$ \\
\cline { 2 - 4 } & SI & 4 & $2,4 \%$ \\
\hline
\end{tabular}


Relativas al estado periodontal y la necesidad de tratamiento así como la presencia de pendientes en labios y lengua.

Tabla 5.4.1a: Resumen del estado periodontal, necesidad de tratamiento y utilización de pendientes en labios y lengua de la muestra estudiada en su primera visita.

\begin{tabular}{|c|c|c|c|}
\hline & & $\mathbf{n}$ & $\boldsymbol{\%}$ \\
\hline \multirow{4}{*}{ ESTADO PERIODONTAL } & Sano & 25 & $14,7 \%$ \\
\cline { 2 - 4 } & Hemorragia & 6 & $3,5 \%$ \\
\cline { 2 - 4 } & Cálculo & 123 & $72,4 \%$ \\
\cline { 2 - 4 } & Bolsa $4-5 \mathrm{~mm}$ & 16 & $9,4 \%$ \\
\hline \multirow{2}{*}{$\begin{array}{c}\text { NECESIDAD DE } \\
\text { TRATAMIENTO PERIODONTAL }\end{array}$} & $\begin{array}{c}\text { Instrucciones de } \\
\text { higiene }\end{array}$ & 5 & $2,9 \%$ \\
\cline { 2 - 4 } & No precisa & 20 & $11,8 \%$ \\
\cline { 2 - 4 } & $\begin{array}{c}\text { Raspado y alisado } \\
\text { radicular }\end{array}$ & 16 & $9,4 \%$ \\
\cline { 2 - 4 } & Tartrectomía & 129 & $75,9 \%$ \\
\hline \multirow{2}{*}{ PENDIENTE EN LENGUA } & NO & 159 & $93,5 \%$ \\
\cline { 2 - 4 } & SI & 11 & $6,5 \%$ \\
\hline \multirow{2}{*}{ PENDIENTE EN LABIO } & NO & 165 & $97,1 \%$ \\
\cline { 2 - 4 } & SI & 5 & $2,9 \%$ \\
\hline
\end{tabular}

Tabla 5.4.2a: Resumen del estado periodontal, necesidad de tratamiento y utilización de pendientes en labios y lengua de la muestra estudiada en su segunda visita.

\begin{tabular}{|c|c|c|c|}
\hline \multicolumn{2}{|c|}{} & $\mathbf{n}$ & $\mathbf{\%}$ \\
\hline \multirow{4}{*}{ ESTADO PERIODONTAL } & Sano & 61 & $35,9 \%$ \\
\cline { 2 - 4 } & Hemorragia & 7 & $4,1 \%$ \\
\cline { 2 - 4 } & Cálculo & 76 & $44,7 \%$ \\
\cline { 2 - 4 } & Bolsa 4-5 mm & 26 & $15,3 \%$ \\
\hline \multirow{3}{*}{$\begin{array}{c}\text { NECESIDAD DE } \\
\text { TRATAMIENTO } \\
\text { PERIODONTAL }\end{array}$} & $\begin{array}{c}\text { Instrucciones de } \\
\text { higiene }\end{array}$ & 26 & $15,3 \%$ \\
\cline { 2 - 4 } & No precisa & 40 & $23,5 \%$ \\
\cline { 2 - 4 } & $\begin{array}{c}\text { Raspado y } \\
\text { alisado radicular }\end{array}$ & 26 & $15,3 \%$ \\
\cline { 2 - 4 } & Tartrectomía & 78 & $45,9 \%$ \\
\hline \multirow{2}{*}{ PENDIENTE EN LENGUA } & NO & 160 & $94,1 \%$ \\
\cline { 2 - 4 } & SI & 10 & $5,9 \%$ \\
\hline \multirow{2}{*}{ PENDIENTE EN LABIO } & NO & 165 & $97,1 \%$ \\
\cline { 2 - 4 } & SI & 5 & $2,9 \%$ \\
\hline
\end{tabular}


Relativas al estado de prótesis y necesidad de tratamiento y presencia de implantes.

Tabla 5.6.1a: Resumen del estado de las prótesis, necesidad de tratamiento y presencia de implantes correspondiente a la primera visita.

\begin{tabular}{|c|c|c|c|}
\hline & & $\mathbf{n}$ & $\%$ \\
\hline \multirow{4}{*}{ ESTADO PRÓTESIS SUPERIOR } & Ninguna & 158 & $92,9 \%$ \\
\hline & Puente & 9 & $5,3 \%$ \\
\hline & Más de un puente & 2 & $1,2 \%$ \\
\hline & $\begin{array}{c}\text { Puentes y parcial } \\
\text { removible }\end{array}$ & 1 & $0,6 \%$ \\
\hline \multirow{4}{*}{ ESTADO PRÓTESIS INFERIOR } & Ninguna & 166 & $97,6 \%$ \\
\hline & Puente & 1 & $0,6 \%$ \\
\hline & Más de un puente & 1 & $0,6 \%$ \\
\hline & Parcial removible & 2 & $1,2 \%$ \\
\hline \multirow{4}{*}{$\begin{array}{l}\text { NECESIDAD DEPRÓTESIS } \\
\text { SUPERIOR }\end{array}$} & Ninguna & 125 & $73,5 \%$ \\
\hline & Prótesis Unitaria & 38 & $22,4 \%$ \\
\hline & Prótesis multiunitaria & 6 & $3,5 \%$ \\
\hline & $\begin{array}{c}\text { Combinación de prótesis } \\
\text { unitaria y multiunitaria }\end{array}$ & 1 & $0,6 \%$ \\
\hline \multirow{3}{*}{$\begin{array}{l}\text { NECESIDAD DE PRÓTESIS } \\
\text { INFERIOR }\end{array}$} & Ninguna & 117 & $68,8 \%$ \\
\hline & Prótesis Unitaria & 39 & $22,9 \%$ \\
\hline & Prótesis multiunitaria & 14 & $8,2 \%$ \\
\hline \multirow[b]{2}{*}{ IMPLANTES } & Inferiores & 3 & $100 \%$ \\
\hline & Superiores & 3 & $100 \%$ \\
\hline
\end{tabular}


Tabla 5.6.2a: Resumen del estado de las prótesis, necesidad de tratamiento y presencia de implantes correspondiente a la segunda visita.

\begin{tabular}{|c|c|c|c|}
\hline & & $\mathbf{n}$ & $\%$ \\
\hline \multirow{5}{*}{ ESTADO PRÓTESIS SUPERIOR } & Ninguna & 155 & $91,2 \%$ \\
\hline & Puente & 10 & $5,9 \%$ \\
\hline & Más de un puente & 3 & $1,8 \%$ \\
\hline & Parcial removible & 1 &, $6 \%$ \\
\hline & Puentes con implantes & 1 &, $6 \%$ \\
\hline \multirow{5}{*}{ ESTADO PRÓTESIS INFERIOR } & Ninguna & 166 & $97,6 \%$ \\
\hline & Puente & 1 &, $6 \%$ \\
\hline & Más de un puente & 1 & ,6\% \\
\hline & Parcial removible & 1 & ,6\% \\
\hline & Puentes con implantes & 1 &, $6 \%$ \\
\hline \multirow{4}{*}{$\begin{array}{c}\text { NECESIDAD DE PRÓTESIS } \\
\text { SUPERIOR }\end{array}$} & Ninguna & 107 & $62,9 \%$ \\
\hline & Prótesis Unitaria & 49 & $28,8 \%$ \\
\hline & Prótesis multiunitaria & 13 & $7,6 \%$ \\
\hline & $\begin{array}{c}\text { Combinación de prótesis } \\
\text { unitaria y multiunitaria }\end{array}$ & 1 &, $6 \%$ \\
\hline \multirow{3}{*}{$\begin{array}{l}\text { NECESIDAD DE PRÓTESIS } \\
\text { INFERIOR }\end{array}$} & Ninguna & 106 & $62,4 \%$ \\
\hline & Prótesis Unitaria & 42 & $24,7 \%$ \\
\hline & Prótesis multiunitaria & 22 & $12,9 \%$ \\
\hline \multirow[b]{2}{*}{ IMPLANTES } & Inferiores & 16 & $100 \%$ \\
\hline & Superiores & 14 & $100 \%$ \\
\hline
\end{tabular}


Estudio epidemiológico de la salud bucodental y ...

Tablas de las visitas 1 y 2 relativas al estado oclusal (anomalías dentofaciales), presencia de tratamientos ortodóncicos y la necesidad de exodoncia de los terceros molares y presencia de dientes parcialmente erupcionados.

Tabla 5.7.1a. Resumen del estado oclusal, presencia de tratamientos ortodoncicos, presencia de dientes parcialmente erupcionados y necesidad de exodoncia de los $3^{\circ}$ molares, de la primera visita.

\begin{tabular}{|c|c|c|c|}
\hline & & $\mathbf{n}$ & $\mathbf{0}$ \\
\hline \multirow{2}{*}{ ESTADOOCLUSAL } & Ninguna & 79 & $46,5 \%$ \\
\cline { 2 - 4 } & Leve & 49 & $28,8 \%$ \\
\cline { 2 - 4 } & Moderada-Grave & 42 & $24,7 \%$ \\
\hline \multirow{2}{*}{ TRATAMIENTO ORTODONCIA } & No & 150 & $88,2 \%$ \\
\cline { 2 - 4 } & Llevó fija & 12 & $7,1 \%$ \\
\cline { 2 - 4 } & Lleva fija & 3 & $1,8 \%$ \\
\cline { 2 - 4 } & $\begin{array}{c}\text { Llevó fija (y lleva un } \\
\text { retenedor) }\end{array}$ & 5 & $2,9 \%$ \\
\hline \multirow{2}{*}{ ERUPCIONADO PARCIAL } & Inferiores & 51 & $85 \%$ \\
\cline { 2 - 4 } & Superiores & 9 & $15 \%$ \\
\hline \multirow{2}{*}{ NECESIDAD DE EXODONCIA } & Inferiores & 50 & $75,8 \%$ \\
\cline { 2 - 4 } & Superiores & 28 & $56,0 \%$ \\
\hline
\end{tabular}

Tabla 5.7.2a. Resumen del estado oclusal, presencia de tratamientos ortodoncicos, presencia de dientes parcialmente erupcionados y necesidad de exodoncia de los $3^{\circ}$ molares, de la segunda visita.

\begin{tabular}{|c|c|c|c|}
\hline \multicolumn{2}{|c|}{} & $\mathbf{n}$ & $\%$ \\
\hline \multirow{3}{*}{ ESTADO OCLUSAL } & Ninguna & 80 & $47,1 \%$ \\
\cline { 2 - 4 } & Leve & 50 & $29,4 \%$ \\
\cline { 2 - 4 } & Moderada-Grave & 40 & $23,5 \%$ \\
\hline \multirow{3}{*}{$\begin{array}{c}\text { TRATAMIENTO } \\
\text { ORTODONCIA }\end{array}$} & No & 150 & $88,2 \%$ \\
\cline { 2 - 4 } & Llevó fija & 14 & $8,2 \%$ \\
\cline { 2 - 4 } & Lleva fija & 1 &, $6 \%$ \\
\cline { 2 - 4 } & $\begin{array}{c}\text { Llevó fija (y lleva } \\
\text { un retenedor) }\end{array}$ & 5 & $2,9 \%$ \\
\hline \multirow{2}{*}{ ERUPCIONADO PARCIAL } & Inferiores & 43 & $78,2 \%$ \\
\cline { 2 - 4 } & Superiores & 12 & $21,8 \%$ \\
\hline \multirow{2}{*}{$\begin{array}{c}\text { NECESIDAD DE } \\
\text { EXODONCIA }\end{array}$} & Inferiores & 16 & $24,2 \%$ \\
\cline { 2 - 4 } & Superiores & 22 & $44,0 \%$ \\
\hline
\end{tabular}




\section{Discusión}


Estudio epidemiológico de la salud bucodental y ... 


\section{DISCUSIÓN}

La discusión que se aborda en este capítulo se apoya en la comparación entre los estudios realizados, sobre el mismo colectivo, en dos visitas espaciadas por 9 años. Por este motivo las tablas comparativas de nuestro estudio en vez de aparecer en el capitulo de resultados, se incorporan como anexo a este capítulo de la discusión. Estas tablas se numeran $(6.1 \mathrm{a}, 6.2 \mathrm{a}, \ldots)$, el "6" del capitulo, el " 1 " para el número de tabla y la "a" indica el anexo. Tal y como aparece en las líneas que siguen, y luego en las conclusiones, los resultados de este estudio demuestran "la necesidad de incrementar la concienciación ciudadana y la de la administración acerca de la importancia de la prevención en la salud oral”. Por ejemplo, las mejoras de aquellas patologías de carácter muy general que pueden ser corregidas con un adecuado y continuado seguimiento, así como las actuaciones, en tiempo, de aquellas otras, que exigen un tratamiento clínico. Este hecho, que tiene repercusiones importantes en la población general, en esta discusión se demuestra que es fundamental para la población militar en relación con la valoración del grado de aptitud dental. Con el fin de facilitar la lectura y mantener la coherencia del texto la discusión se ha organizado con la misma estructura que se ha utilizado para presentar los capítulos de material y métodos y el de los resultados. 


\subsection{Hábitos de cepillado, tabaquismo y frecuencia de visitas al dentista}

Aunque la importancia de la higiene oral no es puesta en duda por ningún colectivo (población y especialistas), parece ser un problema endémico el que los ciudadanos la realicen, en general, de forma apropiada y eficiente ${ }^{101,102}$. En relación con la salud oral, un análisis bibliográfico indica que abundan los trabajos que la analizan en función de la edad, educación, etc., sin embargo, existen muchos menos, en los que se estudia la respuesta a una planificación de salud oral de una población acotada, analizada a lo largo de un período temporal suficientemente largo. En este punto es necesario reseñar que las encuestas de salud responden a programas generales y el colectivo no es el mismo, aunque al tratarse de muestras amplias los promedios estadísticos son significativos. A modo de ejemplo, entre los pocos estudios temporales encontrados, se puede tomar como referencia el que estudia la conducta de higiene oral ${ }^{103}$ (cepillado y uso de complementos para la higiene) de 214 participantes, aunque sea bastante más limitado que el realizado para este trabajo, que estudia a los mismos sujetos en dos momentos diferentes con un espacio de tiempo de nueve años. Por este motivo el presente estudio puede tener una importante repercusión para las personas en general y para el organismo en el que trabajan en particular; en este caso las fuerzas armadas.

En este apartado, además de las figuras se tienen en cuenta los datos que aparecen en las Tablas 6.1a, 6.2a, 6.3a y 6.4a del anexo. En la Figura 6.1 se presenta un resumen de la evolución en la frecuencia de cepillado entre la primera y la segunda visita. Se puede comprobar que los tres primeros hábitos, que indican una atención oral deficiente, disminuyeron notablemente $\mathrm{y}$, sin embargo los dos últimos, dos y tres veces de cepillado al día, han experimentado un importante incremento. La suma de ambos representa un $77 \%$ de la población estudiada lo que indica una situación de salud oral que, si se diera en la población joven, se aseguraría una notable mejoría en esa población cuando alcanzase la edad de los sujetos de este estudio. 

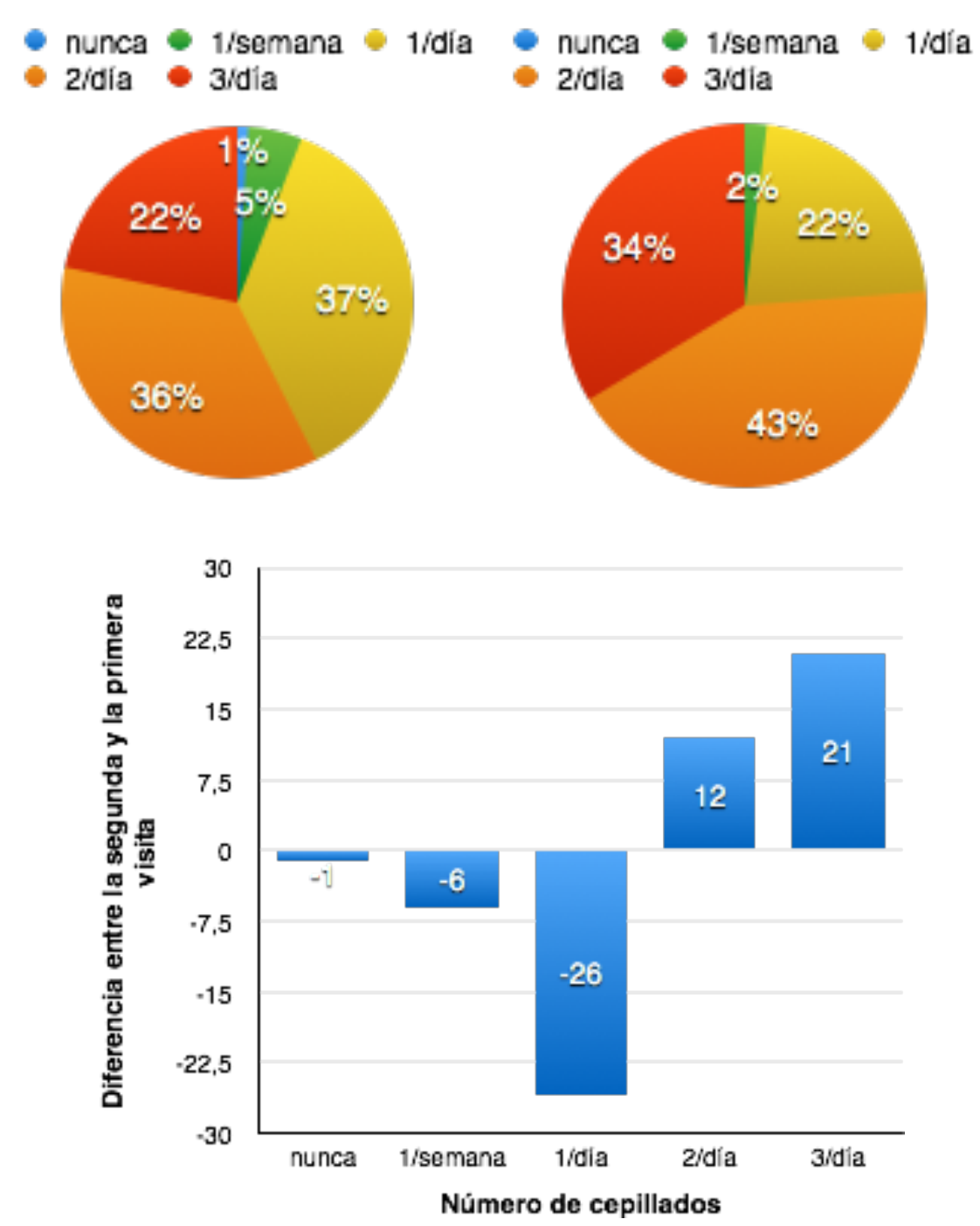

Figura 6.1. Evolución de la frecuencia de cepillado, para el número total de los sujetos del estudio entre las dos visitas. Las gráficas superiores muestran el \% en cada visita y la inferior la diferencia numérica entre las dos visitas.

Comparando este resultado con los de otros estudios realizados sobre el cepillado en diferentes países, aunque con una sola visita (estáticos), se observa que las cifras, son similares a los de aquellos que poseen de nivel cultural medio-alto. Sin embargo debido a que los estudios se hacen sobre muestras heterogéneas, existen dificultades para realizar extrapolaciones y comparaciones de detalles. A modo de ejemplo se analizan los datos de un estudio con 80 participantes (68\% mujeres y 32\% hombres), con una edad media de 35,43 años realizado en una Facultad de Odontología ${ }^{104}$. En dicho estudio encuentran que el 
número de personas que realizan el cepillado dos veces al día es el máximo de la distribución. Pero lo interesante es que la suma de estos con el número de personas que se cepillan tres veces al día es la misma que la de la segunda visita en la Figura 6.1. Sin embargo, el resultado de ese estudio no se puede extrapolar, debido a que no es representativo de la población general por varios factores: La proporción de mujeres, el estatus social de los participantes, el estilo de vida y el nivel de educación (el 50\% tenían nivel universitario). Todos son factores que influyen notablemente en la salud oral ${ }^{105,106}$. Aún así, el resultado de la segunda visita de la población militar estudiada, además de ser comparable a los valores medios de los países de nivel cultural medio-alto es, también, bastante similar al de la referencia [104], en la cual se analiza una muestra con un alto nivel educativo y social de un país con un nivel medio más bajo que el nuestro. Todos los estudios comparativos indican que en este sector de población (educación media-alta) las diferencias, entre países, sobre la necesidad de mantener una salud oral son, más bien, pequeñas.

Si se considera el concepto de cepillado regular diario, sin distinguir si se hace una, dos o tres veces al día, los resultados del presente estudio dan para la muestra estudiada unos valores de $94,8 \%$ para la primera visita y $98,8 \%$ para la segunda. Este resultado, además de indicar una notable mejoría como consecuencia de las recomendaciones realizadas por el especialista, presenta valores comparables a los mejores datos recientes reseñados para la población española en $2005^{107,108}$ que oscilan entre un $85 \%$ y un $94 \%$ y se equiparan a los resultados de 2007 de una muestra universitaria en la que se reduce a un $2 \%$ el número de ciudadanos que o no tienen regularidad en el cepillado o no lo hacen nunca $^{109}$. En los resultados también se manifiesta el hecho de que las mujeres tienen el hábito de cepillado regular más arraigado que los hombres. En el presente estudio el resultado es sorprendente, ya que el $100 \%$ de las mujeres se cepillan con regularidad una, dos o tres veces al día.

Los resultados sobre el hábito de cepillado de este estudio son mucho mejores que los que aparecen en estudios anteriores referidos también a muestras de militares españoles que van desde una prevalencia de cepillado diario del $63 \%$ hasta cifras entre el $15 \%$ y el $40 \%$ para las épocas de militares de remplazo ${ }^{110,111}$.

También es interesante, como indica la Figura 6.2, analizar los resultados en función del tipo de cepillo utilizado. Este dato, así como la forma y tiempo de cepillado o el tipo de dentífrico utilizado, está relacionado con las recomendaciones realizadas en la primera visita sobre una higiene oral bien realizada. Las figuras 6.1 y 6.2 muestran una mejora en la salud oral asociada al tipo de cepillo y frecuencia de cepillado respectivamente. La figura 6.2 indica que los sujetos examinados, en la segunda visita, siguen utilizando el cepillo manual con mayor frecuencia pero que el eléctrico gana adeptos, siendo su uso 
solo $(22,9 \%)$ o combinado $(14,7 \%)$, es decir se incrementa casi un $16 \%$ su uso con respecto a la primera cita. La diferencia entre hombres y mujeres es prácticamente inapreciable, siendo los sujetos de la escala de tropa y los mayores de 27 años, los que más recurren al uso del cepillo eléctrico. Sin embargo, se puede explicar si se tiene en cuenta la edad ya que la percepción de la necesidad de mantener las acciones preventivas para la salud oral es relativamente reciente en España. También encontramos resultados similares en otro trabajo, referido a otro país ${ }^{104}$. El acceso a los servicios de salud oral por las clases más desfavorecidas incrementan notablemente el cuidado de la boca. Conclusión a la que también llegan en un estudio comparativo entre cinco países relacionado con la pérdida de piezas bucales ${ }^{112}$. En dicho estudio también aparece un país Sur-Americano mostrando las pequeñas diferencias que se han comentado anteriormente. En los sujetos de nuestro estudio, el acceso al servicio de odontología es libre y pueden hacer uso del mismo cuando lo necesiten, lo cual influye muy positivamente en la mejora de su salud oral.

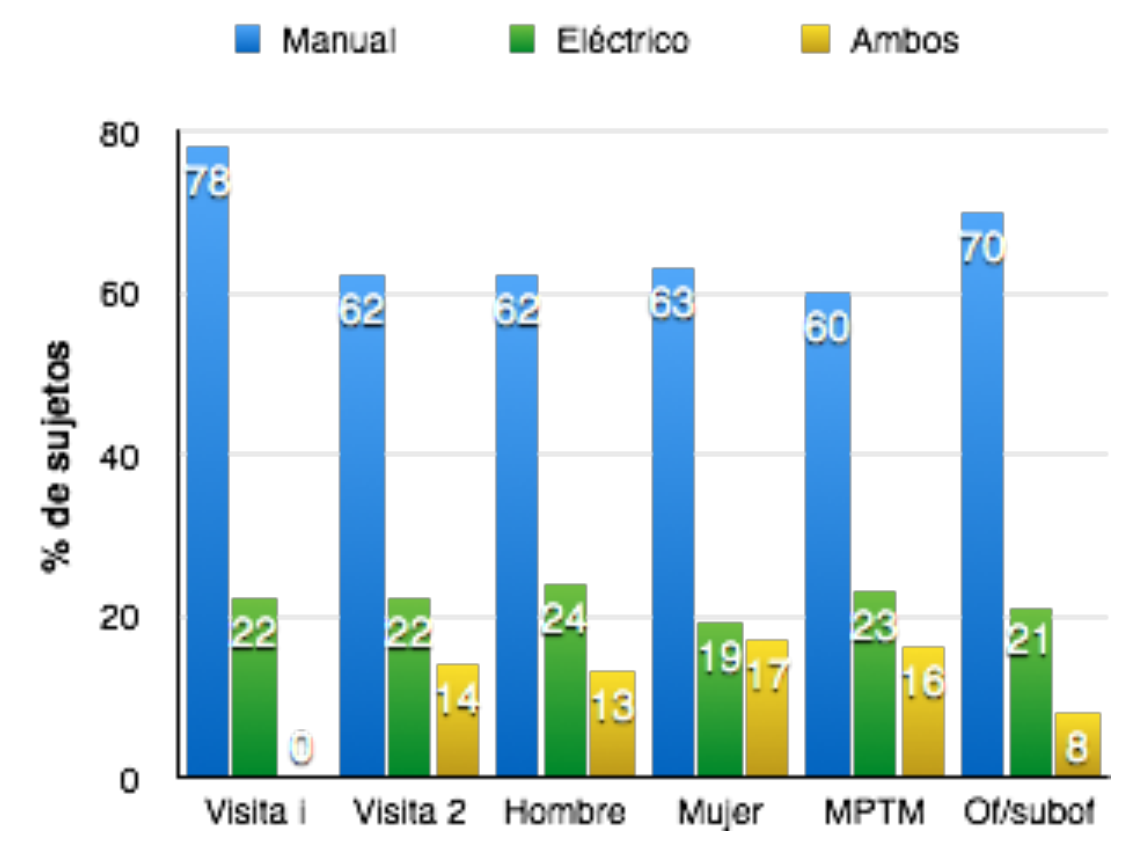

Figura 6.2. Comparación entre las visitas 1 y 2 del número total de sujetos estudiados en función del tipo de cepillo utilizado. La misma comparación entre hombres y mujeres y MPTM y of/subof correspondiente a la segunda visita.

La incorporación del tabaquismo en este estudio es motivada por el hecho de que se ha demostrado que el tabaco es un importante factor de riesgo, debido a que reduce la vascularización gingival, inhibe la respuesta inmune y cambia la micro-flora de la boca, la cual se vuelve más patógena ${ }^{113}$. Se ha demostrado en 
diferentes estudios que el tabaco tiene una correlación directa con la destrucción de los tejidos periodontales e incrementa la progresión de pérdida de hueso marginal ${ }^{114-116}$. En cualquier caso, y a pesar de la importancia de este hábito, los estudios comparativos son difíciles de realizar debido a que los resultados dependen de varios factores (tiempo de fumador, sexo, edad, cigarros, pipa, etc.) que no aparecen especificados en muchos de los estudios realizados.

El estudio prospectivo de la salud bucodental en España $2020^{14}$ no habla de un objetivo en porcentaje de gente que va a dejar de fumar, pero sí propone un valor (al menos el 65\%) para aquellos dentistas que aconsejarán en sus consultas sobre la importancia de dejar de fumar. Función que se ha venido realizando en este trabajo antes, durante y después de la exploración en las dos visitas realizadas. Se han explicado con detalle las ventajas que, para la salud oral, se derivan al eliminar este hábito. El resumen de los resultados conseguidos aparecen en la Figura 6.3 y la Tabla II.1c del anexo.

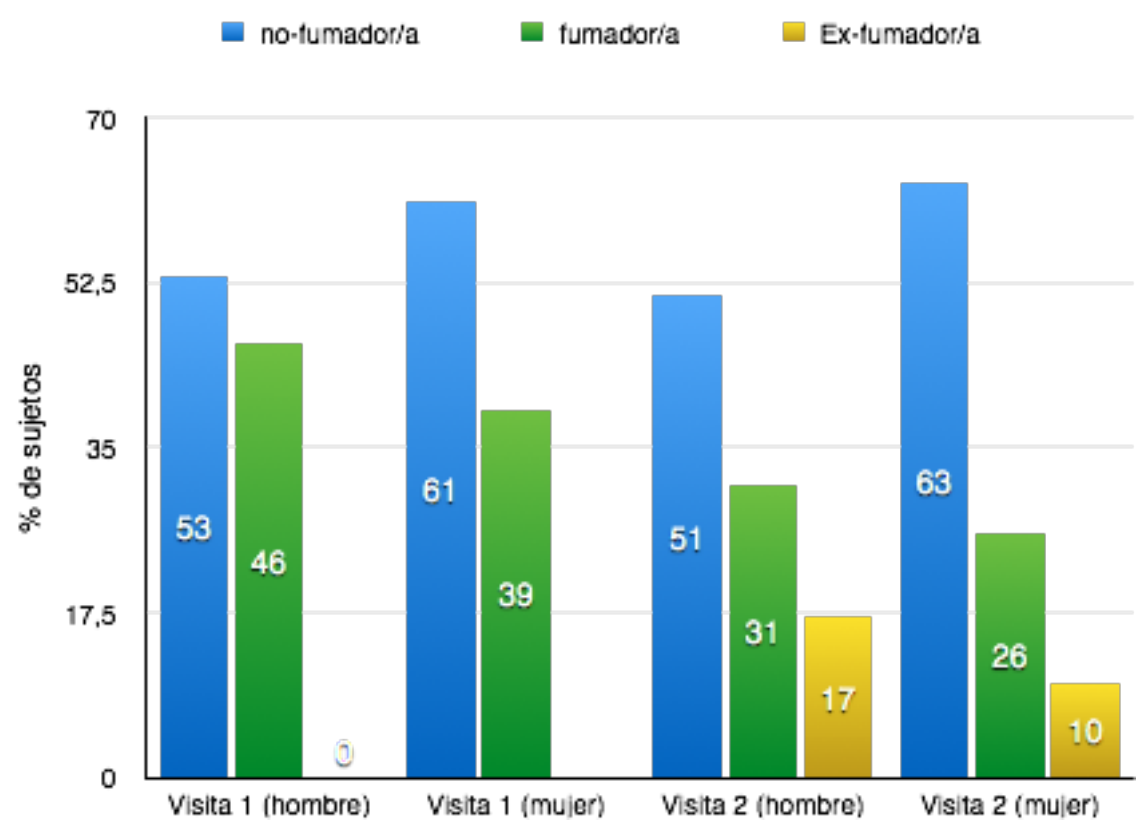

Figura 6.3. Variación en el habito de tabaquismo entre las dos visitas en función del sexo.

El número de no fumadores en la segunda visita es mayor en las mujeres, en la escala de oficiales y suboficiales y también, en los de mayor edad. En las diferencias de fumadores por sexo se puede decir que se pueden extrapolar de la tendencia que se ha observado desde $1997^{117-120}$. Es una tendencia a igualarse, aunque, si tenemos en cuenta los resultados de este estudio, el acercamiento ya 
ha comenzado a amortiguarse. Este resultado de los hábitos de tabaquismo de una población militar difieren de los encontrados en $2010^{110}$ en dónde los porcentajes de fumadores eran más altos y las mujeres superaban con mayor diferencia a los hombres. Esta diferencia puede ser una confirmación de la rápida disminución del hábito de tabaquismo que se está produciendo en España y otros países socioeconómicamente avanzados ${ }^{121-125}$. Los demás datos en función de la edad y la escala encajan dentro de lo que es usual en todos los estudios militares revisados. Un dato a tener en cuenta cuando se comparan poblaciones militares y civiles son las situaciones de estrés. Por ejemplo, estudios en despliegues en situación de combate han demostrado que se incrementa, de una manera apreciable, el número de fumadores, no solo entre los militares de tropa, sino también entre el personal sanitario y de otros servicios y, sin diferencias apreciables entre sexos o escalas ${ }^{124-126}$.

Sin embargo, lo realmente interesante de este estudio, en relación con el hábito del tabaquismo, es que en ambas visitas, ya partimos de la base que el número de no-fumadores es inferior al de fumadores para todas las escalas, sexos y edades. Y, sobre todo, que después del examen y las recomendaciones dadas por el odontólogo en la primera visita el número de fumadores disminuyó en el entorno del 15\% (exfumadores). Esto hace que en la segunda visita la suma de no fumadores y exfumadores para hombres y mujeres se hayan aproximado muchísimo. Además, las repercusiones en el estado de la salud oral, al dejar el tabaco, se vieron reflejadas ya en algunos sujetos. Sin embargo, así como para ver los efectos del tabaco en la salud general se necesita un periodo algo más largo de análisis, unos 10 años $^{115}$, para poder confirmar que, efectivamente, al dejar de fumar se produce una mejora general de la salud oral se necesita un periodo temporal incluso más grande.

En la Figura 6.4 y en la Tabla 6.4a del anexo se presentan los datos recogidos sobre la frecuencia de visitas al dentista. Estos datos tienen, mucho que ver, con la salud bucodental, ya que las revisiones rutinarias son el mejor método para prevenir y poder detectar de forma temprana las alteraciones que puedan surgir en la cavidad oral ${ }^{127,128}$. En este estudio, con el diagnóstico general de la primera visita se les recomienda incrementar las visitas al dentista a aquellos que no lo hacían. Se observó en todos los colectivos un importante incremento, alcanzando el valor máximo en el caso de oficiales y suboficiales. Resultado que está de acuerdo con otros estudios relacionados con el nivel cultural de los sujetos y con el hecho de que son las directivas del odontólogo las que tienen el mayor efecto en los comportamientos de higiene oral ${ }^{104}$. Por ejemplo entre los sujetos que van esporádicamente al dentista, nunca o solo con clínica, se ha podido constatar que algunos, en un proporción similar a otros estudios ${ }^{127,129}$, actúan así por miedo (ansiedad) al dentista. En nuestro estudio un buen número 
de sujetos con un cambio de actitud grande, aumentaron la frecuencia de visitas al dentista, como en el caso de la tropa, dónde el nivel cultural se les presupone mas bajo. Hecho que confirma la apreciación anterior sobre la influencia del odontólogo.

nunca $\square$ esporadicamente $\square$ periódicamente $\square$ solo con clínica

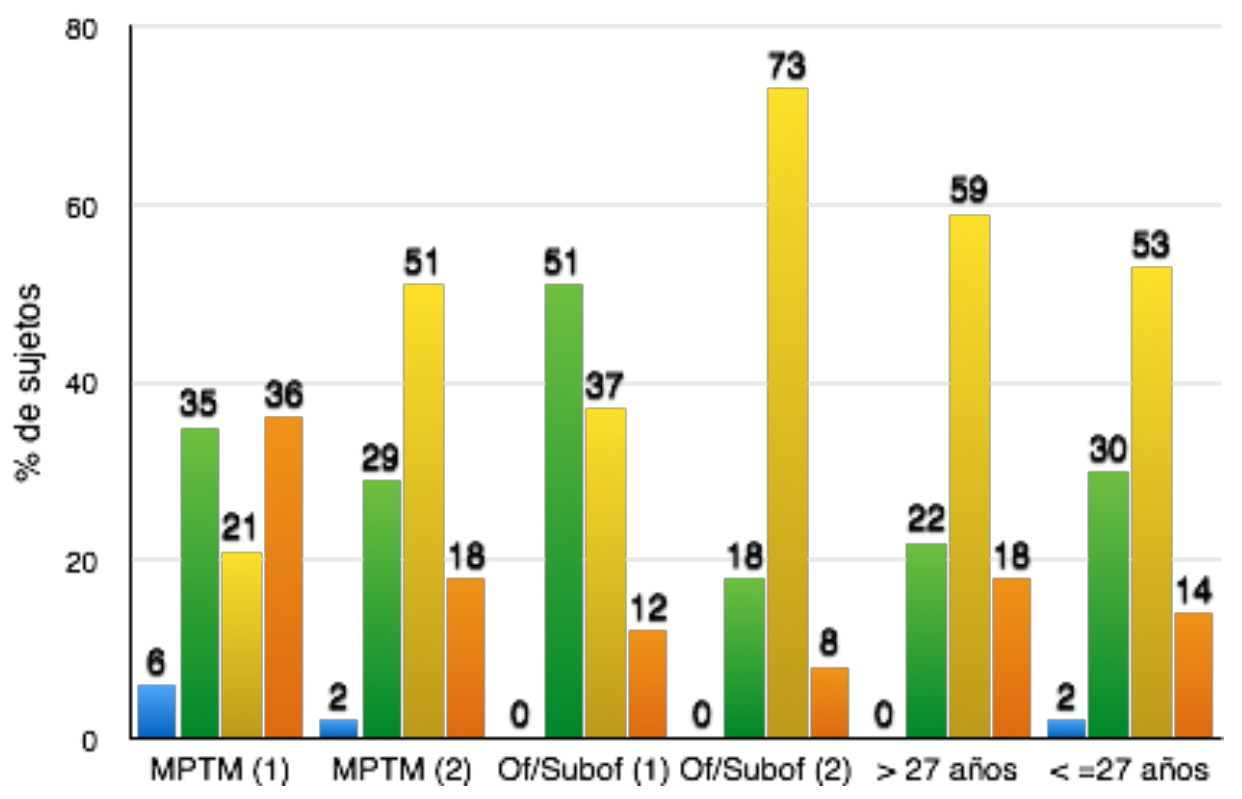

Figura 6.4.Variación en la frecuencia de visitas al dentista entre las dos tomas de datos ((1) y (2) para MPTM y of/subof. Los datos relacionados con la edad corresponden a la segunda visita.

En definitiva, si comparamos los resultados de nuestro estudio con la prospectiva de la salud bucodental en España $2020^{14}$ se encuentra que la muestra estudiada se mantiene en unos porcentajes algo superiores a los que se marcan como objetivo para esa fecha (al menos el 52\%). Este dato es una clara manifestación de la eficacia de un continuado y exigente programa de actuación sobre la salud bucodental que, además, en la muestra estudiada, está fortalecido por la necesidad de conseguir el grado de aptitud dental de este personal para poder acudir a misiones y operaciones internacionales. 


\subsection{Estado de la articulación témporo-mandibular, presencia de bruxismo, utilización de férulas oclusales y presencia de torus mandibulares}

En la muestra estudiada no se han encontrado diferencias notables en el estado de la articulación temporo-mandibular (ATM) entre las dos visitas. En lo que se refiere a desordenes (dolor o disfunción) de la ATM, un estudio detallado es algo muy complejo que queda fuera de los objetivos de este trabajo. Una de las clasificaciones más utilizadas es la del "Headache Classification Committee"130 la cual, sin embargo, es considerada incompleta por algunos investigadores clínicos ${ }^{131}$. Debido a la complejidad clínica y funcional de la ATM está claro que a la hora de hacer comparaciones hay que tener en cuenta que diferentes criterios clínicos conducirán a resultados no superponibles. En este estudio se han tenido en cuenta, la ausencia de síntomas y tres signos: la presencia de chasquidos, la movilidad reducida de la mandíbula y el dolor a la palpación.

El primer resultado a reseñar es que, en la muestra estudiada, no se ha encontrado ningún caso de los que requiere hacer uso de la sub-especialización a la que hacen referencia algunos autores ${ }^{132,133}$. En nuestro caso se puede decir que si extrapolamos la muestra estudiada a la población general, el número de alteraciones que requieren operación es ligeramente inferior a los encontrados por otros autores ${ }^{134}$. En nuestra muestra en la primera visita, observamos que un 9\% de los sujetos estudiados presentaba algún síntoma y en la evaluación de la ATM apreciamos un $8 \%$ de sujetos que presentaba chasquidos y un solo caso con dolor a la palpación. Ningún sujeto examinado tenía movilidad reducida de la mandibula. Fue casi idéntico lo que apreciamos en la segunda visita excepto que un caso de los que presentaba chasquidos paso a tener movilidad reducida de la mandibula en el momento de la exploración.

La presencia de chasquidos es el signo que más hemos apreciado, siendo ligeramente mayor en las mujeres, en la escala de oficiales y suboficiales y en el grupo de menor edad. Si comparamos nuestros resultados con lo observado en las encuestas de salud oral realizadas en España ${ }^{15,106}$ las cifras en el 2000 eran del $11 \%$ en el 2005 del 14\% en 2010 del 10,2\% y el 13,3\% en 2015. Datos cercanos 
a los recogidos por nosotros. Pero en lo que a signos detectados se refiere, apreciaron signos en un $29 \%$ un $24,5 \%$ y un $30 \%$ en las sucesivas encuestas de salud oral, porcentajes mucho mayores a los diagnosticados por nosotros. Aunque si coincidimos en la detección del chasquido como signo más prevalente (en nuestro caso el 8\%).

Evidentemente, estamos hablando del análisis de un colectivo concreto al que se le aplicaron ciertos criterios de salud general y oral para su selección. De hecho para poder acceder a una plaza dentro de las FAS los candidatos no deben presentar alteraciones graves de la ATM, lo cual seria un motivo de exclusión. Este es un motivo para entender la gran diferencia en la presencia de alteraciones de la ATM, entre la población general española y la de nuestro estudio.

En la Figura 6.5 se puede observar que el número de sujetos con ausencia de signos y síntomas de disfuncionalidad es superior al $90 \%$. En cuanto a la escala, los oficiales y suboficiales presentaron alguna alteración mas en la primera visita $(18,7 \%)$ con respecto a la segunda $(10,8 \%)$, en la que se redujeron dichas alteraciones debido al ligero aumento de MPTP que ascendió a la escala de suboficiales y nos modifico esos valores. En cuanto a los desórdenes, la misma figura y la tabla $6.5 \mathrm{a}$ del anexo indican que la presencia de chasquidos es la alteración a considerar. De los otros dos factores solo se encontró un sujeto con dolor a la palpación y otro al que se le detectó una movilidad reducida de la mandibula en la segunda visita. En ambos casos se recomendó acudir a un especialista, por prevención, para tratar de mejorar esas alteraciones, a pesar de que hasta el momento de las revisiones no les afectaba a su calidad de vida. De acuerdo con otros estudios ${ }^{135-137}$ no se encontraron diferencias entre sexos o edades. En cuanto a los sujetos con signos de dolor se puede decir que está por debajo del $0,7 \%$ el cual está en la parte baja de los estudios que dan una horquilla entre el $0,3 \%$ y el $10 \%{ }^{135,138}$. Por ejemplo en un estudio anterior sobre militares españoles encontraron un $4,4 \%{ }^{110}$.

En cuanto a los sujetos con presencia de chasquidos, se observa que su número es prácticamente el mismo entre la primera y la segunda visita, excepto el caso de la escala de oficiales y suboficiales que vuelve a tener un comportamiento anómalo respecto a la tropa, debido a ese cambio de escala de algunos sujetos antes mencionado. En este caso también disminuyo la incidencia entre la primera y segunda visita. Debido a que parece que hay una fuerte correlación entre el dolor de cabeza y disfunciones como el chasquido o el dolor durante el movimiento mandibular ${ }^{140}$ se examinó este dato pero el resultado no ha sido significativo, probablemente debido al tamaño reducido de la muestra, ya que 
estamos hablando de solo un $15 \%$ de un total muy pequeño. El que corresponde a escala de oficiales y suboficiales.

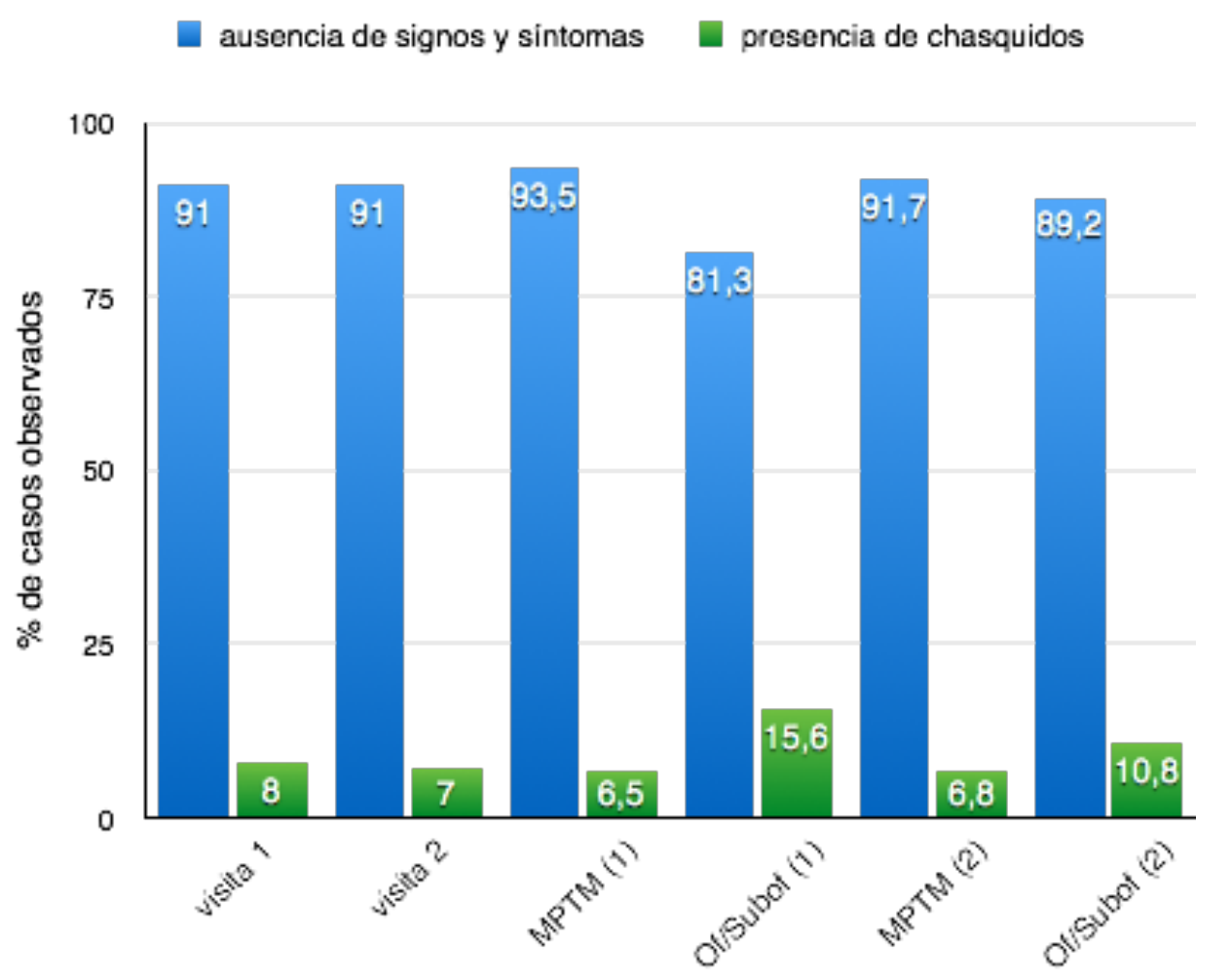

Figura 6.5. Estado de la articulación témporo-mandibular. Además de los síntomas que aparecen en la figura se ha examinado el dolor a la palpación y la movilidad reducida de la mandíbula que, al ser sus porcentajes muy pequeños, no se observan en el gráfico, sin embargo se comentan en el texto.

Okeson $^{99}$ define bruxismo como el golpeteo o el rechinar de los dientes de forma inconsciente y no funcional. Está asociado a dos momentos: Por un lado el apretamiento diurno (bruxismo despierto) que parece ligado a factores psicológicos como el estrés o la ansiedad ${ }^{141}$, o el bruxismo del sueño (dormido) que podría estar asociado al consumo de alcohol, tabaco, café e, incluso, a ciertas drogas ${ }^{142-144}$. Por otro lado está la posible asociación entre las diferentes manifestaciones de bruxismo y el dolor del desorden de la $\mathrm{ATM}^{145-147}$. Como se observa, las consecuencias del bruxismo pueden afectar, notablemente, la aptitud de los miembros de las fuerzas armadas para los servicios en general, pero sobre todo, para los servicios especiales. En el presente estudio se encuentra que el número de sujetos con dolor en la ATM (Figura 6.5) es mucho más pequeño que el de aquellos que presentan síntomas de bruxismo (Figura 6.6), por lo que se puede decir, que aún admitiendo la interacción entre ambas patologías el grupo estudiado estaría entre los que no presentan dolor en la ATM. 
En la Figura 6.6 se observa que no se producen variaciones entre las dos visitas manteniéndose un porcentaje alrededor del $8 \%$. El cual es mayor en los hombres y es de reseñar el hecho de que los mayores de 27 años presentan una incidencia de bruxismo ligeramente superior que los de menos edad. Lo mismo sucede con la escala de oficiales y suboficiales respecto a la clase de tropa. Los dos resultados estarían de acuerdo con la idea de que la prevalencia del bruxismo se incrementa con la edad ${ }^{148}$. También es importante comentar que en la Figura 6.6 se muestra que la prevalencia de bruxismo, en este estudio, coincide, más o menos, con el límite inferior de los resultados encontrados en estudios de la población general ${ }^{149}$, los cuales indican que la incidencia de esta patología está entre el $8 \%$ y el $31,4 \%$.

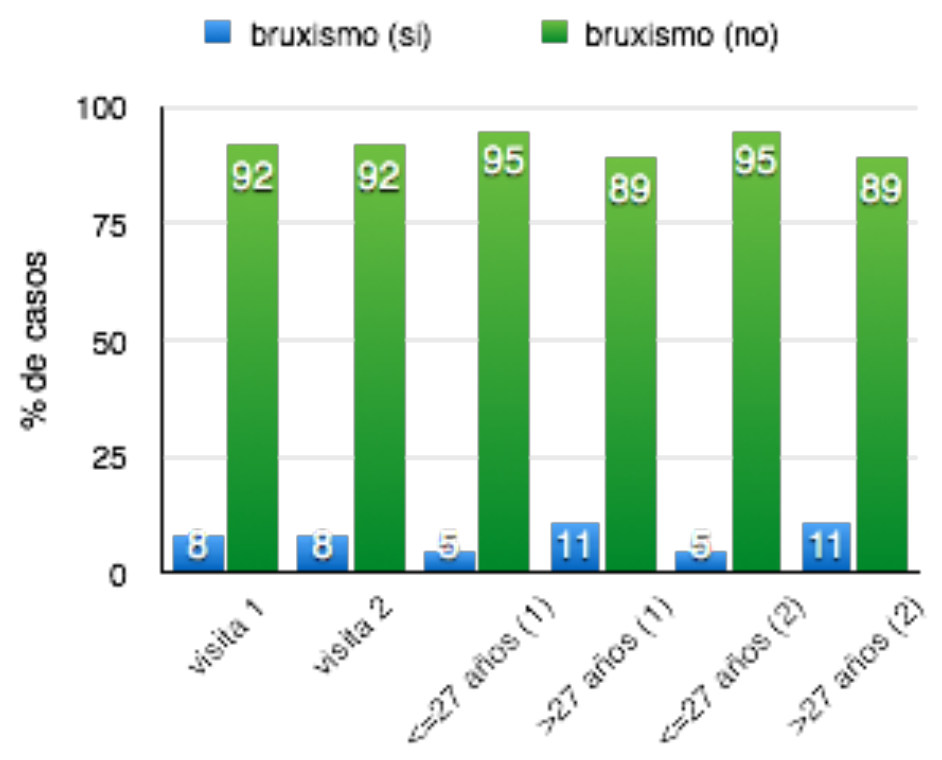

Figura 6.6. Tanto por cien de los sujetos que presentan bruxismo en la primera y segunda visita. Se muestran dos datos. Uno correspondiente al número total de sujetos estudiados y el otro en función de las edades.

En una reciente revisión de literatura ${ }^{150}$ concluyen que las férulas oclusales tienen un efecto positivo en la resistencia al desgaste y fractura de los dientes. Entre los estudios sobre sujetos que presentan este tipo de aparatos ${ }^{151}$ existen grandes discrepancias entre unos y otros, ya que depende del país, dentro del país, de la región y dentro de la región, si son urbanos o rurales. Como se puede ver en la Figura 6.7 la incidencia de férulas oclusales en la población estudiada 
es pequeña, pero es de reseñar que aumenta casi al doble en la segunda visita (4\%). Aumentan en un caso las de mantenimiento y en dos las de descarga. Las férulas de descarga son las indicadas en pacientes con bruxismo, mientras que las de mantenimiento son las utilizadas posteriormente a un tratamiento de ortodoncia. Los individuos por norma general son reticentes al uso de férulas porque en muchos de los casos acuden a la consulta sin molestia alguna y el odontólogo se la recomienda en base a lo que observa y a futuras complicaciones, que pueden surgir. El personal militar portador de férulas oclusales en ningún caso tendrá problemas de aptitud dental para ir de misión, puesto que la patología que tuviera estaría controlada.

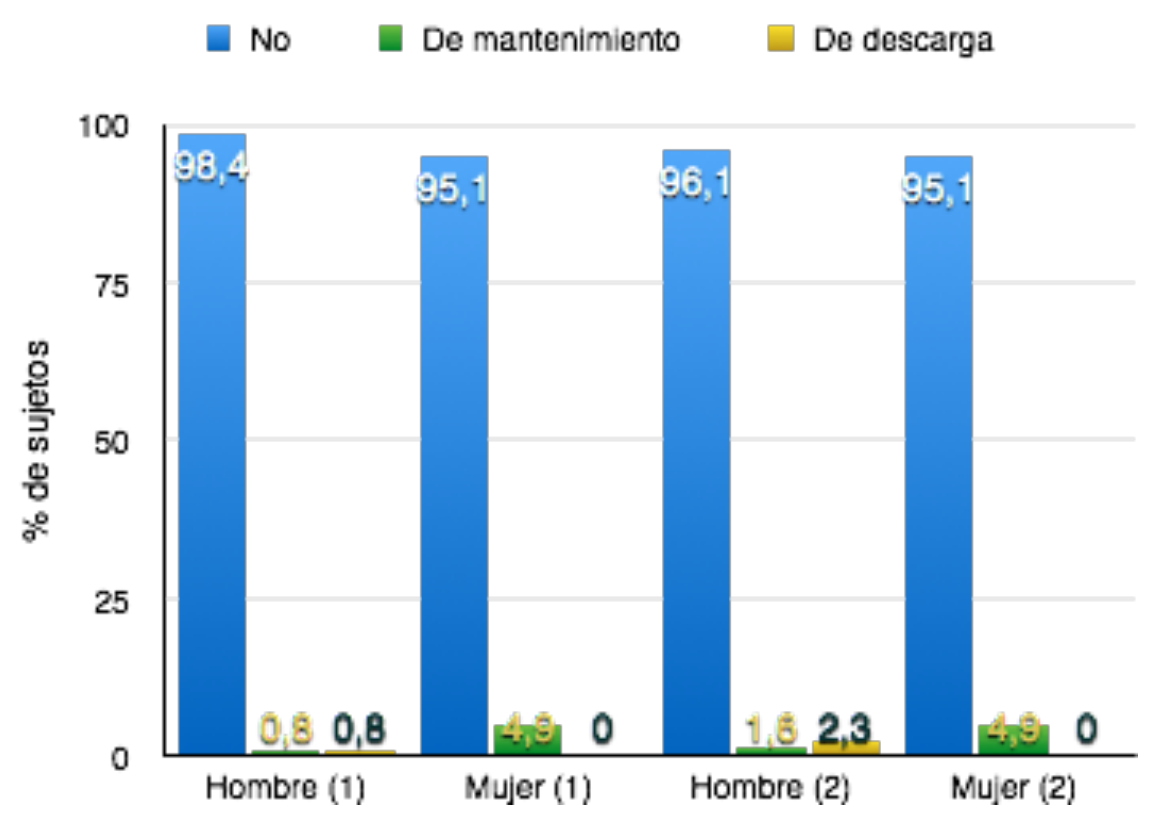

Figura 6.7. Presencia de férulas oclusales en función del sexo entre las dos visitas. Se indican los porcentajes de los sujetos que no presentan férulas y los que las tienen, pudiendo ser de mantenimiento o de descarga.

La presencia de torus mandibulares es rara en la primera década de vida, pero luego se desarrolla con la edad e incluso se sugiere que continúa su desarrollo hasta el comienzo de la senectud, momento en el que deja de crecer pero no se reabsorbe ${ }^{152,153}$. El resultado del presente estudio indica un valor cercano al $8 \%$ porcentaje que no experimenta ningún cambio entre la primera y la segunda visita (ver Tabla II.2d y las del capitulo de resultados). En lo que se refiere a la distribución por escala, sexo y edad se debe indicar que se observo mas en los MTPM y en los menores de 27 años. En donde se encuentra una mayor diferencia es por sexos siendo mas frecuente en los hombres, tal y como se 
indica en la Figura 6.8. En la literatura se encuentran los tres tipos de resultados: preponderancia en hombres ${ }^{154}$, preponderancia en mujeres ${ }^{155}$ y diferencias insignificantes en la prevalencia entre hombres y mujeres ${ }^{156}$. Incluso en un mismo estudio sobre dos poblaciones de dos islas se han encontrado diferencias en una de las poblaciones y similitud de prevalencia en la otra ${ }^{157}$. Además, otros parámetros utilizados como la alimentación, la raza, etc., no pueden ser aplicados al presente estudio para explicar las diferencias de la prevalencia de torus mandibulares en función del sexo. En cualquier caso es interesante reseñar que el número de estudios recientes sobre esta prevalencia en Europa es más bien escaso.

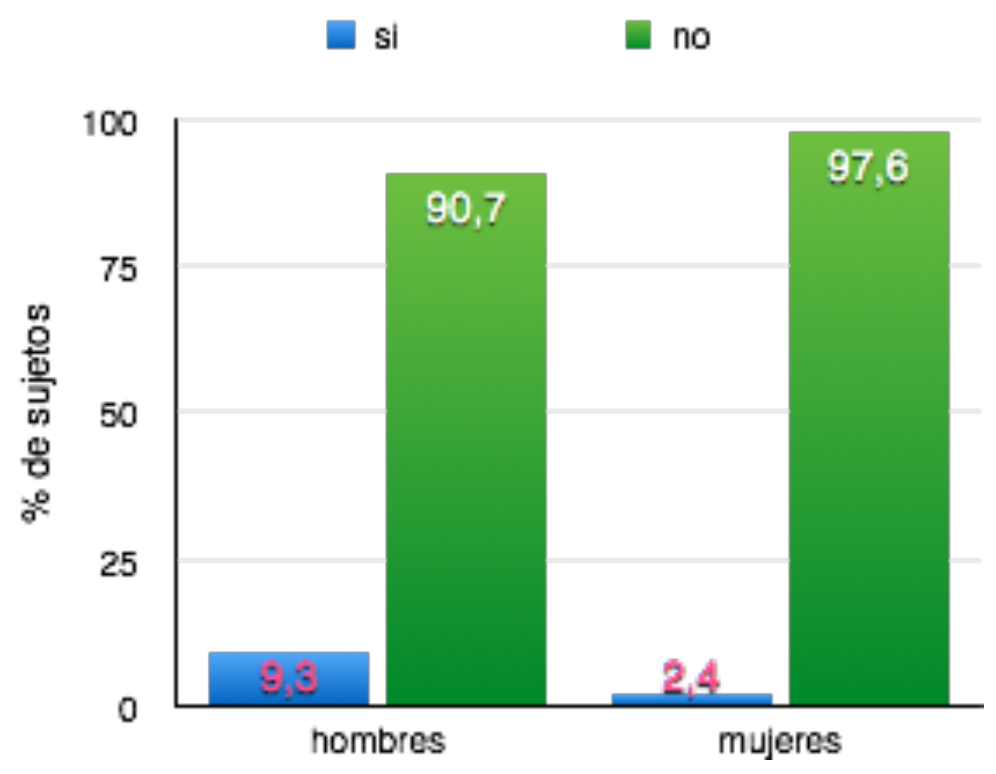

Figura 6.8. Diferencia en la prevalencia de torus mandibulares entre hombres y mujeres.

\subsection{Opacidades e hipoplasias del esmalte y tinción por tetraciclinas}

Tanto la clasificación como el diagnóstico de los defectos en el desarrollo del esmalte es complicado de realizar y a menudo pasan inadvertidos. Además, 
revisiones y modificaciones de los índices utilizados ${ }^{158,159}$ dificultan sobremanera el desarrollo de programas y políticas de salud asociadas a su presencia. Por eso en nuestro estudio hemos utilizado, siguiendo las recomendaciones de la $\mathrm{OMS}^{12,13}$, el índice de desarrollo de defectos del esmalte (DDE) modificado para aquellos defectos a los que no se les puede asignar una causa o etiología concreta y, simplemente, se describen las alteraciones clínicamente visibles en el esmalte, debidas a cambios ocurridos durante la biomineralizacion o durante la secreción de la matriz del esmalte.

En cuanto a la prevalencia de estas alteraciones, la bibliografía revisada muestra resultados bastante variables, y la mayoría de estudios son sobre población infantil, debido a que es en edades tempranas cuando suelen hacer presencia y aparecen las preocupaciones, porque los DDE se asocian sobre todo a aumento de caries, fracturas dentales e hipersensibilidad dentinal, algo que también debemos tener en cuenta en nuestra población de estudio a la hora de valorar su grado de aptitud dental ${ }^{17,81}$, aunque estas alteraciones por norma general no son definitivas en la valoración.

De acuerdo con la Figura 6.16, de los sujetos examinados en la muestra solo un $12 \%$ presentaba alguna alteración en la primera visita, cifra que se mantuvo igual en la segunda.

Las alteraciones más observadas fueron las opacidades difusas, luego las delimitadas y en tercer lugar las hipoplasias y otros defectos, que se correspondieron con aquellos defectos que no pudimos clasificar fácilmente entre los otros tres tipos básicos.

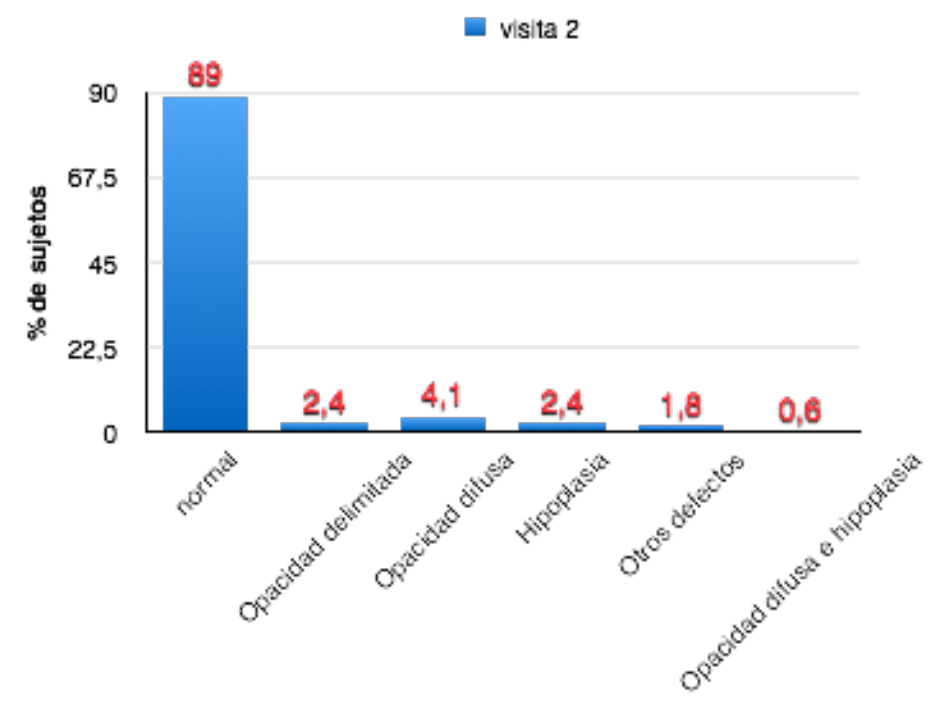

Figura 6.16. Porcentaje de opacidades e hipoplasias del esmalte. Solo aparece la segunda visita debido a que los datos coinciden completamente con la primera. 
En la segunda visita solo se produjeron ligeros cambios, no significativos, en función de la escala, debido al ascenso de alguno de los sujetos de tropa a la escala de suboficiales. Tampoco fue significativo en cuanto al sexo y la edad aunque el valor de los índices de defectos ha sido ligeramente mayor para las mujeres y para los mayores de 27 años. La Figura 6.17 muestra esta diferencia entre hombres y mujeres, observándose que la mayor diferencia se da en la opacidad difusa la cual está presente en un 4,9\% de mujeres y solo en un 3,9\% de hombres.

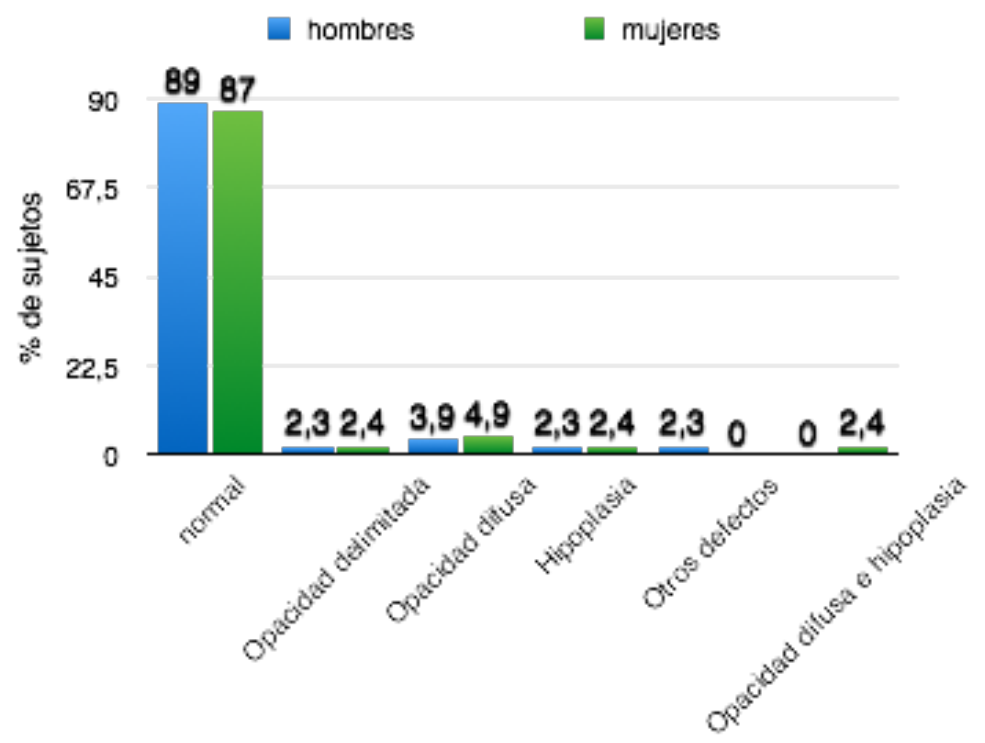

Figura 6.17. Porcentaje de opacidades e hipoplasias del esmalte en función del sexo.

En la literatura ${ }^{160}$ se encuentra que para una muestra algo mayor que la de este estudio un $23 \%$ de los sujetos presentaba, al menos, un defecto o alteración de la superficie del esmalte. Además la mayor prevalencia corresponde a las opacidades que, sumándolas todas les da un 93\%. Cifra algo superior a la de nuestro trabajo que está en el $71 \%$. Aquí, debido a que los valores de la proporción de cada índice son pequeños y si la muestra no tiene el tamaño adecuado, se pueden introducir errores importantes. También, en concordancia con nuestros resultados, las mujeres tienen una ligera mayor prevalencia que los hombres. Resultados similares fueron encontrados por otros investigadores ${ }^{161}, \mathrm{y}$ en todos ellos con una ligera mayor prevalencia entre las mujeres.

Las alteraciones de color por tetraciclinas no son en ningún caso, causa de baja por aptitud dental. Sin embargo, al valorar en nuestras exploraciones los DDE nos aparecieron algunos casos con este tipo de tinción, que a su vez pueden estar implicadas en las hipoplasias del esmalte de dientes temporales y permanentes. 
Por ello nos pareció correcto añadirlo en nuestro estudio al objeto de ver su prevalencia y explicar a los sujetos examinados los tratamientos restauradores que podrían realizarse y sobre todo para que las políticas de salud bucodental hagan hincapié en la prevención de estas manchas en edades tempranas.

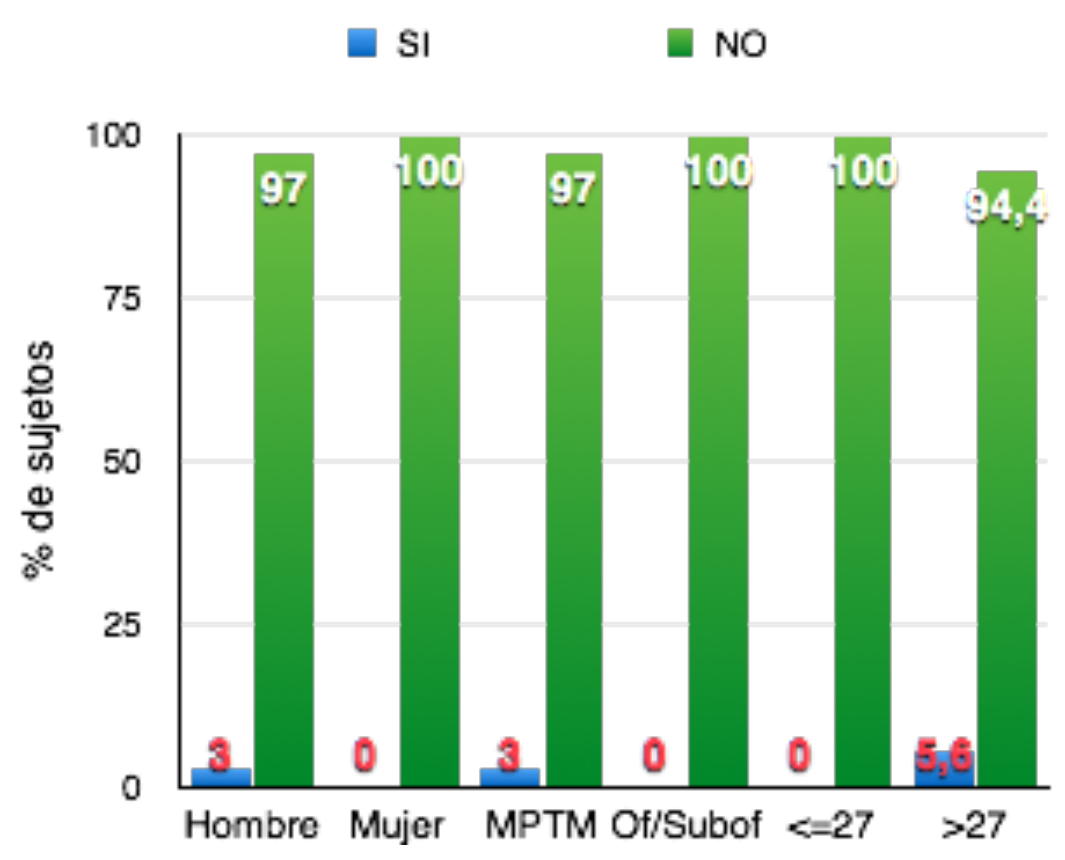

Figura 6.18. Porcentaje de las alteraciones de color por tetraciclinas en función del sexo, la escala y la edad. Los datos fueron los mismos en la primera y en la segunda visita.

Las tetraciclinas se han utilizado para el tratamiento de infecciones comunes, tanto en niños como en adultos y pueden afectar tanto la dentición temporal como la permanente, dependiendo de cuándo se administre el antibiótico. Sin embargo, se ha observado que la dentición permanente se tiñe con menor intensidad, aunque más difusamente que los dientes temporales ${ }^{162}$.

La coloración puede variar desde amarillo a gris, pasando por marrones, lo cual dependerá del estado de mineralización del diente, de la dosis, del tipo de tetraciclina y de la duración del tratamiento. Hay por ello una clasificación según el grado de afectación ${ }^{163}$. Pero nosotros, como ya comentamos en el apartado de material y métodos, solo anotamos si el sujeto estudiado presenta tinción, con independencia del grado y gravedad de la tinción dental.

En nuestra muestra encontramos un 2,4\% que presenta esta tinción dental. Y se da en los hombres englobados en la escala de tropa (MTPM) y mayores de 27 años. En general, la tinción con tetraciclinas se observa solo en adultos debido a que, actualmente ${ }^{161}$, ya no se recomienda durante el embarazo, ni para niños. La 
terapéutica ante este tipo de coloración puede variar desde un blanqueamiento en los casos menos severos hasta tratamientos protésicos en los casos más graves.

\subsection{Estado periodontal y la necesidad de tratamiento y presencia de pendientes en labios y lengua}

Los datos epidemiológicos del 2010 de la Encuesta de Salud Oral en España ${ }^{15}$ muestran que las enfermedades periodontales siguen siendo muy prevalentes en la población española. El porcentaje de sujetos sin ningún signo de enfermedad fue del 16\% para adultos jóvenes (cohorte 35-44 años). En nuestra muestra observamos (Tabla 6.11a) que, con carácter general, el número de sujetos sanos es del $14,7 \%$ en la primera visita y del $35,9 \%$ en la segunda. Este segundo dato se acerca al porcentaje que se espera tener en el año 2020 según el estudio prospectivo de la salud bucodental en España $2020^{14}$. Esto es debido en gran medida a la mejora de los hábitos de salud oral y al aumento de la frecuencia de visitas al dentista que se produce en la segunda visita de nuestra muestra y que ya se expuso en el apartado correspondiente. Es interesante reseñar que la proporción de sujetos sanos de nuestra primera visita casi dobla a los indicados en otro estudio anterior sobre una muestra de militares españoles ${ }^{110}$. Dato que también es mejor que el porcentaje de la población mundial que, con datos hasta el 2008, se estimaban entre $0 \%$ y $10,5 \%{ }^{158-167}$. Sin embargo, todos estos datos deben mirarse con cierta cautela debido a que de acuerdo con una revisión crítica de los estudios periodontales, realizados con carácter global, concluyen que muy pocos de los estudios epidemiológicos usan muestras nacionales representativas y, la mayoría, utilizan criterios dispares para decidir si el paciente tiene enfermedad periodontal moderada o extrema ${ }^{166,168}$.

Con el fin de poder analizar algunas de las posibles causas de la enfermedad periodontal, a partir de datos comparativos, se ha elegido un estudio que utiliza una muestra de la población de California que presentaba un porcentaje de enfermedad periodontal cercano al de nuestra primera visita $(9 \%)$ pero muy inferior a lo que observamos en nuestra segunda cita $^{169}$. La muestra, sociológicamente, está muy mezclada por su origen (hispanos, asiáticos, negros, etc), por su formación (desde la escuela hasta graduados), por sus ingresos y por el conocimiento del inglés y en un rango de edad más extenso que el utilizado por nosotros. La proporción que dan del $9 \%$ es próximo, pero aún así superior, al encontrado para la población general americana para edades de 30 años y 
mayores ${ }^{170}$. También, como ocurre con nuestro estudio, muestra discrepancias importantes con otros estudios en los que se ha acotado la elección de la muestra $^{171}$.

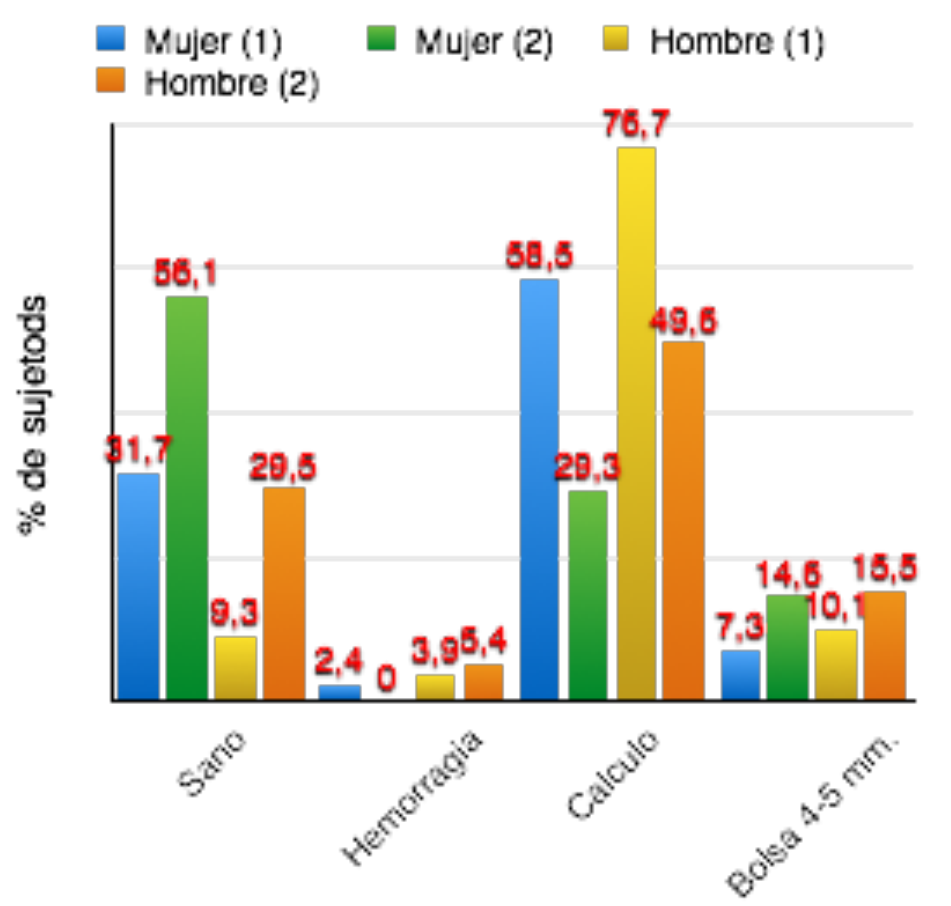

Figura 6.9. Estado periodontal entre la primera (1) y la segunda (2) visita para los hombres y las mujeres del estudio.

Pero, volviendo a California, las discrepancias con nuestro estudio podrían estar asociadas a los llamados factores de riesgo o a características especiales entre las diferentes poblaciones estudiadas. Por ejemplo, con el número de fumadores o ex-fumadores o con la raza o la genética. Así, si nos fijamos en el tabaquismo, la comparación entre los datos de la Figura 6.3 y los de las referencias [169] y [171], se encuentra que para hombres la muestra del presente trabajo tiene mayor número de fumadores $\mathrm{y}$, tanto para mujeres como para hombres, el número de ex-fumadores es también mayor. Por tanto el tabaco no parece ser una causa excesivamente importante. Puede colaborar a la enfermedad periodontal pero no parece ser una causa primaria. Otro aspecto podría ser el nivel de estudios. Sin embargo, si tenemos en cuenta que, en el presente estudio, los oficiales se pueden asimilar a graduados y los suboficiales a una formación intermedia, la suma de las dos escalas es del $19 \%$ y en los de las referencias anteriores la suma de graduados y título intermedio es del 20,3\% (Figura 6.10). Por tanto tampoco el factor cultural parece ser excesivamente decisorio. Si se tiene en cuenta el sexo, el número de mujeres en este estudio es muy inferior a 
los de California y Carolina del Norte y EEUU que rondan el 50\%. Si además se tiene en cuenta que el número de sanos entre las mujeres es mucho mayor que entre los hombres (Figura 6.9), este factor actuaría negativamente. Lo mismo ocurre con el factor edad (Figura 6.11).

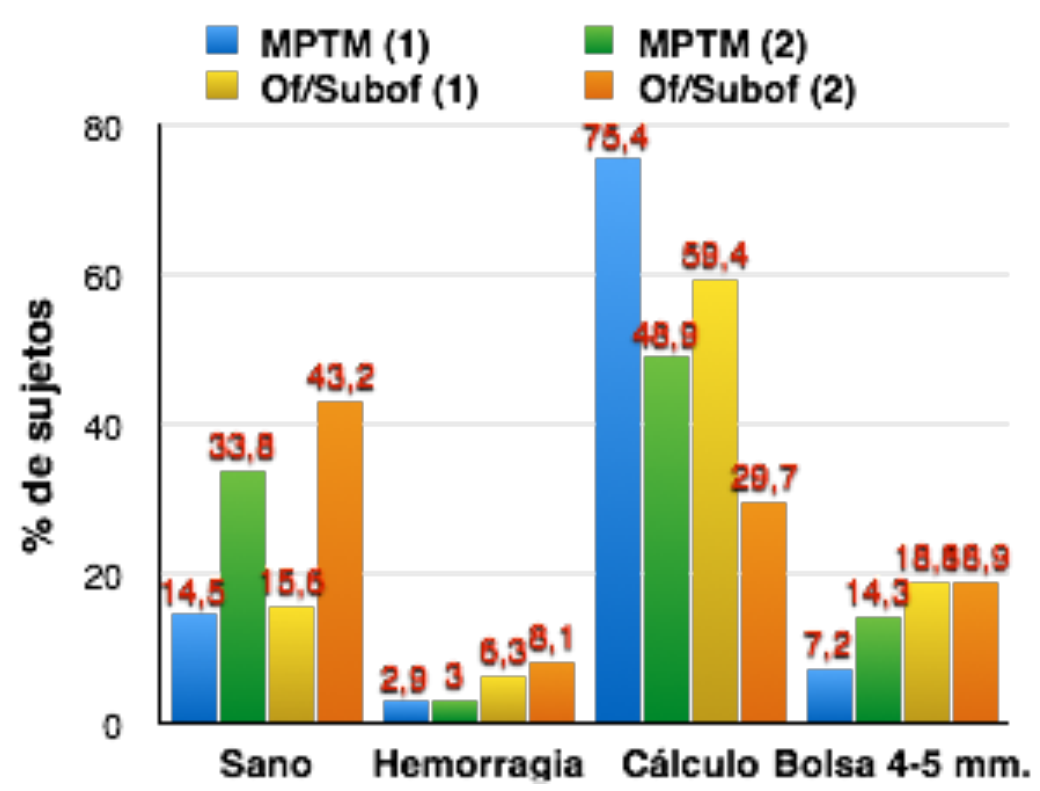

Figura 6.10. Estado periodontal entre la primera (1) y la segunda (2) visita para las dos escalas: MPTM y of/subof.

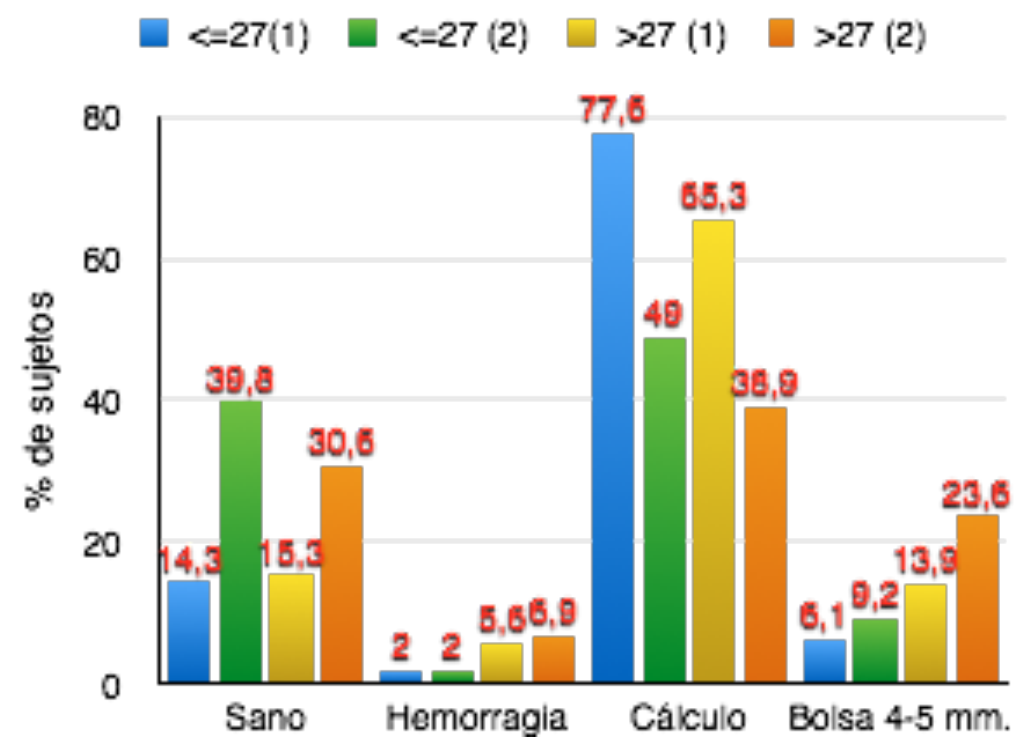

Figura 6.11. Estado periodontal entre la primera (1) y la segunda (2) visita en función de la edad. 
Por tanto, si a esta discusión se le añaden las diferencias entre la primera y la segunda visita, que aparecen reflejadas en las tres figuras anteriores, encontramos que el factor educacional así como el sexo, en relación con la importancia de la salud oral, podrían ser algo más determinantes que los demás. El incremento de la proporción de sujetos sanos en función del factor educacional, entre las dos visitas, es mucho más alto en la población del presente estudio que en otras poblaciones. Este resultado parece ser un determinante común en nuestro trabajo y es también comentado por otros autores ${ }^{169,172}$.

La hemorragia en los más jóvenes es mucho menos prevalente que en los de más edad y lo mismo sucede con respecto a las bolsas. En nuestro caso, a diferencia de otros estudios ${ }^{108,110,173}$, no se detectó la presencia de bolsas profundas en ninguna de las visitas. El comportamiento de ambos, hemorragia y bolsas, con independencia de los datos numéricos, es común a, prácticamente, todos los estudios examinados de poblaciones civiles ${ }^{108,173}$. Estos índices en la población militar son más variables y oscilan entre los autores que dan para la hemorragia valores por debajo del $10 \%$ hasta los que superan con creces este dato $^{174177}$. Por este motivo es difícil establecer comparativas. En general se aprecia un deterioro de estos índices de salud periodontal con la edad.

En nuestra muestra el 72,4\% presentó cálculo en la primera visita y el 44,7\% en la segunda, con valores inferiores en esta visita a la prevalencia de cálculo (sin bolsas) de la Encuesta de Salud Oral en España $2010{ }^{15}$ que da un valor del 53\% en la cohorte de 35-44 años. Además, esta encuesta dice que el 11\% de los adultos jóvenes presentó bolsas periodontales poco profundas, y el 5\% profundas, mientras que nosotros encontramos, en la primera visita, un porcentaje del $9,4 \%$ de bolsas $4-5 \mathrm{~mm}$ (poco profundas) y no observamos bolsas profundas. En la segunda visita este porcentaje de bolsas de $4-5 \mathrm{~mm}$ fue algo mayor $(15,3 \%)$ debido en gran medida al aumento de edad de los sujetos examinados (nueve años mas), y tampoco observamos bolsas profundas.

En cuanto al cálculo, se observa una mayor prevalencia en hombres que en mujeres, entre los más jóvenes y entre la tropa respecto a la escala de oficiales y suboficiales para las dos visitas. Estas diferencias que aparecen muy claras en las Figuras 6.9, 6.10 y 6.11, así como en las Tablas 6.11a-14a, no aparecen tan claras en otras publicaciones, excepto en lo que se refiere al sexo. En este caso la prevalencia en varones es más alta que en mujeres ${ }^{108,110173,178}$.

En lo que se refiere a la necesidad de tratamiento periodontal como indicamos en el apartado de material y métodos, se valoró durante la exploración a medida que se estudiaba cada diente. Los que fueron diagnosticados como sanos no 
precisaron de ningún tratamiento y esto se observó en el $11.8 \%$ en la primera visita y en el $23,5 \%$ en la segunda cita. En los siguientes casos los sujetos ya presentaron alguna patología y requirieron tratamientos acumulativos desde el más básico que fueron los examinados que precisaron de instrucciones de higiene oral, que fueron el $2,9 \%$ en la primera cita y del 15,3\% en la segunda, algo que se hizo como refuerzo en aquellos sujetos que ya habían mejorado en esta visita su estado de salud periodontal . Esta proporción es muy pequeña si la comparamos con la de otros estudios civiles y militares en los que, incluso, se llega al 90\% ${ }^{108,173,176,179}$. Seguidamente están los que además necesitan una tartrectomia, debido a la presencia de cálculo, que fueron el $75,9 \%$ en la primera visita y el 45,9\% en la segunda. Y aquellos que presentaron bolsas de 4$5 \mathrm{~mm}$ que requieren, además de todo lo anterior, un raspado y alisado radicular: el 9,4\% en la primera cita y el 15,3\% en la segunda. En muchos estudios los dos tratamientos aparecen no diferenciados. En esos casos los resultados de la literatura son, mayoritariamente, inferiores a los encontrados en este trabajo para la primera visita pero superiores a los de la segunda visita ${ }^{108,173}$.

Sin embargo existen casos especiales en los cuales los resultados de la literatura se aproximan a los de la segunda visita. Por ejemplo, los estudios sobre estudiantes universitarios ${ }^{108}$. En la muestra estudiada no apreciamos ningún sujeto con bolsas de $6 \mathrm{~mm}$ o más que hubieran requerido tratamientos más complejos. Requerimientos que aparecen en pequeña proporción (2\%-5\%) en recientes estudios sobre personal militar ${ }^{110} y$ civil ${ }^{108,173}$. Sin embargo el requerimiento de estos tratamientos, hace unos años, tenía cifras significativas [11\%-17\%] y han disminuido hasta los bajos valores actuales. En cualquier caso las cohortes de más edad son las que muestran más necesidad de tratamiento.

En las Figuras $6.12,6.13$ y 6.14 se presentan los resultados de la necesidad de tratamiento periodontal comparativos entre las dos visitas en función del sexo, escala y edad. Los resultados, como debía ser, coinciden con el diagnóstico resumido en las Figuras 6.9, 6.10 y 6.11. El número de sujetos que no necesitan tratamiento o a los que solo se les dan instrucciones para mejorar su higiene es similar al de sujetos sanos. Estos números son muy elevados, sobre todo, en la segunda visita debido a que gran parte de ellos pasan de necesitar una tartrectomia a requerir solo unas mejoras en los hábitos de higiene bucal que retrasarán la necesidad de realizarse otra tartrectomia. Los datos en relación con el sexo, escala y edad siguen la misma tónica que los comentarios del párrafo anterior. 


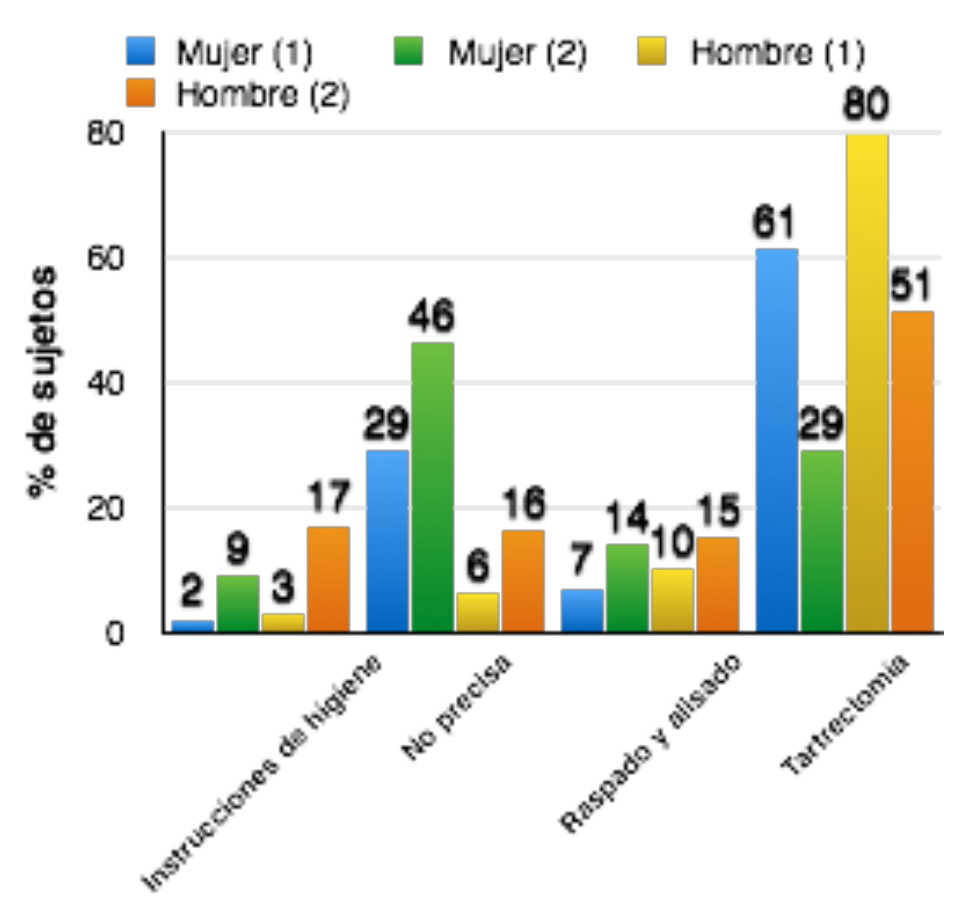

Figura 6.12. Resultados sobre la necesidad de tratamiento periodontal en mujeres y hombres para la primera (1) y la segunda (2) visita.

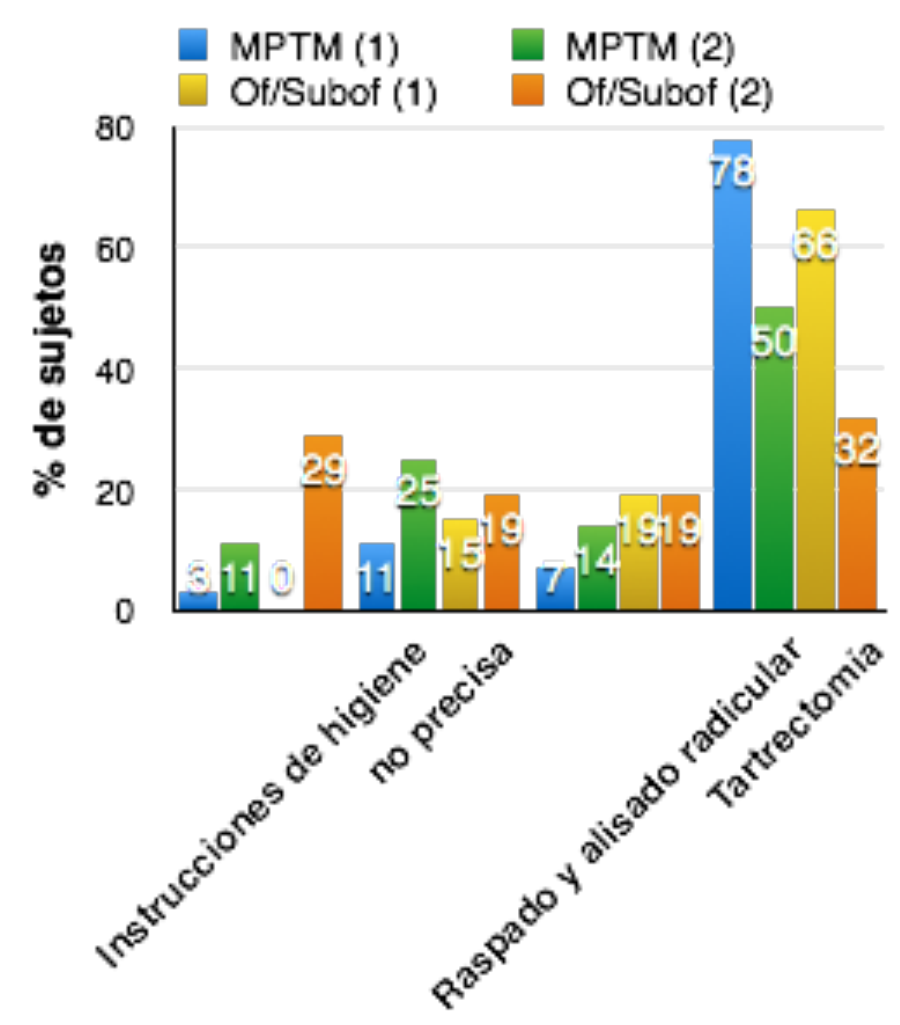

Figura 6.13. Resultados sobre la necesidad de tratamiento periodontal en las dos escalas estudiadas para la primera (1) y la segunda (2) visita. 


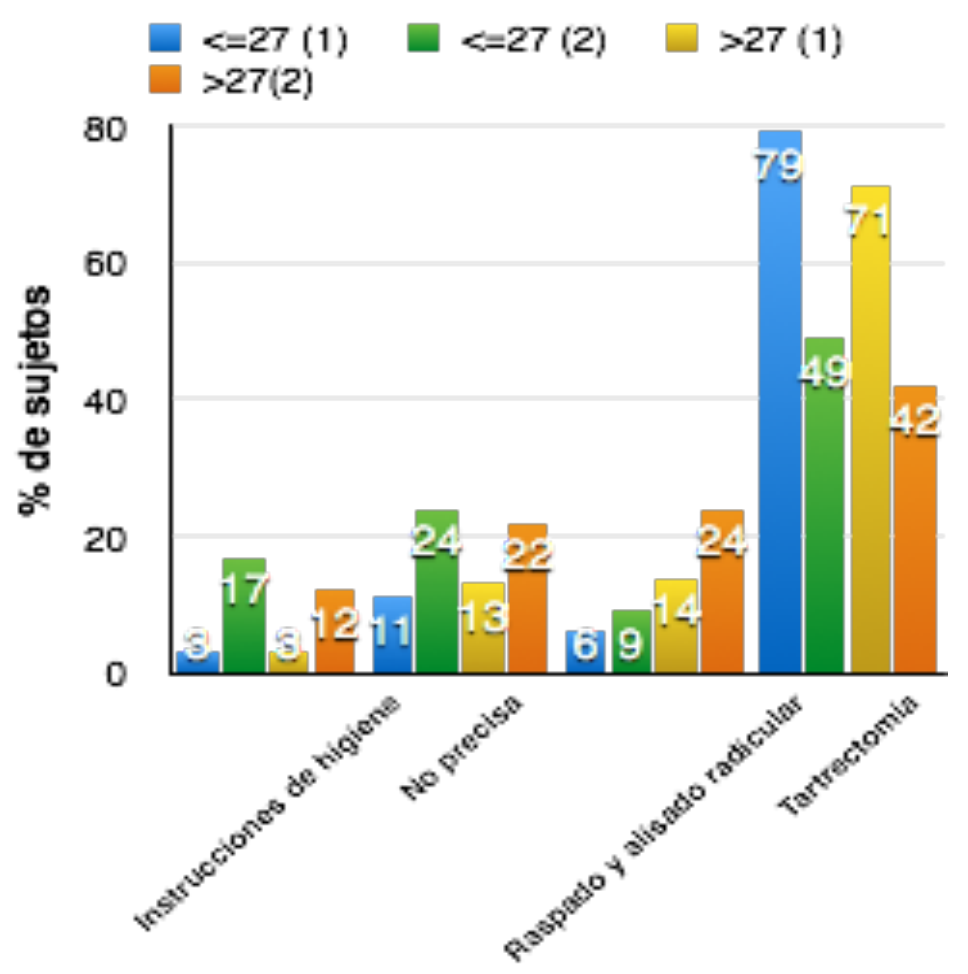

Figura 6.14. Resultados sobre la necesidad de tratamiento periodontal en función de la edad para la primera (1) y la segunda (2) visita.

En las figuras se observa que en los tres casos, por sexo, escala o edad, la tartrectomía es necesaria para un número de sujetos muy superior a los que requieren raspado y alisado radicular. Además, mientras que el número de sujetos que requiere raspado y alisado radicular se incrementa de la primera a la segunda visita, los que requieren tartrectomía disminuyen notablemente. De nuevo nos encontramos ante un proceso en el que la salud oral se ha incrementado notablemente entre las dos visitas. En cuanto a la tartrectomía se observa que el número de sujetos que la necesitan es mayor en los hombres que las mujeres, en los MPTM que en la escala de oficiales y suboficiales y entre los menores de 27 años que entre los mayores de esa edad. En lo que se refiere al raspado y alisado radicular también existen diferencias entre los tres colectivos, pero son a la inversa y con valores inferiores. También es de reseñar que el número de sujetos que requieren este tratamiento se incrementa en la segunda visita. 


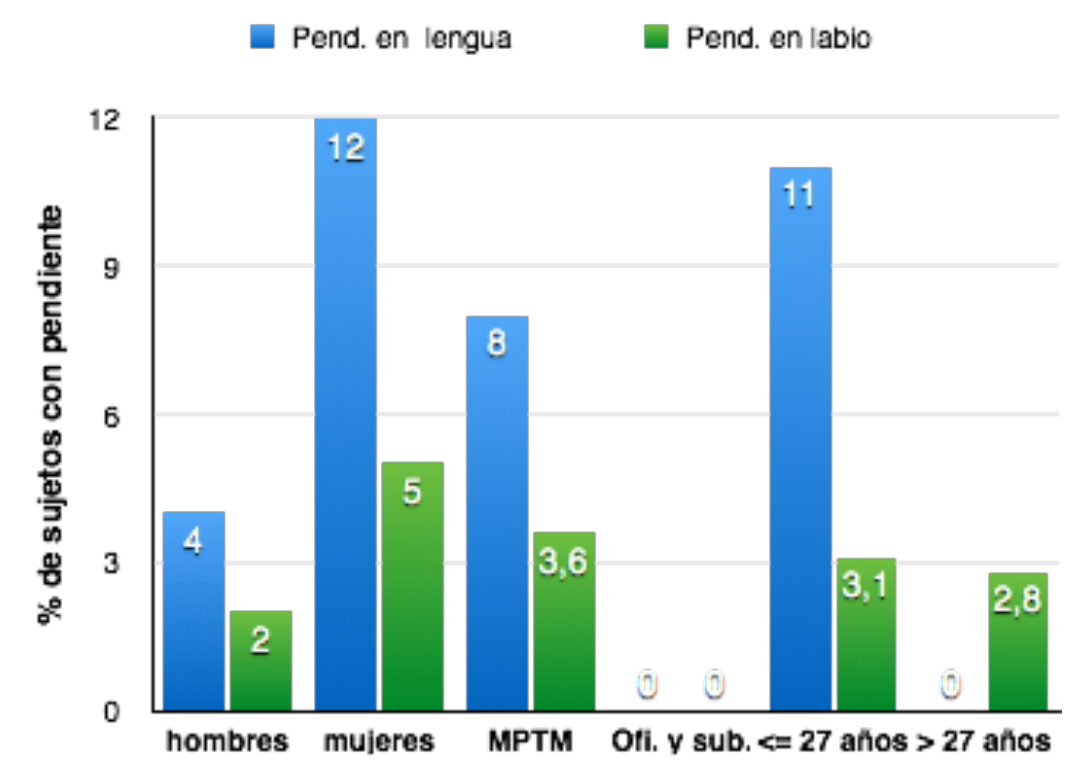

Figura 6.15. Porcentajes de sujetos con pendiente en función del sexo, la escala y la edad. Solo se muestra la primera visita debido a que no existen diferencias apreciables en la segunda.

Los pendientes (piercings) en labios y lengua se introducen en este estudio porque en los cuestionarios de salud general que se realizan en el Botiquín, aparece un elevado número de sujetos que comenta llevar pendientes en la cavidad orofacial, equiparable a la sociedad en general, a pesar de las complicaciones y enfermedades derivadas de su utilización ${ }^{183}$.

En la literatura nos dicen que la incidencia de recesiones gingivales es de un $50 \%$ en sujetos con pendientes en labio y de un $44 \%$ en sujetos con pendientes en lengua ${ }^{184}$. Otra de las complicaciones observadas en ese y otros estudios, es la cifra del $26 \%$ de fracturas en dientes por traumatismos o golpes para los que llevan pendientes en labio y del $37 \%$ para los que lo llevan en lengua ${ }^{183-188}$. Y, por supuesto, su uso aumenta el riesgo de padecer cáncer oral.

Si nos fijamos en la población joven adulta, se estima que un 5,2\% utiliza estos pendientes (varía entre un $0,8 \%$ hasta un $12 \%)^{187}$. Algo que se aproxima a lo observado en nuestro estudio en el cual, el 6,9\% de los examinados presentó pendientes en la lengua en la primera visita, porcentaje que disminuyó un poco en la segunda visita porque uno de los sujetos comentó que dejo de usarlo. En cuanto a la presencia de pendientes en el labio fue de 2,9\% en ambas visitas. Recordemos que la lengua, seguida del labio inferior, es la zona oral donde se colocan más pendientes, con una prevalencia de $81 \%$ y $38,1 \%$ respectivamente en Estados Unidos ${ }^{188}$. 
En la Figura 6.15 se indica en porcentaje el número de pendientes en función del sexo, escala y edad. Se confirma que el número de pendientes en la lengua es más frecuente en las mujeres y en cuanto a los labios también el número de mujeres que lo presentan supera al de los hombres pero con menor diferencia. En lo que se refiere a las escalas se observa que todos los pendientes reseñados los presenta la tropa (MPTM). Resultado asociado a un cambio cultural y a la edad. En la Figura 6.15 se ve que todos los pendientes de lengua están para edades inferiores a 27 años, mientras que los de labio están en proporción similar en los dos rangos de edad analizados. Este resultado coincide con otros de la literatura ${ }^{187}$ pero el promedio incluyendo hombres y mujeres está ligeramente por encima del promedio que dan para la población general del $5,3 \%$. Esta pequeña diferencia indica que en nuestro estudio, así como en los demás apartados de salud oral había un mayor control que la media general, en este caso el deseo estético de llevar pendientes es capaz de superar las complicaciones de salud derivadas de su uso, tanto en territorio nacional como mas aun en las misiones en el extranjero, donde los accesos a la higiene son mas deficitarios.

\subsection{Estado dental y necesidad de tratamiento}

La valoración de la presencia de caries se suele realizar a través del índice CAO-D. Sin embargo, está fundamentado el hecho de que los análisis comparativos basados en este índice presentan varios puntos débiles ${ }^{189}$. Así, nos encontramos con diferentes demografías, la falta de una visión homogénea para todos los exploradores o falta de uniformidad en las mismas condiciones de la exploración, por citar tres ejemplos ${ }^{190-192}$. A pesar de lo indicado, sigue siendo el índice más utilizado y, por ello, el que permite hacer comparativas más extensas. Por estas razones es por las que se ha utilizado en este trabajo, siguiendo las recomendaciones de la OMS. Como punto de partida de la discusión se tiene el hecho de que en todos los países, al instaurar los programas de prevención, el índice CAO-D disminuyó notablemente ${ }^{193-196}$. Estos estudios sistemáticos también han demostrado que la experiencia de caries depende de las condiciones sociales, económicas y culturales de la población. Por ejemplo en EEUU este hecho se ha detectado a través de diferencias notables en el índice CAO-D entre la población anglosajona, la hispana y la negra ${ }^{197}$. Diferencias que se están acortando en estos momentos. Estudios similares realizados en España ${ }^{15,198}$, han demostrado que en los 
últimos 10 años observamos una disminución de la prevalencia de caries en la población de la franja de edad entre 35 y 44 años, debido a la llegada a esta cohorte de edad de las generaciones que recibieron, por primera vez en nuestro país (década de los años 80 del siglo pasado), medidas de salud pública y de promoción y prevención de la caries dental (instrucción en higiene oral, enjuagues fluorados a escolares así como programas profesionales de aplicación de flúor profesional y sellados de fisura $)^{15,198}$. En la Figura 6.16 se muestra la evolución a la baja que ha experimentado el índice CAO-D en España pasando de una valor de 11,6 en 1984 a 6,8 en 2010.

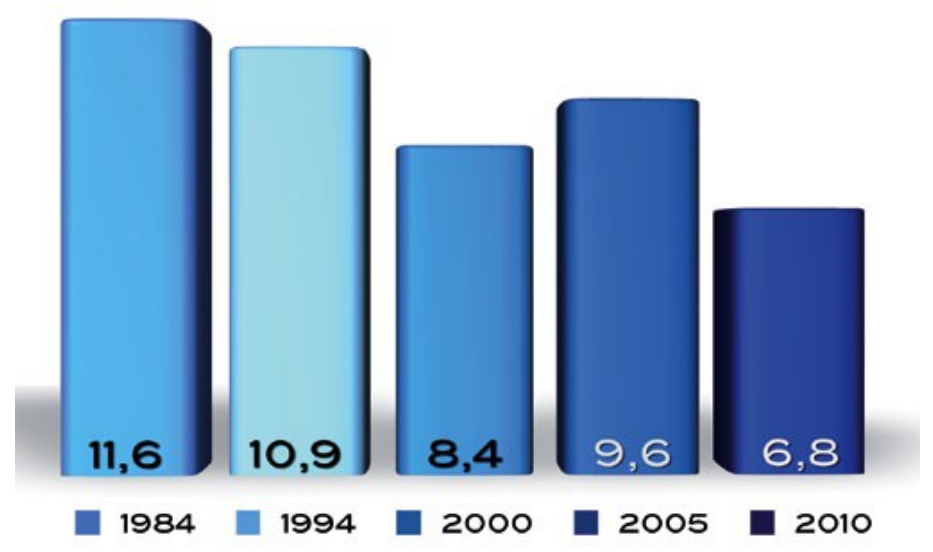

Figura 6.16. Evolución del índice CAO-D en España entre 1984 y $2010^{15}$

En la Tabla 6.1 y la Figura 6.17 se muestran, en forma de comparativa entre las dos visitas, los resultados de nuestro estudio. En primer lugar observamos que el índice CAO-D en la segunda visita fue algo superior al de la primera. Esto es debido a un incremento en los componentes de obturaciones $(\mathrm{O})$ y ausentes por caries (A), algo que está en concordancia con la mayor edad de los sujetos en la segunda visita. Mientras que el índice de caries (C), en cambio, fue superior en la primera visita. Algo que también observamos en las encuestas de salud oral, en las que se observa cómo se ha ido reduciendo este índice con los años.

Nuestros resultados en cuanto al índice CAO-D tanto para la primera como para la segunda visita se asemejan a los observados en la encuesta de salud oral en España $2010^{15}$ (Figura 6.16). Siendo mas bajos que los obtenidos en 2000 y 2005 ( 8,4 y 9.6) pero no tanto como los de $2010(6,75)$. Valores que sitúan a nuestro país entre aquellos con un nivel de caries bajo en este grupo etario según la OMS (franja CAO D entre 5 y 8.9) y que en nuestro estudio también se aprecian (7,59 en la primera visita y 7,99 en la segunda). Sin embargo, hay dos 
diferencias importantes cuando comparamos nuestro trabajo con las encuestas generales que se han hecho en España porque la edad máxima en ellas es 44 años, dato que concuerda con el de la primera visita del estudio. Sin embargo, para la segunda visita, tenemos que contar con que nuestra población es casi 9 años mayor, pero no lo suficiente como para entrar a formar parte del grupo etario de 65-74. Cuando hemos comparado nuestros resultados con otros estudios de poblaciones militares, tanto de España ${ }^{95,199-202}$ como de otros países ${ }^{203-}$ ${ }^{205}$ se ve que sucede lo mismo. Estamos en números similares, pero con la diferencia que en ninguno de ellos se ha realizado un seguimiento en dos momentos, tan espaciados en el tiempo y con los mismos sujetos, como ocurre con nuestro estudio.

Tabla 6.1. Análisis comparativo del índice CAO-D y componentes entre la primera y la segunda visita para el total de la muestra.

\begin{tabular}{|c|c|c|c|c|c|c|c|c|}
\hline & \multirow{2}{*}{\multicolumn{2}{|c|}{ Visita 1}} & \multirow{2}{*}{\multicolumn{2}{|c|}{ Vista 2}} & \multicolumn{3}{|c|}{ Diferencias relacionadas } & \multirow{3}{*}{$\begin{array}{c}\text { p- } \\
\text { valor }\end{array}$} \\
\hline & & & & & \multirow{2}{*}{ Media } & \multicolumn{2}{|c|}{$\begin{array}{l}95 \% \text { Intervalo de } \\
\text { confianza }\end{array}$} & \\
\hline & Media & $\begin{array}{c}\text { Desviación } \\
\text { típica }\end{array}$ & Media & $\begin{array}{l}\text { Desviación } \\
\text { típica }\end{array}$ & & Inferior & Superior & \\
\hline Edad & 27,24 & 6,12 & 35,44 & 6,20 & $-8,20$ & $-8,34$ & $-8,08$ & $<0,001$ \\
\hline $\begin{array}{l}\text { Índice } \\
\text { caries }\end{array}$ & 2,75 & 3,06 & 1,11 & 1,82 & 1,64 & 1,23 & 2,04 & $<0,001$ \\
\hline $\begin{array}{c}\text { Índice } \\
\text { Obturación }\end{array}$ & 3,78 & 3,62 & 5,36 & 3,86 & $-1,58$ & $-1,93$ & $-1,24$ & $<0,001$ \\
\hline $\begin{array}{c}\text { Índice } \\
\text { Ausentes }\end{array}$ & 1,07 & 1,81 & 1,52 & 2,02 & $-0,45$ & $-0,63$ & $-0,27$ & $<0,001$ \\
\hline $\begin{array}{l}\text { Índice } \\
\text { CAOD }\end{array}$ & 7,59 & 4,45 & 7,99 & 4,65 & $-0,40$ & $-0,94$ & $-0,35$ & $<0,001$ \\
\hline
\end{tabular}

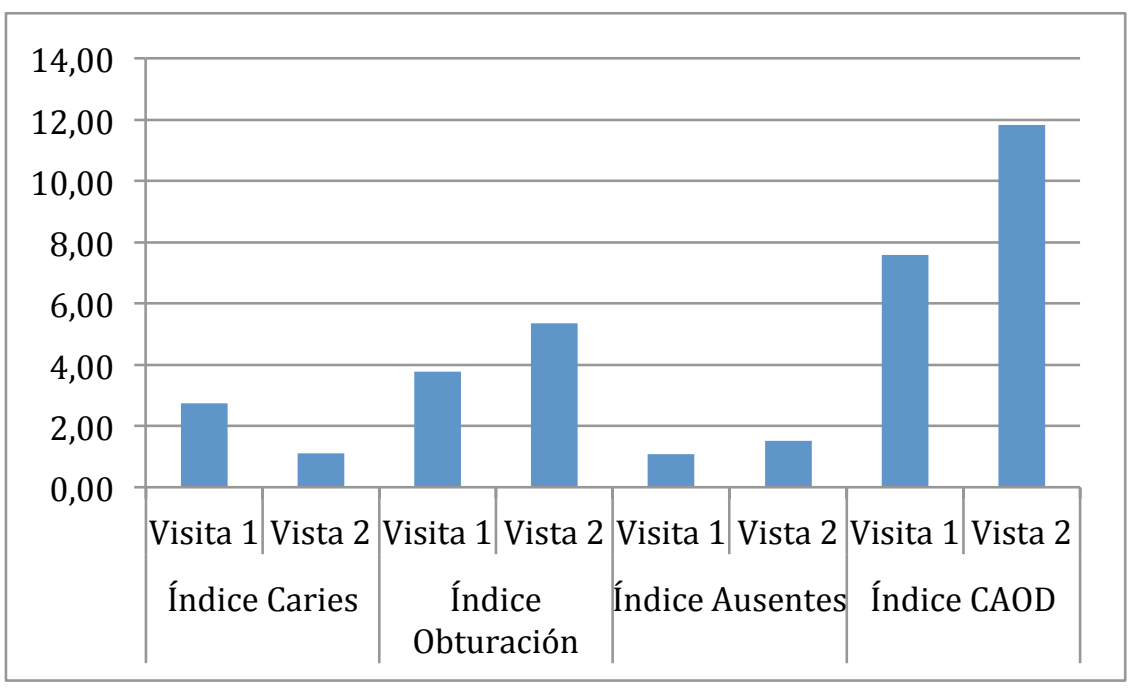

Figura 6.17. Análisis comparativo del índice CAO-D y componentes entre la primera y la segunda visita. 
Si comparamos los resultados del índice CAO-D en ambas visitas en función de la escala (Tabla 6.2), observamos que, en las dos citas, dicho índice es superior en la escala de of/subof. Para ambas escalas el valor del índice se incrementa, notablemente, en la segunda visita debido, fundamentalmente, al aumento de las obturaciones (O) y a la ausencias por caries (A). El índice de caries (C) es más elevado en la tropa (MPTM) tanto en la primera como en la segunda visita pero, para ambas escalas, disminuye en la segunda cita.

Tabla 6.2. Análisis comparativo del índice CAO-D y componentes entre la primera y la segunda visita en función de la escala.

\begin{tabular}{|c|c|c|c|c|c|c|c|c|c|}
\hline & & \multicolumn{4}{|c|}{ ESCALA Visita 1} & \multicolumn{4}{|c|}{ Prueba $T$ para la igualdad de medias } \\
\hline & & \multicolumn{2}{|c|}{ MPTM } & \multicolumn{2}{|c|}{$\begin{array}{c}\text { Suboficiales + } \\
\text { Oficiales }\end{array}$} & \multirow[b]{2}{*}{$\begin{array}{c}\text { p- } \\
\text { valor }\end{array}$} & \multirow[b]{2}{*}{$\begin{array}{l}\text { Diferencia } \\
\text { de medias }\end{array}$} & \multicolumn{2}{|c|}{$\begin{array}{c}95 \% \text { Intervalo de } \\
\text { confianza para la } \\
\text { diferencia }\end{array}$} \\
\hline & & Media & $\begin{array}{c}\text { Desviación } \\
\text { típica }\end{array}$ & Media & $\begin{array}{c}\text { Desviación } \\
\text { típica }\end{array}$ & & & Inferior & Superior \\
\hline \multirow{4}{*}{ VISITA 1} & $\begin{array}{l}\text { Índice } \\
\text { caries }\end{array}$ & 2,92 & 3,02 & 2,00 & 3,16 & 0,126 & 0,92 & $-0,26$ & 2,10 \\
\hline & $\begin{array}{c}\text { Índice } \\
\text { Obturación }\end{array}$ & 3,42 & 3,71 & 5,31 & 2,79 & 0,002 & $-1,89$ & $-3,06$ & $-0,72$ \\
\hline & $\begin{array}{c}\text { Índice } \\
\text { Ausentes }\end{array}$ & 0,87 & 1,34 & 1,94 & 2,98 & 0,056 & $-1,07$ & $-2,16$ & 0,03 \\
\hline & $\begin{array}{l}\text { Índice } \\
\text { CAO-D }\end{array}$ & 7,21 & 4,55 & 9,25 & 3,57 & 0,008 & $-2,04$ & $-3,52$ & $-0,56$ \\
\hline \multirow{4}{*}{ VISITA 2} & $\begin{array}{l}\text { Índice } \\
\text { caries } \\
\end{array}$ & 1,22 & 1,91 & 0,66 & 1,29 & 0,049 & 0,56 & 0,00 & 1,12 \\
\hline & $\begin{array}{c}\text { Índice } \\
\text { Obturación }\end{array}$ & 5,01 & 3,89 & 6,91 & 3,39 & 0,012 & $-1,90$ & $-3,37$ & $-0,43$ \\
\hline & $\begin{array}{c}\text { Índice } \\
\text { Ausentes }\end{array}$ & 1,41 & 1,95 & 2,00 & 2,24 & 0,139 & $-0,59$ & $-1,37$ & 0,19 \\
\hline & $\begin{array}{l}\text { Índice } \\
\text { CAO-D }\end{array}$ & 7,64 & 4,65 & 9,57 & 3,67 & 0,023 & $-1,93$ & $-3,02$ & $-0,46$ \\
\hline
\end{tabular}

Si comparamos los resultados del índice CAO-D en ambas visitas en función de los grupos de edad, observamos que es superior en los mayores de 27 años en las dos visitas. Al igual que en los casos anteriores los valores del índice fueron superiores en la segunda cita debido al aumento de las obturaciones $(\mathrm{O})$ y a las ausencias por caries (A). El índice de caries (C) es más elevado en los menores de 27 años tanto en la primera como en la segunda visita, y su valor disminuye en la segunda cita. Los datos tienen la misma tendencia que lo comentado anteriormente para la escala; los índices de obturaciones $(\mathrm{O})$ y ausencias (A) aumentan con la edad, lo que sucede en la segunda visita de nuestro estudio y sin embargo el índice de caries (C) disminuye. Valores, todos ellos comparables a los encontrados en la población general y, solo, ligeramente superiores a los de los alumnos universitarios ${ }^{15,198}$. 
Estudio epidemiológico de la salud bucodental y ...

Tabla 6.3. Análisis comparativo del índice CAO-D y componentes entre la primera y la segunda visita en función de la edad.

\begin{tabular}{|c|c|c|c|c|c|c|c|c|c|}
\hline & & \multicolumn{4}{|c|}{ Grupos de Edad } & \multicolumn{4}{|c|}{ Prueba T para la igualdad de medias } \\
\hline & & \multicolumn{2}{|c|}{$<=27$} & \multicolumn{2}{|r|}{$>27$} & \multirow{2}{*}{$\begin{array}{l}\text { p- } \\
\text { valor }\end{array}$} & \multirow{2}{*}{$\begin{array}{l}\text { Diferencia } \\
\text { de medias }\end{array}$} & \multicolumn{2}{|c|}{$\begin{array}{c}95 \% \text { Intervalo de } \\
\text { confianza para la } \\
\text { diferencia }\end{array}$} \\
\hline & & Media & $\begin{array}{c}\text { Desviación } \\
\text { típica }\end{array}$ & Media & $\begin{array}{c}\text { Desviación } \\
\text { típica }\end{array}$ & & & Inferior & Superior \\
\hline \multirow{4}{*}{$\begin{array}{c}\text { VISITA } \\
1\end{array}$} & Índice caries & 3,02 & 2,88 & 2,38 & 3,28 & 0,175 & 0,65 & $-0,29$ & 1,58 \\
\hline & $\begin{array}{c}\text { Índice } \\
\text { Obturación }\end{array}$ & 3,13 & 3,65 & 4,65 & 3,42 & 0,006 & $-1,52$ & $-2,61$ & $-0,43$ \\
\hline & $\begin{array}{c}\text { Índice } \\
\text { Ausentes }\end{array}$ & 0,55 & 0,81 & 1,78 & 2,45 & 0,000 & $-1,23$ & $-1,82$ & $-0,63$ \\
\hline & Índice CAOD & 6,70 & 4,49 & 8,81 & 4,12 & 0,002 & $-2,10$ & $-3,43$ & $-0,77$ \\
\hline \multirow{4}{*}{$\begin{array}{c}\text { VISITA } \\
2\end{array}$} & Índice caries & 1,22 & 1,65 & 0,96 & 2,02 & 0,347 & 0,27 & $-0,29$ & 0,82 \\
\hline & $\begin{array}{c}\text { Índice } \\
\text { Obturación }\end{array}$ & 4,76 & 3,92 & 6,19 & 3,64 & 0,016 & $-1,44$ & $-2,61$ & $-0,27$ \\
\hline & $\begin{array}{c}\text { Índice } \\
\text { Ausentes } \\
\end{array}$ & 1,10 & 1,69 & 2,10 & 2,28 & 0,002 & $-1,00$ & $-1,63$ & $-0,36$ \\
\hline & Índice CAOD & 7,08 & 4,59 & 9,25 & 4,76 & 0,020 & $-2,17$ & $-4,81$ & $-0,41$ \\
\hline
\end{tabular}

Tabla 6.4. Análisis comparativo del índice CAO-D y componentes entre la primera y la segunda visita en función del sexo.

\begin{tabular}{|c|c|c|c|c|c|c|c|c|c|}
\hline & \multicolumn{4}{|c|}{ SEXO } & \multicolumn{4}{|c|}{ Prueba $\mathrm{T}$ para la igualdad de medias } \\
\hline & & \multicolumn{2}{|c|}{ Hombre } & \multicolumn{2}{|r|}{ Mujer } & \multirow{2}{*}{$\begin{array}{c}\text { p- } \\
\text { valor }\end{array}$} & \multirow{2}{*}{$\begin{array}{c}\text { Diferencia } \\
\text { de } \\
\text { medias }\end{array}$} & \multicolumn{2}{|c|}{$\begin{array}{c}95 \% \text { Intervalo de } \\
\text { confianza para la } \\
\text { diferencia }\end{array}$} \\
\hline & & Media & $\begin{array}{l}\text { Desviación } \\
\text { típica }\end{array}$ & Media & $\begin{array}{c}\text { Desviación } \\
\text { típica }\end{array}$ & & & Inferior & Superior \\
\hline \multirow{4}{*}{$\begin{array}{c}\text { VISITA } \\
1\end{array}$} & Índice caries & 2,84 & 3,19 & 2,44 & 2,63 & 0,461 & 0,41 & $-0,68$ & 1,49 \\
\hline & $\begin{array}{c}\text { Índice } \\
\text { Obturación } \\
\end{array}$ & 3,53 & 3,57 & 4,56 & 3,70 & 0,111 & $-1,03$ & $-2,31$ & 0,24 \\
\hline & $\begin{array}{c}\text { Índice } \\
\text { Ausentes }\end{array}$ & 1,17 & 1,95 & 0,76 & 1,22 & 0,201 & 0,41 & $-0,22$ & 1,05 \\
\hline & Índice CAOD & 7,54 & 4,58 & 7,76 & 4,06 & 0,790 & $-0,21$ & $-1,79$ & 1,36 \\
\hline \multirow{4}{*}{$\begin{array}{c}\text { VISITA } \\
2\end{array}$} & Índice caries & 1,20 & 1,95 & 0,83 & 1,32 & 0,255 & 0,37 & $-0,27$ & 1,02 \\
\hline & $\begin{array}{c}\text { Índice } \\
\text { Obturación }\end{array}$ & 5,12 & 3,90 & 6,12 & 3,70 & 0,150 & $-1,00$ & $-2,36$ & 0,36 \\
\hline & $\begin{array}{c}\text { Índice } \\
\text { Ausentes }\end{array}$ & 1,70 & 2,15 & 0,98 & 1,41 & 0,014 & 0,72 & 0,15 & 1,30 \\
\hline & Índice CAOD & 8,02 & 4,62 & 7,93 & 4,12 & 0,214 & $-0,09$ & $-1,19$ & 0,94 \\
\hline
\end{tabular}

Por último, comparamos los resultados del índice CAO-D de ambas visitas en función del sexo, observamos que son las mujeres las que presenta un valor más alto en las dos citas. Los componentes de caries (C) y de ausencias (A) son más elevados en los hombres tanto en la primera como en la segunda visita, pero para el índice de caries (C) se observa una disminución en la segunda cita como sucede en las comparativas por escala y edad. Además, para hombres y mujeres, por las mismas razones comentadas anteriormente, el índice CAO-D es más alto 
en la segunda visita. Los resultados están de acuerdo con el comportamiento usual en todos los países, incluyendo España, en los cuales se observa un mayor CAO-D en las mujeres que en los hombres ${ }^{206-211}$ Aunque en nuestro estudio en la segunda visita las mujeres presentan un índice CAO-D ligeramente más bajo que el de los hombres aunque presentan mas obturaciones $(\mathrm{O})$ pero en el global del índice tienen menos ausencias (A) y menor índice de caries (C).

Como comentario final a la presencia de caries se puede decir que en el caso de los militares, además de tener los factores de riesgo usuales, comunes para toda la población, pueden existir situaciones de estrés, derivadas de misiones $\mathrm{u}$ operaciones que pueden incrementar el riesgo. Por ejemplo, esto se ha podido estudiar en la segunda guerra mundial y en la más próxima de Bosnia y Herzegovina $^{83,212-214}$, y por ello es tan importante la prevención y las revisiones periódicas, para evitar en la medida de lo posible esas emergencias dentales.

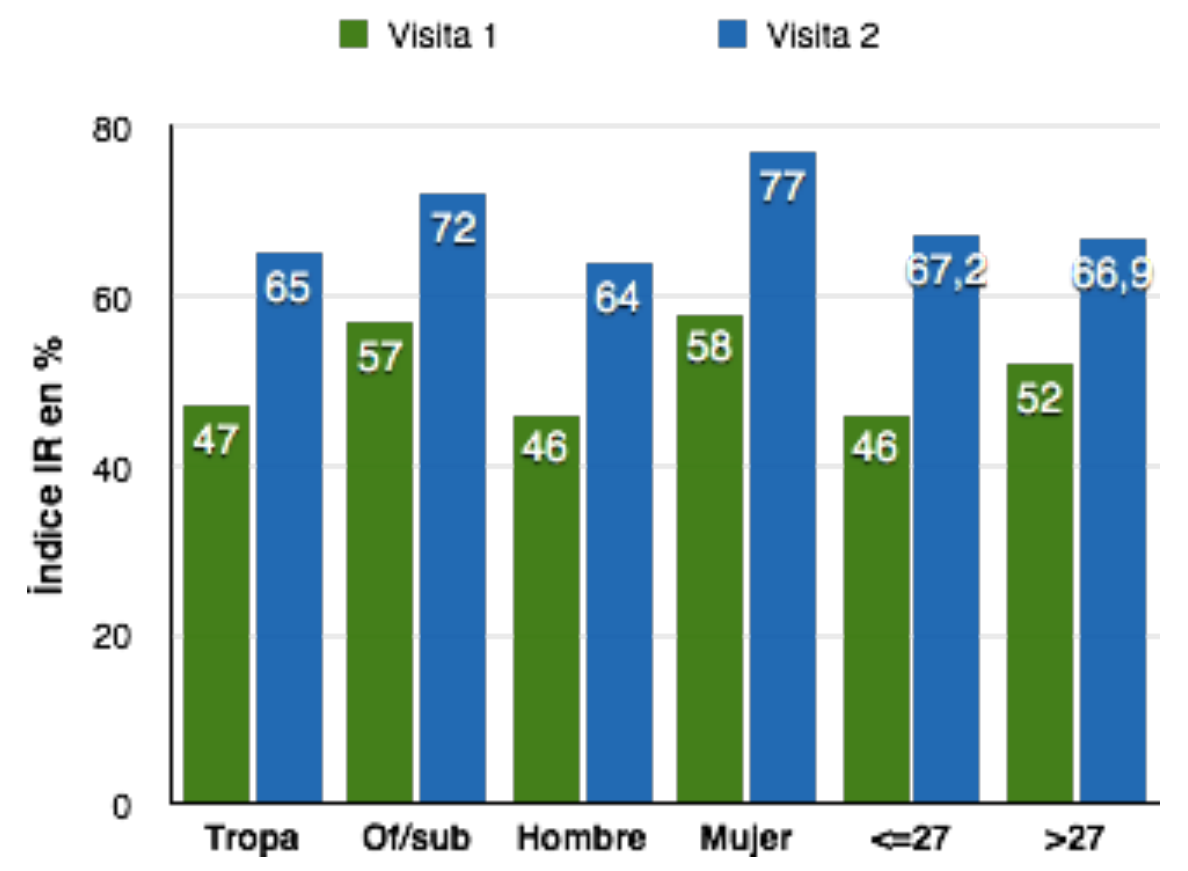

Figura 6.18. Análisis comparativo del índice de restauración (IR) entre la primera y la segunda visita por escala, sexo y edad.

En relación al índice de restauración (IR), según lo observado en las encuestas de salud oral en España ${ }^{15,108.198}$, se duplicó en una década pasando de un $13 \%$ en 1984 a $27 \%$ en 1993. Casi llegó a cuadruplicarse en menos de dos décadas (periodo 1984-2000) alcanzando un valor de un $49 \%$ en el año 2000. En nuestro estudio es interesante reseñar que el índice de restauración (IR) obtenido en la primera visita tiene un valor de 58,76\% similar al observado en 2005 (54\%) 
En la segunda visita nuestro IR está en $68,82 \%$ algo mayor que el valor histórico alcanzado en la encuesta de salud oral nacional de 2010(65\%). En el ámbito militar, el índice de restauración es superior en la escala de of/subof con respecto a la tropa, aunque en la segunda visita los valores del índice son cercanos. También es de reseñar que los valores encontrados en este estudio se aproximan a los encontrados entre otros estudios de los militares españoles ${ }^{95,201}$ y los de otros países $^{215-219}$ que están en valores del $61,66 \%$ y $65,77 \%$ respectivamente.

En cuanto a la necesidad de tratamiento por caries la Tabla 6.5 y la Figura 6.19 muestran una comparación entre las dos visitas. En la primera cita observamos que el $50 \%$ de los sujetos requería de algún tipo de tratamiento, porcentaje que en la segunda visita se redujo a la mitad. Debemos tener en cuenta que en las cohortes de adultos, aunque se está observando una disminución discreta pero significativa en la prevalencia de caries en las ultimas encuestas, la caries continúa siendo un proceso universal que afecta a casi toda la población adulta. Los datos de nuestro estudio son comparables, en ambas visitas, a la evolución que ha experimentado la población joven adulta española entre $1983^{181}$ con un $80 \%$ de población con necesidad de tratamiento por caries, hasta el $47,6 \%$ en $2005^{101,108}$ y $38,7 \%$ en la encuesta de salud oral en $2015^{198}$. Debe tenerse en cuenta que los datos anteriores son de población adulta joven (35-44 años) que corresponderían a los sujetos estudiados en la primera visita entre el 2006 y 2008 mientras que los examinados en la segunda visita son casi 9 años mayores y se revisaron durante el 2015. Evidentemente también difieren con los de otros países con diferentes condiciones socioeconómicas ${ }^{220}$.

Tabla 6.5. Análisis comparativo de la necesidad de tratamiento por caries.

\begin{tabular}{|c|c|c|c|c|c|}
\hline \multirow{2}{*}{$\begin{array}{c}\text { NECESIDAD DE } \\
\text { TRATAMIENTO }\end{array}$} & \multicolumn{2}{|c|}{ VISITA 1 } & \multicolumn{2}{c|}{ VISITA 2 } & \multirow{2}{*}{ p-valor } \\
\cline { 2 - 5 } & $\mathbf{n}$ & $\%$ & $\mathbf{n}$ & $\%$ & $<0,001$ \\
\hline Ninguno & 86 & $50,6 \%$ & 128 & $75,3 \%$ & $<0,001$ \\
\hline $\begin{array}{c}\text { Obturación de 1 } \\
\text { superficie }\end{array}$ & 104 & $61,2 \%$ & 67 & $39,41 \%$ & $<0,001$ \\
\hline $\begin{array}{c}\text { Obturación de 2 ó más } \\
\text { superficies }\end{array}$ & 59 & $34,7 \%$ & 30 & $17,65 \%$ & $<0,001$ \\
\hline $\begin{array}{c}\text { Tratamiento pulpar y } \\
\text { restauración }\end{array}$ & 28 & $16,5 \%$ & 1 &, $59 \%$ & $<0,004$ \\
\hline Exodoncia & 40 & $23,5 \%$ & 21 & $12,35 \%$ & 0,00 \\
\hline
\end{tabular}




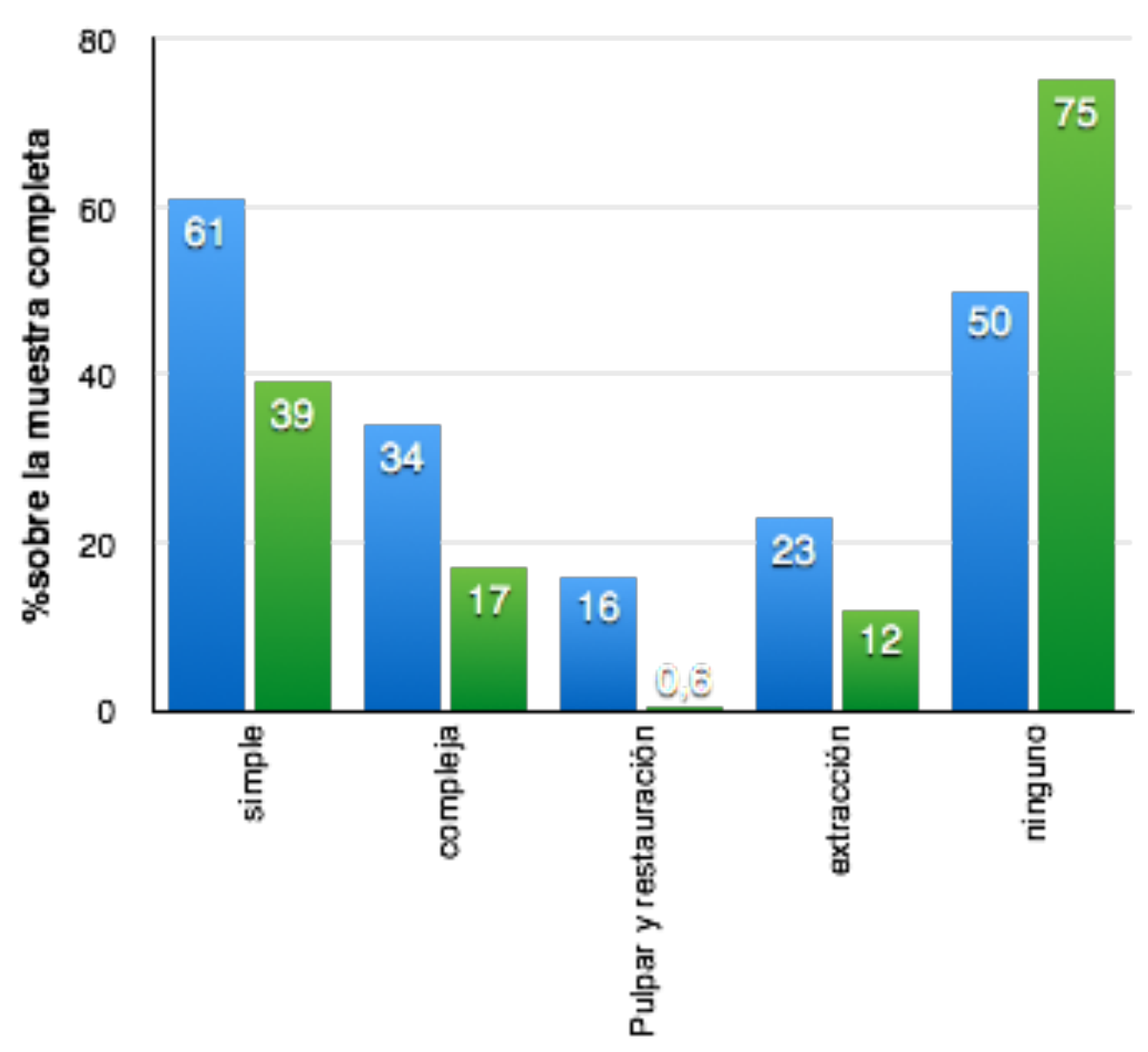

Figura 6.19. Análisis comparativo de la necesidad de tratamiento por caries en la que se indica: simple (obturación de una superficie), compleja (obturación de dos o más superficies), tratamiento pulpar y restauración, extracción y ninguno (ningún tratamiento).

En cuanto al tipo de tratamiento restaurador necesario, observamos que las necesidades se corresponden fundamentalmente con restauraciones simples de una superficie en el $61,2 \%$ de los casos en la primera visita y con casi la mitad en la segunda $(39,41 \%)$. Son mucho menores las necesidades de restauraciones complejas (de 2 ó más superficies) diagnosticadas en el 34,7\% de los casos en la primera visita y siendo al igual que las obturaciones simples casi la mitad en la segunda cita. Los tratamientos pulpares son requeridos en el 16,5\% de los examinados en la primera visita, pasando a un solo caso en el momento de la segunda cita. Y las necesidades de exodoncia son cercanas al $24 \%$ en la primera visita pasando a ser casi la mitad en la segunda.

Es interesante comparar nuestros resultados con los de las encuestas de salud oral en España ${ }^{15,108,198}$. Por ejemplo los resultados de 2005 para el grupo de 35-44 años muestran que las necesidades de restauraciones simples y complejas son similares aunque algo mayor el porcentaje de las obturaciones que abarcaban 
dos ó más superficies ( $27,8 \%$ y $31,3 \%$, respectivamente). Valores que en nuestro estudio eran mucho mayores para el año 2006 y sí que había diferencias significativas entre los tipos de obturación. Sin embargo en la encuesta de 2015 se observa que las necesidades de restauraciones simples y complejas eran más parejas y se habían reducido en número (23\% y $24 \%$ respectivamente). Algo parecido sucede en nuestro estudio, en el cual en la segunda visita diagnosticamos casi la mitad de obturaciones, aunque sigue habiendo mucha diferencia entre las simples y las complejas. Estas últimas descienden incluso más que lo observado en la encuesta de $2015^{198}$.

Los tratamientos pulpares y las exodoncias son requeridos por el 7,2\% y el $12,0 \%$ de la muestra en la encuesta de 2005 respectivamente, mientras que nosotros diagnosticamos algo más del doble de casos de tratamientos pulpares $(16,5 \%)$ y de exodoncias $(23,5 \%)$ en la primera visita. En la encuesta de 2015 ellos observan una ligera disminución de la necesidad de tratamientos pulpares $(6,5 \%)$ y exodoncias $(10,7 \%)$ mientras que en nuestra segunda visita el tratamiento pulpar se reduce a un solo caso y la necesidad de exodoncia se reduce casi a la mitad $(12,35 \%)$ y se equipara a los valores obtenidos en la encuesta de salud oral en España en 2015.

Con el fin de resaltar la necesidad de prevención en las poblaciones militares, es interesante reseñar que según estudios sobre la asistencia sanitaria a militares españoles desplegados en misiones, aquellas que lo fueron por problemas derivados de las caries supusieron, por ejemplo, el 55,3\% en la guerra de Bosnia-Herzegovina $^{83}$. Por otra parte se ha encontrado otro trabajo ${ }^{110}$ que observo que el $15 \%$ de los sujetos requerian de obturaciones simples y que las obturaciones de dos o mas superficies las necesitarían más sujetos $(21 \%)$. Según este estudio el $9 \%$ necesitaría realizarse un tratamiento pulpar y el $28 \%$ una exodoncia. Datos que se equiparan a los observados por nosotros pero que reflejan solo un momento dado y no una evolución en el tiempo de los sujetos.

\subsection{Situación de prótesis y necesidad de prótesis}

En la Figura 6.20 se observa que en relación al estado de prótesis de la población de nuestro estudio, alrededor del $10 \%$ de los sujetos estudiados en la primera visita y cerca del $13 \%$ en la segunda cita son portadores de algún tipo de prótesis. En cuanto al tipo de prótesis en ninguna de las visitas se encontraron prótesis completas, pero sí observamos, presencia de prótesis removible en un 
$2 \%$ de los examinados en la primera visita que se redujo al $1 \%$ en la segunda por la presencia de puentes con implantes. La presencia de prótesis fija es lo más abundante, siendo en el maxilar superior cerca del $7 \%$ en la primera cita y del $8 \%$ en la segunda y del $2 \%$ en la mandíbula en ambas citas.

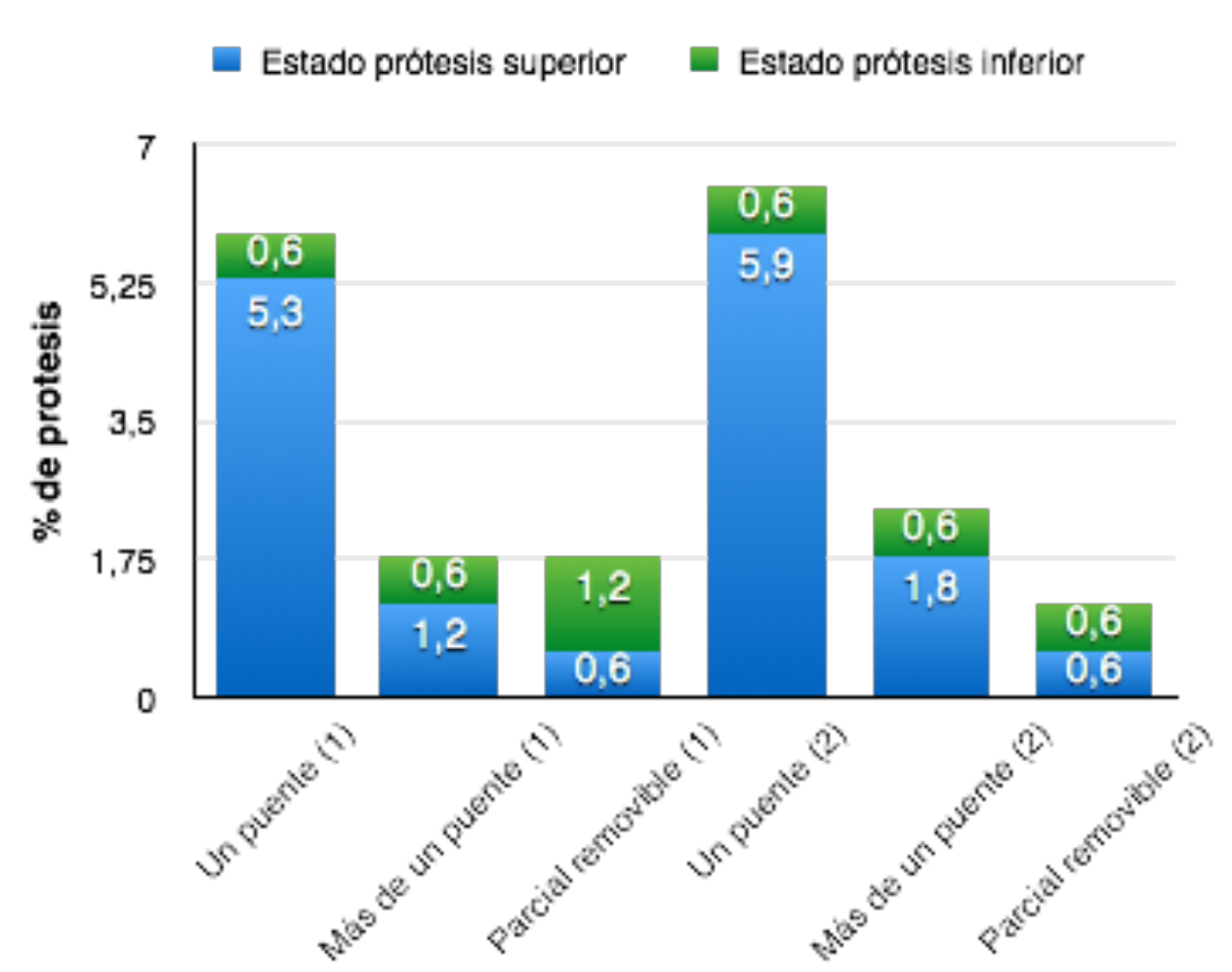

Figura 6.20. Estado de la prótesis superior e inferior para la primera (1) y segunda (2) visita. No se ha representado la no existencia de prótesis pues su valor está entre el $91 \%$ y el $97 \%$ y se sale de la escala. Además no es significativa, ya que lo que se analiza son, justamente, las prótesis.

$\mathrm{Si}$ comparamos nuestros resultados con los obtenidos en los trabajos de encuestas de salud bucodental en España ${ }^{15,108,198}$ podemos apreciar que nuestro estudio, que abarca casi 9 años desde la primera a la segunda visita, presenta unos resultados equiparables. Al igual que sucede en la encuesta de salud oral de 2015, observamos que nuestros resultados en porcentaje de sujetos portadores de prótesis fija aumentan ligeramente y sobre todo que empiezan a aparecer prótesis fijas sobre implantes. En nuestro estudio también se refleja es el aumento de implantes, que en la primera visita son 6 casos $(3$ implantes superiores y 3 inferiores) y en la segunda cita pasamos a observar 16 implantes inferiores y 14 superiores. Dato que contrasta con la encuesta del año 2005, en dónde se indica que un $0,7 \%$ de los encuestados presentaba implantes maxilares y un $0,1 \%$ implantes mandibulares. También podemos decir que en nuestro 
trabajo, como en la población adulta estudiada en las encuestas de salud oral, la presencia de prótesis maxilar es mayor que la mandibular.

En los estudios realizados en el ámbito militar ${ }^{10.201}$ se observan unos porcentajes muy similares a los nuestros con una baja prevalencia de presencia de prótesis (alrededor del $10 \%$ siendo del $7 \%$ en el maxilar superior y del $4 \%$ en la mandíbula). Y también refieren la presencia de algunos implantes, dato equiparable al encontrado por nosotros en la primera visita pero que en la segunda cita de nuestro estudio es mucho mayor. En estos estudios ${ }^{110}$ han encontrado que la presencia de prótesis maxilares fue más prevalente en los of/subof y en las cohortes de más edad. Además no encontraron diferencias estadísticamente significativas en las cohortes por edad de of/subof y lo mismo observaron para las prótesis mandibulares. En este caso la significación estadística no se presentó en las cohortes por edad y de tropa. En nuestro trabajo hemos observado que la presencia de prótesis es más prevalente en los hombres, en los oficiales y suboficiales y en los mayores de 27 años.

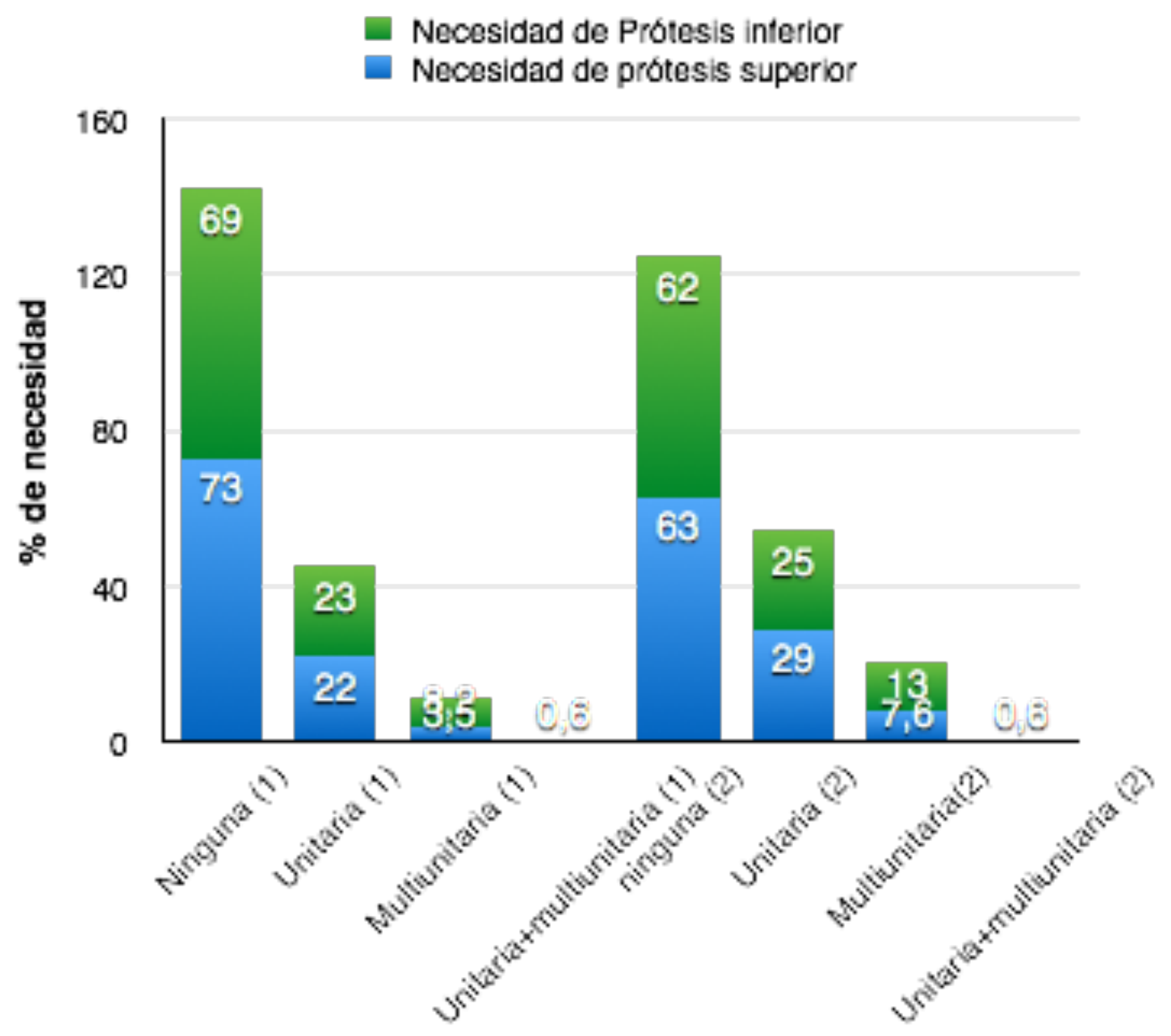

Figura 6.21. Necesidad de prótesis superior e inferior para la primera (1) y segunda (2) visita. No se ha considerado la necesidad de prótesis unitaria y multiunitaria inferior. Por ello solo aparece el dato para la superior. 
En cuanto a las necesidades de prótesis en nuestro estudio observamos que el $27 \%$ requiere de algún tipo de prótesis en el maxilar superior y algo más del $30 \%$ en el inferior en la primera visita. Siendo esa necesidad casi del $37 \%$ en la arcada superior y del $38 \%$ en la inferior en la segunda visita.

En las encuestas nacionales de salud oral ${ }^{15,108,198}$ de la población general española de los adultos jóvenes (35-44 años) la necesidad de prótesis maxilar se situó en el $26,7 \%$ y el $18,0 \%$, en los años 2000 y 2005 . En la de 2010 nos dice que el $18 \%$ requiere de algún tipo de prótesis superior que se incrementa hasta el $24 \%$ para la arcada inferior y en la de 2015 el $23.6 \%$ (en maxilar superior) y $37.5 \%$ (maxilar inferior). Lo que comprobamos con los datos de estas encuestas es que en todas se observó el aumento de la prevalencia de la necesidad así como el estado de prótesis conforme avanzaban en edad y con mayor porcentaje las prótesis en la arcada inferior, como se observa en los resultados de nuestro estudio que han evolucionado más o menos a la par, aunque con menor diferencia entre las necesidades de cada maxilar.

En función del tipo de prótesis requerida, observamos en nuestro estudio que las necesidades de prótesis unitarias oscilan según el maxilar entre el 22,4\% (superior) y $22,9 \%$ (inferior) en la primera visita y entre el $28,8 \%$ y el $24,7 \%$ en la segunda cita y las multiunitarias en torno al 3,5\% y el $8.2 \%$ en la primera visita y 7,6\% y el 12,9\% en la segunda cita. La combinación de prótesis unitaria y multiunitaria únicamente la observamos en un caso en ambas visitas en el maxilar superior. No se requiere tratamiento de prótesis completa en esta cohorte.

Según las encuestas nacionales de salud oral ${ }^{15,108,198}$ en 2005 las necesidades de prótesis unitarias oscilaban entre el 5-7\% y las multiunitarias en torno al 12$13 \%$. Siendo sólo el $0,4 \%$ de los adultos jóvenes los que requerían una prótesis completa. En 2010 las necesidades de prótesis unitarias supusieron el 11\% y el de las multiunitarias llegó a ser del 8,5\%. Manteniéndose igual la necesidad de una prótesis completa. Ya en 2015 las necesidades de prótesis unitarias oscilaban en función del maxilar entre el $12.1 \%$ (superior) $17.8 \%$ (inferior) y las multiunitarias en torno al $10.7 \%$ y el $18.2 \%$ en la arcada inferior. En este estudio se observa que no se requiere tratamiento de prótesis completa para esta cohorte, como sucede en nuestro trabajo.

Un análisis similar de las necesidades de prótesis aparece en algunos estudios de la población militar española ${ }^{110,201}$. En ellos la necesidad de prótesis está entre un $24 \%$ y un $13 \%$ en uno de los trabajos y alrededor de un $30 \%$ en el otro. 
Según el tipo de prótesis hablan de cerca de un $15 \%$ de una prótesis unitaria en el maxilar superior y de algo más del $16 \%$ en el inferior. En cuanto a prótesis multiunitarias dan el $6.6 \%$ para el maxilar superior y el $11.4 \%$ para el inferior. Además, como sucede en los otros estudios de la población general española y en el nuestro,fueron muy pocas las necesidades de una combinación de prótesis unitaria y multiunitaria, como sucedia en los otros estudios de la población general española y en el nuestro.

Por último es interesante reseñar que las necesidades de prótesis observadas en nuestro estudio corresponden en mayor porcentaje a los hombres, en ambas arcadas dentarias, siendo esta diferencia mayor en el maxilar inferior cerca del $33 \%$ en la primera visita y del $40 \%$ en la segunda. En cuanto a la escala militar, son los of/subof los que más requieren de prótesis superior e inferior tanto en la primera cita como en la segunda aunque en ésta la necesidad va en aumento. Y en cuanto a los grupos de edad, son los mayores de 27 años los que más requieren de prótesis en ambas visitas y en mayor porcentaje en la segunda. Los datos son del mismo orden que el que aparece citado anteriormente ${ }^{10}$ en el cual se observa que las necesidades de prótesis para la escala de Oficiales y Suboficiales fue del $21 \%$, en el maxilar superior y del $27 \%$ para el inferior. En ese mismo trabajo los mayores de 23 años presentaron más necesidad de prótesis superior e inferior. Y las mujeres y hombres presentaron semejantes porcentajes de necesidad de prótesis.

\section{7. Estado oclusal (anomalías dentofaciales)}

En relación al estado oclusal de la población de nuestro estudio, observamos que alrededor del $54 \%$ de los sujetos examinados en la primera visita y el $53 \%$ en la segunda presentan alguna anomalía oclusal. Cerca del 29\% son catalogadas de tipo leve y en torno al $24 \%$ de tipo moderado/grave. No hemos encontrado trabajos en el ámbito militar español que hablaran de esta variable de salud oral, pero sí hemos podido comparar nuestros resultados con los datos recogidos relativos al análisis de maloclusiones para el grupo de edad de 35-44 años de las encuestas de salud oral ${ }^{15,108,198}$ en los últimos 15 años en España.

En la encuesta del 2000, que utiliza el índice de estética dental (DAI), el porcentaje de sujetos con maloclusion moderada/severa que requeriría tratamiento de ortooncia fue del $16,8 \%$. En la del año 2005 se vuelve a la 
utilización simplificada del índice de maloclusiones (anomalías dentofaciales) de la OMS (el mismo que seguimos nosotros en el estudio) y observaron que en torno al $40 \%$ de la muestra presentaba algún tipo de anomalía del estado oclusal. Aproximadamente una cuarta parte de los sujetos de ambos grupos presentó una maloclusión catalogada como leve y el intervalo 11-12\% una maloclusión moderada o severa.

En la del 2010 observan en los datos recogidos que casi el 44\% de la muestra presentaba algún tipo de maloclusion. Y cerca de una cuarta parte de los sujetos estudiados en este trabajo presenta una maloclusion leve y el 19,2\% una del tipo moderada o severa. Los valores observados en nuestro estudio se acercan mucho a los de la encuesta de salud oral del 2015 que habla de un 27,3\% de maloclusion de tipo leve y un $22,7 \%$ de maloclusion moderada/severa, muy cercanas al $29 \%$ y $24 \%$ que observamos nosotros.

En nuestro trabajo hemos querido analizar en este apartado también la variable de tratamientos de ortodoncia debido a que los sujetos de la muestra, examinados en las encuestas de salud general realizadas en el botiquín, comentaron, en un porcentaje elevado, estar bajo tratamiento dental, refiriéndose específicamente al tratamiento ortodóntico. A este motivo se debe añadir el hecho de que en las encuestas de salud oral en España también hacían referencia de los sujetos portadores de aparatología ortodóntica. En ellas observamos que en el grupo de 15 años el porcentaje de sujetos con maloclusión moderadasevera, que requiere de tratamiento de ortodoncia era similar para las tres encuestas $(16,8 \%$ en el $2000,11,9 \%$ en 2005 y 19,2\% en 2010). En la encuesta del 2015 se señala que el $14,6 \%$ de los sujetos requirieron tratamiento de ortodoncia. Dato parejo a las tres encuestas nacionales anteriores.

Por último, es de reseñar que el porcentaje de portadores de ortodoncia, alcanzó un $10.9 \%$ y un $17.8 \%$ en los sujetos de 12 y 15 años respectivamente, y que incluso en la cohorte de 35-44 alcanza al $2.7 \%$ de la población. Este dato confirma el acceso de este último grupo etario a un tratamiento tradicionalmente vinculado a las cohortes infantojuveniles. Este resultado también aparece en nuestro estudio en el cual observamos que en la primera visita el 10\% había sido tratado con ortodoncia fija (un 2,9\% llevaba un retenedor) y casi el $2 \%$ de los explorados llevaba ortodoncia en ese momento. Mientras que en la segunda cita hay un $11 \%$ de sujetos que han llevado ortodoncia fija, habiendo solo un caso de los explorados que llevaba ortodoncia en ese momento. Esto es debido a que en el estudio se ha seguido la evolución de los sujetos y alguno ya había terminado el tratamiento. 


\subsection{Grado de aptitud dental}

Para recibir la "aptitud dental" el personal militar tiene que presentar un estado oral que previsiblemente no requiera de asistencia o tratamiento en los doce meses siguientes, con el fin de poder asegurar el correcto desarrollo de su actividad profesional. Este grado lo concede el oficial odontólogo que realiza las revisiones bucales, bajo su responsabilidad y siguiendo los criterios de pérdida de aptitud dental. Criterios que aparecen en los requisitos sanitarios exigibles al personal militar que se desplace a una zona de operaciones y que fueron descritos en la introducción ${ }^{17,31}$.

El personal militar al que se le ha hecho una evaluación de su estado de salud bucal y ha sido diagnosticado como "no apto", en ese primer momento lo clasificamos de "no apto temporal", y que corresponde a los que padecen algún proceso que impida su alistamiento pero que se prevé su resolución a corto plazo. En estos casos fijaremos plazo de revisión, por si da tiempo antes del inicio de la misión a realizarse los tratamientos marcados y revertir su grado de aptitud $^{31}$.

La evaluación del grado de aptitud dental, es un parámetro que valoramos en las FAS y que no se rige por las indicaciones de la OMS, ya que es puramente de ámbito militar y solo podemos compararlo con trabajos dentro de este campo.

En nuestro estudio observamos que en la primera visita un $30 \%$ de los sujetos examinados fueron considerados "no aptos", mientras que en la segunda cita ese porcentaje se redujo al 8,2\% siendo en ambas visitas los hombres, la escala de tropa (MTPM) y los menores de 27 años a los que con mayor porcentaje se les dio ese grado de aptitud.

En estudios sobre otros ejércitos, por ejemplo el americano (US military), el porcentaje de sujetos que seria "no apto" era incluso mayor que el de nuestro trabajo en la primera visita, porque decían que entre el $40 \%$ y el $50 \%$ de los reclutas que ingresaron en el ejercito entre los años 1994-98, presentaron al menos una causa para no conseguir la aptitud para el despliegue. ${ }^{203,219,221,222}$. En el mismo ámbito, en una exploración de los factores que influyen en la necesidad percibida de atención dental entre 2711 reclutas, entre febrero y julio de 1994, los sujetos recibieron un examen oral completo por un dentista y respondieron a preguntas sobre sus cuidados bucales. Los resultados, con diferencias estadísticamente significativas entre muchos factores demográficos y clínicos, 
mostraron que el $61 \%$ de los reclutas necesitarían atención dental, por lo que serían considerados "no aptos" 221 .

El estado de salud oral previo a operaciones en el extranjero de los militares españoles ha estado determinado por las exploraciones bucales previas a las misiones. Estas se comenzaron a realizar sobre los años noventa, pero es con la aparición de la Instrucción Técnica 01/03 de 10 de julio de 2003 de la Inspección General de Sanidad (IGESAN) cuando se protocolizan las revisiones dentales previas a misión y que son uno de los requisitos obligatorios para todo el personal militar que va a participar en una misión u operación acorde con la Instrucción técnica de 15 julio de 2011 de la Inspección General de Sanidad, actualizada a 30 julio de 2013 sobre "Requisitos sanitarios exigibles al personal militar que se desplace a zona de operaciones". Los datos sobre "aptitud dental" en el Ejercito Español, que hemos recogido para comparar con los datos de nuestro estudio son a partir de ese primer protocolo en el que se regulan y se hacen obligatorias las revisiones dentales en los meses previos al despliegue, para dar tiempo a aquellos sujetos considerados "no aptos temporales" a tratarse las lesiones orales que pudieran ser motivo de emergencia en los próximos 12 meses. Lo cual puede ser una de las razones de mejoría de la salud bucal de los militares españoles de nuestro estudio (con respecto por ejemplo a los militares americanos antes referidos), con la marcada disminución en el numero de "no aptos" en la segunda visita.

En la actualidad se dispone de poca información del estado de salud oral de la población militar española en relación con el grado de aptitud dental. Entre las referencias es de interés un estudio epidemiológico observacional, con una muestra de 522 militares del Ejército de Tierra desplegables a la misión Líbano. En este estudio cada sujeto fue sometido a una exploración bucodental y cuestionario de salud oral y el resultado fue de 13,6\% de "no aptos" ${ }^{\text {"223 }}$.En relación a los militares que forman parte de una base militar, un estudio con una muestra de 387 encuentran que la presencia de lesiones alcanzó el 40,1\% de la muestra ${ }^{80}$. Este dato se podría equiparar al número de no "no aptos". Aceptando esta hipótesis el valor sería igual que en nuestro trabajo para la escala de tropa. 


\section{ANEXO (capítulo 6)}

El apéndice muestra las tablas comparativas entre las visitas 1 y 2 junto con los datos estadísticos de cada uno de los factores estudiados en esta memoria.

Tablas comparativas entre la visita 1 y 2 relativas al cepillado, tabaquismo y frecuencia de visitas al dentista.

Tabla 6.1a.

FRECUENCIA DE CEPILLADO

$(\mathrm{p}$-valor $=0,004)$

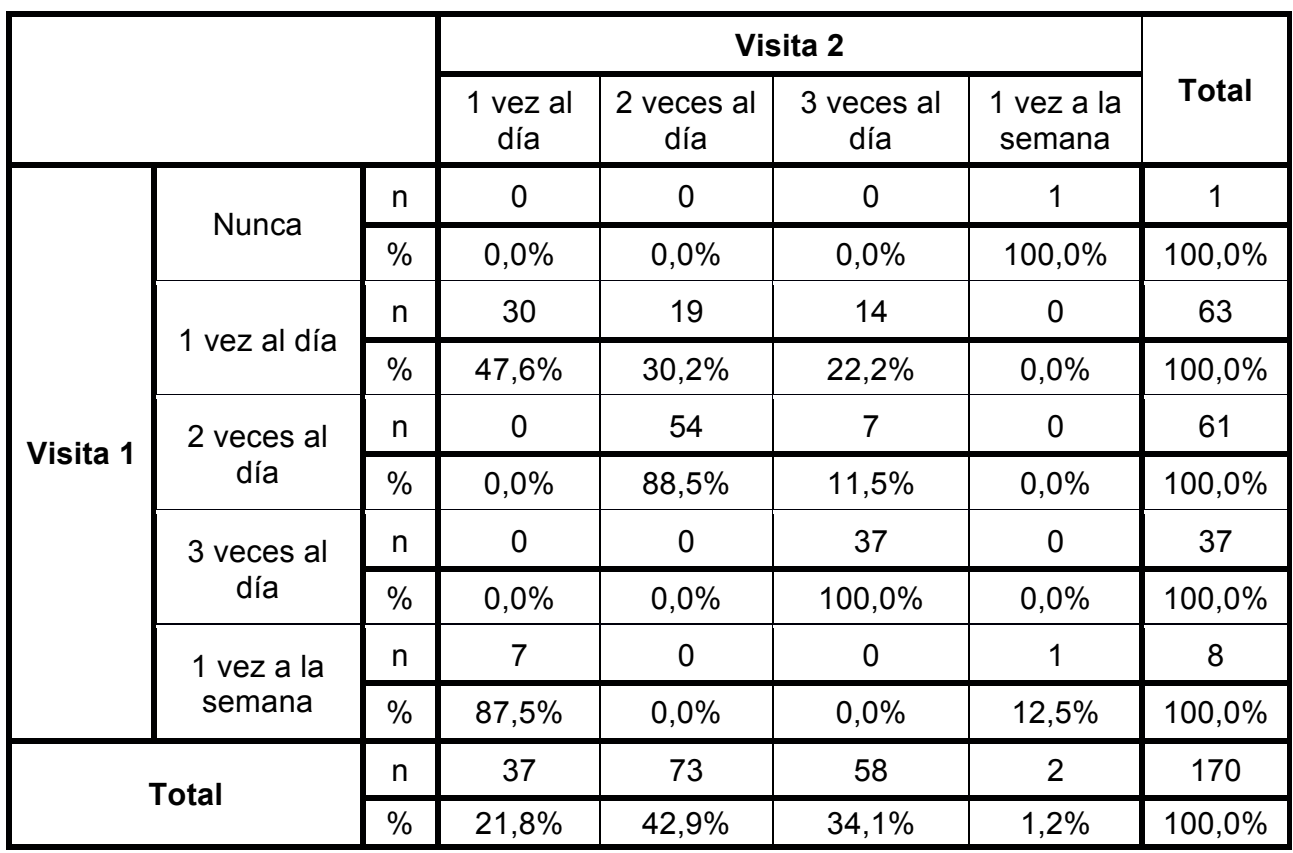

Tabla 6.2a.

TIPO DE CEPILLADO

$(p$-valor $<0,001)$

\begin{tabular}{|c|c|c|c|c|c|c|}
\hline \multicolumn{2}{|c|}{} & \multicolumn{3}{|c|}{ Visita 2 } & \multirow{2}{*}{ Total } \\
\cline { 3 - 7 } \multicolumn{2}{|c|}{} & & Manual & Eléctrico & Ambos & \\
\hline \multirow{3}{*}{ Visita 1 } & \multirow{2}{*}{ Manual } & $\mathrm{n}$ & 69 & 39 & 25 & 133 \\
\cline { 3 - 7 } & \multirow{3}{*}{ Eléctrico } & $\%$ & $51,9 \%$ & $29,3 \%$ & $18,8 \%$ & $100,0 \%$ \\
\cline { 3 - 7 } & & $\mathrm{n}$ & 37 & 0 & 0 & 37 \\
\cline { 3 - 7 } & & $100,0 \%$ & $0,0 \%$ & $0,0 \%$ & $100,0 \%$ \\
\hline \multirow{2}{*}{ Total } & $\mathrm{n}$ & 106 & 39 & 25 & 170 \\
\cline { 3 - 7 } & $\%$ & $62,4 \%$ & $22,9 \%$ & $14,7 \%$ & $100,0 \%$ \\
\hline
\end{tabular}


Tabla 6.3a.

HÁBITO DE TABAQUISMO

(p-valor $<0,001$ )

\begin{tabular}{|c|c|c|c|c|c|c|}
\hline & & & \multicolumn{3}{|c|}{ Visita 2} & \multirow[b]{2}{*}{ Total } \\
\hline & & & $\begin{array}{c}\text { No } \\
\text { Fumador }\end{array}$ & Exfumador & Fumador & \\
\hline \multirow{4}{*}{ Visita 1} & \multirow{2}{*}{$\begin{array}{c}\text { No } \\
\text { Fumador }\end{array}$} & $\mathrm{n}$ & 91 & 0 & 0 & 91 \\
\hline & & $\%$ & $100,0 \%$ & $0,0 \%$ & $0,0 \%$ & $100,0 \%$ \\
\hline & \multirow{2}{*}{ Fumador } & $\mathrm{n}$ & 1 & 26 & 52 & 79 \\
\hline & & $\%$ & $1,3 \%$ & $32,9 \%$ & $65,8 \%$ & $100,0 \%$ \\
\hline \multirow{2}{*}{\multicolumn{2}{|c|}{ Total }} & $\mathrm{n}$ & 92 & 26 & 52 & 170 \\
\hline & & $\%$ & $54,1 \%$ & $15,3 \%$ & $30,6 \%$ & $100,0 \%$ \\
\hline
\end{tabular}

Tabla 6.4a.

FRECUENCIA VISITAS AL DENTISTA

(p-valor $<0,001$ )

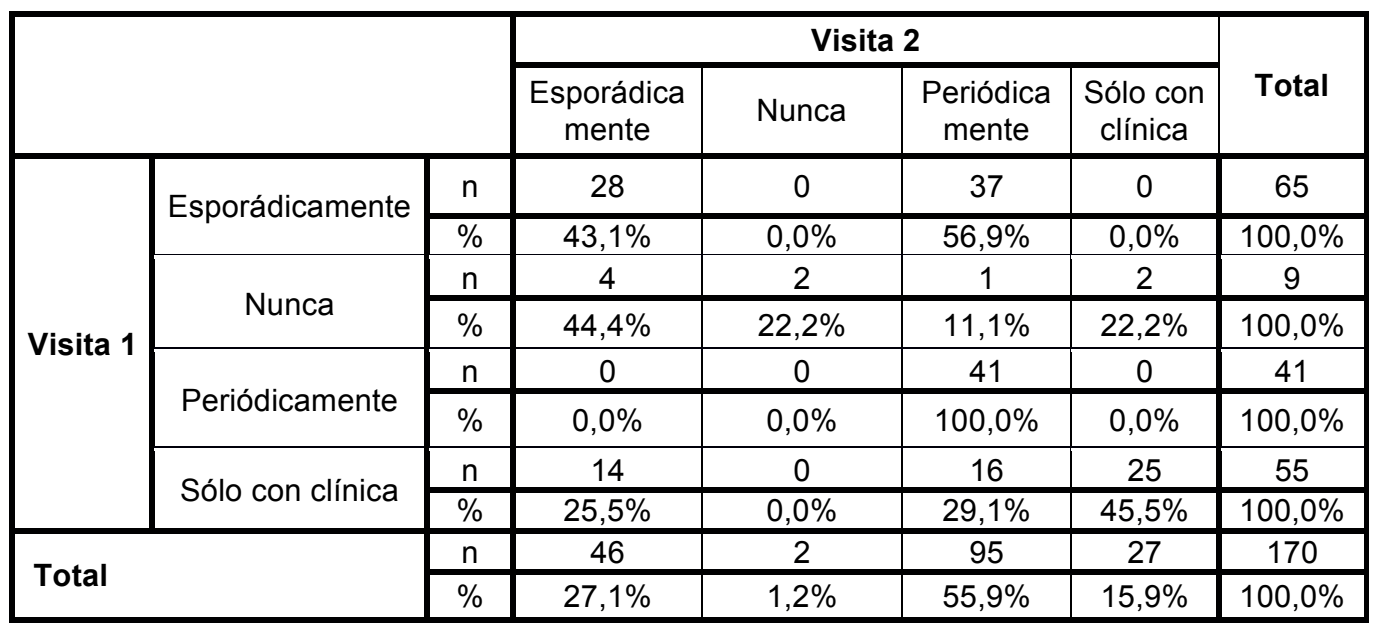


Tablas comparativas entre la visita 1 y 2 relativas a la articulación temporomandibular, bruxismo, utilización de férulas oclusales y presencia de torus mandibulares.

Tabla 6.5a.

ESTADO DE LA ATM

(p-valor $=0,655)$

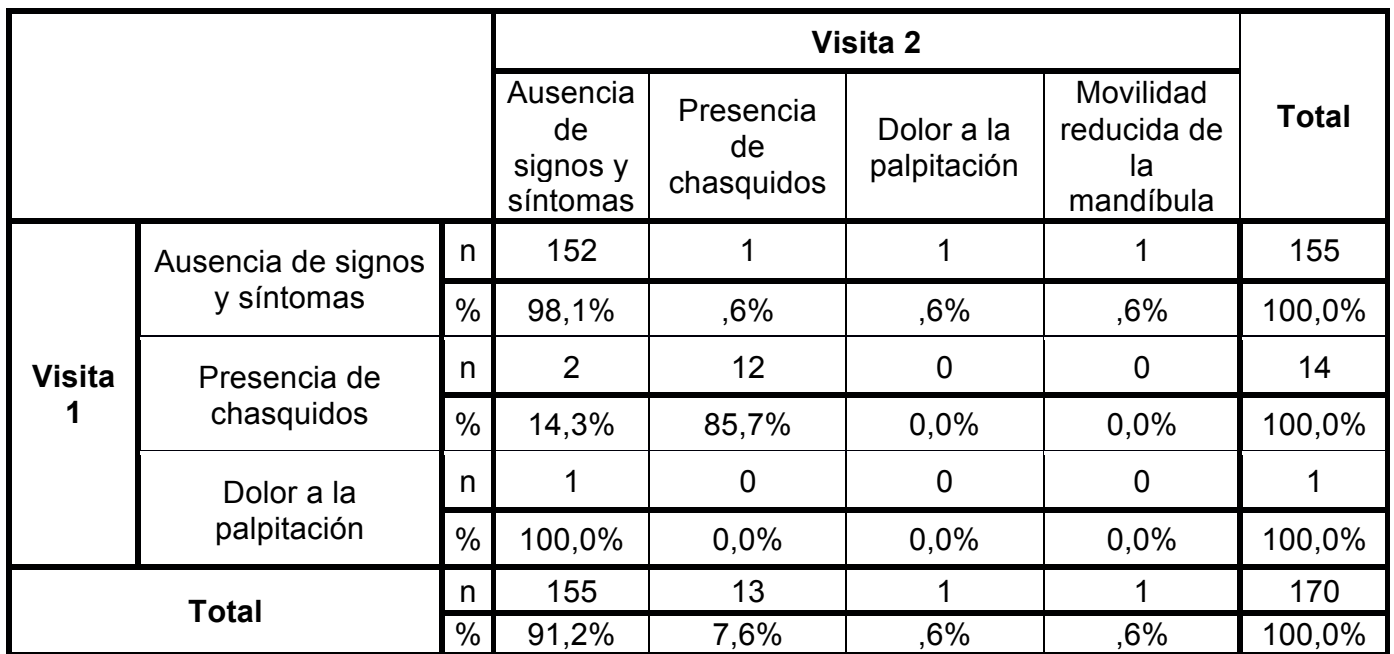

Tabla 6.6b.

BRUXISMO

(p-valor $=1,000)$

\begin{tabular}{|c|c|c|c|c|c|}
\hline & & & \multicolumn{2}{|c|}{ Visita 2} & \multirow{2}{*}{ Total } \\
\hline & & & NO & SI & \\
\hline \multirow{4}{*}{ Visita 1} & \multirow{2}{*}{$\mathrm{NO}$} & $\mathrm{N}$ & 157 & 0 & 157 \\
\hline & & $\%$ & $100,0 \%$ & $0,0 \%$ & $100,0 \%$ \\
\hline & \multirow{2}{*}{ SI } & $\mathrm{N}$ & 0 & 13 & 13 \\
\hline & & $\%$ & $0,0 \%$ & $100,0 \%$ & $100,0 \%$ \\
\hline \multirow{2}{*}{\multicolumn{2}{|c|}{ Total }} & $\mathrm{N}$ & 157 & 13 & 170 \\
\hline & & $\%$ & $92,4 \%$ & $7,6 \%$ & $100,0 \%$ \\
\hline
\end{tabular}


Tabla 6.7a.

FERULAS OCLUSALES

(p-valor $=0,513$ )

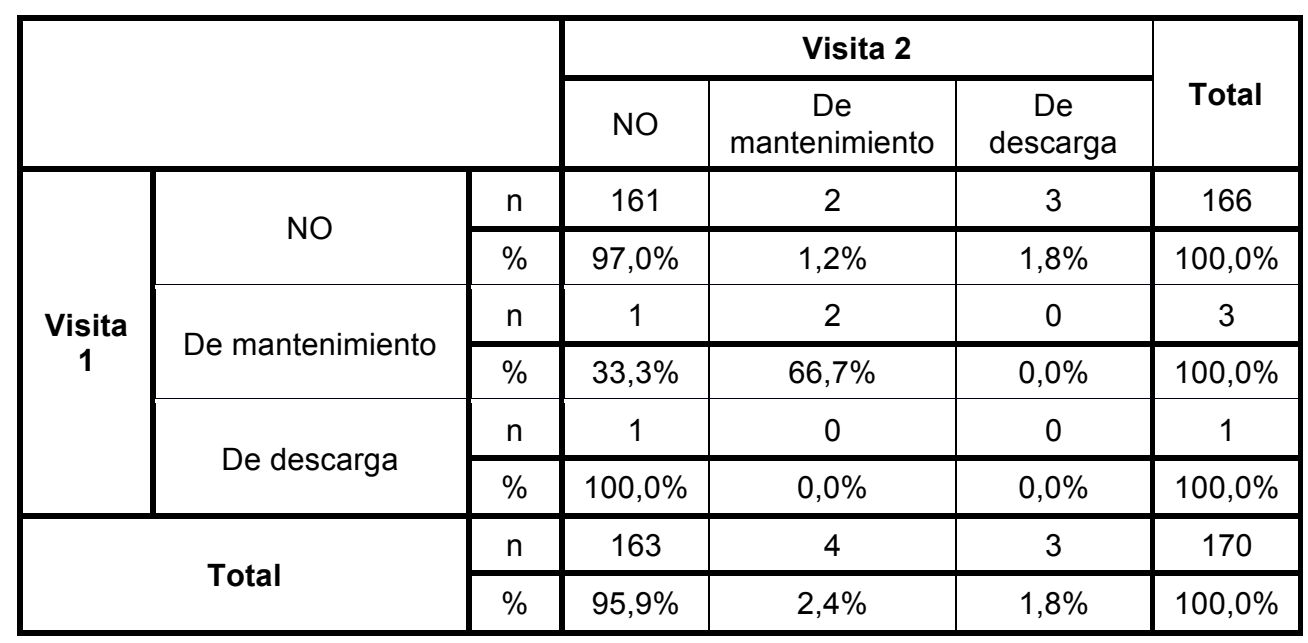

Tabla6.8a.

TORUS MANDIBULARES

$(\mathrm{p}$-valor $=1,000)$

\begin{tabular}{|c|c|c|c|c|c|}
\hline & & & \multicolumn{2}{|c|}{ Visita 2} & \multirow[t]{2}{*}{ Total } \\
\hline & & & NO & SI & \\
\hline \multirow{4}{*}{ Visita 1} & \multirow{2}{*}{$\mathrm{NO}$} & $\mathrm{n}$ & 157 & 0 & 157 \\
\hline & & $\%$ & $100,0 \%$ & $0,0 \%$ & $100,0 \%$ \\
\hline & \multirow{2}{*}{ SI } & $\mathrm{n}$ & 0 & 13 & 13 \\
\hline & & $\%$ & $0,0 \%$ & $100,0 \%$ & $100,0 \%$ \\
\hline \multirow{2}{*}{\multicolumn{2}{|c|}{ Total }} & $\mathrm{n}$ & 157 & 13 & 170 \\
\hline & & $\%$ & $92,4 \%$ & $7,6 \%$ & $100,0 \%$ \\
\hline
\end{tabular}


Tablas comparativas entre la visita 1 y 2 relativas a las opacidades e hipoplasias del esmalte y tinción por tetraciclinas.

Tabla 6.9a

OPACIDADES HIPOPLASIAS DEL ESMALTE p-valor $=1,000$

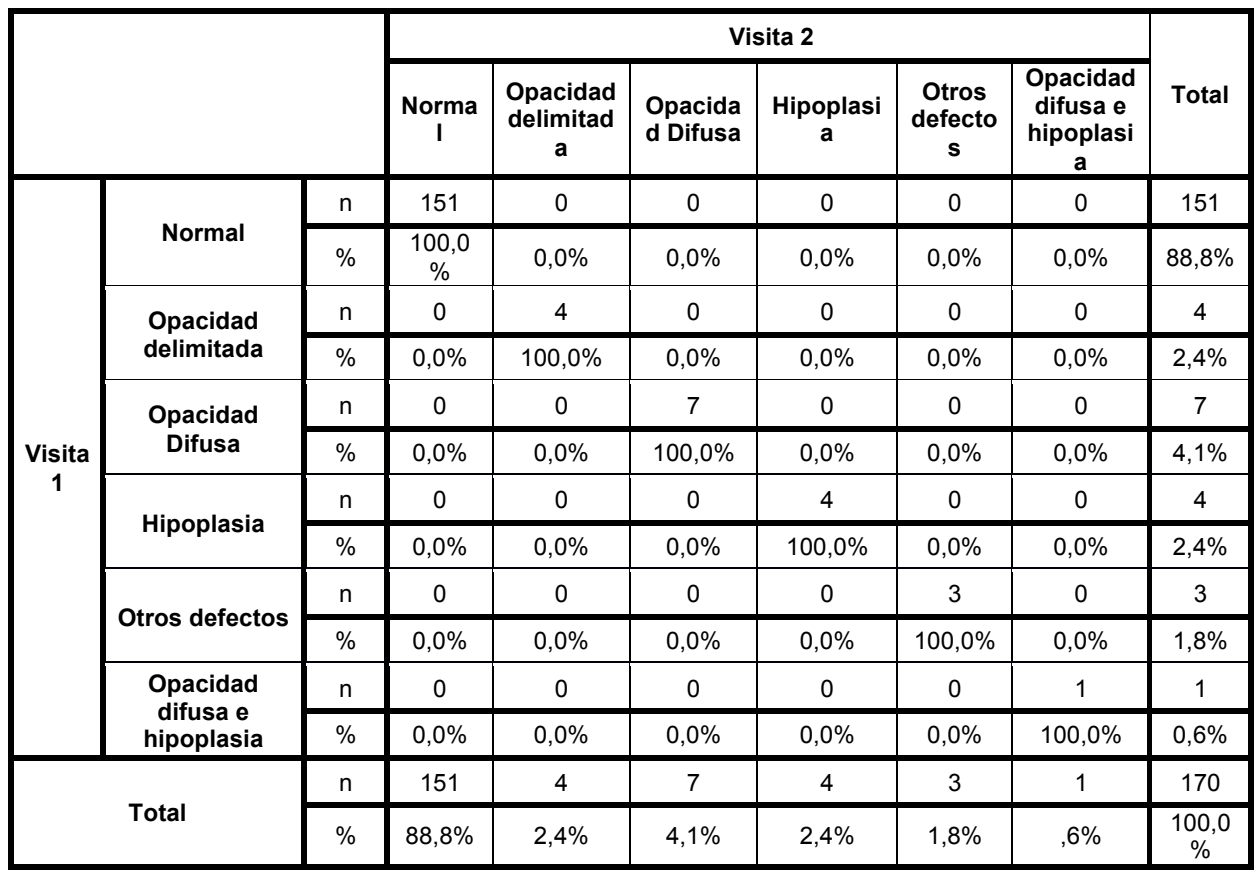

Tabla 6.10a

TINCIÓN TETRACICLINAS

p-valor $=1,000$

\begin{tabular}{|c|c|c|c|c|c|}
\hline & & & \multicolumn{2}{|c|}{ Visita 2} & Total \\
\hline & & & NO & SI & \\
\hline \multirow{4}{*}{ Visita 1} & \multirow{2}{*}{ NO } & $\mathrm{n}$ & 166 & 0 & 166 \\
\hline & & $\%$ & $100,0 \%$ & $0,0 \%$ & $97,6 \%$ \\
\hline & \multirow{2}{*}{ SI } & $n$ & 0 & 4 & 4 \\
\hline & & $\%$ & $0,0 \%$ & $100,0 \%$ & $2,4 \%$ \\
\hline \multirow{2}{*}{\multicolumn{2}{|c|}{ Total }} & $\mathrm{n}$ & 166 & 4 & 170 \\
\hline & & $\%$ & $97,6 \%$ & $2,4 \%$ & $100,0 \%$ \\
\hline
\end{tabular}


Tablas comparativas entre la visita 1 y 2 relativas al Análisis del estado periodontal y necesidad de tratamiento y la presencia de pendientes en labios y lengua

Tabla 6.11a

ESTADO PERIODONTAL

(p-valor $<0,001$ )

\begin{tabular}{|c|c|c|c|c|c|c|c|}
\hline & & & \multicolumn{4}{|c|}{ Visita 2} & \multirow[t]{2}{*}{ Total } \\
\hline & & & Sano & $\begin{array}{c}\text { Hemorragi } \\
\text { a }\end{array}$ & Cálculo & $\begin{array}{c}\text { Bolsa 4-5 } \\
\text { mm }\end{array}$ & \\
\hline \multirow{8}{*}{ Visita 1} & \multirow[t]{2}{*}{ Sano } & $n$ & 25 & 0 & 0 & 0 & 25 \\
\hline & & $\%$ & $100,0 \%$ & $0,0 \%$ & $0,0 \%$ & $0,0 \%$ & $100,0 \%$ \\
\hline & \multirow[t]{2}{*}{ Hemorragia } & $n$ & 4 & 2 & 0 & 0 & 6 \\
\hline & & $\%$ & $66,7 \%$ & $33,3 \%$ & $0,0 \%$ & $0,0 \%$ & $100,0 \%$ \\
\hline & \multirow[t]{2}{*}{ Cálculo } & $n$ & 30 & 4 & 72 & 17 & 123 \\
\hline & & $\%$ & $24,4 \%$ & $3,3 \%$ & $58,5 \%$ & $13,8 \%$ & $100,0 \%$ \\
\hline & \multirow{2}{*}{$\begin{array}{l}\text { Bolsa 4-5 } \\
\mathrm{mm}\end{array}$} & $n$ & 2 & 1 & 4 & 9 & 16 \\
\hline & & $\%$ & $12,5 \%$ & $6,3 \%$ & $25,0 \%$ & $56,3 \%$ & $100,0 \%$ \\
\hline \multirow{2}{*}{\multicolumn{2}{|c|}{ Total }} & $\mathrm{n}$ & 61 & 7 & 76 & 26 & 170 \\
\hline & & $\%$ & $35,9 \%$ & $4,1 \%$ & $44,7 \%$ & $15,3 \%$ & $100,0 \%$ \\
\hline
\end{tabular}

Tabla 6.12a

NECESIDAD DE TRATAMIENTO PERIODONTAL

(p-valor $<0,001)$

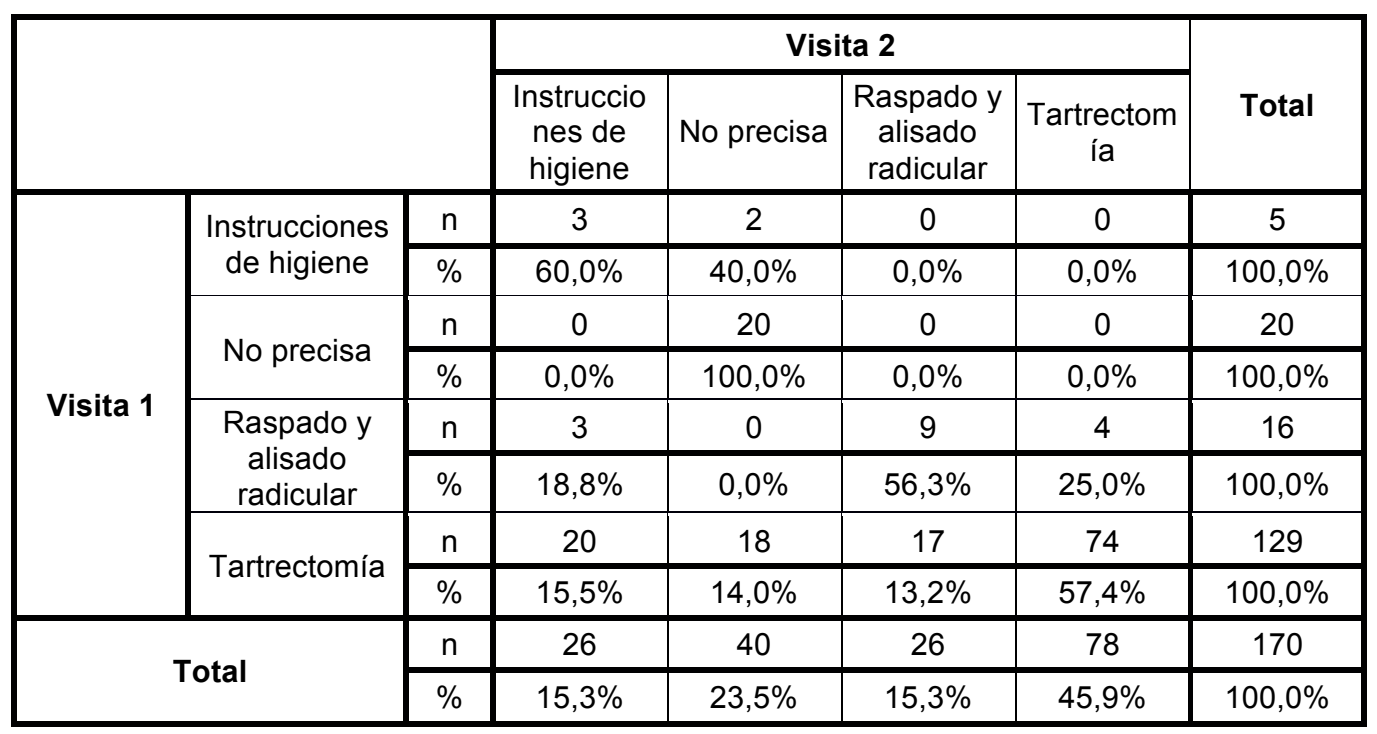


Tabla 6.13a

PENDIENTE EN LENGUA

$$
(p=1,000)
$$

\begin{tabular}{|c|c|c|c|c|c|}
\hline & & & \multicolumn{2}{|c|}{ Visita 2} & Total \\
\hline & & & NO & SI & \\
\hline \multirow{4}{*}{ Visita 1} & \multirow{2}{*}{ NO } & $n$ & 159 & 0 & 159 \\
\hline & & $\%$ & $100,0 \%$ & $0,0 \%$ & $100,0 \%$ \\
\hline & \multirow{2}{*}{ SI } & $\mathrm{n}$ & 1 & 10 & 11 \\
\hline & & $\%$ & $9,1 \%$ & $90,9 \%$ & $100,0 \%$ \\
\hline \multirow{2}{*}{\multicolumn{2}{|c|}{ Total }} & $\mathrm{n}$ & 160 & 10 & 170 \\
\hline & & $\%$ & $94,1 \%$ & $5,9 \%$ & $100,0 \%$ \\
\hline
\end{tabular}

Tabla6.14a

PENDIENTE EN LABIO

$$
\mathrm{p}=1,000
$$

\begin{tabular}{|c|c|c|c|c|c|}
\hline & & & \multicolumn{2}{|c|}{ Visita 2} & \multirow[t]{2}{*}{ Total } \\
\hline & & & NO & SI & \\
\hline \multirow{4}{*}{ Visita 1} & \multirow{2}{*}{ NO } & $\mathrm{n}$ & 165 & 0 & 165 \\
\hline & & $\%$ & $100,0 \%$ & $0,0 \%$ & $100,0 \%$ \\
\hline & \multirow{2}{*}{ SI } & $\mathrm{n}$ & 0 & 5 & 5 \\
\hline & & $\%$ & $0,0 \%$ & $100,0 \%$ & $100,0 \%$ \\
\hline \multirow{2}{*}{\multicolumn{2}{|c|}{ Total }} & $\mathrm{n}$ & 165 & 5 & 170 \\
\hline & & $\%$ & $97,1 \%$ & $2,9 \%$ & $100,0 \%$ \\
\hline
\end{tabular}


Tablas comparativas entre la visita 1 y 2 relativas a la situación de prótesis y necesidad de prótesis.

Tabla6.15a

ESTADO PROTESIS SUPERIOR

p-valor $=1,000$

\begin{tabular}{|c|c|c|c|c|c|c|c|c|}
\hline & & & \multicolumn{5}{|c|}{ Visita 2} & \multirow[b]{2}{*}{ Total } \\
\hline & & & Ninguna & Puente & $\begin{array}{c}\text { Más de un } \\
\text { puente }\end{array}$ & $\begin{array}{l}\text { Parcial } \\
\text { removible }\end{array}$ & $\begin{array}{c}\text { Puentes } \\
\text { con } \\
\text { implantes }\end{array}$ & \\
\hline \multirow{8}{*}{ Visita 1} & \multirow{2}{*}{ Ninguna } & $\mathrm{n}$ & 158 & 1 & 1 & 1 & 0 & 158 \\
\hline & & $\%$ & $92,9 \%$ & $6 \%$ &, $6 \%$ & $6 \%$ & $0,0 \%$ & $100,0 \%$ \\
\hline & \multirow{2}{*}{ Puente } & $\mathrm{n}$ & 0 & 9 & 0 & 0 & 0 & 9 \\
\hline & & $\%$ & $0,0 \%$ & $5,3 \%$ & $0,0 \%$ & $0,0 \%$ & $0,0 \%$ & $100,0 \%$ \\
\hline & \multirow{2}{*}{$\begin{array}{l}\text { Más de un } \\
\text { puente }\end{array}$} & $\mathrm{n}$ & 0 & 0 & 2 & 0 & 0 & 2 \\
\hline & & $\%$ & $0,0 \%$ & $0,0 \%$ & $1,2 \%$ & $0,0 \%$ & $0,0 \%$ & $100,0 \%$ \\
\hline & \multirow{2}{*}{$\begin{array}{c}\text { Puentes y } \\
\text { parcial } \\
\text { removible }\end{array}$} & $\mathrm{n}$ & 0 & 0 & 0 & 0 & 1 & 1 \\
\hline & & $\%$ & $0,0 \%$ & $0,0 \%$ & $0,0 \%$ & $0,0 \%$ &, $6 \%$ & $100,0 \%$ \\
\hline \multirow{2}{*}{\multicolumn{2}{|c|}{ Total }} & $\mathrm{n}$ & 155 & 10 & 3 & 1 & 1 & 170 \\
\hline & & $\%$ & $91,2 \%$ & $5,9 \%$ & $1,8 \%$ &, $6 \%$ &, $6 \%$ & $100,0 \%$ \\
\hline
\end{tabular}

Tabla 6.16a

ESTADO PROTESIS INFERIOR

p-valor $=0,317$

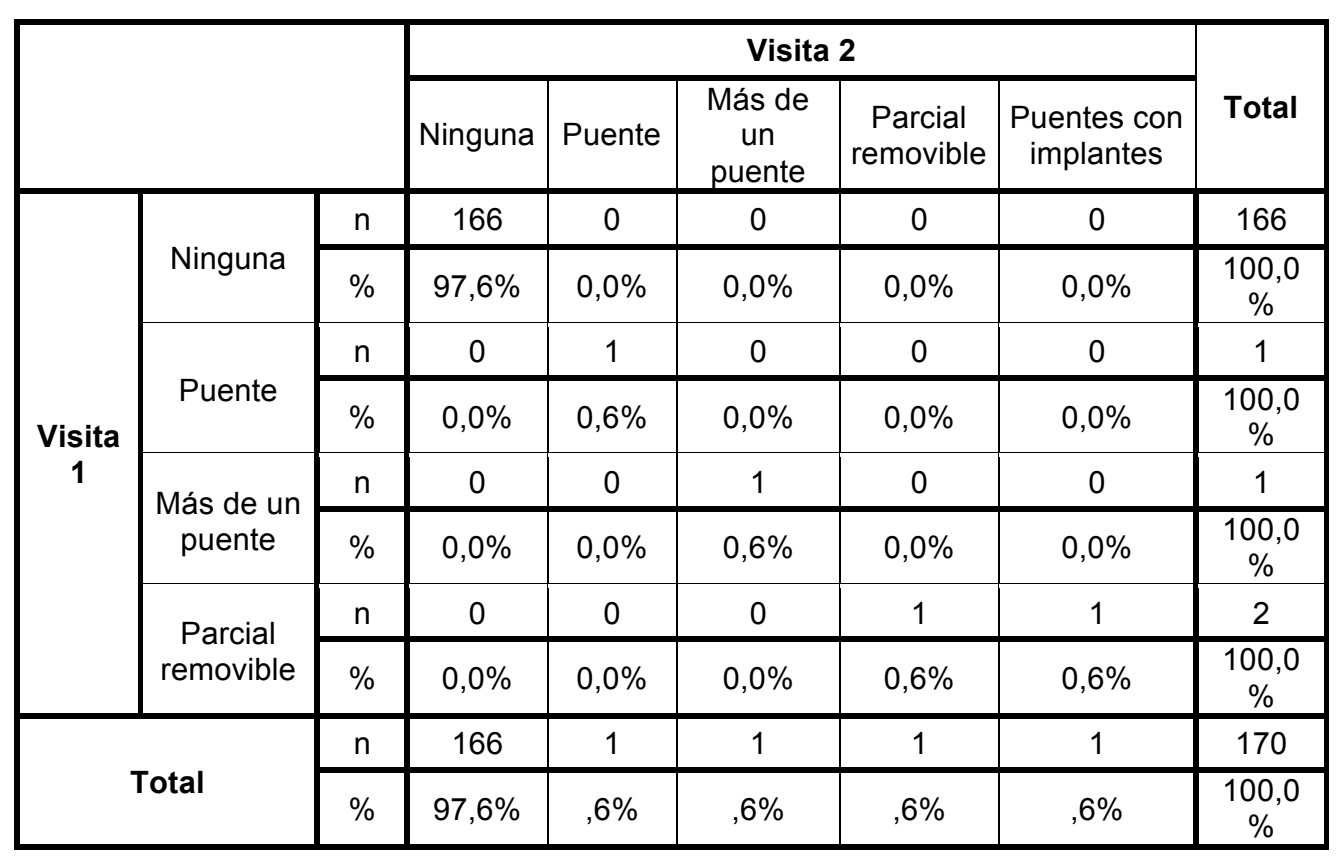


Tabla 6.17a

NECESIDAD DE PRÓTESIS SUPERIOR

p-valor $<0,001$

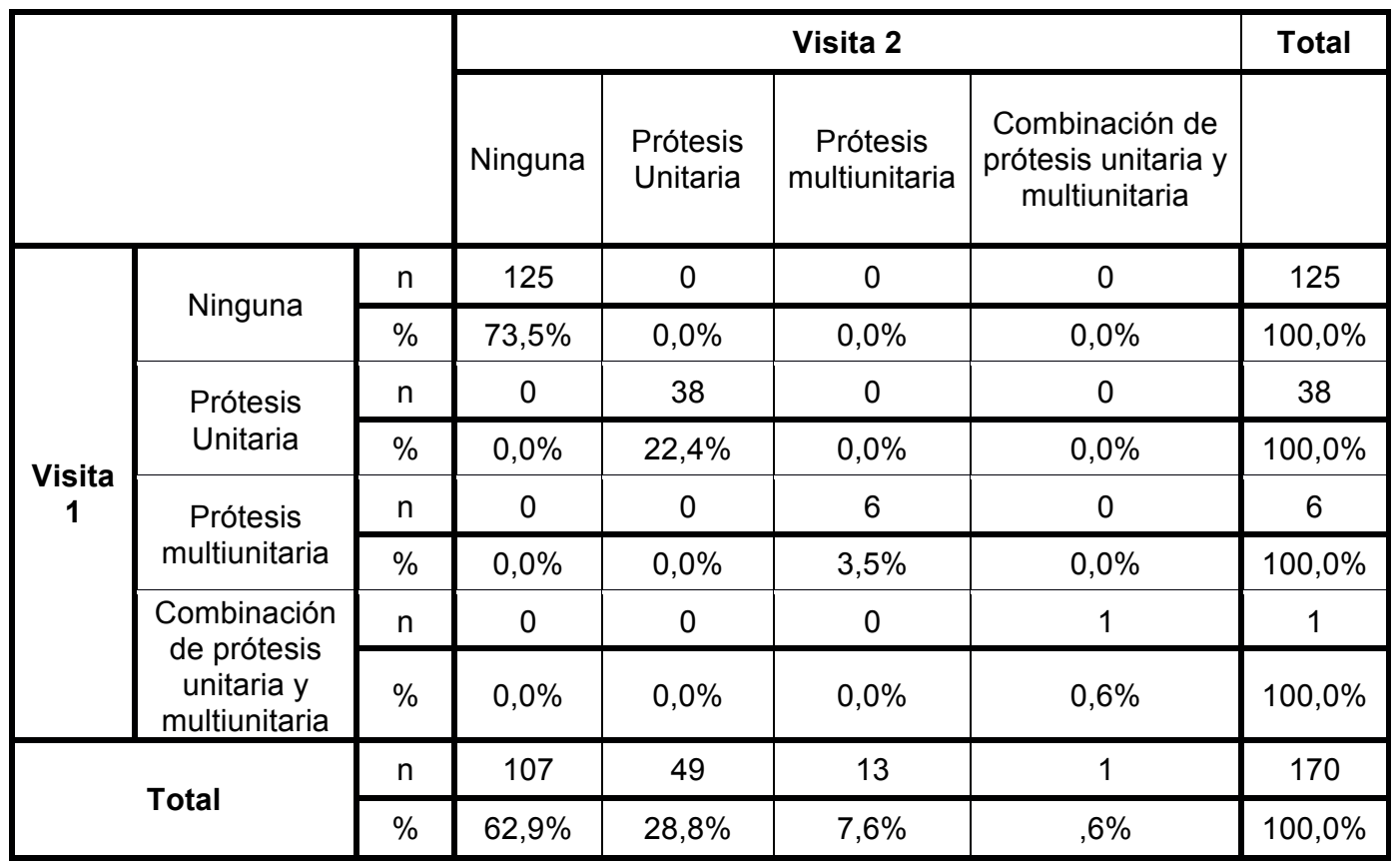

Tabla 6.18a

NECESIDAD DE PROTESIS INFERIOR

p-valor $<0,001$

\begin{tabular}{|c|c|c|c|c|c|c|}
\hline & & & \multicolumn{3}{|c|}{ Visita 2} & \multirow[t]{2}{*}{ Total } \\
\hline & & & Ninguna & $\begin{array}{l}\text { Prótesis } \\
\text { Unitaria }\end{array}$ & $\begin{array}{c}\text { Prótesis } \\
\text { multiunitaria }\end{array}$ & \\
\hline \multirow{6}{*}{ Visita 1} & \multirow{2}{*}{ Ninguna } & $\mathrm{n}$ & 117 & 0 & 0 & 117 \\
\hline & & $\%$ & $68,8 \%$ & $0,0 \%$ & $0,0 \%$ & $100,0 \%$ \\
\hline & \multirow{2}{*}{$\begin{array}{l}\text { Prótesis } \\
\text { Unitaria }\end{array}$} & $\mathrm{n}$ & 0 & 39 & 0 & 39 \\
\hline & & $\%$ & $0,0 \%$ & $22,9 \%$ & $0,0 \%$ & $100,0 \%$ \\
\hline & \multirow{2}{*}{$\begin{array}{c}\text { Prótesis } \\
\text { multiunitaria }\end{array}$} & $\mathrm{n}$ & 0 & 0 & 14 & 14 \\
\hline & & $\%$ & $0,0 \%$ & $0,0 \%$ & $8,2 \%$ & $100,0 \%$ \\
\hline \multirow{2}{*}{\multicolumn{2}{|c|}{ Total }} & $\mathrm{n}$ & 106 & 42 & 22 & 170 \\
\hline & & $\%$ & $62,4 \%$ & $24,7 \%$ & $12,9 \%$ & $100,0 \%$ \\
\hline
\end{tabular}


Tabla6.19a

IMPLANTES

p-valor $=0,765$

\begin{tabular}{|c|c|c|c|c|}
\hline & \multicolumn{2}{|c|}{ Visita 1} & \multicolumn{2}{|c|}{ Visita 2} \\
\hline & $\mathbf{n}$ & $\%$ & $\mathbf{n}$ & $\%$ \\
\hline inferiores & 3 & $50,0 \%$ & 16 & $53,3 \%$ \\
\hline superiores & 3 & $50,0 \%$ & 14 & $46,7 \%$ \\
\hline
\end{tabular}

Tablascomparativas entre la visita 1 y 2 relativas al análisis del estado oclusal (anomalías dentofaciales), presencia de tratamientos ortodoncicos y la necesidad de exodoncia de los terceros molares y presencia de dientes parcialmente erupcionados.

Tabla6.20a

ESTADO OCLUSAL

p-valor $=0,368$

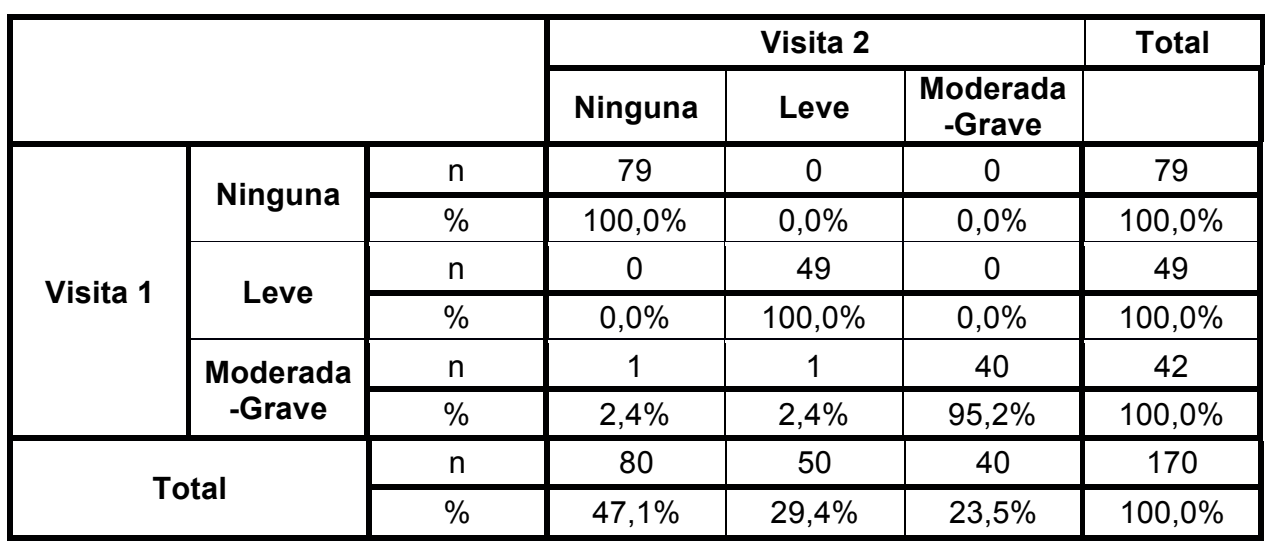


Tabla6.21a

TRATAMIENTO ORTODONCIA

p-valor=0,306

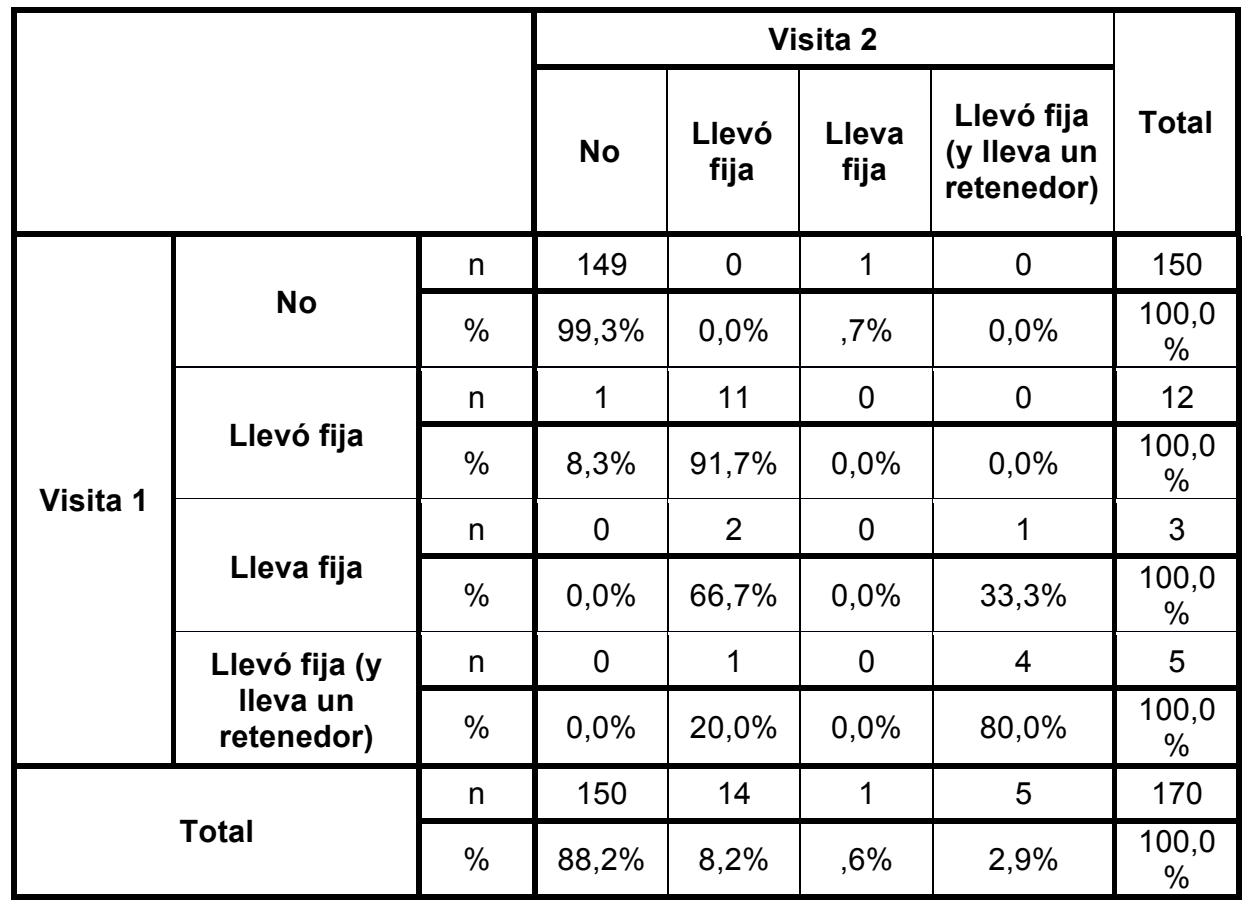




\section{Conclusiones}


Estudio epidemiológico de la salud bucodental y ... 


\section{CONCLUSIONES}

1. Entre la primera y la segunda visita se incrementó hasta el $77 \%$ los que se cepillan dos ó tres veces al día siendo las mujeres y los del grupo etario de menor edad los que muestran mayor frecuencia.

2. La presencia de torus mandibulares fue cercana al $8 \%$, porcentaje que no experimentó ningún cambio entre la primera y la segunda visita, y se vio más en los hombres, de la escala de tropa y el grupo etario de menor edad.

3. Los defectos del esmalte más observados fueron las opacidades difusas, luego las delimitadas $\mathrm{y}$ en tercer lugar las hipoplasias. No experimentaros cambios entre las dos visitas como ocurre con las alteraciones de color por tetraciclinas.

4. Se duplicó el número de sujetos sanos referidos a la salud periodontal entre la primera y la segunda visita representando las mujeres el mayor porcentaje.

5. Entre los tratamientos periodontales la tartrectomía es la más requerida, experimenta una notable disminución en la segunda visita. El número de hombres que requieren este tratamiento es superior al de mujeres como ocurre con los menores de 27 años y los de la escala de tropa, mientras que el raspado y alisado radicular tiene el comportamiento inverso.

6. El índice CAO-D en la segunda visita $(7,99)$ fue superior al de la primera $(7,59)$ debido a un incremento en los componentes de obturaciones y ausentes por caries, mientras que el índice de caries fue superior en la primera visita. Los valores del CAO-D de nuestro estudio se sitúan entre aquellos obtenidos en los países con un nivel de caries bajo en este grupo etario. 
7. En la segunda visita se aprecia una disminución significativa en la necesidad de tratamiento por caries.

8. El índice de restauración (IR) se incrementó en la segunda visita debido a que el incremento de edad en la población estudiada determina una patología dental subsidiaria que demanda tratamientos restauradores.

9. El porcentaje de prótesis fijas aumenta ligeramente en la segunda visita, siendo las necesidades mayores las prótesis unitarias y multiunitarias,

10. Las anomalías oclusales varían ligeramente entre la primera y a segunda visita. Nuestro grupo etario presenta tratamientos de ortodoncia que, hasta no hace mucho, estaban, fundamentalmente, vinculados a las cohortes infantojuveniles, constituyendo las maloclusiones leves el mayor porcentaje.

11. El grado de aptitud dental "no apto" paso de un $30 \%$ en la primera visita a un $8,2 \%$ en la segunda, por lo que se percibe la tendencia de llegar al $100 \%$ de aptos dentales. En ambas visitas los hombres, la escala de tropa y los menores de 27 años son los grupos a los que con mayor porcentaje se les dio un "no apto".

12. En nuestro estudio hemos podido comprobar que con el programa educativo de salud oral instaurado en el gabinete de odontología de la Base Militar y la consiguiente mejora de los hábitos de salud se puede mejorar el estado de salud bucodental, con su repercusión en la salud general de la población. 



\section{Referencias bibliográficas}


Estudio epidemiológico de la salud bucodental y ... 


\section{REFERENCIAS BIBLIOGRAFICAS}

1. World Health Organization (WHO). (2013). Plan de acción mundial para la prevención y el control de las enfermedades no transmisibles 20132020. Proyecto revisado y actualizado. Geneva, Switzerland

2. Estrategia de Promoción de la Salud y Prevención en el Sistema Nacional de Salud. Ministerio de Sanidad, Servicio Sociales e Igualdad. En el marco del abordaje de la cronicidad en el SNS . 18 de diciembre de 2013

3. Estrategia de Promoción de la Salud y Prevención en el Sistema Nacional de Salud. Ministerio de Sanidad, Servicio Sociales e Igualdad. Memoria de implementación 2014-2015 y evaluación preliminar. 29 de enero de2016.

4. Europa 2020: la estrategia europea de crecimiento. 2013. (felman.es). Los detalles y el seguimiento de la implantación de las diferentes políticas en: http//ec.europa.eu/europe2020/index_es.htm

5. Rengifo, Adolfo Contreras. La promoción de la salud general y la salud oral: una estrategia conjunta. Revista clínica de periodoncia, implantología y rehabilitación oral, 9 (2016) 193-202.

6. El Desafío de las Enfermedades Bucodentales - Una llamada a la acción global. Atlas de Salud Bucodental. 2a ed. Ginebra: Federación Dental Internacional (FDI); 2015. Capitulo 2, p. 12-36.

7. El Desafío de las Enfermedades Bucodentales - Una llamada a la acción global. Atlas de Salud Bucodental. $2^{\mathrm{a}}$ ed. Ginebra: Federación Dental Internacional (FDI); 2015. Capitulo 2, p. 79-89.

8. World Health Organization. Declaración de Adelaida sobre la salud en todas las politicas: hacia una gobernanza compartida en pro de la salud y el bienestar. Organización Mundial de la Salud 2010. ISBN 978924 3599724

9. Bourgeois, Denis M.; Llodra, J. C. (edts.) Health surveillance in Europe. European global oral health indicators development project. Paris: Quintessence International, 2004. ISBN 2-912550-31-9

10. Ottolenghi, L., Muller-Bolla, M., Strohmenger, L., \& Bourgeois, D. Oral health indicators for children and adolescents. European perspectives. European Journal of Paediatric Dentistry. 8 (4) (2007) 205-210.

11. Asamblea Mundial de la Salud, S. S. A. Asamblea Mundial de la Salud: primera reunión extraordinaria, Ginebra, 9 de noviembre de 2006: resoluciones y decisión: anexo. 2007. Resolución WHA60.17 (Undécima sesión plenaria, 23 de mayo de 2007). 
12. World Health Organization. Oral Health Surveys-Basic Methods. 1997, Geneva. World Health Organization 4.

13. World Health Organization. Oral health surveys: basic methods. World Health Organization 2013.

14. Llodra Calvo, JC.; Bourgeois, D.. Estudio prospectivo Delphi. La salud bucodental en España 2020.Tendencias y objetivos de salud oral. Consejo General de Odontólogos y Estomatólogos de España [en línea][consultado el 21/03/2016]. Disponible en www. consejodentistas. es/pdf/0912\% 20Libro\% 20Estu dio\% 20Delphi.pdf (2009)

15. Llodra Calvo JC.. Encuesta de Salud Oral en España 2010 RCOE. 17 (2012) 13-41.

16. Nithila, A., Bourgeois, D., Barmes, D. E., \& Murtomaa, H. Banco Mundial de Datos sobre Salud Bucodental de la OMS, 1986-1996: panorámica de las encuestas de salud bucodental a los 12 años de edad. Revista Panamericana de Salud Pública. 4 (6) (1998) 411-418

17. Instrucción Técnica No3 de 13 de Mayo de 2014, de la Inspección General de Sanidad de la Defensa, sobre "Asistencia Odontológica en las Fuerzas Armadas".

18. Inspección General de Sanidad. Sanidad militar en las operaciones humanitarias y de paz. Publicaciones de Defensa. Fecha de edición. 2007

19. Sánchez Moreno, V.. I Congreso Internacional de Sanidad. Revista Española de Defensa. Diciembre 2014. Pág. 14-17.

20. Allied Joint Publication AJP-4.10, Edition B, Version 1, Allied Joint Doctrine for Medical Support. The agreement of nations to use this publication is recorded in STANAG 2228.28 May 2015.

21. Doctrina Sanitaria Conjunta (DOSACON). Documento del Estado Mayor de la Defensa (Ministerio de Defensa) del 01/01/2010.

22. Norma General xx/12 Subsistema de Sanidad (SUSAN). Abril 2012.

23. Publicación Doctrinal. Sanidad en Operaciones (PD4-616). 15 de abril de 2011.

24. STANAG 2061 MED (EDITION 5) - Procedures for Disposition of Allied Patients by Medical Installations.16 October 2001.

25. Allied Medical Publication AMedP-1.3 Edition A, Version 1 Guidelines a for Multinational Medical. The agreement of nations to use this publication is recorded in STANAG 2552. 5 July 2013.

26. Chereguini Pavón, E.; Blasco Ferrándiz, R. La Sanidad Militar Operacional, en el contexto multinacional. Sanidad Militar, 71 (2015, 109-116.

27. Publicación Doctrinal. Compañía de Sanidad (PD4-600 Anexo E). 12-62015.

28. Gobierno de España. LEY 44/2003, de 21 de noviembre, de ordenación 
de las profesiones sanitarias. Recuperado de: http://www. boe. es/boe/dias/2003/11/22/pdfs/A41442-41458. Pdf, 2003.

29. CICR. Servicio de Asesoramiento en Derecho Internacional Humanitario. ¿Qué es el derecho internacional humanitario?.07/2004.

30. López, José María Relanzón; Escribano, Francisco Calleja; Sierra, Francisco Martín. La Subinspección General de Sanidad LogísticoOperativa. Ejército: de tierra español, 838 (2011 54-61.

31. Instrucción Técnica de 15 julio de 2011 de la Inspección General de Sanidad de la Defensa, actualizada a 30 julio de 13 sobre "requisitos sanitarios exigibles al personal militar que se desplace a zona de operaciones".

32. Campillo Laguna, J. R. Bases históricas del escalonamiento del Servicio de Sanidad en operaciones. Sanid. mil, (2008) 43-51.

33. Kvasnicka, Delene, et al. AR 40-66 06/17/2008 Medical Record Administration and Health Care Documentation, Survival Ebooks. Delene Kvasnicka www. survivalebooks. Com, 2008.

34. Allied Medical Publication AMedP-8.1 Edition A, Version 1, Documentation Relative to Initial Medical Treatment and Evacuation. The agreement of nations to use this publication is recorded in STANAG 2132. 11 June 2013.

35. Allied Medical Publication AMedP-35 Edition A, Version 1-The Extend of Dental and Maxillofacial Treatment at Role 1-3 Medical Support. is a nonclassified publication. The agreement of NATO nations to use this publication is recorded in STANAG 2453. 6 June 2012.

36. Navarro Suay, R., et al. Despliegue y capacidades sanitarias en la región oeste de Afganistán (provincia de Badghis y Herat) de agosto a noviembre 2012. Sanidad Militar, 69 (2013) 48-60.

37. Hernández Abadía de Barbará, Alberto. Sistema de telemedicina de las Fuerzas Armadas Españolas. Unidad de Telemedicina del Hospital Central de la Defensa. IGESAN. Ministerio de Defensa. 2006.

38. Allied Medical Publication AMedP-37 - Development and Implementation of Teleconsul Tation Systems is a non-classified publication, the agreement of NATO nations to use this publication is recorded in STANAG 2517. 31 January 2012.

39. Hillán García, L.; Setién Dodero, F.; Del Real Colomo, A. El Sistema de Telemedicina Militar en España: una aproximación histórica. Sanidad Militar. 70 (2014) 121-131.

40. Protocolo de actuación con el sistema de Telemedicina, emitido por la Unidad de Telemedicina del Hospital Central de la Defensa "Gómez Ulla”. 03/10/07.

41. Linares, Manuel José Guiote; Blanco, Pedro Encinas. Tele Medicina a nivel táctico: un proyecto pionero en desarrollo. Ejército: de tierra 
español, 861 (2012) 10-16.

42. Bellod, Enrique Selva. El nuevo hospital de campaña. Ejército: de tierra español. 851 (2012) 74-83.

43. Laguardia Chueca, J. C., et al. Definición de un ROLE 1 sobre contenedor" 6 en 1" de la Unidad Médica Aérea de Apoyo al Despliegue (UMAAD) Zaragoza. Sanidad Militar, 68 (2012) 40-43.

44. Instrucción 01/2015 del Comandante del Mando de Operaciones (CMOPS) sobre "seguimiento de evacuados a TN por motivos médicos que no causan baja en la operación".

45. Fernández Díez, Ángel. Hacia el nuevo Hospital Central de la Defensa" Gómez Ulla". Sanidad Militar, 67 (2011) 55.

46. Bel Blesa, A. La odontología forense en las Fuerzas Armadas: Una asignatura pendiente. Sanidad Militar, 67 (2011) 375-380.

47. Sáenz Aznárez, A.. La Inspección General de Sanidad. Ejército: de tierra español, 838 (2011) 40-45.

48. García González, J.A. “Análisis sobre la sanidad militar: posibles soluciones". www.onemagazine.es. 4 de Noviembre de 2011.

49. Orden Ministerial 17/2012, de 15 de marzo, por la que se regula la estructura de la Red Sanitaria Militar. (B.O.D n ${ }^{\circ} 59$, de 23 de marzo).

50. Instrucción 2/2013, de 15 de enero, de la Subsecretaria de Defensa, por la que se asignan funciones y cometidos en el ámbito de la Inspección General de Sanidad de la Defensa y se describe su estructura orgánica. (B.O.D n ${ }^{\circ} 18$, de 25 de enero).

51. Grueso García, E. la sanidad militar operativa. Adaptación de la inspección general de sanidad de la defensa al proceso de transformación de las fuerzas armadas. 30 de abril de 2014.

52. Real Decreto Legislativo $1 / 2000$, de 9 de junio, por él que se aprueba el texto refundido de la Ley sobre Seguridad Social de las Fuerzas Armadas (B.O.E $\mathrm{n}^{\circ} 142$, de 14 de junio).

53. Real Decreto 1726/2007, de 21 de diciembre, por el que se aprueba el Reglamento General de la Seguridad Social de las Fuerzas Armadas (B.O.E n ${ }^{\circ} 310$, de 27 de diciembre).

54. Gutiérrez, José Alfonso Delgado. La Subinspección General de Sanidad Asistencial. Ejército: de tierra español, 838 (2011) 46-53.

55. Manual de Medicina Preventiva en Operaciones. Instituto de Medicina Preventiva de la Defensa. Fecha de edición: abril 2007.

56. Quílez Guerrero, S. C.; Quílez Caballero, E.; Pichoto Urbano, J. L. Eficacia de la Sanidad Militar en la prevención cardiovascular del contingente de Melilla: relevancia de la Telemedicina. Sanidad Militar, 70 (2014) 147-156.

57. Recomendaciones higiénico-sanitarias en operaciones y ejercicios. Instituto de Medicina Preventiva de la Defensa. $6{ }^{\text {a }}$ edición. Fecha de 
edición: marzo 2015.

58. Alsina Álvarez, J.. "La Medicina Preventiva Militar cumple 125 años". Boletín sanidad, 4 (2010) 17.

59. Torres León, J., et al. Análisis de las repatriaciones por causas médicas en el contingente español de la ISAF durante los años 2009-2012 y de los fallecimientos ocurridos en Afganistán desde el inicio de la misión hasta Diciembre de 2012. Sanidad Militar, 69 (2013) 154-163.

60. Real Decreto 96/2009, de 6 de febrero, por el que se aprueban las Reales Ordenanzas para las Fuerzas Armadas (B.O.E n 33 , de 7 de febrero de 2009).

61. Linares, Manuel José Guiote. La Sanidad Operativa: una necesidad imperiosa. Ejército: de tierra español, 851 (2012) 64-73.

62. Allied Medical Publication AJMedP-3, Edition A, Version 1, Allied Joint Medical Doctrine for Medical Intelligence. The agreement of nations to use this publication is recorded in STANAG 2547. 28 May 2015.

63. Commandant, Marine Corps. Field Hygiene and Sanitation. 21 June 2000.

64. Instrucción Técnica de 15 de enero de 2008, de la Inspección General de Sanidad, sobre "Vacunaciones en las Fuerzas Armadas" (actualizada a 29 de junio de 2012).

65. Guía De Salud Del Soldado Y El Marinero. Instituto de Medicina Preventiva de la Defensa. $2^{\circ}$ edición. Fecha de edición: marzo 2010.

66. Memoria Justificativa del Plan de Estudios de Teniente Del Cuerpo Militar De Sanidad Escala de Oficiales. Madrid, 1 de abril de 2013.

67. Allied Medical Publication AMedP-4.1 Edition A, Version 1, Deployment Health Surveillance. The agreement of nations to use this publication is recorded in STANAG 2535. 24 July 2014.

68. Instrucción Técnica de 7 de febrero de 2006, de la Inspección General de Sanidad, sobre la Ficha de Identificación Sanitaria y Huella Genética (actualizada a 14 de mayo de 2012).

69. Allied Medical Publication AMedP-4.8 Edition A, Version 1, Pre- And Post- Deployment Health Assessment. The agreement of nations to use this publication is recorded in STANAG 2235. 18 December 2013.

70. Instrucción 59/2013, de 30 de julio, de la Subsecretaría de Defensa, por la que se regula el Funcionamiento del Hospital Central de la Defensa «Gómez Ulla» y se describe su Organización Básica. (B.O.D n¹57, de 12 de agosto de 2013).

71. Instrucción Técnica 06/2003 sobre "Organización y funcionamiento del servicio de sanidad en las bases, acuartelamientos y establecimientos".

72. Real Decreto 2394/2004 de 30 de diciembre, por el que se aprueba el Protocolo para la recuperación, identificación, traslado e inhumación de los restos mortales de los miembros de las Fuerzas Armadas, Guardia Civil y Cuerpo Nacional de Policía fallecidos en operaciones fuera del 
territorio nacional. (B.O.E $\mathrm{n}^{\circ} 13$, de 15 de enero de 2005).

73. Martínez Chicón, J.; Luna Del Castillo, J. D.; Valenzuela Garach, A. La variabilidad de los tratamientos dentales en una población militar española y su importancia para la estimación de la probabilidad de identificación dental. Cuadernos de Medicina Forense. 53-54 (2008) 223-233.

74. BEL BLESA, A. La odontología forense en las Fuerzas Armadas: Una asignatura pendiente. Sanidad Militar, 67 (2011) 375-380.

75. Allied Medical Publication AMedP-3.1, Edition A, Version 1, Military Forensic Dental Identification. The agreement of nations to use this publication is recorded in STANAG 2464. 1 December 2014.

76. Allied Medical Publication AMedP-36 Edition A, Version 1, Tasks and Skills for Appropriate Staffing of Dental Personnel for Operational Deployment. The agreement of NATO nations to use this publication is recorded in STANAG 2465. 23 February 2012.

77. Allied Medical Publication AMedP-1.12, Edition A, Version 1, Medical and Dental Supply Procedures. The agreement of nations to use this publication is recorded in STANAG 2128. 21 January 2014.

78. Procedimiento operativo logístico S-1 "Abastecimiento, mantenimiento y transporte de recursos clase VIII" actualizado 15 febrero 2015.

79. Allied Medical Publication AMedP-1.10, Edition A, Version 1, Medical Aspects In The Management Of A Major Incident/Mass Casualty Situation. The agreement of nato nations to use this publication is recorded in STANAG 2879. 3 December 2015.

80. Boletín Epidemiológico de las Fuerzas Armadas. "Plan de prevención bucodental en las Fuerzas Armadas". Vol.19. n²26. Agosto 2012.

81. Allied Medical Publication AMedP-4.4, Edition A, Version 1, Dental Fitness Standards for Military Personnel and the Nato Dental Fitness Classification System. The agreement of nations to use this publication is recorded in STANAG 2466. 10 October 2014.

82. González Santiago, María del Mar; Martinez-Sahuquillo Marquez, Angel; Bullón Fernández, Pedro. Prevalencia de las barodontalgias y su relación con el estado bucodental en el personal con responsabilidad en vuelo militar. Medicina Oral, Patología Oral y Cirugía Bucal (Ed. impresa), 9 (2004) 92-105.

83. Mombiedro Sandoval, Rafael; Llena Puy, Carmen. Emergencias orales en los militares españoles desplegados en Bosnia Herzegovina: Incidencias durante 9 semanas (2000-2001). RCOE, 12 (, 2007) 237-244.

84. Lostao, Lourdes, et al. Evolución de las diferencias socioeconómicas en la utilización y accesibilidad de los servicios sanitarios en España entre 1987 y 1995/97. Revista Española de Salud Pública, 75 (2001) 115-128.

85. Nieto García, Víctor Miguel, et al. Salud oral de los escolares de Ceuta: 
influencias de la edad, el género, la etnia y el nivel socioeconómico. Revista española de salud pública, 75 (2001) 541-550.

86. Mombiedro Sandoval, R. Misiones de la Sanidad Militar, Especialidad fundamental odontología: propuesta de empleo. Sanidad Militar, 69 (2013) 266-273.

87. Allied Medical Publication AMedP-1.13, Edition A, Version 1, Essential Physical Requirements and Performance Characteristics of Field Type High Pressure Steam Sterilizers. The agreement of nations to use this publication is recorded in STANAG 2906. 8 January 2015.

88. Directrices de Oslo. Directrices sobre la utilización de recursos militares y de la defensa civil extranjeros en operaciones de socorro en casos de desastre. Revisión 1.1, noviembre de 2007.

89. Allied Joint Publication AJP-3.4.9 Edition A, Version 1, Allied Joint Doctrine For Civil-Military Cooperation. The agreement of nations to use this publication is recorded in STANAG 2509. 8 February 2013.

90. Real Decreto 944/2001 de 3 de agosto por el que se aprueba el Reglamento para la determinación de la aptitud psicofísica del personal de las Fuerzas Armadas. (B.O.D, $\mathrm{n}^{\mathrm{o}}$ 155, de 8 de agosto de 2001).

91. Orden Ministerial 23/2011, de 27 de abril, por la que se aprueban las normas para la valoración de la aptitud médica del personal de las Fuerzas Armadas con responsabilidad de vuelo. (BOD n 88, de 6 de mayo de 2011).

92. Orden ministerial delegada núm. 282/1982, de 20 de octubre, del Almirante Jefe del Estado Mayor de la Armada, por la que se aprueba el Reglamento de las Especialidades y Aptitudes de Buceo de la Armada.

93. STANAG 2122 MEDSTD (edition 3) (ratification draft 1) Requirement for Training in First-Aid, Emergency Care in Combat Situations and Basic Hygiene for all Military Personnel. 16 December 2009.

94. Protocolo de Asistencia sanitaria a bajas NBQ en primeros escalones (Protocolos Generales). Inspección General de Sanidad de la Defensa. 20 de Mayo de 2008.

95. Mombiedro Sandoval, R.; Llena Puy, C. Caries en una población militar española. Sanidad Militar, 67 (2011) 36-42.

96. Bosch Robaina, R.; Rubio Alonso, Margarita; García Hoyos, Felisa. Conocimientos sobre salud bucodental y evaluación de higiene oral antes y después de una intervención educativa en niños de 9-10 años. Avances en odontoestomatología, 28 (2012) 17-23.

97. IUHPE, Informe. La Evidencia de la Eficacia de la Promoción de la Salud. Configurando la Salud Pública de la Nueva Europa. Madrid: Ministerio de Sanidad y Consumo, 2000.

98. Okeson, Jeffrey P. Tratamiento de oclusión y afecciones 
temporomandibulares + Evolve. Ed. Elsevier España, 2013.

99. Gil Loscos, F., et al. Sistemática de la higiene bucodental: el cepillado dental manual. Periodoncia: Revista Oficial de la Sociedad Española de Periodoncia, 15 (2005) 43-58.

100.Real Decreto 815/2001, de 13 de julio, sobre justificación del uso de las radiaciones ionizantes para la protección radiológica de las personas con ocasión de exposiciones médicas. (BOE núm. 168, de 14 de julio de 2001).

101.Kay, E.J. and Locker, D. Is dental health education effective?. A systematic review of current evidence. Community Dentistry and Oral Epidemiology, 22 (1996) 231-234.

102.Davidson, P.L., Rams, T.E. and Andersen, R.M. Socio-behavioral determinants of oral higiene practices among USA ethnic and age groups. Advanced Dental Health Research11 (1997) 245-253.

103.Freeman, R and Linden, G. Health directed and health related dimensions of oral health behaviours of periodontal referrals. Community Dental Health12 (1995) 48-51.

104.Buunk-Werkhoven, Y. A., Dijkstra, A., van der Schans, C. P., Jaso, M. E., Acevedo, S., \& Estellano, G. P. (2016). Evaluación y promoción de la actitud hacia la higiene oral en pacientes de la Facultad de Odontología de la Universidad Católica del Uruguay. Actas Odontológicas, 5(2), 1320.

105.Sakki, T. K., Knuuttila, M. L., \& Anttila, S. S. (1998). Lifestyle, gender and occupational status as determinants of dental health behaviour. Journal of clinical periodontology, 25(7), 566-570.

106.Schou, L. (2000). The relevance of behavioural sciences in dental practice. International dental journal, 50(S6_Part1), 324-332.

107.Casals-Peidró, E. Hábitos de hygiene oral en la población escolar y adulta española. RCOE 12 (2007) 23-29.

108.Bravo-Pérez, M., Casals-Peidró, E., Cortés-Martinicorena, F., LlodraCalvo, J. C., Álvarez-Arenas Pardina, I., Hermo-Señariz, P., ... \& Tamayo-Fonseca, N. P. (2006). Encuesta de salud oral en España 2005. RCOE, 11(4), 409-456.

109.Fernández-Rivero P., Gonzalvez-Becerra P., Leis-Filloy C., SmythChamosa E. Tabaco y salud oral en estudiantes de la Universidad de Santiago de Compostela. RCOE 10 (2007) 23-29.

110. Mombiedro R. Estado de salud y necesidad de asistencia oral en una población militar. Tesis Doctoral. U. Complutense de Madrid. 2010.

111.Fernández T., De la Torre J., Lozano M., Alba J. Estudio epidemiológico de la higiene bucodental en soldados de la base de Cerro Muriano (Córdoba). Med. Mil. 5 (1994) 524-527 
112.Elani, H. W., Harper, S., Thomson, W. M., Espinoza, I. L., Mejia, G. C., Ju, X., ... \& Kaufman, J. S. (2017). Social inequalities in tooth loss: A multinational comparison. Community Dentistry and Oral Epidemiology (en borrador).

113.Kinane, D. F., \& Chestnutt, I. G. (2000). Smoking and periodontal disease. Critical Reviews in Oral Biology \& Medicine, 11(3), 356-365.

114.Bergström, J. (2004). Influence of tobacco smoking on periodontal bone height. Long-term observations and a hypothesis. Journal of clinical periodontology, 31(4), 260-266.

115.Bahrami, G., Væth, M., Kirkevang, L. L., Wenzel, A., \& Isidor, F. (2017). The impact of smoking on marginal bone loss in a 10-year prospective longitudinal study. Community dentistry and oral epidemiology, 45(1), 59-65.

116.Machuca, G., Rosales, I., Lacalle, J. R., Machuca, C., \& Bullón, P. Effect of cigarette smoking on periodontal status of healthy young adults. Journal of periodontology, 71(1) (2000) 73-78.

117.Encuestas nacionales de salud en España. Ministerio de Sanidad y Consumo.URL:http//www.msc.es/estadEstudios/estadisticas/solicitud.ht $\mathrm{ml}$

118.Global Youth Tobacco Survey Collaborating Group. Differences in worldwide tobacco use by gender: findings from the Global Youth Tobacco Survey. The Journal of school health, 73(6) (2003) 207.

119.Wellman, R. J., Dugas, E. N., Dutczak, H., O’Loughlin, E. K., Datta, G. D., Lauzon, B., \& O'Loughlin, J. Predictors of the onset of cigarette smoking: A systematic review of longitudinal population-based studies in youth. American journal of preventive medicine, 51(5) (2016) 767778.

120.Smith, D. R., \& Leggat, P. A. An international review of tobacco smoking among dental students in 19 countries. International dental journal, 57(6) (2007) 452-458.

121.Reibel, J. Tobacco or oral health. Bulletin of the World Health Organization, 83(9) (2005) 643-643.

122.Meysman, M., Boudrez, H., Nackaerts, K., Dieriks, B., Indemans, R., \& Vermeire, P. Smoking cessation rates after a nurse-led inpatient smoking cessation intervention. Journal of Smoking Cessation, 5(01) (2010) 6976.

123.De Granda -OriveJ. I., Peña-Miguel, T., Jiménez-Ruiz, D. C., \& SolanoReina, D. S. Distribution of stages of change in smoking behavior in a group of young smokers (transtheoretical model). Military medicine,

124.Smith, B., Ryan, M. A., Wingard, D. L., Patterson, T. L., Slymen, D. J., Macera, C. A., \& Millennium Cohort Study Team. Cigarette smoking 
and military deployment: a prospective evaluation. American journal of preventive medicine, 35(6) (2008) 539-546.

125.Hermes, E. D., Wells, T. S., Smith, B., Boyko, E. J., Gackstetter, G. G., Miller, S. C., \& Smith, T. C. Smokeless tobacco use related to military deployment, cigarettes and mental health symptoms in a large, prospective cohort study among US service members. Addiction, 107(5) (2012) 983-994.

126. Talcott, G. W., Cigrang, J., Sherrill-Mittleman, D., Snyder, D. K., Baker, M., Tatum, J., ... \& Ebbert, J. O. Tobacco use during military deployment. nicotine \& tobacco research, 15(8) (2013) 1348-1354.

127.Sohn, W., \& Ismail, A. I. Regular dental visits and dental anxiety in an adult dentate population. The Journal of the American Dental Association, 136(1) (2005) 58-66.

128.Bhatti, T., Rana, Z., \& Grootendorst, P. (2007). Dental insurance, income and the use of dental care in Canada. J Can Dent Assoc, 73(1) (2007) 57.

129. Schuller, A. A., Willumsen, T., \& Holst, D. (2003). Are there differences in oral health and oral health behaviour between individuals with high and low dental fear?. Community dentistry and oral epidemiology, 31(2), 116-121.

130.Headache Classification Committee of the International Headache Society (IHS. (2013). The international classification of headache disorders, (beta version). Cephalalgia, 33(9) (2013) 629-808.

131. Okeson, J. P. The classification of orofacial pains. Oral and maxillofacial surgery clinics of North America, 20(2) (2008) 133-144.

132. Scarr, G., \& Harrison, H. Examining the temporo-mandibular joint from a biotensegrity perspective: a change in thinking. Journal of Applied Biomedicine, 15(1) (2017) 55-62.

133.Elledge, R., Green, J., \& Attard, A. (2017). Training in surgery of the temporomandibular joint: the UK trainers' perspective. British Journal of Oral and Maxillofacial Surgery, 55(1), 61-66.

134.Rajapakse, S., Ahmed, N., \& Sidebottom, A. J. (2017). Current thinking about the management of dysfunction of the temporomandibular joint: a review. British Journal of Oral and Maxillofacial Surgery. 55 351-356

135.Al-Jundi, M. A., John, M. T., Setz, J. M., Szentpetery, A., \& Kuss, O. Meta-analysis of treatment need for temporomandibular disorders in adult nonpatients. Journal of orofacial pain, 22(2) (2008) 97-107.

136. Manfredini, D., Arveda, N., Guarda-Nardini, L., Segù, M., \& Collesano, V. Distribution of diagnoses in a population of patients with temporomandibular disorders. Oral surgery, oral medicine, oral pathology and oral radiology, 114(5) (2012) e35-e41.

137.Manfredini, D., Guarda-Nardini, L., Winocur, E., Piccotti, F., Ahlberg, J., \& Lobbezoo, F. Research diagnostic criteria for temporomandibular 
disorders: a systematic review of axis I epidemiologic findings. Oral Surgery, Oral Medicine, Oral Pathology, Oral Radiology, and Endodontology, 112(4) (2011) 453-462.

138.Poveda Roda, R., Bagán, J. V., Díaz Fernández, J. M., Hernández Bazán, S., \& Jiménez Soriano, Y. Review of temporomandibular joint pathology: Part I: Classification, epidemiology and risk factors. Medicina Oral, Patología Oral y Cirugía Bucal (Internet), 12(4) (2007) 292-298.

139. Chokalingam, S., \& DAS, F. Malocclusion and TMJ disease-A review of literature. IOSR JDMS, 13(1) (2014) 71-73.

140.Di Paolo, C., D’Urso, A., Papi, P., Di Sabato, F., Rosella, D., Pompa, G., \& Polimeni, A. Temporomandibular Disorders and Headache: A Retrospective Analysis of 1198 Patients. Pain Research and Management. 2017 (2017) 3203027 (8 pgs.).

141.Manfredini, D., \& Lobbezoo, F. Role of psychosocial factors in the etiology of bruxism. Journal of orofacial pain, 23(2) (2009)

142.Winocur, E., Gavish, A., Voikovitch, M., Emodi-Perlman, A., \& Eli, I. Drugs and bruxism: a critical review. Journal of orofacial pain, 17(2) (2003) 99-111.

143.Rintakoski, K., \& Kaprio, J. Legal psychoactive substances as risk factors for sleep-related bruxism: a nationwide Finnish Twin Cohort study. Alcohol and alcoholism, 48(4) (2013) 487-494.

144.Abe, Y., Suganuma, T., Ishii, M., Yamamoto, G. O. U., Gunji, T., Clark, G. T., ... \& Baba, K. Association of genetic, psychological and behavioral factors with sleep bruxism in a Japanese population. Journal of sleep research, 21(3) (2012) 289-296.

145.Manfredini, D., \& Lobbezoo, F. (2010). Relationship between bruxism and temporomandibular disorders: a systematic review of literature from 1998 to 2008. Oral Surgery, Oral Medicine, Oral Pathology, Oral Radiology, and Endodontology, 109(6), e26-e50.

146.Berger, M., Szalewski, L., Szkutnik, J., Ginszt, M., \& Ginszt, A. (2017). Different association between specific manifestations of bruxism and temporomandibular disorder pain. Neurologia i neurochirurgia polska, 51(1) (2017) 7-11.

147.Murali, R. V., \& Priyadarshni Rangarajan, A. M. Bruxism: Conceptual discussion and review. Journal of pharmacy \& bioallied sciences, 7(Suppl 1) (2015) S265.

148.Manfredini, D., Piccotti, F., Ferronato, G., \& Guarda-Nardini, L. Age peaks of different RDC/TMD diagnoses in a patient population. journal of dentistry, 38(5) (2010) 392-399.

149.Manfredini, D., Winocur, E., Guarda-Nardini, L., Paesani, D., \& Lobbezoo, F. Epidemiology of bruxism in adults: a systematic review of the literature. J Orofac Pain, 27(2) (2013) 99-110. 
150.Julowski, J., Radovic,I., Goracci, C., Vulicevic, Z.R., \& Ferrari, M. Ferrule effect: a literature review. J. Endod, 38 (2012) 11-19

151.Ting, L. I. N. An epidemiological investigation of state of occlusal support in Fujian. Journal of Chongqing Medical University 2 (2010) 047.

152.Hrdlička, A. Mandibular and maxillary hyperostoses. American Journal of Physical Anthropology, 27(1) (1940). 1-67.

153.Muller, T. P., \& Mayhall, J. T. Analysis of contingency table data on torus mandibularis using a log linear model. American journal of physical anthropology, 34(1) (1971) 149-153.

154.Ossenberg, N. S. Mandibular Torus: A Synthesis of New and Previously Reported Data and a Discusssion of its Cause. (2016). Queens University. http://hdl.handle.net/1974/14652

155.Austin, J. E., Radford, G. H., \& Banks, S. O. Palatal and Mandibular Tori in the Negro. The New York state dental journal, 31 (1965) 187191.

156.King, D. R., \& King, A. C. Incidence of tori in three population groups. Journal of oral medicine, 36(1) (1980) 21-23.

157.Eggen, S., \& Natvig, B. Variation in torus mandibularis prevalence in Norway A statistical analysis using logistic regression. Community dentistry and oral epidemiology, 19(1) (1991) 32-35.

158.Clarkson, J. Review of terminology, classifications, and indices of developmental defects of enamel. Advances in dental research, 3(2) (1989) 104-109.

159. Sierra, M. C. N. Terminología, clasificación y medición de los defectos en el desarrollo del esmalte. Revisión de literatura/Terminology, Classification and Measuring of the Developmental Defects of Enamel. Literature Review. Universitas Odontologica, 32(68) (2013) 33.

160.Sorano, L.; Mourelle, R.; Gracia, P. Alteraciones en la estructura del esmalte dental en niños que cursan con la aparición de manchas blancas. Rev. Científ formac contin, 4 (1) (2003) 23-27.

161. Slayton, Rebecca L., et al. Prevalence of enamel hypoplasia and isolated opacities in the primary dentition. Pediatric dentistry, 23 (2001) 32-43.

162.Billings, R. J., Berkowitz, R. J., \& Watson, G. Teeth. Pediatrics, 113(Supplement 3) (2004) 1120-1127.

163.Barbero J.G. Patología y terapéutica dental. Cap. 15, pp 253-261. Editorial Síntesis. Madrid 2000.

164.Holtfreter, B., Kocher, T., Hoffmann, T., Desvarieux, M., \& Micheelis, W. Prevalence of periodontal disease and treatment demands based on a German dental survey (DMS IV). Journal of clinical periodontology, 37(3) (2010) 211-219. 
165.Mamai-Homata, E., Polychronopoulou, A., Topitsoglou, V., Oulis, C., \& Athanassouli, T. Periodontal diseases in Greek adults between 1985 and 2005-Risk indicators. International dental journal, 60(4) (2010) 293-299.

166.Jacob, S. Global prevalence of periodontitis: a literarure review. International Arab Journal of Dentistry, 3(1) (2012)

167.WHU Collaboratin Centre N.U., WHO Oral Health Country/area Profile Programme http://www.dent.niigata-u.ac.jp/orevent/perio/contents.html

168.Dye, B. A. Global periodontal disease epidemiology. Periodontology 2000, 58(1) (2012) 10-25.

169.Holtzman, J. S., Atchison, K. A., Macek, M. D., \& Markovic, D. Oral Health Literacy and Measures of Periodontal Disease. Journal of Periodontology, 88(1) (2017) 78-88.

170.Eke, P. I., Dye, B. A., Wei, L., Thornton-Evans, G. O., \& Genco, R. J. Prevalence of periodontitis in adults in the United States: 2009 and 2010. Journal of dental research, 91(10) (2012) 914-920.

171.Wehmeyer, M. M., Corwin, C. L., Guthmiller, J. M., \& Lee, J. Y. The impact of oral health literacy on periodontal health status. Journal of public health dentistry, 74(1) (2014) 80-87.

172.Özcan, M. Clinical dental biomaterials: dentists wealthy-patients healthy. Groningen: Facilitair Bedrijf, University of Groningen (2008)

173.Llodrá Calvo J.C., Bravo Pérez M., Cortés Martinicorena F.J. Ecuesta de salud oral en España (2000). RCOE 7 (2002) 19-63

174.Horev, T., Katz, J., Almog, D., \& Goldberg, A. Oral health disparities between ranks in a military environment: Israel Defense Force as a model. Military medicine, 168(4) (2003) 326.

175.Senna, A., Campus, G., Gagliani, M., \& Strohmenger, L. Socioeconomic influence on caries experience and CPITN values among a group of Italian call-up soldiers and cadets. Oral health \& preventive dentistry, 3(1) (2005) 39-46

176.Sandoval, R. M., \& Puy, C. L. Periodontal status and treatment needs among Spanish military personnel. Med Oral Patol Oral Cir Bucal, 13(7) (2008) 464-9.

177.Querna, J. C., Rossmann, J. A., \& Kerns, D. G. Prevalence of periodontal disease in an active duty military population as indicated by an experimental periodontal index. Military medicine, 159(3) (1994) 233236.

178.Sgan-Cohen, H. D., Donchin, M., Goultschin, J., Soskolne, A., \& Brayer, L. Periodontal treatment needs, by CPITN, among employees of a Jerusalem hospital. International dental journal, 42(2) (1992) 92-96.

179.Rodríguez, M., Muñoz Bruguier, M., Vera González, V., Rodríguez, M., \& Muñoz Bruguier, C. Estudio de las necesidades de tratamiento 
bucodental de una muestra española. Avances en Odontoestomatología, 15(9) (1999) 497-505.

180.Marker, O. T., Vigild, M., \& Praetorius, F. Oral health problems and treatment needs in Danish military personnel recruited for United Nations service. Military medicine, 162(6) (1997) 416-421.

181. Cuenca E. La encuesta de la OMS sobre la salud buco-dental en España. Una aproximación personal. Arch. Odontoestomatol 2 (1986) 15-22

182.Bravo, M., Cortés, F., Casals, E., Llena, C., Almerich-Silla, J. M., \& Cuenca, E. Basic oral health goals for Spain 2015/2020. International dental journal, 59(2) (2009) 78-82.

183. Aguilar, L. H., Prieto, D. S., \& García, M. G. Y. El piercing: moda actual y sus consecuencias en la salud bucal. Acta Médica del Centro, 10(4) (2016) 67-71.

184.Hennequin-Hoenderdos, N. L., Slot, D. E., \& Van der Weijden, G. A. The incidence of complications associated with lip and/or tongue piercings: a systematic review. International journal of dental hygiene, 14(1) (2016) 62-73.

185.Greif, J., Hewitt, W., \& Armstrong, M. L. Tattooing and body piercing body art practices among college students. Clinical Nursing Research, 8(4) (1999) 368-385.

186. Mayers, L. B., Judelson, D. A., Moriarty, B. W., \& Rundell, K. W. Prevalence of body art (body piercing and tattooing) in university undergraduates and incidence of medical complications. In Mayo Clinic Proceedings 77 (2002) 29-34). Elsevier.

187.Hennequin-Hoenderdos, N.L., Slot D.E. \&Weijden G.A. The prevalence of oral and perioral piercing in young adults: a systematic review. International Journal of dental hygiene 10 (3) (2012) 223-228.

188. De Urbiola Alís, I., \& Viñals Iglesias, H. Algunas consideraciones acerca de los piercings orales. Avances en odontoestomatología, 21(5) (2005) 259-269.

189.Larmas, M., \& Mäkinen, K. K. Insufficiency of currently used dental indices in epidemiology. British Journal of Medicine and Medical Research, 4(10), (2014) 2058.

190.Segura-Egea J.J. Sensibilidad y especificidad de los métodos diagnósticos convencionales de la caries oclusal según la evidencia científica disponible. RCOE 5 (2002) 491-501

191. Assaf A.V., Mneghim M.C., Zanin L., Mialh F.L., Pereira A.C., Ambrosano G.M. Assessment of different methods for diagnosing dental caries in epidemiological surveys. Community Dent Oral Epidemiol 32 (2004) 418-425. 
192.Costa, S. M., Martins, C. C., Bonfim, M. D. L. C., Zina, L. G., Paiva, S. M., Pordeus, I. A., \& Abreu, M. H. A systematic review of socioeconomic indicators and dental caries in adults. International journal of environmental research and public health, 9(10) (2012) 35403574.

193.Nishi, M., Stjernswärd, J., Carlsson, P., \& Bratthall, D. Caries experience of some countries and areas expressed by the Significant Caries Index. Community dentistry and oral epidemiology, 30(4) (2002), 296-301.

194.Skinner, J., Byun, R., \& Blinkhorn, A. (2016). Utilization of public oral health services by New South Wales teenagers, 2004-05 to 2014-15. Australian Dental Journal, 61(4), (2016) 514-520.

195.Lagerweij, M. D., \& van Loveren, C. (2015). Declining caries trends: are we satisfied?. Current oral health reports, 2(4), (2015) 212-217.

196. Madléna, M., \& Lipták, L. Prevention of dental caries with fluorides in Hungary. Paediatrics Today, 10(2), (2014) 84.

197.Brown, L. J., \& Swango, P. A. Trends in caries experience in US employed adults from 1971-74 to 1985: cross-sectional comparisons. Advances in dental research, 7(1), (1993) 52-60.

198. Rodriguez M, Muñoz M, Vera V, Rodrigues M, Muñoz C. Estudio de las necesidades de tratamiento buco dental de una muestra española. Av. Odontoestomatolol 15 (1999) 395-402

199.Rodriguez R., Castaño A., Gonzalez A. Estado de la salud dental de una muestra de la población militar española. Rev. Eur. Odont-Estomatol 4 (2001) 195-204.

200.García García B., Lobo Román, et alts. Estudio epidemiológico de salud oral. (2015)

201.Garcia Garcia, Bernardo. Estudio epidemiológico de salud oral de una población militar de Sevilla. Tesis Doctoral. Universidad de Sevilla 2014.

202.Villota, D. D., Cardona, M., Vivas, J., Toro, J. A., Arango, Y. I., Sánchez, L. E., \& Martínez, C. H. Prevalencia y factores relacionados con caries y periodontopatías en los cadetes de la escuela Militar de Aviación. Journal Odontológico Colegial, 4, 55.

203.Halquist, T. C. (2012). Dental Caries Progression Among US Marine Corps Personnel Following Operational Deployment. Uniformed Services University Of The Health Sciences Bethesda United States.

204.Bartoloni, J. A., Chao, S. Y., Martin, G. C., \& Caron, G. A. (2006). Dental caries risk in the US Air Force. The Journal of the American Dental Association, 137(11) (2006) 1582-1591.

205.Hopcraft, M., \& Morgan, M. V. (2005). Dental caries experience in Australian Army recruits 2002-2003. Australian dental journal, 50(1) (2005), 16-20.

206.WHO Oral Health-The CAPP index. (2008). http/www.whocollab. od.mah.se/index.html. 
207. Marthaler, T. M. Changes in dental caries 1953-2003. Caries research, 38(3) (2004) 173-181.

208.Lukacs, J. R. (2011). Sex differences in dental caries experience: clinical evidence, complex etiology. Clinical oral investigations, 15(5), 649-656.

209.Jindal, A., McMeans, M., Narayanan, S., Rose, E. K., Jain, S., Marazita, M. L., ... \& Resick, J. M. (2011). Women are more susceptible to caries but individuals born with clefts are not. International journal of dentistry, 2011.

210.Downer, M. C. (1994). Caries prevalence in the United Kingdom. International dental journal, 44(4 Suppl 1), 365-370.

211. Marthaler, T. M. (2004). Changes in dental caries 1953-2003. Caries research, 38(3), 173-181.

212. Schour, I. \&Massler, M. Dental caries experience in postwar Italy (1945): I. Prevalence in various age groups. The Journal of tue American Dental Association, 35(1) (1947) 1-6.

213.Ivankovic A., Lukic I.K., Ivankovic Z., Radic A., Vukic I. \& Simic A. Dental caries in postwar Bosnia and Herzegovina. Community dentistry and oral epidemiology, 31 (2003) 100-104.

214. Toverud, G. Dental caries in Norwegian children during and after the second world war. Journal of the American Dietetic Association, 26(9) (1950) 673.

215.Christen, A. G., Park, P. R., Graves, R. C., Young, J. M., \& Rahe, A. J. United States Air Force survey of dental needs, 1977: methodology and summary of findings. The Journal of the American Dental Association, 98(5) (1979) 726-730.

216.Sobotta, B. A., Reiber, T., \& Nitschke, I. Oral health of seafarers-a review. Int Marit Health, 62(1) (2011) 8-16.

217.Bartoloni, J. A., Chao, S. Y., Martin, G. C., \& Caron, G. A. Dental caries risk in the US Air Force. The Journal of the American Dental Association, 137(11) (2006) 1582-1591.

218. Antoft, P., Rambusch, E., Antoft, B., \& Christensen, H. W. Caries experience, dental health behaviour and social status--three comparative surveys among Danish military recruits in 1972, 1982 and 1993. Community dental health, 16(2) (1999) 80-84.

219. Hayman J. et alts. The military oral health care system as a model for eliminating disparities in oral health. The Journal of tue American Dental Association, 135(3) (2006) 372-378.

220. Medina Castro, J. F. (2009). Prevalencia de caries dental y necesidad de tratamiento en pacientes adultos con demanda de atención diagnóstica. Tesis Doctoral. U. Nacional Mayor de San Marcos (2009).

221. York, A. K., Moss, D. L., \& Martin, G. A longitudinal study of dental experience during the first four years of military experience. Military medicine, 173.( 2007).

222.Chisick, M. C., Poindexter, F. R., \& York, A. K. Factors influencing perceived need for dental care by United States military recruits. Clinical oral investigations, 2(1) (1998) 47-51. 
223.Martínez Alonso, L., Fajó Pascual, M., \& Monticelli, F. Indicadores de salud en el diseño de programas de prevención para una adecuada aptitud dental. Sanidad Militar, 70 (2014)15-16. 